Claremont Colleges

Scholarship@ Claremont

KGI Theses and Dissertations

KGI Student Scholarship

7-31-2017

\title{
Drug Repurposing Using the Anthrax Toxin Internalization Pathway
}

Leeor Zilbermintz

\section{Recommended Citation}

Zilbermintz, Leeor. (2017). Drug Repurposing Using the Anthrax Toxin Internalization Pathway. KGI Theses and Dissertations, 7. https://scholarship.claremont.edu/kgi_theses/7. doi: 10.5642/kgitd/7

This Restricted to Claremont Colleges Dissertation is brought to you for free and open access by the KGI Student Scholarship at Scholarship @ Claremont. It has been accepted for inclusion in KGI Theses and Dissertations by an authorized administrator of Scholarship @ Claremont. For more information, please contact scholarship@cuc.claremont.edu. 


\section{Drug Repurposing Using the Anthrax Toxin Internalization Pathway}

PhD in Applied Life Sciences

by

Leeor Zilbermintz

2017

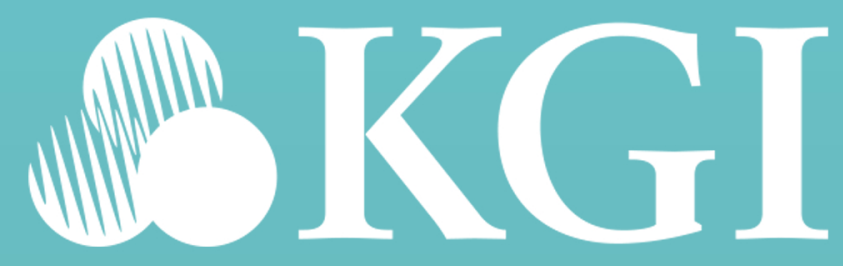

Keck Graduate Institute 


\section{Drug Repurposing Using the Anthrax Toxin Internalization Pathway}

BY

Leeor Zilbermintz

A Dissertation submitted to the Faculty of Keck Graduate Institute of Applied Life Sciences in partial fulfillment of the requirements for the degree of Doctor of Philosophy in Applied Life Sciences

Claremont, California 2017

Approved by:

Mikhail Martchenko

Mikhail Martchenko Ph.D.

Copyright (C) by Leeor Zilbermintz 2017

All rights Reserved 
We, the undersigned, certify that we have read this dissertation of Leeor Zilbermintz and approve it as adequate in scope and quality for the degree of Doctor of Philosophy.

Dissertation Committee:

Mikhail Martchenko

Mikhail Martchenko (Jul 28, 2017)

Mikhail Martchenko Ph.D., Chair

Coug th cleme

Craig Adams Ph.D., Member

Stephen V. Fiacco

Stephen V. Fiacco Ph.D., Member

lumblero

Animesh Ray Ph.D., Member

John L. Krstenansky, Ph.D. MBA, PhD Program Director

Larry Grill

Larry Grill Ph.D., PhD Program Director 


\section{Abstract of the Dissertation \\ Drug Repurposing Using the Anthrax Toxin Internalization Pathway \\ By \\ Leeor Zilbermintz}

\section{Keck Graduate Institute of Applied Life Sciences: 2017}

Pathogens and pathogenic agents such as lethal toxin, exploit host proteins for their success. Antibiotic discovery efforts have been focused on developing drugs that selectively target pathogens, despite the potential for drug resistance and providing no guarantee of fewer side effects for the patient. This dissertation describes the systematic efforts to identify drugs that alter those host proteins that are involved in the anthrax toxin internalization pathway. Anthrax is a rare and lethal disease caused by the toxin producing, gram-positive bacterium, Bacillus anthracis. The lethality of anthrax is largely attributed to the toxins that circulate within the host, destroying host tissues as well as the immune system, thus hampering host efforts to destroy the bacteria. Drug candidates were identified through cellular and protein-based screens using a drug library comprised of previously approved and off-patent drugs. Such a library creates the potential for identifying therapies for new indications, while potentially reducing the time and capital necessary for regulatory approval. We have successfully identified an anthrax antitoxin drug that interferes with host Cathepsin B, a lysosomal protein necessary for authophagic flux. On the observation that Cathepsin B is necessary for the success of other pathogenic agents, we demonstrated that our drug hit could prevent other infections, such as Ebola. Subsequent screens were designed to optimize the search for broad-spectrum therapies that interfere with those host proteins involved in the anthrax toxin internalization pathway but which play a role in internalizing other pathogenic agents such as Pseudomonas exotoxin A, Cholera, and Diphtheria toxin. We were able to identify a drug that inhibits host caspases, proteases involved in programmed cell death, and showed that this drug was a successful broad-spectrum therapy for Zika virus. Finally we aimed to indentify drugs that could simultaneously interfere with host proteins and anthrax lethal toxin, and identified two drugs. Drug optimization and drug combinations based on our host-oriented and broad-spectrum identification methods could provide for more effective and better-tolerated therapies for patients suffering from infectious diseases. 
Dedication

To my Ima and Aba who've supported my learning and education for nearly three decades 


\section{Acknowledgments}

Science has always been a part of me. From the four year old child who postulated that cutting off her curly hair could make way for new straight locks, to the elementary-age girl who demanded (nicely) that her science teacher explain exactly how the brain works and what enables humans to make voluntary movements, curiosity was never in short supply. But just like a seed that has the potential to grow into a mighty tree with the proper environmental conditions, I too would be nowhere near where I ended up today, without the proper support systems in my life. I am extremely lucky that opportunity, guidance, encouragement, and mentorship was never in short supply.

It is my greatest pleasure to express my sincerest gratitude to Professor Mikhail Martchenko. I could not envision a more kind, intelligent, and motivated principal investigator. Dr. Martchenko introduced me to the exciting new field of microbiology and drug discovery, that up until then, I had only read about in books and learned about in my classes. Mikhail rekindled my childhood dream of discovering therapies for patients, and with my acquired experience I hope to continue working on this dream for the rest of my life. Mikhail encourages his students to think, ask good questions, and work well, all while being a real friend. I would also like to thank Mikhail's wife (the neck that turns the head). I know Anastasia must have Mikhail grounded during the difficult times of starting a new lab. Anastasia is a warm-hearted and kind teacher who has always been available to listen to those presentations that make me so nervous, give me advice during my own difficult times, and even managed to find an emergency committee member for me.

Most of my committee members have been my teachers at KGI. I will look back fondly at Dr. Craig Adams' lectures, and I'll always be sure remember the components of blood and strive to improve my professional speaking skills. I will smile when I am reminded of Dr. Animesh Ray and his braintingling philosophical questioning or his whiteboard drawings of genetic regulation. I am grateful for all the courses and learning that KGI and its faculty have provided me, and I am especially thankful to Dr. Ray and Dr. Adams for their guidance and mentorship. Thank you as well to my outside committee member Dr. Stephen Fiacco, who has also provided invaluable guidance and mentorship and who took the time to commute to KGI. I am also thankful to Dr. Fiacco for helping me to start realizing my confidence as a scientist.

I would be nowhere without my family. Thank you to my parents who have supported me and my education throughout these many long years. My mother has always pushed me to have high expectations for myself and my dad has always encouraged me to find a fulfilling career. Thank you to my wonderful husband who has done everything from making sure I have enough snacks while studying finals, tutoring me in finance, listened to presentations, and talked me out of my insecurities during tough times, all while providing the best advice.

I owe a special thank you to Dr. William Leonardi who is a fantastic scientist, human being, and friend. I feel honored that I have been able to work with and learn from him. Thank you as well to the passionate Dr. Kevin Kim for always cheering me on, since the very first day at KGI.

I would like to thank all my friends, colleagues, lab mates, students, and collaborators who I've ever worked with, as my experience at KGI was enriching and fulfilling because of them, and I am a better person and scientist as a result. 


\section{Preface}

It is not the most intellectual of the species that survives; it is not the strongest that survives; but the species that survives is the one that is able best to adapt and adjust to the changing environment in which it finds itself.

-Paraphrased by Leon C. Megginson from Charles Darwin's “On the Origin of Species"(1963) 


\section{Table of Contents}

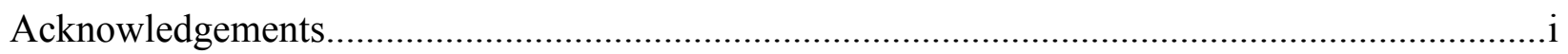

List of Figures and Tables ....................................................................................................

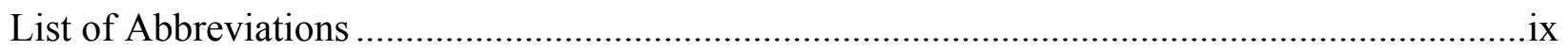

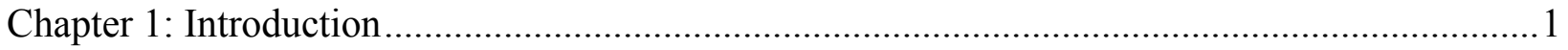

1.1 The Pre Antibiotic Era ............................................................................... 1

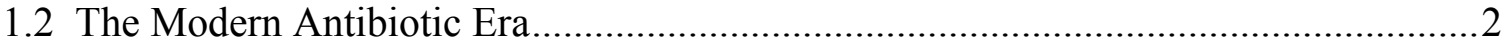

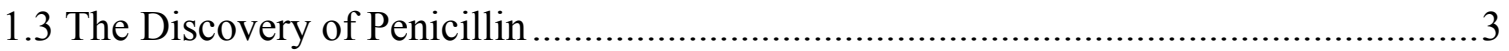

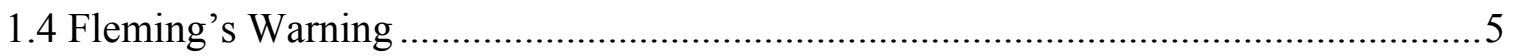

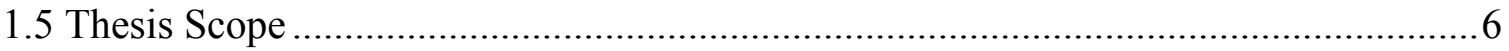

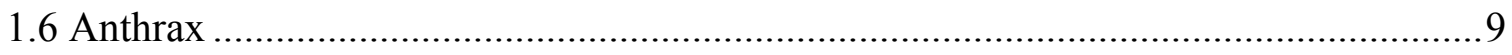

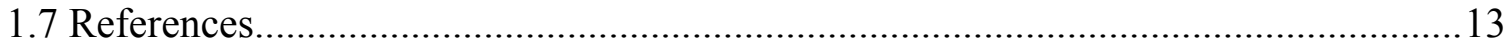

Chapter 2: Repurposing FDA approved drugs against the human fungal pathogen, Candida

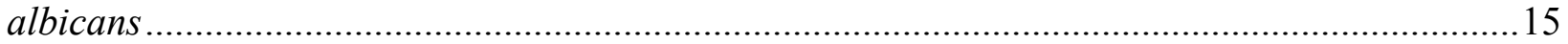

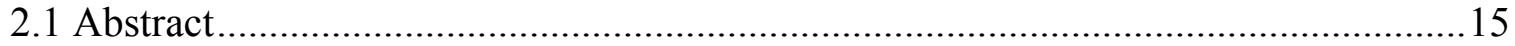

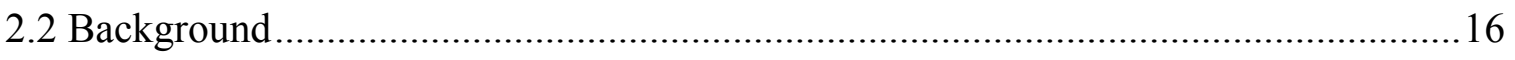

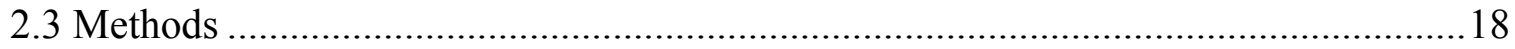

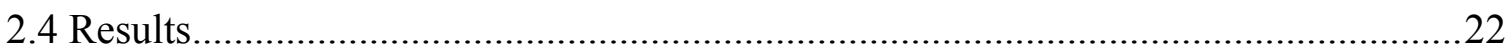

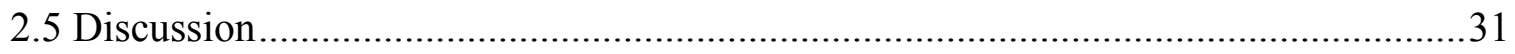

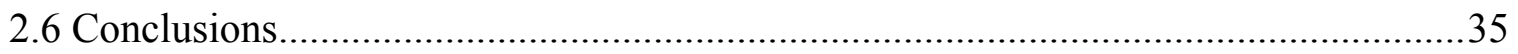

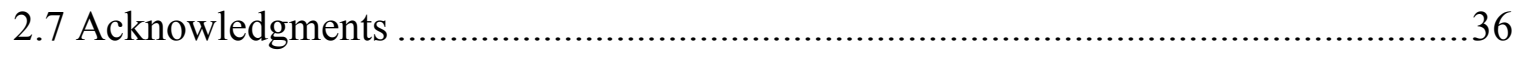

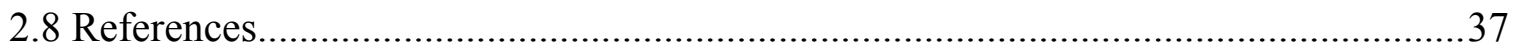

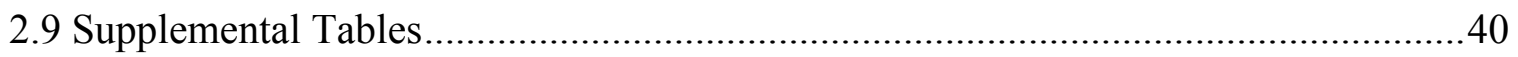


Chapter 3: Identification of agents effective against multiple toxins and viruses by host-oriented cell targeting

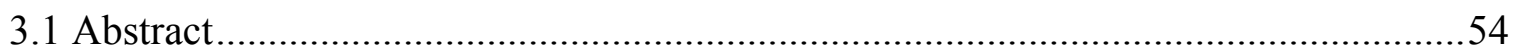

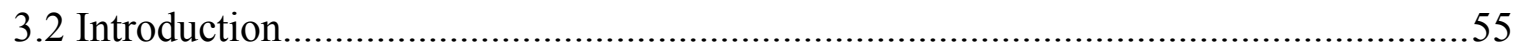

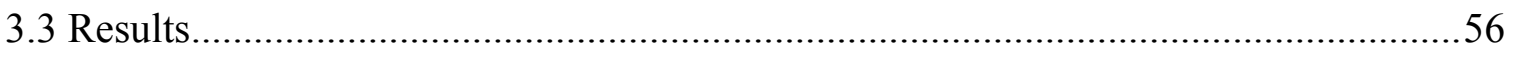

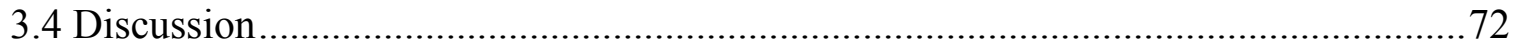

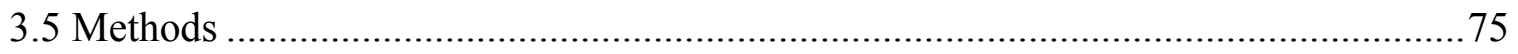

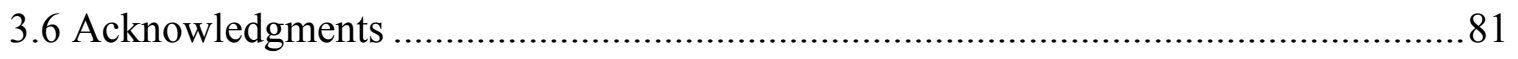

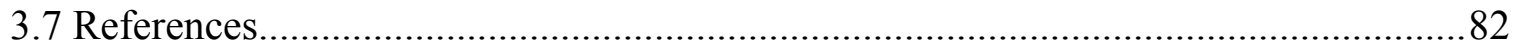

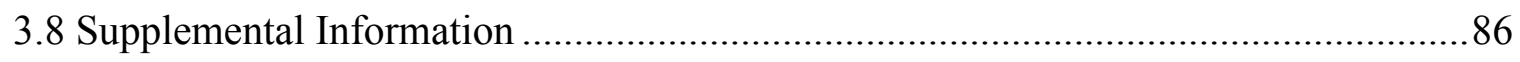

Chapter 4: Bithionol blocks pathogenicity of bactieral toxins, ricin, and Zika virus ..................97

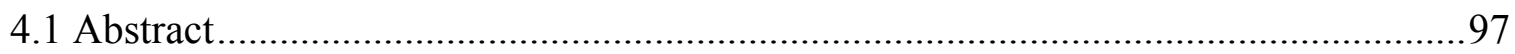

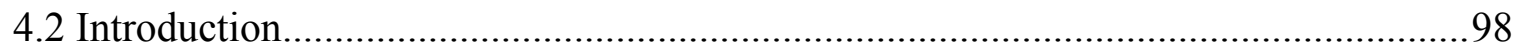

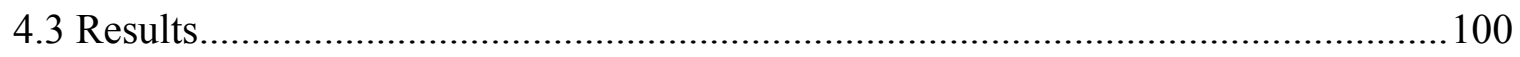

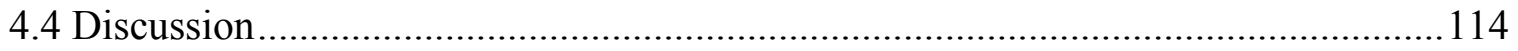

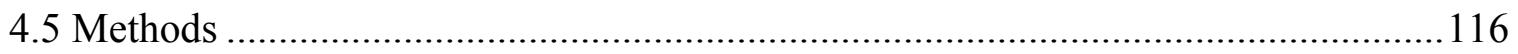

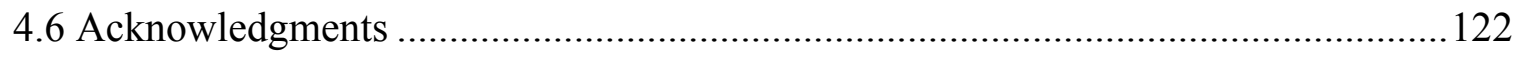

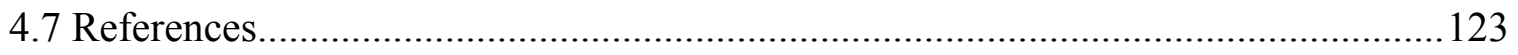

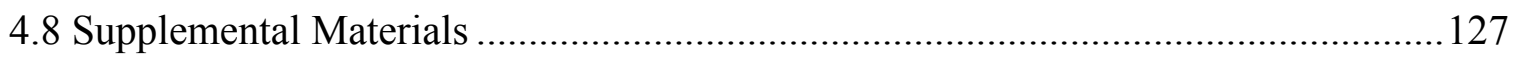

Chapter 5: Cross-inhibition of pathogenic agents and the host proteins they exploit ................134

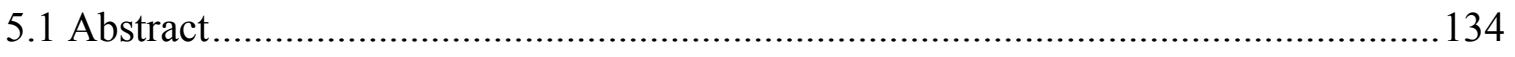

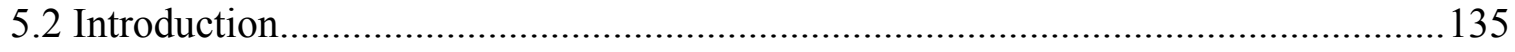

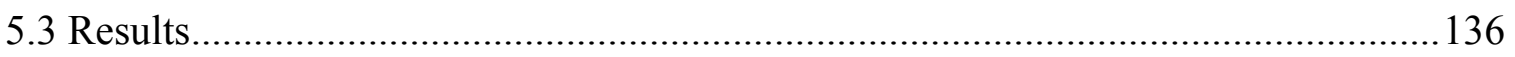

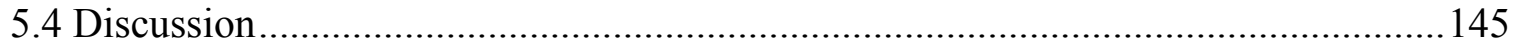




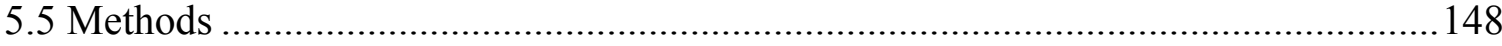

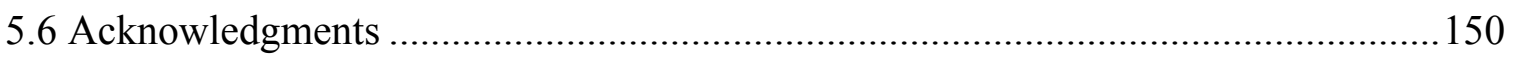

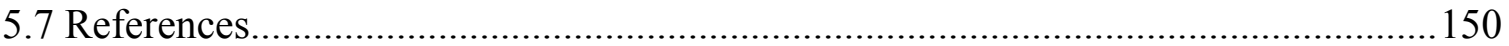

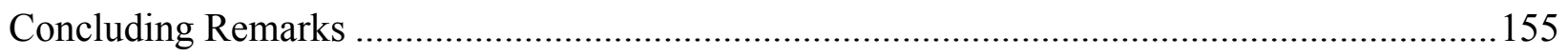


ADP - Adenosine diphosphate

ADP-RT - Adenosine diphosphate ribosyltransferase

AMC - 7-Amino-4-methylcoumarin

AP2 - Adipocyte protein 2

AQ - Amodiaquine

ARAP3 - ANK repeat and PH domain-containing protein 3

ARRB1 - Arrestin, beta 1

ARRB2 - Arrestin, beta 2

ASTD - Amplification factor

ATCC - American Type Culture Collection

BCA - Bicinchoninic acid assay

BoNT/A - Botulinum neurotoxin A

BSA - Bovine serum albumin

c-Jun - A protein in humans that is encoded by the JUN gene

CASP - Caspase

Cath B - Cathepsin B

CBL - E3 ubiquitin-protein ligase

CC50 - Cytotoxic concentration of the extracts to cause death to $50 \%$ of viable cells in the host

CCL - Clinical compound library

CD44 - An antigen / cell-surface glycoprotein

CdTB - Clostiridium difficile toxin B

CEU - Utah population from Europe

$\mathrm{CHB}$ - Han Chinese from Beijing China

CHIV - Chikungunya virus

CLSI - Clinical Laboratory Standards Institute

CLTCL1 - Clathrin havy chain like 1

CMAX - The maximum (or peak) serum concentration that a drug achieves in a specified compartment or test area of the body after the drug has been administrated and before the administration of a second dose.

CMC - Critical micelle concentration

CMG2 - Capillary morphogenesis gene-2

CPE - Primary cytopathic effect

$\mathrm{CQ}$ - Chloroquine

CT - Cholera toxin

D2O - Deuterium oxide

DABCYL - 4-((4-(dimethylamino)phenyl)azo)benzoic Acid

DEAQ - Desethylamodiaquine

DECQ - Desethylchloroquine

DMEM - Dulbecco's modified Eagle's Medium

DMSO - Dimethyl Sulfoxide

DNM2 - Dynamin-2 
DT - Diphtheria toxin

EBOV - Ebola virus

EC50 - The effective concentration of a drug that gives half-maximal response

EF - Edema Factor

ER - Endoplasmic reticulum

ERK1 - A serine/threonine kinase of the GMGC group (MAPK3)

ERK2 - A serine/threonine kinase of the GMGC (MAPK1)

ET - Edema toxin (edema factor + edema toxin)

EU - European Union

FAM FLICA - fam)-labeled inhibitors of caspases

FBS - Fetal Bovine Serum

FDA - Food and Drug Administration

FITC - Fluorescein isothiocyanate

FLICA - Fluorochrome Inhibitor of Caspases (assay)

FP59 - Fusion protein 59

FRET - Fluorescence Resonance Energy Transfer

FYN - Proto-oncogene tyrosine-protein kinase Fyn

GMP - Good manufacturing practices

GP - Glycoprotein

Green DND - A green fluorescent dye that stains acidic compartments in live cells

$\mathrm{H \#}$ - Hydrogen number

HEPES - 4-(2-hydroxyethyl)-1-piperazineethanesulfonic acid

HIV - Human immunodeficiency virus

HPEP - Host protein exploited by pathogen

IACUC - The Institutional Animal Care and Use Committee

IgG - Immunoglobulin G

ITGB1 - Integrin beta 1

JHCCL - John Hopkin's Clinical Compound Library

JPT - Japanese in Tokyo

JUNV - Junin Virus

LB - Lysogeny Broth

LD100 - Lethal Dose 100\% (dose having 100\% probability of causing death)

LF - Lethal Factor

LPR6 - Low-density lipoprotein receptor-related protein 6

LT - Lethal toxin (lethal factor + protective antigen)

MAP2K - Mitogen-activated protein kinase kinase

MAPKK - Mitogen-activated protein kinase kinase

MAPKKIDE - Fluorescently labeled substrate for quantitative detection of anthrax lethal factor MCC - Minimal Cytotoxic Concentration

MEK - A kinase enzyme which phosphorylates mitogen-activated protein kinase

MEK2 - A kinase enzyme which phosphorylates mitogen-activated protein kinase

MOI - Multiplicity of infection

MSF - Médecins Sans Frontières 
MTT - 3-(4,5-dimethylthiazol-2-yl)-2,5-diphenyltetrazolium bromide NLRP1 - NLR Family Pyrin Domain Containing 1

NMR - Nuclear magnetic resonance spectroscopy

P38 - A mitogen-activated protein kinase

PA20 - Protective antigen

PA63 - Protective antigen

PA83 - Protective antigen

PD - Pharmacodynamics

$\mathrm{PE}$ - Pseudomonas aeruginosa exotoxin A

$\mathrm{pH}$ - Potential of hydrogen

PK - Pharmacokinetics

RIPA - Radioimmunoprecipitation assay buffer

rRNA - Ribosomal ribonucleic acid

SARS - Severe acute respiratory syndrome

SD - Standard deviation

SDS - Sodium dodecyl sulfate

SDS-PAGE - Sodium dodecyl sulfate polyacrylamide gel

SI50 - Selectivity index

SNAP - Selective non-peptide agonist

SRC - Proto-oncogene tyrosine-protein kinase Src

STD - Saturation-transfer difference

TEM8 - Tumor endothelial marker-8

VEEV - Venezuelan equine encephalitis virus

YPD - Yeast extract peptone dextrose

YRI - Yoruba in Ibadan

ZIKV - Zika Virus 


\section{Chapter 1}

\section{Figures and Tables}

Table $1.1^{*} \quad$ Common antibiotics and their side effects 3

Figure 1.1 An advertisement for Penicillin during World War II ................................................... 4

Figure 1.2 The discovery and consequent development of antibiotic resistance...............................

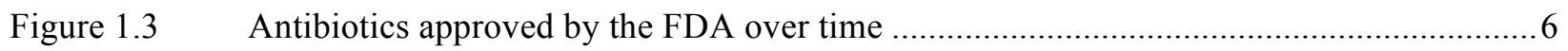

Figure 1.4 The global emergence and re-emergence of infectious diseases .....................................

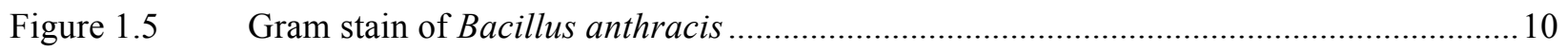

Figure 1.6 The role of lethal toxin and edema toxin in anthrax infection........................................ 11

\section{Chapter 2}

Figure 2.1 Analysis of C. albicans strain SN250 treated with various drugs and diagram......

Figure 2.2 Agar drug diffusion susceptibility assay of Candida albicans SN250.....

Figure 2.3 Agar Octodrine diffusion susceptibility assay of Candida albicans .28

Figure 2.4 The sensitivities of Candida albicans, Escherichia coli, and Bacillus cereus to neat Octodrine

Table 2.1* Minimal cytotoxic concentration (MCC) calculations for the cell lines RAW264.7 and C32 treated with selected drugs

Figure 2.5 Chemical structures of 15 drugs shown to have anti-Candida albicans activity in our screen

Supplemental

Table 2.1 Quantification of the zone of inhibition post-treatment of various drugs on C. albicans strain SN250

Table 2.2 Quantification of the zone of inhibition post-treatment of various serially diluted drugs on C. albicans strain SN250 .....

Table 2.3 Serial dilution experiments of Octodrine on serum and YPD plates. .51

Table 2.4 Quantification of the zone of inhibition of Octodrone in neat form against Candida albicans, Escherichia coli, and Bacillus cerues

\footnotetext{
${ }^{*}$ Indicates a figure or table that the author directly contributed to
} 
Figure 2.1 Elucidation of Candida albicans sensitivity to Octodrine

\section{Chapter 3}

Figure 3.1* The use of Johns Hopkins Clinical Compound Library (JHCCL) to screen for inhibitors

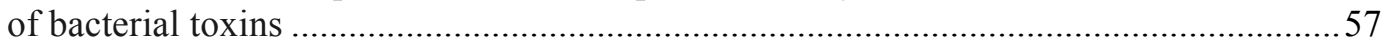

Figure 3.2* The anti-LF-PA efficacy of Amodiaquine (AQ) and its metabolite Desethylamodiaquine (DEAQ) in intro and in vivo 60

Figure 3.3* Amodiaquine inhibits cellular cellular entry of LF ..... 63

Figure 3.4 Amodiaquine inhibits host cathepsin B. .66

Table 3.1 The effect of AQ, CQ, and its metabolites, DEAQ AND DECQ, on the pathogenicity of EBOV in HeLa cells .70

Table 3.2 The effect of time of AQ and its metabolite treatments on the pathogenicity of EBOV ..70

Table $3.3^{*} \quad$ Sensitivities of Category A, B, and C pathogens to Amodiaquine. 71

Figure 3.5 Mechanism of action of Amodiaquine .73

Supplemental

Figure 3.1* The effect of quinoline anti-malarials on sensitivities of cells treated with anthrax toxins

Figure 3.2* Amodiaquine reduces cellular sensitivity to LF+PA83 and LF+PA63..... .88

Figure 3.3 The effect of Amodiaquine, Choloroquine, and their metabolites on host cathepsin B....89

Figure 3.4* The effect of Amodiaqine on sensitivities of cells treated with bacterial toxins..............90

Table 3.1 Amodiaquine, Chloroquine, and their metabolites inhibit Ebola virus in HFF-1 cells ..... 91

Table 3.2 Amodiaquine and its metabolite inhibits Chikungunya (CHIV) and Junin (JUNV) viruses in host cells

\section{Chapter 4}

Figure 4.1 Inhibitors of hubs of human disease networks

Figure 4.2* The effect of Bithionol on P. aeruginosa exotoxin A in human B-lymphoblastoid cells

\footnotetext{
${ }^{*}$ Indicates a figure or table that the author directly contributed to
} 
Figure 4.3* The use of the Clinical Compound Library (CCL) to screen for inhibitors of hubs of human disease networks ............................................................................................. 104

Figure 4.4* Bithionol reduces pathogenicity of toxins by inhibiting host caspases ......................... 107

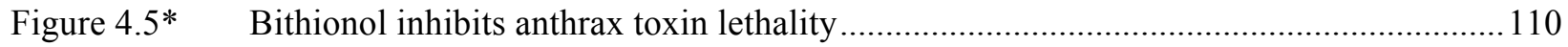

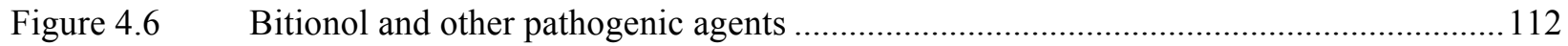

Supplemental

Figure 4.1 Caspase-7 and Caspase-3 SNPs associated with log sensitivity of B-lymphoblastoid cells to Pseudomonas aeruginosa exotoxin A in indicated populations.................................. 132

Table 4.1 The effect of Bithionol on the pathogenicity of Zika virus in cells.............................. 133

\section{Chapter 5}

Table 5.1 The observation that many pathogenic and host proteins they exploit belong to the same

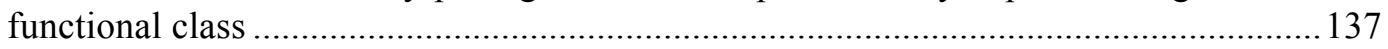

Figure 5.1* The use of the Johns Hopkins Clinical Compound Library (JHCCL) to screen for inhibitors of anthrax lethal toxin and host proteases .................................................... 138

Table 5.2* The potencies of ten JHCCL drugs for inhibition of anthrax LF, as well as human proteases exploited by it in biochemical FRET assays

Table 5.3 The potencies of truncated versions of salmon sperm protamine and full-length human protamines in LF and furin FRET assays

Table 5.4 $\quad$ The potency of full length and truncated versions of human protamine in LF FRET assay

Figure 5.2 Ascorbic acid 6-palmitate and salmon sperm protamine act as broad-spectrum anti-toxins

\footnotetext{
${ }^{*}$ Indicates a figure or table that the author directly contributed to
} 


\section{Chapter 1}

\section{The Pre Antibiotic Era}

Antimicrobials are not only one of the most successful forms of chemotherapy, or treating diseases with chemical substances, but they are arguably one of the most important medical advances in human history. In 1941, during the Second World War, Selman Waksman coined the word antibiotic to describe a small molecule made from a microorganism that is intended to prohibit the growth of other microbes [1]. Penicillin, which was being manufactured at high quantities during this time, and was discovered from a mold, is considered to be one of the first antibiotics in the "antibiotic era [2]."

Antibiotic use by humans, whether purposeful or by accident, can be traced back to ancient civilizations. For example, Tetracycline, which is produced by the genus Streptomyces, and is known to aggregate in the calcium of bones, was identified in the remains of the ancient Nubian people who died around 350-550 CE. It is hypothesized that the conditions in which these people stored grains for beer were ideal for a Streptomyces contamination. Mass spectrometry of these bones indicates the presence of Tetracyclines in the Nubian diet. Histological studies of femoral mid shafts from Roman skeletons from the Dakhleh Oasis in Egypt, also exhibit tetracycline in the diet as evidenced by discrete fluorochrome labeling [3]. The Nubian people had less evidence of bone infections and infections in general. Nowadays people still use Tetracycline for a wide range of antibiotic infections and those who have taken it at a young age, often have visible stains on their teeth as a result. There is still no consensus whether these ancient people realized the antibiotic properties of their beer [3].

Since Tetracycline binds to bone, there is a physical marker of antibiotic use. However, other antibiotics do not leave behind much evidence and their use can only be attributed to 
ancient customs and practices left behind in historical writings or as traditions passed down from several generations back. For example, Jordanian red soil is still used today as a topical antibiotic. Actinomycins have been extracted from this type of soil, which explains the rationale behind its use. Chinese medicine has incorporated several plants and components that contain antibiotic-like molecules, most notably qinghaosu, or Artemisia plants, which contain an ingredient used in modern antimalarials [3].

\section{The Modern Antibiotic Era}

Paul Ehrlich who developed a method for staining tubercle bacillus and is credited with developing the foundation of gram staining, envisioned a method for discovering antibiotics based on selective staining of cell types. Ehrlich sought to find a "magic bullet," or chemicals that have high selectively in targeting pathogens but a low affinity for affecting the patient. To do this, Ehrlich tested hundreds of organically synthesized arsenic derivative compounds in a rabbit animal model infected with syphilis. Ehrlich discovered a compound that he called "salvarsarin," to treat syphilis and it was considered a great improvement over the standard of care at the time, which was an inorganic mercury compound. This was one of the first systematic attempts to discover an antimicrobial chemotherapy. Such a method of discovery was expensive and timely, as it was screened in an animal model. In addition, salvasarin was not without side effects, indicating that it was not the perfect "magic bullet" that Ehrlich envisioned [4].

Even with advancements in drug discovery, the available chemotherapies for infectious diseases continue to have side effects in the patient. The most commonly used antibiotics cannot be taken without risk, as can be seen in Table 1.1 below. The fact that pathogen-targeting drugs are not perfect "magic bullets," begets the question of "is it time to either change or expand the targets of our antibiotic chemotherapies?" Specifically in our research, we aim to see if we can 
identify those host proteins that pathogens exploit in order to exert their toxic effects within the host. Such as approach is relatively new in the field of infectious diseases. However it is important to note that drugs for other diseases that are not caused by pathogenic agents due in fact aim to correct the disease by altering factors within the host. The simplest example that comes to mind, are over-the-counter pain medications. Ibuprofen works in the host by inhibiting the production of prostaglandins, lipid like compounds that are a result of inflammation.

\section{Table 1.1: Common antibiotics and their side-effects}

\begin{tabular}{|c|c|}
\hline Penicillin & Hypersensitivity \\
\hline Cephalosporin & Hypersensitivity \\
\hline Clindamycin & diarrhea, psuedomembrane colitis \\
\hline Aminoglycoside & kidney damage, neurotoxicity \\
\hline Metronidazole & neurotoxicity, thrombophlebitis \\
\hline Vancomycin & bone marrow suppression \\
\hline Chloramphenicol & mild GI disturbance \\
\hline Erythromycin & Tooth discoloration, photosensitivity \\
\hline Tetracyclin & \\
\hline
\end{tabular}

\section{The Discovery of Penicillin}

Even before that fateful day in 1928 when Alexander Fleming returned from his summer vacation to find his staphylococci plates contaminated with mold, there are accounts of people using mold-contamination in an attempt to treat infections. However it was Fleming's observation that eventually led to the mass production of Penicillin. Thanks to being able to produce Penicillin in mass quantities, several hundreds of lives were saved from septicemia and blood poisoning during World War 2 [5]. 
Figure 1.1: An advertisement for Penicillin during World War II [5]

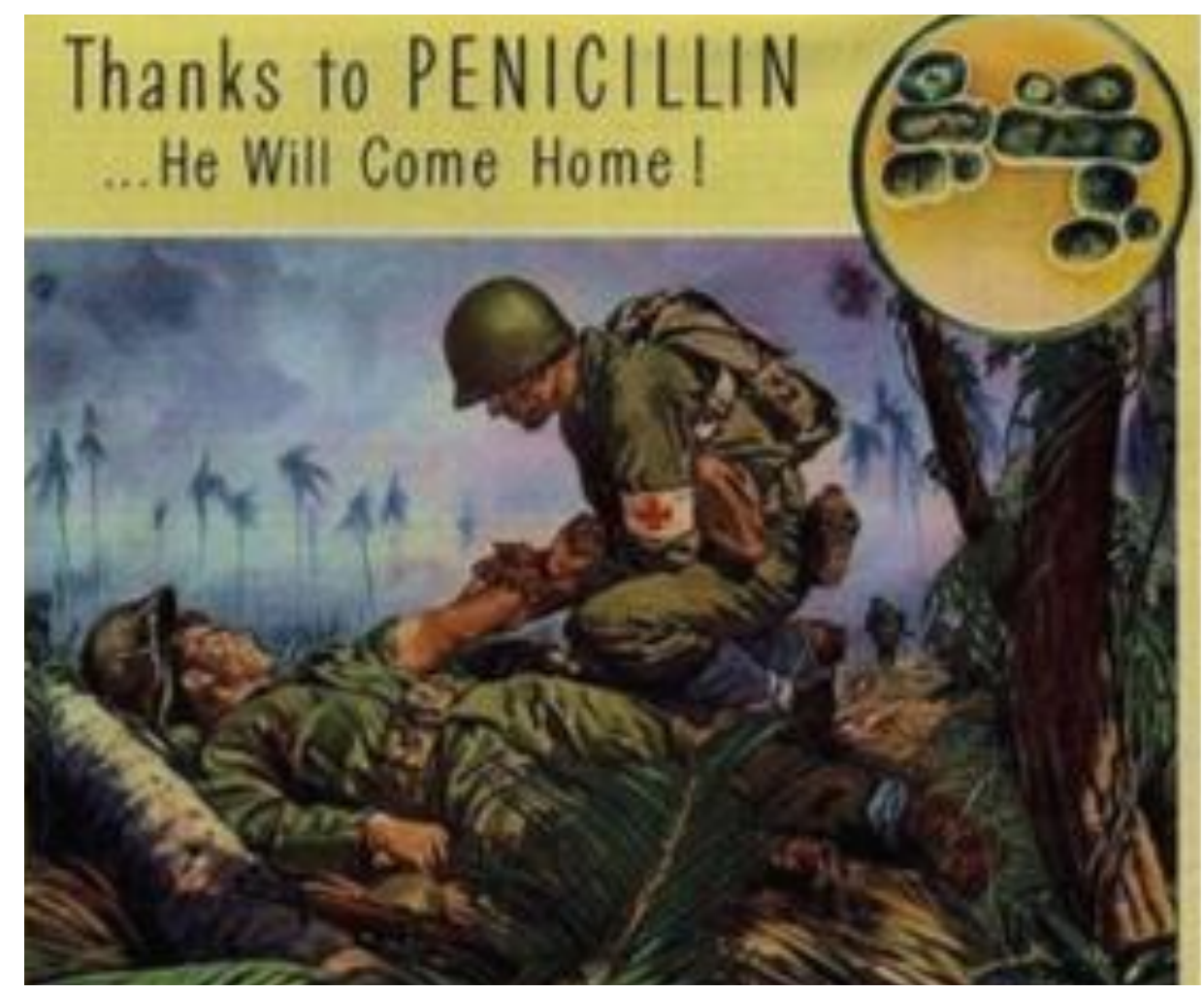

This discovery also ushered in the golden age for discovery and development of antibiotics. As can be seen in Figure $\mathbf{1 . 2}$ below, several major antibiotic therapies were developed in the 1940s [6]. In Chapter 2 of this report, we describe studies that strongly echo Alexander Fleming's discovery, in which varying concentrations of drugs from a drug library were tested for their ability to inhibit the growth of the fungal pathogen, Candida albicans. Drug hits were then tested for their cytotoxicity in cellular assays to assess their safety profiles as potential repurposed drugs. 
Figure 1.2: The discovery and consequent development of antibiotic resistance [6]

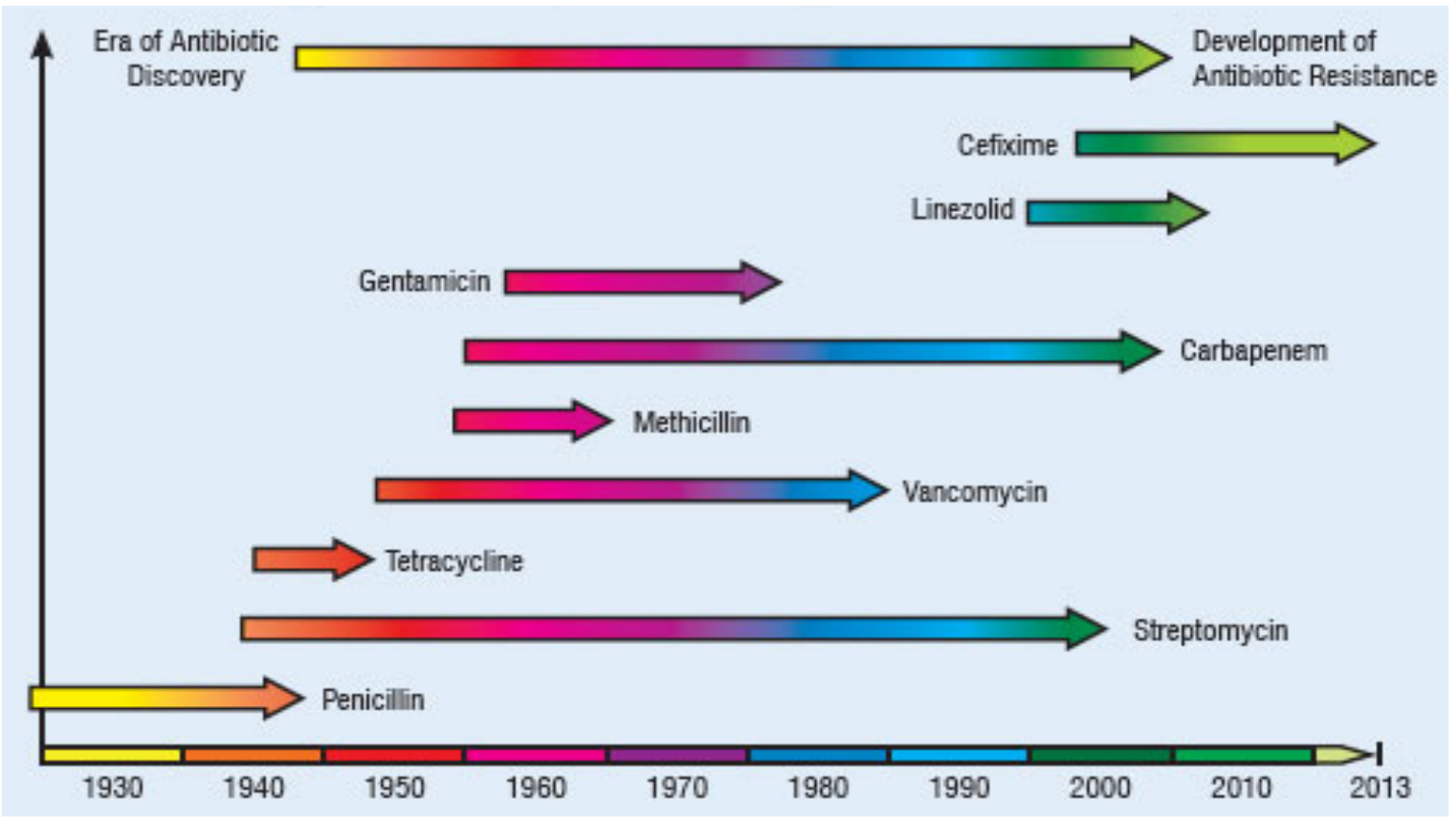

\section{Fleming's Warning}

Arguably as important as Fleming's discovery of Penicillin, was the warning that accompanied it. Fleming observed that his bacterial samples had the ability to evolve resistance to Penicillin and he stated, "The thoughtless person playing with penicillin treatment is morally responsible for the death of the man who succumbs to infection with the penicillin-resistant organism [7]." One of the biggest threats of modern times as seen by scientists who study infectious diseases, is the emergence of drug resistance, which is predicted to ten million people by the year 2050. Drug resistance can be attributed to many factors such as, over-prescription of antibiotics (physicians often prescribe them when they suspect a viral infection), over-use of sanitizers, prevalent use of antibiotics to raise livestock, improper disposal of antibiotics, and improper use of antibiotics (such as not finishing a course) [8]. It remains to be tested, and is an interesting line of inquiry, whether a drug that interferes with host machinery, is less likely to become resistant than a drug that is designed to be specifically toxic to the pathogen. 


\section{Thesis Scope}

The past century has seen the golden era of antibiotic discovery and a significant reduction in mortality from infectious diseases. Unfortunately, developing countries are seeing more incidences of infections (viral, bacterial, fungal, and parasitic) that are becoming resistant to the last lines of treatment by the strongest chemotherapies [9]. In developing countries as well as all over the world, ease of travel and increasingly populated locations allows for the reemergence of infectious diseases as well as emergence of new epidemics. The truth remains that drug discovery for infectious diseases needs to be a continuous effort, as well as an effort that requires new approaches and creativity [10]. In this dissertation, I will highlight the novel ways with which we attempt to discover drugs for pathogenic agents, with an emphasis on anthrax toxins. Our creative approach involves the search for drugs that disrupt host machinery that are commonly exploited by pathogens, rather than the common method of finding drugs that attempt to disrupt the pathogens directly.

We have attempted different methodologies in order to accomplish the discovery of hostoriented drugs, or what we termed as those drugs that will target host proteins exploited by pathogens (HPEP). In the research that resulted in the third chapter, we focused on finding a drug that disrupted the anthrax intoxication pathway. In order to accomplish the discovery of an HPEP through a cell survival assay, we chose to conduct an additional toxin-challenge cell assay with a toxin that has a similar method of cell entry to that of anthrax toxin, but that is different in its enzymatic mechanism of lethality. The hope was that a drug that could save cells from both toxins, would likely be an HPEP. An ideal toxin that matched our criteria was diphtheria toxin, in that its method of entry is very similar to the method of entry of anthrax toxin, having both a receptor binding component, as well as acidification of the early endosome to release the 
enzymatic toxic component into the cytosol. Anthrax lethal toxin is a zinc metalloprotease while diphtheria toxin is an ADP ribosyltransferase [11] [12]. After identifying drug hits from our cell screens, we sought to show the mechanism of repurposed-drug mechanism.

Hosts and pathogens have evolved alongside each other, placing reciprocal selective pressure on each other in order to adapt [13]. As such, bacteria and their toxins often exploit host cellular mechanisms to gain entry into host cells [14] [15]. There is extensive literature describing the mechanism by which anthrax toxin is able to enter cells as is summarized above. Other toxins and pathogenic agents share some of the HPEPs that are necessary for the anthrax toxin internalization pathway. By identifying drugs that disrupt HPEPs, we were able to identify other pathogens that could be disrupted by the same drug, giving us a broad-spectrum therapy. One example was showing that our anthrax toxin drug, which worked by means of lowering host Cathepsin B, (necessary for autophagic flux) is also necessary for the Ebola virus. These studies can also be found in Chapter 3.

In subsequent studies, we attempted different methodologies for identifying HPEPs. In Chapter 4, we discuss multiplex screening, involving simultaneous toxin/cell assays with protein-based screens for drugs that are capable of interfering with host caspases, a family of host proteins that are expressed when cells are under stress, and ready to undertake programmed cell death [16]. In Chapter 5, we screen the drug library in protein-based assays and afterwards tested the drug hits for the ability to save cells from toxins without being cytotoxic themselves.

Although it had been done before, the entirety of our drugs screens utilized a library of previously FDA approved drugs that are off patent. It was our hope that using this tool could help us to identify drug hits with already known safety, pharmacokinetic and pharmacodynamic profiles (Ashburn 2004). In a time where pharmaceutical companies don't typically endeavor on 
creating drugs for infectious diseases, due to their low profitability and a saturated market, repurposing an old drug creates a situation where it is more quick and affordable to find therapies and get them approved for new indications [17].

Figure 1.3: Antibiotics approved by the FDA over time [17]

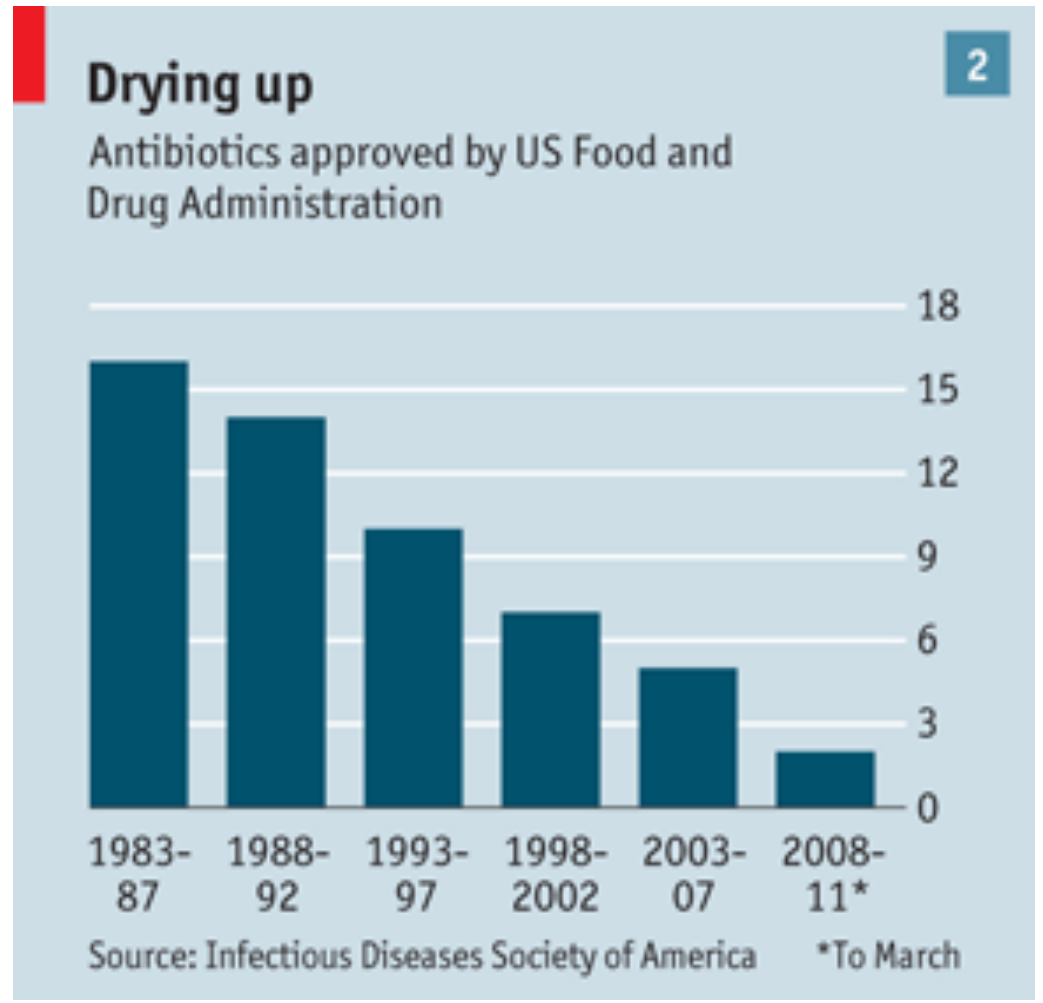

In the case of an infectious disease outbreak, such as the Ebola crisis in 2013 and the Zika virus spread in the summer of 2016, finding a previously approved therapy can be accomplished quickly and previously established manufacturing and distribution channels make it easier to get the chemotherapy to the patients and control the quick spread of disease as soon as possible.

As it is known, only one infectious disease, smallpox, has been completely eradicated [18] [19]. Other infectious diseases, especially viruses, continue to re-emerge or newly emerge, often causing serious health crises around the globe (Brower 2003). With drug repurposing, it is possible to quickly design and execute a drug screen to identify a potential solution for an 
infectious disease epidemic. With a repurposed drug there is the possibility of a quicker road to FDA approval due to the known safety data from the approval of that drugs' previous indication.

Figure 1.4: The global emergence and re-emergence of infectious diseases [20]

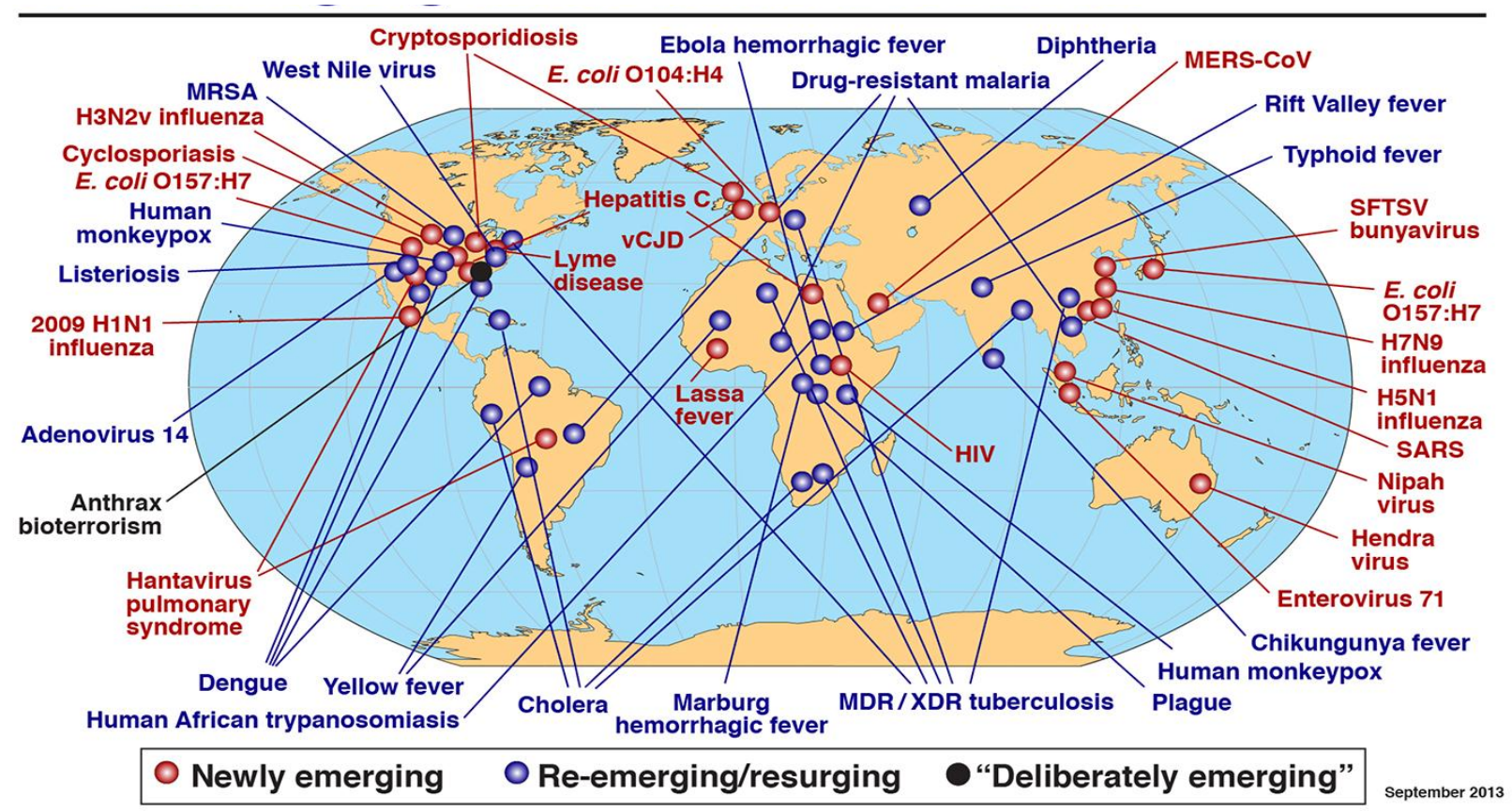

\section{Anthrax}

Robert Koch, the German physician and microbiologist, is credited with discovering that anthrax is the disease caused by the gram-positive bacteria, Bacillus anthracis. Koch made the discovery in 1896, after mass livestock deaths across Europe [21]. This discovery was significant, as it was the first time that a link was made between an organism and a disease. The bacteria are often found in the soil where it may remain in a hardy spore-form for several decades, despite harsh conditions [22]. Livestock will usually pick up the spores while they graze, and pass on the bacterium to any animals or humans that come in contact with them. There are three main routes of infection for anthrax (in order of least lethal to most lethal), cutaneous, gastrointestinal, and pulmonary. Recently in northern Europe, incidences of anthrax have been spread by contaminated needles, directly into the bloodstream and muscles. The 
symptoms of bloodstream anthrax are similar to those of cutaneous anthrax. Anthrax in itself is difficult to diagnose, as the inhalational disease is similar to symptoms of the flu or a whole slew of other diseases [22].

Figure 1.5: Gram stain of Bacillus anthracis [23]

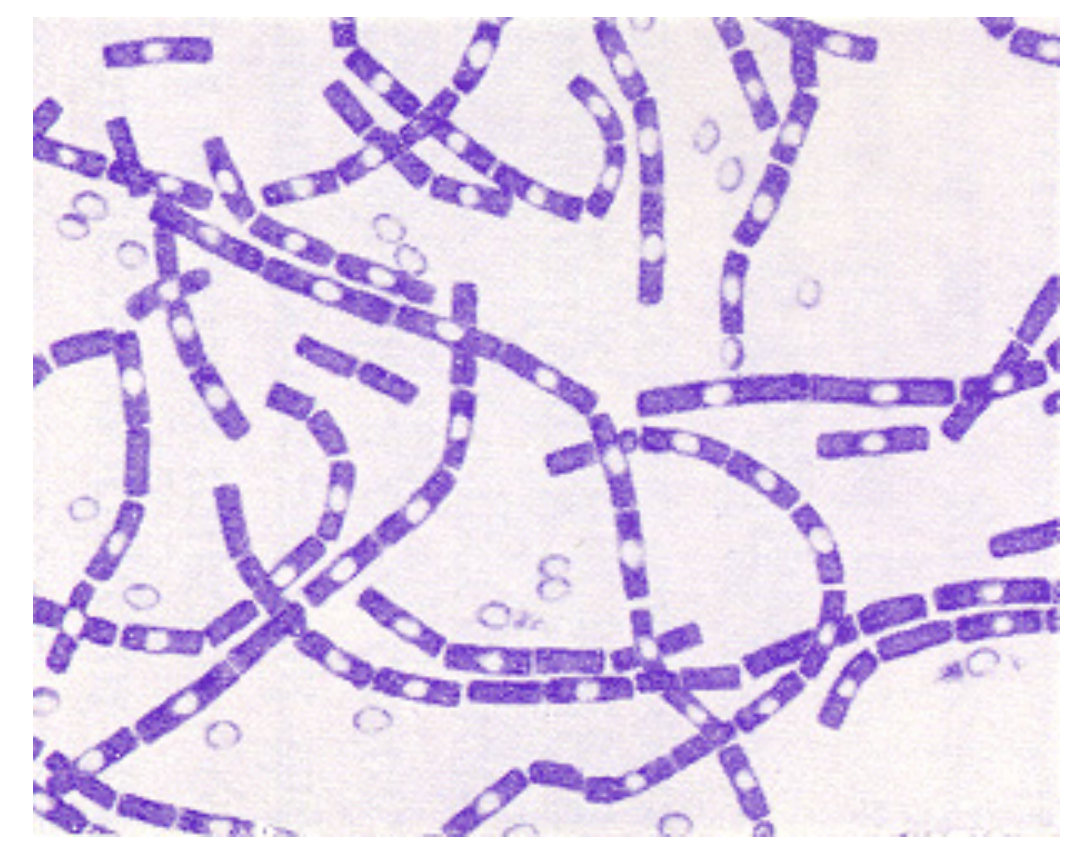

Anthrax infections are rare in developing countries, however most people are aware of it due to its use as a biological weapon, during ancient times, World Wars I and II, and most recently in 2001, when aerosolized spores were sent to various American senators and news media offices. As a result of the postal anthrax attacks, five individuals were killed. It is estimated that between 5,000-8,000 spores are sufficient to cause inhalational anthrax, with there being a clear genetic component contributing to anthrax toxin sensitivity (Martchenko). It is known that several governments and terrorist organizations have worked to weaponize anthrax. Despite the potential for being nefarious, anthrax is a wonderful tool for studying pathogenic mechanisms.

A lot is understood about the way in which anthrax spreads and becomes lethal within the host. Three toxic proteins produced by the bacterium are credited with largely damaging host 
cells, in order to allow infection to spread. The three toxic components are: protective antigen (PA), lethal factor (LF), and edema factor (EF). PA is a receptor-binding domain, that allows for the internalization of the other two enzymatic toxins, EF and LF. Our research focuses on the use of LF and PA only. Anthrax toxins are necessary in the initial stages of infection in order to suppress the innate host immune response to enable systemic infection. Anthrax toxins inhibit the scavenger functions of myeloid cells, including neutrophils and macrophages, allowing the vegetative bacteria to propagate. At later stages of infections, the high amounts of toxin kill the host; lethal toxin (LT) destroys cardiomyocytes and smooth muscle, while (edema toxin) ET affects hepatocytes in the liver [11].

Figure 1.6: The roles of lethal toxin and edema toxin in anthrax infection [11]

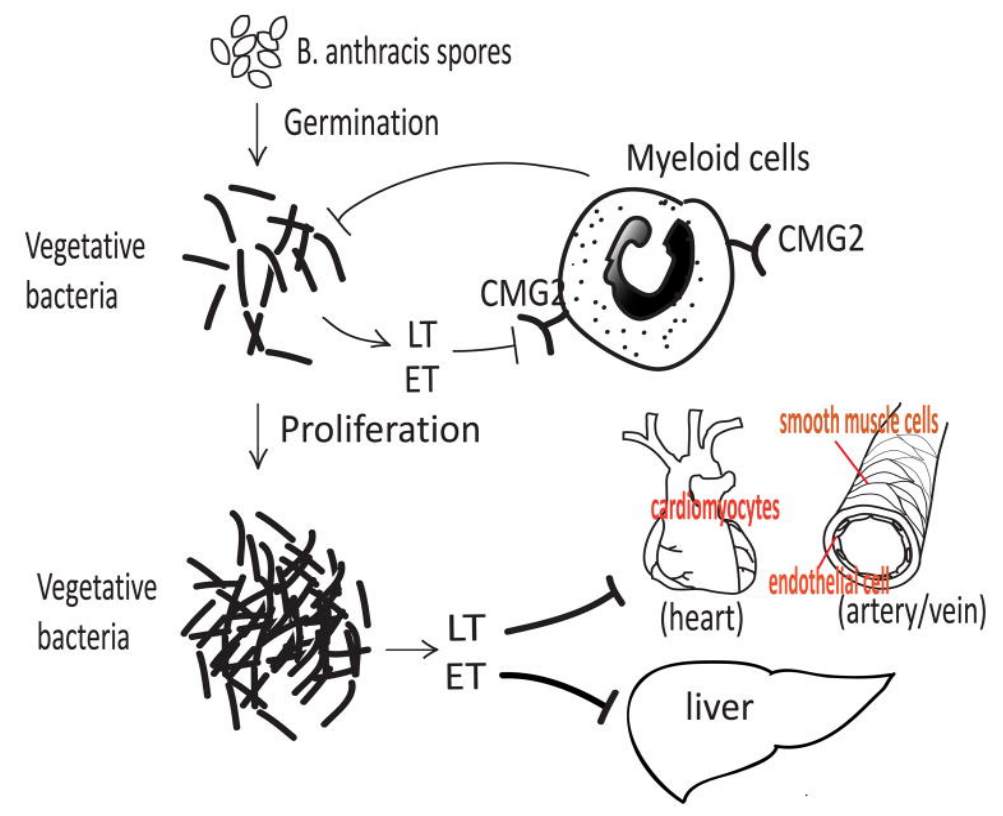

Due to anthrax toxins significant role in contributing to lethality, it is no surprise that antibiotic treatment alone is not very effective unless given in the early stages of disease. It is for this reason that there is value in discovering anthrax antitoxins. In addition, anthrax toxins provide an interesting disease model, as they utilize and exploit host mechanisms to exert their lethal effects. Much is known about the mechanisms exploited by anthrax toxins, and it's been 
observed that those host proteins are also exploited by different pathogens. Identifying chemotherapies that can interfere with lethal toxin internalization, has allowed us to explore broad-spectrum therapies, which is a major theme of this report. Finally, we took advantage of the observation that some pathogenic agents, specifically proteins, also belong to the same protein families as the host proteins they exploit. Using this knowledge, we attempted to indentify drugs that could simultaneously interfere with a pathogenic agent and boost host defenses (discussed in Chapter 5).

Our research may provide a creative and quicker approach to drug discovery, that may have broad-spectrum applications, and potentially reduce antibiotic resistance. This approach can be applied to other types of host proteins and for other pathogens and pathogenic agents. However, our approach is not without limitations. For example, a therapy designed to target a class of proteins, may not be specific enough, binding to other irrelevant yet similar proteins, causing side effects. It may be possible to improve upon our drugs in many ways. For example, indentifying the active chemical motif of our drugs and then engineering them to be more effective. Another method to improve our therapies involves combining drugs, with the hope of reducing the amounts of both drugs, while increasing the efficacy of the therapy as a whole. Our methodologies allowed us to identify drugs that inhibit proteins in the anthrax internalization pathway, and we were able to use our drug hits to suppress other pathogenic agents that exploit similar proteins. As a result of our research, we have compiled a database of all of the drugs in the John Hopkins Clinical Compound Library, and how they performed in a series of cellular and FRET assays involving anthrax intoxication host proteins. Such information is invaluable and can be the basis for future therapies for infectious diseases. 


\section{References:}

1. Philip S Brachman; Infectious diseases_past, present, and future. Int J Epidemiol 2003; 32 (5): 684-686. doi: 10.1093/ije/dyg282

2. Clardy, J., Fischbach, M. A., \& Currie, C. R. (2009). The natural history of antibiotics. Current biology, 19(11), R437-R441.

3. Aminov RI. A Brief History of the Antibiotic Era: Lessons Learned and Challenges for the Future. Frontiers in Microbiology. 2010;1:134. doi:10.3389/fmicb.2010.00134.

4. Gensini, Gian Franco, Andrea Alberto Conti, and Donatella Lippi. "The contributions of Paul Ehrlich to infectious disease." Journal of Infection 54.3 (2007): 221-224.

5. The National WWII Museum. "Thanks to Penicillin, he will come home!” Retrieved from: https://www.nationalww2museum.org/sites/default/files/2017-07/thanks-to-penicillin-lesson.pdf

6. Lumibyte. (2014).“Antimicrobial resistance timeline.” Retrieved from: http://lumibyte.eu/microbiologynews/antimicrobial-resistance-timeline/

7. Bartlett, John G., David N. Gilbert, and Brad Spellberg. "Seven ways to preserve the miracle of antibiotics." Clinical Infectious Diseases 56.10 (2013): 1445-1450.

8. Manfredi, Piero, and Alberto D'Onofrio, eds. Modeling the interplay between human behavior and the spread of infectious diseases. Springer Science \& Business Media, 2013.

9. Neu, Harold C. "The crisis in antibiotic resistance." Science 257.5073 (1992): 1064-1074.

10. Cassell, Gail H., and John Mekalanos. "Development of antimicrobial agents in the era of new and reemerging infectious diseases and increasing antibiotic resistance." Jama 285.5 (2001): 601-605.

11. Liu, Shihui, Mahtab Moayeri, and Stephen H. Leppla. "Anthrax lethal and edema toxins in anthrax pathogenesis." Trends in microbiology 22.6 (2014): 317-325.

12. Wilson, B. A., and R. J. Collier. "Diphtheria toxin and Pseudomonas aeruginosa exotoxin A: active-site structure and enzymic mechanism." ADP-Ribosylating Toxins. Springer Berlin Heidelberg, 1992. 27-41.

13. Didelot, Xavier, et al. "Within-host evolution of bacterial pathogens." Nature reviews. Microbiology 14.3 (2016): 150 .

14. Woolhouse, Mark EJ, et al. "Biological and biomedical implications of the co-evolution of pathogens and their hosts." Nature genetics 32.4 (2002): 569-577.

15. Finlay, B. Brett, and Pascale Cossart. "Exploitation of mammalian host cell functions by bacterial pathogens." Science 276.5313 (1997): 718-725.

16. Leist, Marcel, and Marja Jäättelä. "Four deaths and a funeral: from caspases to alternative mechanisms." Nature reviews. Molecular cell biology 2.8 (2001): 589.

17. The spread of superbugs. The Economist. Mar. 2011. 
18. World Health Organization. The global eradication of smallpox. Final Report of the Global Commission for the Certification of Smallpox Eradication. Vol. 4. Geneva, Switzerland., 1980.

19. Bazin, Hervé. "The eradication of smallpox: Edward Jenner and the first and only eradication of a human infectious disease." (2000).

20. Hektoan International Journal. (2009). "Newly emerging and re-emerging diseases." Retrieved from: http://www.hekint.org/images/article-images/LancetFigure1.JPG

21. Blevins, Steve M., and Michael S. Bronze. "Robert Koch and the 'golden age'of bacteriology." International journal of infectious diseases 14.9 (2010): e744-e751.

22. Lerner, K. L., \& Lerner, B. W. (2003). World of microbiology and immunology. Detroit: Gale.

23. Kenneth Todar. (2016) "Bacillus anthracis and Anthrax. Todar's Online Textbook of Bacteriology. Retrieved from: http://textbookofbacteriology.net/Anthrax.html 


\title{
Chapter 2
}

\section{Repurposing FDA approved drugs against the human fungal pathogen, Candida albicans}

Kevin Kim, Leeor Zilbermintz, and Mikhail Martchenko

\begin{abstract}
The high cost and prolonged timeline of new drug discovery and development are major roadblocks to creating therapies for infectious diseases. Candida albicans is an opportunistic fungal pathogen that is the most common cause of fatal fungal infections in humans and costs \$2-4 billion dollars to treat in the US alone. To accelerate drug discovery, we screened a library of 1581 existing FDA approved drugs, as well as drugs approved abroad, for inhibitors of C. albicans. The screen was done on YPD yeast growth media as well as on the serum plate assay developed in this study. We discovered that fifteen drugs, all which were originally approved for treating various infectious and non- infectious diseases, were able to kill Candida albicans. Additionally, one of those drugs, Octodrine, displays wide- spectrum anti-microbial activity. Compared to other selected anti-Candida drugs. Octodrine was shown to be one of the most effective drugs in killing serum-grown Candida albicans without significantly affecting the survival of host macrophages and skin cells. This approach is useful for the discovery of economically viable new therapies against infectious diseases.
\end{abstract}

Keywords: Antifungal, Drug-discovery, Off-label drug use, Small molecules 


\section{Background}

While almost all of us possess Candida albicans in our oral cavity, gastrointestinal tracts, genitourinary tracts, and on skin as a relatively harmless commensal organism, C. albicans is a major systemic fungal pathogen in humans [1]. Candida evades and escapes from the host's innate immunity, causing irritating and recurrent infections that can range from thrush in immunocompetent colonized hosts, to life- threatening systemic infections in immunocompromised in- dividuals such as patients with HIV, or those receiving immunesuppressing cancer chemotherapy and corticosteroids. Surprisingly, only 10 to $20 \%$ of individuals who develop bloodstream Candida infections are seriously immunocompromised. A large majority of patients develop Candida infections because they have become more susceptible while hospitalized due to the use of broad-spectrum antibiotics, surgery, and intravenous catheters. As a result, infections from C. albicans ranks as the fourth most common hospital-acquired infection in the United States. The cost of treating bloodstream Candida infections is $\$ 2-4$ billion per year in the US alone [2]. In the US, annual incidence of systemic candidiasis is approximately 70,000 cases per year, which results in the death rate of about 30 to $40 \%$, even after treatment with antifungal therapy [3].

The situation is especially grave in cancer patients. The incidence of Candida infection in all cancer patients is very high, ranging from 40 to $88 \%$ [4] [5]. The mortality rate among the Candida infected cancer patients reaches an alarmingly high $75 \%$ amongst the Filipino and Pacific Islanders [5]. Early antifungal treatment, although poorly tolerated by the host, is mandatory to improve the survival of cancer patients. Unfortunately, 30\% of Candida isolates are resistant to all antifungal treatments [6]. 
Host serum plays a prominent role in the pathogenicity of C. albicans. On the one hand, serum promotes morphological switching of Candida from yeast to hyphal forms, which is necessary for its evasion of phagocytosis and organ colonization [7]. On the other hand, serum is known to inhibit the activity of known antifungal drugs [8]. Taken together, these laboratory observations explain in part the clinical mortality observed during Candida blood infections, even when patients are treated with antifungals [5].

Several clinical and laboratory data suggests that currently available antifungal therapies are mostly ineffective in treating Candida infections [9]. Despite extensive research dedicated to the development of new therapeutic strategies, there are only a limited number of available drugs to fight against invasive fungal infections. Indeed, only four molecular classes targeting three distinct fungal metabolic pathways are currently used in clinical practice to treat systemic fungal infections. These include: fluoropyrimidine analogs, polyenes, azoles, and echinocandins [9] [10]. However, the efficacy of some of these drugs is severely limited because of their unacceptable toxicity, poor activity in blood, or the emergence of resistance; thereby underscoring an urgent necessity for new antifungal agents. Several other classes, such as morpholines and allylamines are only used as topical agents due to either their poor efficacy, or severe adverse effects when administered systemically [9] [10].

Unfortunately, the development of an entirely new drug is a long and expensive process. New drugs have to undergo an arduous approval process by the FDA in order to establish safety of the drug for human consumption [11]. We propose that the repurposing of existing FDAapproved drugs as antifungal agents may decrease the time and effort of bringing drugs with novel antifungal activity from the bench to the bedside. Recently, another group investigated the ability of FDA-approved drugs to inhibit $C$. albicans biofilm formation by screening the 
Prestwick Library, a commercially available chemical library of 1200 drugs [12]. However, $C$. albicans biofilm formation is just one of many pathogenesis strategies, such as yeast-to-hyphal phenotypic switching, white-opaque phenotypic switching, ability to adhere to mammalian tissues, and secretion of aspartyl proteinases [1] [7]. The goal of this study is to identify drugs capable of killing blood-borne Candida albicans, and we use serum as an in vitro surrogate of host blood. To this end, we have tested the anti-Candida activity of drugs from the Johns Hopkins Clinical Compound Library (JHCCL) [13] on Candida grown on serum-containing media. This library consists of drug-compounds that are FDA-approved with a diverse range of functions, mechanisms of action and well- characterized pharmacological and toxicological properties.

\section{Methods}

Candida albicans and bacterial strains

Strain SN250 is the wild type reference strain of $C$. albicans. It serves as the reference strain for our genetic knockout library screen. It is derived from the wild type strain SC5314, a human clinical isolate recovered from a patient with generalized candidiasis [14]. SN250 was used for drug screening experiments. The bacterial strains consisted of Bacillus cereus strain 10987 and Escherichia coli strain C600. The genetic screen for mutant sensitivity to Octodrine was tested with three C. albicans libraries that were previously created in [15] [16] [17].

\section{Media and growth conditions}

C. albicans strains were cultured in liquid YPD medium at $30{ }^{\circ} \mathrm{C}$ overnight. E. coli and B. cereus were cultured in liquid LB medium at $37{ }^{\circ} \mathrm{C}$ and $30{ }^{\circ} \mathrm{C}$, respectively, shaking 
overnight. A novel method to incorporate fetal bovine serum to agar was devised. Fetal bovine serum was preheated in a water bath set at $65^{\circ} \mathrm{C}$. We found that isothermal conditions of the two mixtures eliminated the formation of foam upon coalescence. The agar solution for the serum mixture consisted of $16 \mathrm{~g}$ agar, which was then brought up to $300 \mathrm{ml}$ with nanopure water. The agar solution was then autoclaved at $120^{\circ} \mathrm{C}$ for $45 \mathrm{~min}$. The agar and serum mixtures were then amalgamated while in their isothermal states.

\section{Chemicals}

An FDA-approved drug library comprising of 1500 drugs was purchased from Johns Hopkins, titled, Johns Hopkins Clinical Compound Library (JHCCL) version 1.0. The drugs arrived as $10 \mathrm{mM}$ stock solutions in sealed microtiter plates and were made using DMSO or water as solvents. Drugs were arrayed in 96-well plates and screened at a stock concentration of $10 \mathrm{mM}$. Drugs were from Fisher and Sigma and were of the highest purity available. The library was stored at $-20{ }^{\circ} \mathrm{C}$ until use. Prior to use, the library of drugs was thawed at room temperature. Drugs of interest were isolated and reproduced from prepared $10 \mathrm{mM}$ solutions. Antimycin A, Captan, Chlorquinaldol, Clotrimazole, Disulfiram, Fluvastatin, Mycophenolic Acid, Methylbenzethonium Chloride, Miconazole, Nitroxoline, Octodrine, Pyrithione Zinc, Fluconazole, and Octanoic Acid were purchased from Sigma-Aldrich (St. Louis, MO, USA). Nifuroxime was purchased from MP Biochemicals (Solon, OH, USA). All drugs were prepared to $10 \mathrm{mM}$ using DMSO as the solvent. DMSO was purchased from Amresco ${ }^{\circledR}$ (Solon, $\mathrm{OH}$, USA). Fetal bovine serum (Triple Membrane $0.1 \mu \mathrm{m}$ filtered) was purchased from GeneMate BioExpress (Kaysville, UT, USA). 


\section{Screening assay}

The sensitivity of $C$. albicans to drugs was assessed by a chemical screen. The absorbance at optical density at $600 \mathrm{~nm}\left(\mathrm{OD}_{600}\right)$ of yeast and bacterial overnight cultures were determined for each of our experiments. The absorbance values were then converted to cells $/ \mathrm{ml}$ using McFarland's scale. Twenty five million Candida cells were added to all $10 \mathrm{~cm}$ petri dishes; 600 million bacterial cells were added to all $10 \mathrm{~cm}$ bacterial petri dishes. Five microlitre of each drug was placed directly on the agar surface using a multichannel pipette and slight contact of the tip to the agar made to leave an impression to facilitate later analysis. Drugs that were replicated were done on petri dishes, following the same protocol in at least five independent experiments. For the replica- tion studies, only a single drug was placed per plate. The plates were incubated at either 25 or $37^{\circ} \mathrm{C}$ for $24 \mathrm{~h}$. The drugs-of-interest were selected on their ability to produce a distinct zone of inhibition of fungal growth greater than the zone made by DMSO alone and at the same time that is comparable to, if not greater than the positive control, Fluconazole. The zones of inhibition were quantified by measuring their diameters in $\mathrm{mm}$, as recommended by the Clinical Laboratory Standards Institute (CLSI) procedures outlined in the manual M44- A2 [18] [19]. In addition, we utilized the software ImageJ [20] to digitally quantify the magnitude of every zone of inhibition.

E. coli and B. cereus were cultured overnight in liquid LB media at 37 and $30{ }^{\circ} \mathrm{C}$ respectively. The sensitivity of $E$. coli and B. cereus to Octodrine was assessed by spreading $6 \times$ $10^{8}$ cells of their respective overnight cultures onto petri dishes containing solid LB media. $5 \mu$ l of neat Octodrine was placed directly on the agar surfaces. The plates with E. coli were incubated at $37^{\circ} \mathrm{C}$, while plates with $B$. cereus were incubated at $30{ }^{\circ} \mathrm{C}$ for $24 \mathrm{~h}$. 
Determination of minimal effective drug concentrations by drug diffusion susceptibility testing Plates inoculated with $C$. albicans were prepared using the protocol described above. To elucidate the ability of the varying concentrations of drugs to form zones of inhibition, two-fold serial drug dilution experiments were performed. To perform the first two-fold dilution, one part of the $10 \mathrm{mM}$ stock solution was mixed with one part DMSO. Each subsequent dilution was done with aliquots from the prior dilution mixed with equal parts of DMSO. $5 \mu 1$ of each drug dilution was spotted onto a lawn grown on YPD plate, as well as $5 \mu 1$ of DMSO as a negative control. Dilutions beyond $0.07813 \mathrm{mM}$ that were still forming a significant zone of inhibition were further diluted on a separate plate. Drug-treated plates were then incubated at either 25 or $37^{\circ} \mathrm{C}$ for $24 \mathrm{~h}$. Two- fold serial dilutions of Octodrine were done on YPD and Serum plates with undiluted Octodrine as the most con- centrated solution.

\section{Genotypic mutant screening against Octodrine}

Each C. albicans knockout strain from one of the three C. albicans libraries [15] [16] [17] was cultured in individual wells of 96 well plate in $100 \mu$ of YPD media overnight at $30^{\circ} \mathrm{C}$. $5 \mu 1$ of each Candida knockout overnight culture was spotted onto a YPD solid plate using a multichannel pipette. The cells were then left to absorb into the YPD plates for $1 \mathrm{~h}$ at $25^{\circ} \mathrm{C}$. Using a multichannel pipette, $5 \mu 1$ of Octodrine $10 \mathrm{mM}$ was spotted directly on top of the $C$. albicans cells. The plates were then placed in an incubator set at $30{ }^{\circ} \mathrm{C}$ and left overnight. Analysis of plates consisted of isolating any strains that exhibited resistance to $5 \mu 1$ of $10 \mathrm{mM}$ Octodrine. Resistance was noted by the ability of the Candida cells and the subsequent drugtreated spot to lack a zone of inhibition. 
Mammalian cell culture, drug treatment, and survival assay

RAW264.7 mouse macrophage cells (ATCC number TIB- 71) and human melanoma C32 cells (ATCC number CRL-1585) were maintained in DMEM (Sigma-Aldrich) supplemented with $10 \%$ FBS (Bioexpress) and $100 \mu \mathrm{g} / \mathrm{mL}$ penicillin and $100 \mu \mathrm{g} / \mathrm{mL}$ streptomycin. Mammalian cells $(10,000$ per well) were seeded in 96 -well plates $(100 \mu \mathrm{l} /$ well $) 24 \mathrm{~h}$ before the assay. During the assay, $1 \mu \mathrm{l}$ of $10 \mathrm{mM}$ drug was added to $100 \mu \mathrm{l}$ of cell-containing media. Twofold serial dilutions of the media were performed. RAW264.7 and C32 cells were treated with drugs for 24 and $48 \mathrm{~h}$ respectively, and determination of cell viability by 3-(4,5-dimethylthiazol2-yl)-2,5-diphenyltetrazolium bromide (MTT) assay was performed as described in ??? [21]. Each data point shown in the figure for MTT assays represents the average of results from at least two wells in each of at least two separate experiments. Cell viability is shown as the percentage of survivors obtained relative to untreated cells grown in media only $(100 \%)$.

Image capture and image processing

All images were taken with an 8MP iSight camera with an aperture size of F2.4 and touch-to-focus capabilities. Images were standardized with a universal template to allow for direct comparison between images. Images are stock and unaltered by any graphics editing software.

\section{Results}

Moderate ability of Fluconazole to kill serum-grown Candida albicans at $37{ }^{\circ} \mathrm{C}$ It has been reported that host serum markedly inhibits growth of the human fungal pathogen, Candida albicans [22] [23] [24]. We have confirmed these observations by showing that 
Candida wild type strain SN250 [15] is unable to grow in liquid $100 \%$ Fetal Bovine Serum at either 25 or $37{ }^{\circ} \mathrm{C}$ (data not shown). However, during the course of our experiments, we have observed that Candida is able to grow and establish a lawn on solid serum plates containing 62.5 $\% \mathrm{v} / \mathrm{v}$ FBS and $37.5 \% \mathrm{v} / \mathrm{v}$ agar solution, at both temperatures (Fig. 1a).

Figure 2.1: Analysis of $C$. albicans strain SN250 treated with various drugs and diagram

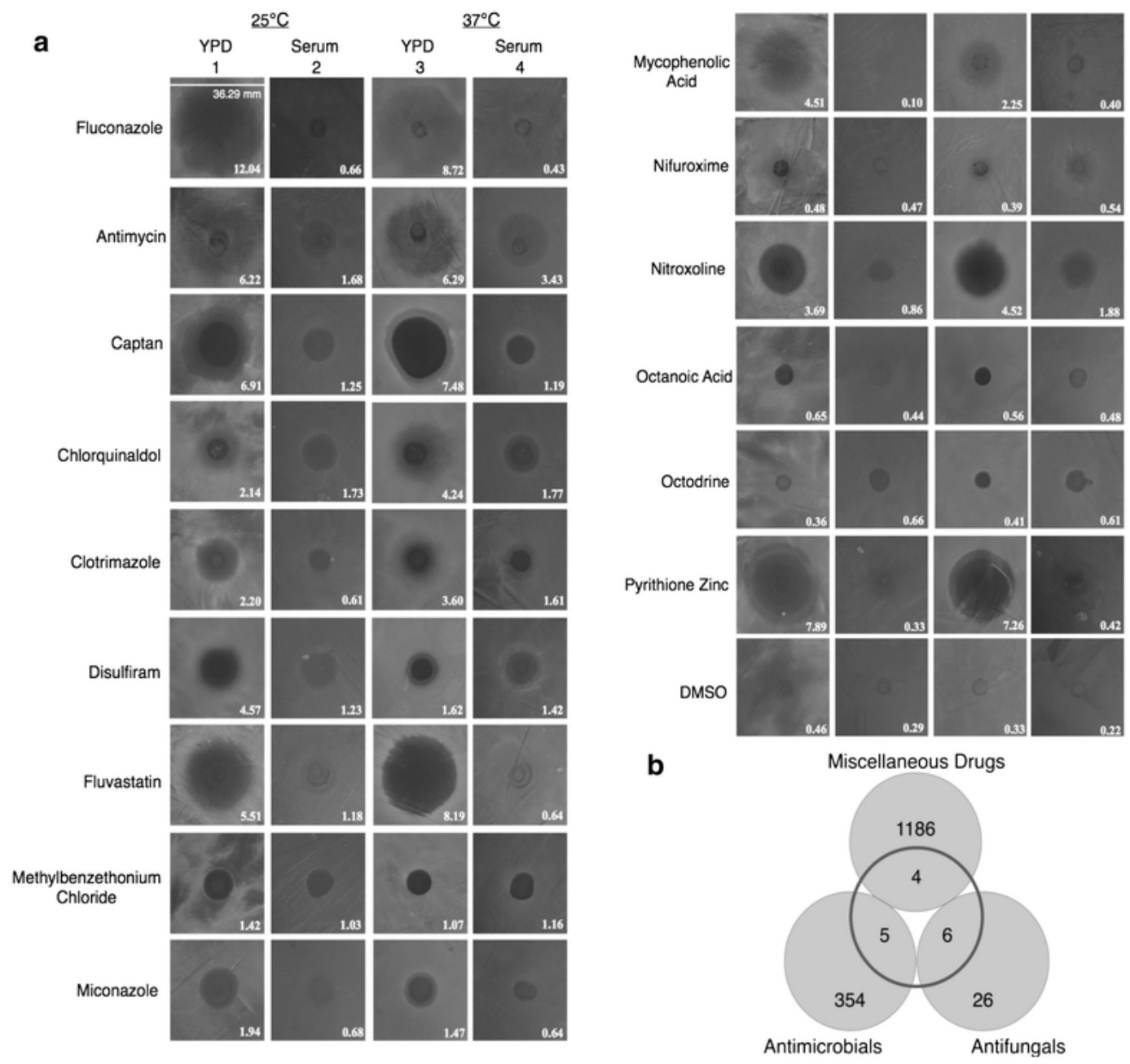

The search for new antifungal drugs. a Analysis of $C$. albicans strain SN250 treated with various drugs. The strains were grown and exposed to drugs determined to be drugs of interest by our chemical screen. The size of the zone of inhibition on each image is shown with the same scale $(\mathrm{mm})$, with standard deviation values are shown in Additional file 1: Table S1. Plates were treated with drugs after spreading of $200 \mu \mathrm{l}$ of liquid Candida culture and left to incubate overnight in either 25 or $37^{\circ} \mathrm{C}$. b The hits were classified into three classes: Antifungal, Antimicrobial, and Miscellaneous drugs. Numbers within grey circles represent number of drugs of each class in JHCCL, while numbers in the transparent middle circle shows the number of hits of drugs from our screen. 
We investigated whether Fluconazole, the widely used anti-Candida drug, was able to kill C. albicans on solid serum plates. While Fluconazole was shown to be an effective inhibitor of Candida growth on standard solid YPD plates, (Fig. 1a), we observed that Fluconazole moderately inhibits the growth of Candida on serum plates (Fig. 1a and Additional file 1: Table S1). It should be noted, however that Fluconazole formed prominent zones of inhibition on the solid YPD plates. In addition, we observed that Fluconazole exhibited diminished effectiveness at forming zone of inhibition at $37^{\circ} \mathrm{C}$ compared to $25^{\circ} \mathrm{C}$ (Fig. 1a and Additional file 1: Table S1). We decided to assess the drug-pathogen interactions at $25^{\circ} \mathrm{C}$ in additional to body temperature because there is a serious problem of Candida growth in catheters where it may be exposed to serum at room temperatures [25].

Screening of inhibitors of Candida albicans lawn formation

In light of the moderate effectiveness of Fluconzole to kill $C$. albicans in serum at the physiologically relevant temperature $\left(37^{\circ} \mathrm{C}\right)$, and in search for alternative anti-fungal drugs, we decided to screen the library of chemicals [13] approved by the FDA for human use for their ability to kill Candida albicans. JHCCL consists of 1581 FDA-approved drugs, as well as drugs approved abroad, consisting of small molecules $(10 \mathrm{mM})$ that are used as treatments for a variety of diseases, including, but not limited to: infectious, neurodegenerative, psychiatric, cardiovascular diseases and cancer.

We identified inhibitors of Candida growth formation by performing a primary screen on the 1581 drugs belonging to the JHCCL. We plated Candida on solid YPD and serum plates, and placed $5 \mu \mathrm{l}$ of each $10 \mathrm{mM}$ drug on top of the fungal lawn. We tested the effect of exposure to each of the drugs from the library on their ability to inhibit Candida growth, as well as their 
ability to form a zone of inhibition within the fungal lawn. Based on this screen, we identified 15 drugs that inhibit Candida growth on solely YPD or on both YPD and serum plates in at least five independent experiments at two temperatures, $25^{\circ} \mathrm{C}$ and $37^{\circ} \mathrm{C}$ (Fig. 1a). We classified the 15 hits into three different classes to facilitate interpretation of our results. They were: 6 hits from 32 known antifungals, 5 hits from 359 antimicrobials/antiseptics, and 4 hits from 1190 other multifunctional drugs (Fig. 1b). While these drugs were chosen in these screens for their ability to inhibit $C$. albicans lawn formation, the actual levels of inhibition varied from weak to strong inhibition (Fig. 1a and Additional file 1: Table S1).

All 6 selected antifungal drugs, Antimycin A, Captan, Clotrimazole, Fluconazole, Miconazole, and Pyrithione Zinc showed strong inhibition of Candida growth on YPD plates at $25^{\circ} \mathrm{C}$ and $37^{\circ} \mathrm{C}$ (Fig. 1a and Additional file 1: Table S1). However, with the exception of the pesticide Captan, all of the antifungals exhibited weak inhibition of Candida growth on serum plates (Fig. 1a and Additional file 1: Table S1).

Out of the five antimicrobial/antiseptic drugs selected by our screen, Chlorquinaldol and Methyl-benzethonium chloride displayed the strongest inhibition of $C$. albicans growth on serum plates. Nifuroxime, Nitroxoline, and Octanoic acid showed weaker inhibition of Candida growth on serum plates (Fig. 1a and Additional file 1: Table S1).

Interestingly, from a drug-repurposing point of view, 4 drugs from 1190 of the other multifunctional drugs, showed anti-Candida activity on YPD plates (Fig. 1a and Additional file 1: Table S1). Of those, Fluvastatin and Mycophenolic acid showed very strong inhibition of YPD grown Candida, but failed to inhibit its growth on serum plates (Fig. 1a and Additional file 1: Table S1). The other 2 drugs, Disulfiram and Octodrine showed a consistent moderate-to-weak anti-Candida activity on YPD and serum plates (Fig. 1a and Additional file 1: Table S1). 
Diffusion susceptibility testing of the hits obtained from the screen

The 15 hits from the primary screen consisting of antifungals, antimicrobials, and miscellaneous drugs were tested in diffusion susceptibility assays in order to determine their potency against $C$. albicans lawns. These confirmatory screenings were performed over a range of drug concentrations, where $5 \mu \mathrm{l}$ of drugs within the range of $10 \mathrm{mM}$ to $0.3 \mu \mathrm{M}$ were applied on YPD-grown Candida cells and plates were incubated for $24 \mathrm{~h}$. YPD plates were chosen as the testing media since some of the drug hits were ineffective in inhibiting fungal growth on serum plates. The efficacy of each drug was evaluated by estimating the inhibitory concentration at which the drug formed a zone of inhibition on a fungal lawn of YPD plates.

We found that with the exception of Fluconazole and Captan, all antifungals were able to inhibit Candida growth in the $\mu \mathrm{M}$ drug range (Fig. 2 and Additional file 1: Table S2). All five antimicrobial and antiseptic drugs were only able to inhibit fungal growth in the $\mathrm{mM}$ drug concentrations (Fig. 2 and Additional file 1: Table S2). Surprisingly, among the drugs approved for non-infectious disease treatments, Fluvastatin was able to inhibit C. albicans growth in the $\mu \mathrm{M}$ drug concentration, while the rest of the drugs were only inhibitory in the $\mathrm{mM}$ drug concentrations. 
Figure 2.2: Agar drug diffusion susceptibility assay of Candida albicans SN250
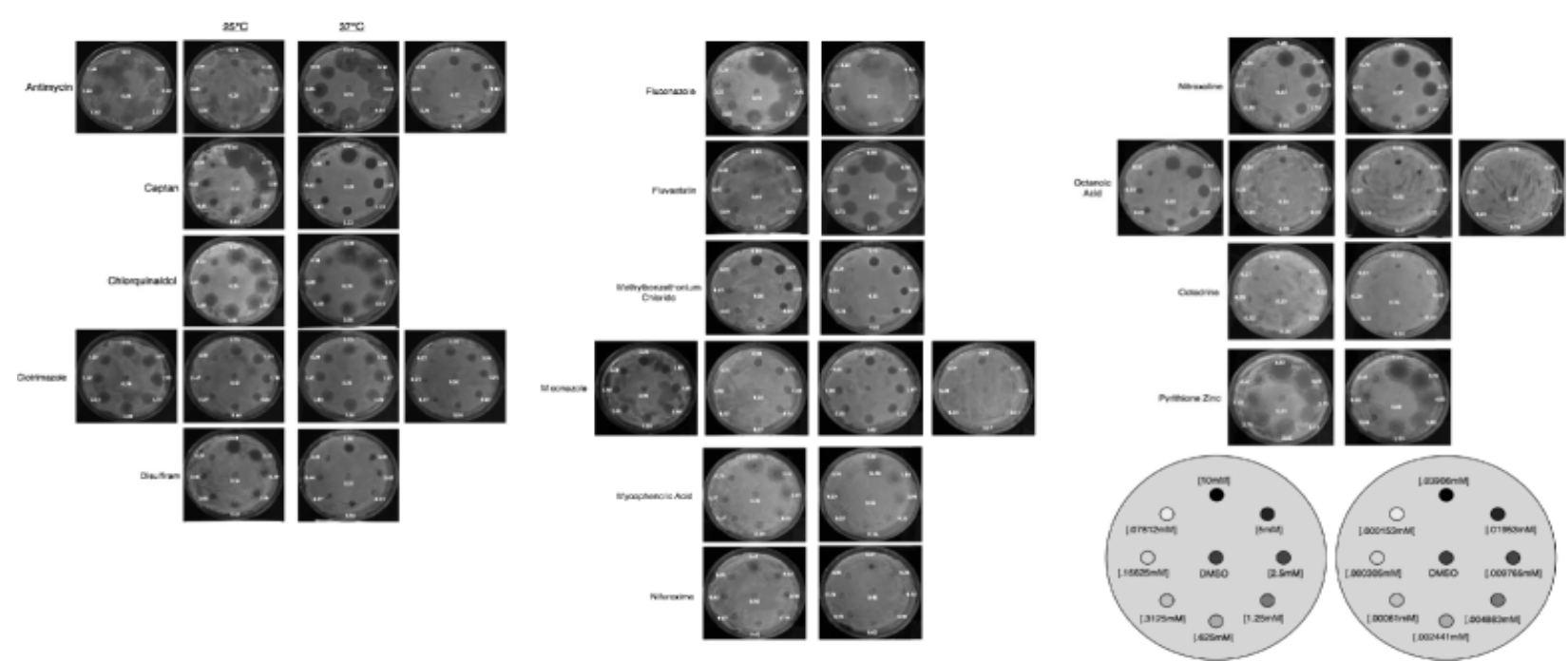

Plates were treated with various concentrations of drugs after spreading of $200 \mu 1$ of liquid Candida culture and left to incubate overnight in either 25 or $37^{\circ} \mathrm{C}$. The middle of the plate served as the negative control, DMSO. Dilutions that failed to exhibit discernable inhibition after one plates were further diluted a second time. The size of the zone of inhibition on each image is shown with the same scale ( $\mathrm{mm}$ ), with standard deviation values are shown in Additional file 1 Table S2

\section{Broad-spectrum antimicrobial properties of Octodrine}

Although nine antimicrobial and non-antimicrobial drugs we discovered have not been approved by FDA to treat fungal infections, eight of them were found previously to kill Candida albicans [26] [27] [28] [29] [30] [31] [32] [33] [34] [35] [36] [37] [38] [39]. Octodrine, the drug previously used as a decongestant [40] [41] showed an ability to kill serum-grown C. albicans when applied at $10 \mathrm{mM} 5 \mu \mathrm{l}$ drop (Fig. 1). Furthermore, Octodrine is the only drug that has not been tested to kill fungi previously. We wanted to investigate whether the application of an even higher concentration of Octodrine would augment its antifungal properties. To test this, we applied $5 \mu$ l of neat, undiluted Octodrine, which is produced in a liquid form, as well as its twofold serial dilutions on the serum and YPD grown Candida lawn. We discovered that the undiluted amount of Octodrine was effective in eliminating the fungal growth (Figs. 3 and 4 and Additional file 1: Tables S3 and S4). We also observed that Octodrine is more effective in 
inhibiting serum grown Candida compared to YPD grown Candida, as the inhibitory concentrations of Octodrine were more pronounced on serum than on YPD plates (Fig. 3, Additional file 1: Table S3).

Figure 2.3: Agar Octodrine diffusion susceptibility assay of Candida albicans SN250.

\section{Serum}
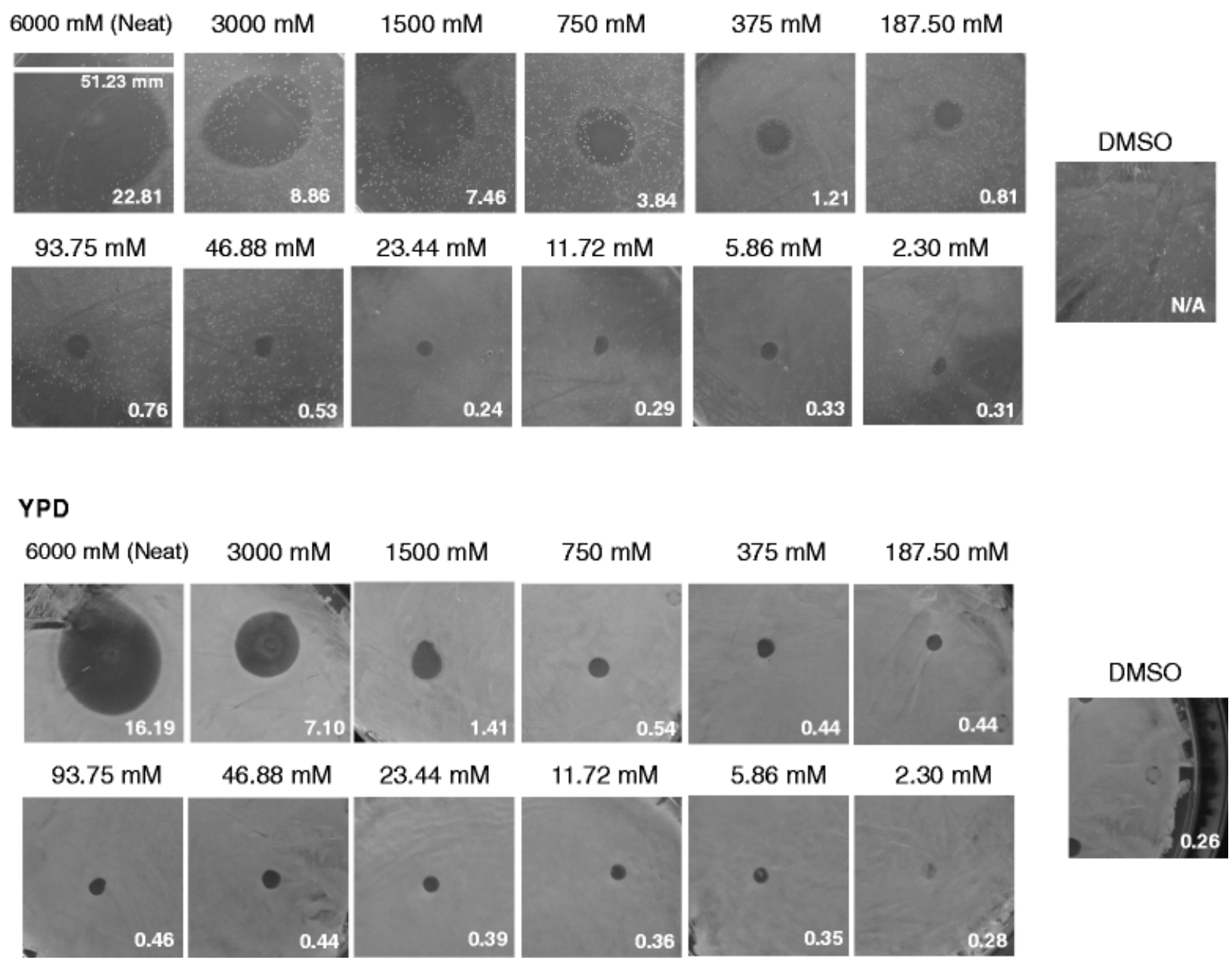

Plates were treated with various concentrations of Octodrine after spreading of liquid Candida culture and left to incubate overnight in either 25 or $37^{\circ} \mathrm{C}$. The equal volume of negative control, DMSO, was also included. The size of the zone of inhibition on each image is shown with the same scale $(\mathrm{mm})$, with standard deviation values are shown in Additional file 1 Table S3

Figure 2.4: The sensitivities of Candida albicans, Escherichia coli, and Bacillus cereus to neat Octodrine 


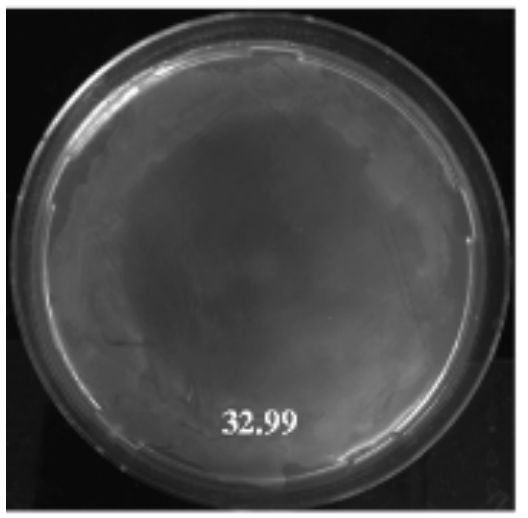

Candida albicans

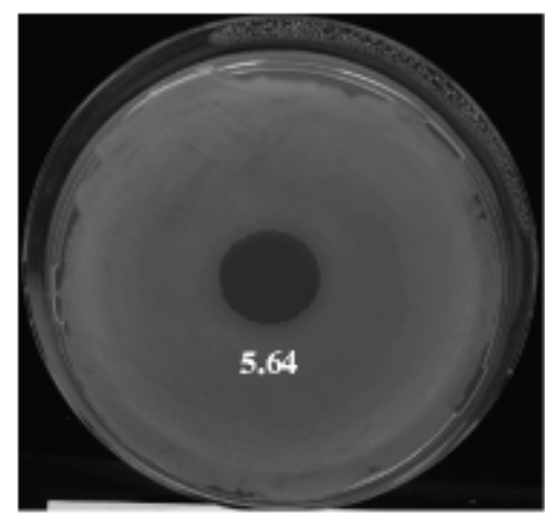

Bacillus cereus

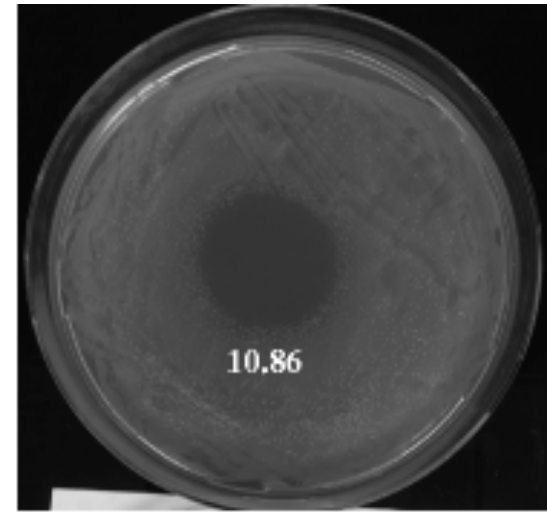

Escherichia coli

Plates were treated with $5 \mu \mathrm{l}$ of undiluted Octodrine after spreading of $200 \mu \mathrm{l}$ of liquid Candida $(25 \times 106$ cells $)$ or bacterial cultures $(600 \times 106$ cells $)$ on $10 \mathrm{~cm}$ petri dish and left to incubate overnight in either $37^{\circ} \mathrm{C}$ for C. albicans and E. coli or in $30{ }^{\circ} \mathrm{C}$ for $B$. cereus. The size of the zone of inhibition on each image is shown with the same scale $(\mathrm{mm})$, with standard deviation values are shown in Additional file 1 Table S4

In order to identify Candida proteins and signaling pathways that mediate the lethality of Octodrine, we screened three C. albicans knockout libraries, collectively consisting of 908 mutant strains lacking one of the previously demonstrated virulence genes, for any alterations in sensitivity to $10 \mathrm{mM}$ Octodrine. These libraries consisted of 647 mutant strains lacking one of the essential virulence genes [15], 96 cell wall protein mutants [42], and 165 transcription factors mutants [43]. We found that all Candida mutants were as sensitive to $5 \mu \mathrm{l}$ of $10 \mathrm{mM}$ Octodrine as the wild type strain (Additional file 1 Figure S1).

We hypothesized that Octodrine may kill microorganisms by targeting their non-protein cellular components. To investigate this we tested the sensitivities of Escherichia coli strain C600 and Bacillus cereus strain 10987, gram-negative and gram-positive bacteria, respectively, and frequent disease-causing bacteria, to Octodrine. These bacterial strains were chosen because they are wild type strains with known genotypes and genomes [44] [45]. We observed that $5 \mu$ l of neat Octodrine formed a prominent zone of inhibition in both E. coli and B. cereus lawns (Fig. 4 and Additional file 1: Table S4), which suggests that Octodrine possesses wide spectrum 
antimicrobial properties.

Since Octodrine was one of the most prominent drugs that killed C. albicans in serum, we tested the sensitivity of mouse macrophage cell line RAW264.7 to Octodrine, and compared it to the rest of selected drugs. Since Octodrine stock was dissolved in DMSO, we had to test the sensitivity of the cell line to this solvent alone. Cell viability was determined by MTT assay (Methods) and was calculated as the percentage of surviving cells in various chemical concentrations relative to cells treated with media alone. We observed that the sensitivity of mouse macrophages to Octodrine was the close to the sensitivity to the DMSO alone (Table 1). This strongly suggests that Octodrine concentrations that kill Candida albicans in serum (Fig. 1a) do not affect the survival of host phagocytes. The sensitivity of RAW264.7 cells to DMSO has previously been reported [46], and is consistent with the cellular sensitivity seen here. We tested the sensitivity of RAW264.7 macrophage like cells because macrophages are first line of defense against Candida, and knowing the sensitivity of those cells to antifungal is an important question. We confirmed these observations by testing sensitivity of human skin melanoma cell line, C32 (Table 1). With the exception of Octodrine, Floconazole, Nifuroxime, and Fluvastatin, all other selected drugs adversely affected the survival of host cells, which suggests that they may have undesirable side effects when used in blood. We chose this cell line because of the relevance of skin to Candida infections. 
Table 2.1: Minimal cytotoxic concentration (MCC) calculations for the cell lines RAW264.7 and C32 treated with selected drugs

\begin{tabular}{|l|l|l|}
\hline Drug & MCC $(\mu \mathrm{M})$ RAW264.7 & MCC $(\mu \mathrm{M}) \mathrm{C} 32$ \\
\hline Fluconazole & 100.00 & 100.00 \\
\hline Antimycin & 3.13 & 0.098 \\
\hline Captan & 12.50 & 12.50 \\
\hline Chlorquinaldol & 0.20 & 6.25 \\
\hline Clotrimazole & 6.25 & 12.50 \\
\hline Disulfiram & 12.50 & 12.50 \\
\hline Fluvastatin & 50.00 & 6.25 \\
\hline Methylbenzethonium Chloride & 6.25 & 1.56 \\
\hline Miconazole & 6.25 & 1.56 \\
\hline Mycophenolic Acid & 0.78 & 1.56 \\
\hline Nifuroxime & 25.00 & 25.00 \\
\hline Nitroxoline & 6.25 & 6.25 \\
\hline Octanoic Acid & 0.78 & 6.25 \\
\hline Octodrine & 25.00 & 25.00 \\
\hline Pyrithione Zinc & 0.78 & 1.56 \\
\hline DMSO & 50.00 & 50.00 \\
\hline
\end{tabular}

The solvent DMSO is used as a negative control. Mammalian cells were treated with drugs at concentrations shown. The drugs were serially-diluted, and the MCC is defined as the first concentration of the drug, which is able to lower cell viability below $100 \%$. Cell viability was determined by MTT assay (Methods) and is shown as the percentage of survivors relative to cells treated with media alone

\section{Discussion}

This study was designed to test FDA and foreign-approved small molecules drugs for their antifungal properties, with the objective of reducing the cost and time necessary to develop much needed anti-Candida albicans therapies. This library consists of an FDA-approved, offpatent collection of 1581 small molecules $(10 \mathrm{mM})$ that are used as drugs for a variety of diseases, including infectious, neurodegenerative, psychiatric, cardiovascular diseases and cancer. Such an approach would rapidly expedite the drug discovery and development process since the general pharmacology, toxicology, and pharmacokinetic properties of all these drugs are already well established. This would facilitate the further analysis of the novel functionalities of the established molecules because the structure, chemical properties, and biological functions of almost all members of this library are known. 
We have developed a serum-based assay to address the limitations of currently used YPD media, whose components do not represent in vivo components that support the growth of Candida. The moderate-to-mild effectiveness of Fluconazole and other FDA approved antifungal drugs on our serum assay is comparable to the effectiveness of Octodrine in killing serum-grown C. albicans.

In our study, fifteen out of 1581 drugs displayed anti-Candida properties. Overall, all drugs discovered in our study could be separated into three structural categories: five-membered heterocyclic drugs, such as azoles and oxoles, six-membered heterocyclic compounds (pyridines), and other structures (Fig. 5). The fact that we selected six drugs that were previously approved by FDA to treat fungal infections biologically validates our approach. The six antifungal drugs obtained as hits from the screen comprised three different chemical classes: azoles (Fluconazole, Captan, Clotrimazole, and Miconazole), pyridine (Pyrithione Zinc), and other structures (Antimycin A). Additionally, we found five antimicrobial/antiseptic drugs to be effective at inhibiting C. albicans lawn formation in the screen. These drugs include general antiseptics and antibacterial antibiotics, and comprise three different chemical classes: oxoles (Nifuroxime), pyridines (Nitroxoline and Chlorquinaldole), and other structures (Octanoic acid and Benzethonium Chloride) (Fig. 5). The fact that these five other drugs that were approved by FDA to treat other non-fungal infectious diseases were also observed to kill Candida albicans shows that these drugs could be repurposed to be broad-spectrum anti-microbial drugs. 
Figure 2.5: Chemical structures of 15 drugs shown to have anti-Candida albicans activity in our screen

\section{5-Member Heterocyclic compounds: Azoles and Oxoles}
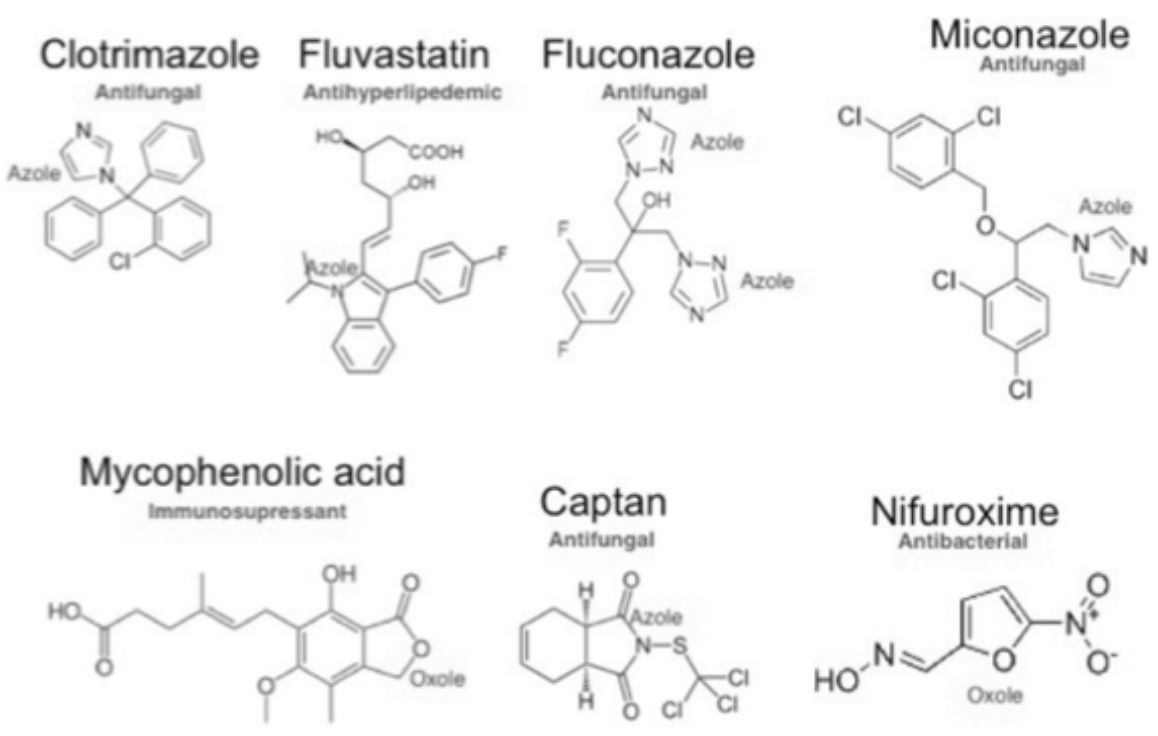

6-Member Heterocyclic compounds: Pyridines

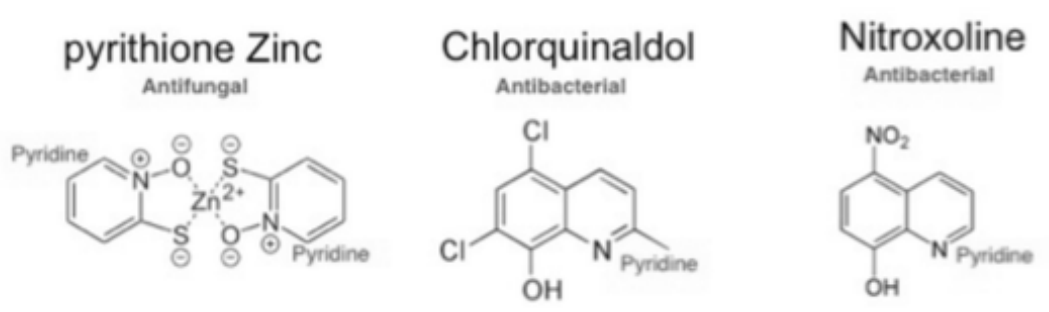

\section{Miscellaneous structures}

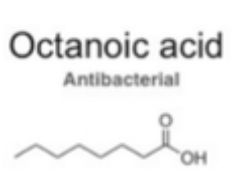

Octanoic acid

$\sim \sim^{\mathrm{O} O H}$
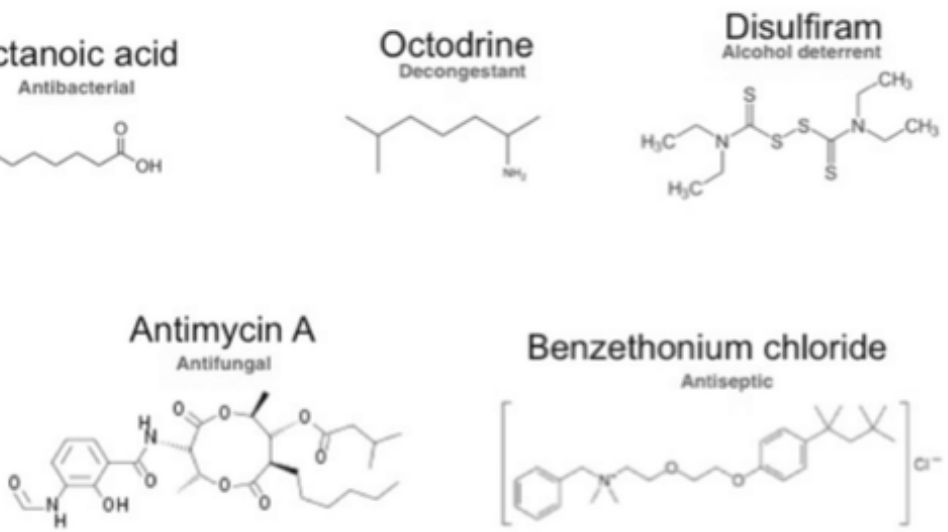

All drugs were categorized into 3 classes: 5-membered heterocyclic (Azoles and Oxoles) and 6-membered heterocyclic (Pyridines) compounds, as well as drugs of other structures. The FDA approved applications are shown in green. Substructures are indicated in red. 
Lastly, from the point of view of drug repurposing, the most interesting class of drugs would be the one with demonstrated activity against a variety of diseases, but with no known or characterized antifungal activity to date. From the screen, we found four drugs belonging to this class to be effective in preventing Candida growth. These drugs have been designed for several indications, including immune-suppression (Mycophenolic acid), deterrent of alcohol consumption (Disulfiram), antihyperlipidemic (Fluvastatin), and decongestant (Octodrine). These drugs comprise three different chemical classes: azole (Fluvastatin), oxole (Mycophenolic acid), and other structures (Disulfiram and Octodrine) (Fig. 5). These four drugs that were approved to treat non-infectious diseases showed antifungal properties and thus, could be repurposed as new antifungal drugs.

Recently, another group investigated the ability of FDA-approved drugs to inhibit $C$. albicans biofilm formation [12] by screening the Prestwick Library, a commercially available chemical library of 1200 drugs. Interestingly, the authors of that paper discovered several antifungal drugs in common to our study: Miconazole, Clotrimazole, and Methylbenzonium chloride. The difference between the two studies is that Siles et al. [12] screened for drugs capable of inhibiting Candida biofilm formation, while we looked for FDA approved drugs capable of inhibiting the growth of non-biofilm $C$. albicans growth. In addition, with the exception of Octodrine, every one out of fifteen discovered drugs in our study had been previously tested for the ability to kill Candida albicans [26] [27] [28] [29] [30] [31] [32] [33] [34] [35] [36] [37] [38] [39].

In this study, Octodrine, which was previously used as a decongestant and registered under the name of Vaporpac (Medley \& James Laboratories) [40] [41], was a drug that had not been previously established as an anti-fungal. We observed that although its anti-Candida 
activity was mild on YPD, it displayed one of the best Candida growth inhibition on serum compared to other drugs. It also has a potential to be one of the safest of the discovered drugs because it did not affect the sensitivity of mammalian cells significantly. The fact that no $C$. albicans mutants showed a decrease in sensitivity to Octodrine argues against the potential emergence of Octodrine-resistant Candida strains, and favors the usage of this drug as a new antifungal treatment against Candida. In addition, we showed that Octodrine is capable of killing Gram-positive as well as Gram-negative bacteria, making it a desirable broad-spectrum antimicrobial countermeasure, that probably kills microbes by targeting their non-protein components. Octodrine was previously shown to agonize Estrogen Receptor Alpha with the potency of $21 \mu \mathrm{M}$ [47]. Thus, any in vivo antimicrobial activity of Octodrine in humans would have to be in the $\mathrm{nM}$ range to avoid this side effect. As the pharmacokinetics of Octodrine had been previously established in numerous animal models [48], this approach is useful for the discovery of economically viable new therapies against infectious diseases.

\section{Conclusions}

In summary, we have screened the Johns Hopkins Clinical Compound Library, a commercially available chemical library of FDA approved 1581 drugs, for the identification of bioactive drugs against $C$. albicans growth. Our results provide the comprehensive survey of the inhibition of Candida growth by existing drugs, one of which hadn't been previously reported to have antifungal properties. From a drug repurposing point of view, the identification of drugs with no known antifungal activity and which demonstrated excellent activity against $C$. albicans growth in serum opens up a valuable new avenue for the rapid development of antifungal agents, which are urgently needed. 


\section{Acknowledgments}

We would like to acknowledge Dr. David Sullivan, John Hopkins School of Medicine, for providing us with JHCCL and for his advices. We would also like to acknowledge Fungal Genetics Stock Center for providing us with Candida albicans knockout libraries. We acknowledge Ralph M. Parson’s Foundation awarded to KGI (PI Dr. Steven Casper).

\section{Additional files}

Additional file 1: Quantification of the zone of inhibition post-treatment of various drugs on C. albicans strain SN250. Quantification of the zone of inhibition post-treatment of various serially diluted drugs on C. albicans strain SN250. Serial dilution experiments of Octodrine on serum and YPD plates. Quantification of the zone of inhibition of Octodrine in neat form against Candida albicans, Escherichia coli and Bacillus cereus. Elucidation of mechanism of Candida albicans: Elucidation of Candida albicans sensitivity to Octodrine.

\section{Competing interests}

The authors declare that they have no competing interests.

\section{Author's contributions}

K.K. and M.M. designed research; K.K., L.Z., and M.M. performed research; K.K., L.Z., and M.M. analyzed data; and K.K., L.Z., and M.M. wrote the paper. All authors read and approved the final manuscript. 


\section{References}

1. Gow NA, van de Veerdonk FL, Brown AJ, Netea MG. Candida albicans morphogenesis and host defence: discriminating invasion from colonization. Nat Rev Microbiol. 2012;10(2):112-22. doi:10.1038/nrmicro2711.

2. Wilson LS, Reyes CM, Stolpman M, Speckman J, Allen K, Beney J. The direct cost and incidence of systemic fungal infections. Value Health. 2002;5(1):26-34. doi:10.1046/j.1524-4733.2002.51108.x.

3. Perlroth J, Choi B, Spellberg B. Nosocomial fungal infections: epidemiology, diagnosis, and treatment. Med Mycol. 2007;45(4):321-46. doi:10.1080/13693780701218689.

4. DiNubile MJ, Hille D, Sable CA, Kartsonis NA. Invasive candidiasis in cancer patients: observations from a randomized clinical trial. J Infect. 2005;50(5):443-9. doi:10.1016/j.jinf.2005.01.016.

5. Fujitani S, Ricardo-Dukelow M, Kamiya T, Sullivan L, Low L. Ethnicity and other possible risk factors for candidemia at 3 tertiary care university hospitals in Hawaii. Infect Control Hosp Epidemiol. 2006;27(11):1261-3. doi:10.1086/508831.

6. Fisher JF, Sobel JD, Kauffman CA, Newman CA. Candida urinary tract infections--treatment. Clin Infect Dis. 2011;6:S457-66. doi:10.1093/cid/cir112.

7. Berman J, Sudbery PE. Candida Albicans: a molecular revolution built on lessons from budding yeast. Nat Rev Gen. 2002;3(12):918-30. doi:10.1038/nrg948.

8. Paderu P, Garcia-Effron G, Balashov S, Delmas G, Park S, Perlin DS. Serum differentially alters the antifungal properties of echinocandin drugs. Antimicrob Agents Chemother. 2007;51(6):2253-6. doi:10.1128/AAC.01536-06.

9. Vandeputte P, Ferrari S, Coste AT. Antifungal resistance and new strategies to control fungal infections. Int J Microbiol. 2012;2012:713687. doi:10.1155/2012/713687.

10. Odds FC, Brown AJ, Gow NA. Antifungal agents: mechanisms of action. Trends Microbio. 2003;11(6):272-9.

11. Behrman REWJ. FDA regulations for drug development. Science. 2010;329:33.

12. Siles SA, Srinivasan A, Pierce CG, Lopez-Ribot JL, Ramasubramanian AK. High-Throughput Screening of a Collection of Known Pharmacologically Active Small Compounds for Identification of Candida albicans Biofilm Inhibitors. Antimicrob Agents Chemother. 2013;57((8):3681-7. doi:10.1128/AAC.00680-13.

13. Chong CR, Chen X, Shi L, Liu JO, Sullivan Jr DJ. A clinical drug library screen identifies astemizole as an antimalarial agent. Nat Chem Biol. 2006;2(8):415-6. doi:10.1038/nchembio806.

14. Gillum AM, Tsay EY, Kirsch DR. Isolation of the Candida albicans gene for orotidine-5'-phosphate decarboxylase by complementation of S. cerevisiae ura3 and E. coli pyrF mutations. MGG. 1984;198(1):179-82.

15. Noble SM, French S, Kohn LA, Chen V, Johnson AD. Systematic screens of a Candida albicans homozygous deletion library decouple morphogenetic switching and pathogenicity. Nat Gene. 2010;42(7):590-8. doi:10.1038/ng.605.

16. Rauceo JM, Blankenship JR, Fanning S, Hamaker JJ, Deneault JS, Smith FJ. Regulation of the Candida albicans cell wall damage response by transcription factor Sko1 and PAS kinase Psk1. Mol Biol Cel. 2008;19(7):2741-51. doi:10.1091/mbc.E08-02-0191. 
17. Homann OR, Dea J, Noble SM, Johnson AD. A phenotypic profile of the Candida albicans regulatory network. PLoS Genet. 2009;5(12), e1000783. doi:10.1371/journal.pgen.1000783.

18. nstitute CaLS, M44-A2. Method for antifungal disk diffusion susceptibility testing of yeasts; approved guideline. 2nd ed. Wayne, PA: Clinical and Laboratory Standards Institute; 2009.

19. Arendrup MC, Park S, Brown S, Pfaller M, Perlin DS. Evaluation of CLSI M44-A2 disk diffusion and associated breakpoint testing of caspofungin and micafungin using a well-characterized panel of wild-type and fks hot spot mutant Candida isolates. Antimicrob Agents Chemother. 2011;55(5):1891-5. doi:10.1128/AAC.01373-10.

20. ImageJ. http://imagej.nih.gov/ij/. Accessed 28 April 2015.

21. Lu Q, Wei W, Kowalski PE, Chang AC, Cohen SN. EST-based genome-wide gene inactivation identifies ARAP3 as a host protein affecting cellular susceptibility to anthrax toxin. Proc Natl Acad Sci U S A. 2004;101(49):17246-51. doi:10.1073/pnas.0407794101.

22. Hendry AT, Bakerspigel A. Factors affecting serum inhibited growth of Candida albicans and Cryptococcus neoformans. Sabouraudia. 1969;7(3):219-29.

23. Elin RJ, Wolff SM. Effect of $\mathrm{pH}$ and iron concentration on growth of Candida albicans in human serum. J Infect Dis. 1973;127(6):705-8.

24. King RD, Khan HA, Foye JC, Greenberg JH, Jones HE. Transferrin, iron, and dermatophytes. I. Serum dematophyte inhibitory component definitively identified as unsaturated transferrin. J Lab Clin Med. 1975;86(2):204-12.

25. Andes D, Nett J, Oschel P, Albrecht R, Marchillo K, Pitula A. Development and characterization of an in vivo central venous catheter Candida albicans biofilm model. Infect Immun. 2004;72(10):6023-31.

doi:10.1128/IAI.72.10.6023-6031.2004.

26. Kot EJ, Olson VL, Rolewic LJ, McClary DO. An alternate respiratory pathway in Candida albicans. Antonie Van Leeuwenhoek. 1976;42(1-2):33-48.

27. Gale GR, Smith AB, Atkins LM, Walker Jr EM, Gadsden RH. Pharmacology of captan: biochemical effects with special reference to macromolecular synthesis. Toxicol Appl Pharmacol. 1971;18(2):426-41.

28. Lovgren T, Salmela I. In vitro sensitivity of Trichomonas vaginalis and Candida albicans to chemotherapeutic agents. Acta Pathol Microbiol Scand B. 1978;86B(3):155-8.

29. Wachtler B, Wilson D, Hube B. Candida albicans adhesion to and invasion and damage of vaginal epithelial cells: stage-specific inhibition by clotrimazole and bifonazole. Antimicrob Agents Chemother. 2011;55(9):4436-9. doi:10.1128/AAC.00144-11.

30. Shukla S, Sauna ZE, Prasad R, Ambudkar SV. Disulfiram is a potent modulator of multidrug transporter Cdr1p of Candida albicans. Biochem Biophys Res Commun. 2004;322((2):520-5. doi:10.1016/j.bbrc.2004.07.151.

31. Molepo J, Musenge E. Clade-related phenotypic switching among fluconazole resistant Candida albicans isolates. SADJ. 2012;67(7):326-8.

32. Nash JD, Burgess DS, Talbert RL. Effect of fluvastatin and pravastatin, HMG-CoA reductase inhibitors, on fluconazole activity against Candida albicans. J Med Microbiol. 2002;51(2):105-9.

33. Ichikawa T, Yano Y, Fujita Y, Kashiwabara T, Nagao K. The enhancement effect of three sugar alcohols on the fungicidal effect of benzethonium chloride toward Candida albicans. J Dent. 2008;36(11):965-8.

doi:10.1016/j.jdent.2008.07.013. 
34. Vandenbosch D, Bink A, Govaert G, Cammue BP, Nelis HJ, Thevissen K. Phytosphingosine-1-phosphate is a signaling molecule involved in miconazole resistance in sessile Candida albicans cells. Antimicrob Agents Chemother. 2012;56(5):2290-4. doi:10.1128/AAC.05106-11.

35. Kohler GA, Gong X, Bentink S, Theiss S, Pagani GM, Agabian N, et al. The functional basis of mycophenolic acid resistance in Candida albicans IMP dehydrogenase. J Biol Chem. 2005;280((12):11295-302. doi:10.1074/jbc.M409847200.

36. Grossman LI. Evaluation of antifungal agents for endodontic use. J Dent Res. 1967;46(1):215-7.

37. Hernandez Molina JM, Llosa J, Ventosa A. In vitro activity of nitroxoline against clinical isolates of Candida species. Mycoses. 1991;34(7-8):323-5.

38. Omura Y, O’Young B, Jones M, Pallos A, Duvvi H, Shimotsuura Y. Caprylic acid in the effective treatment of intractable medical problems of frequent urination, incontinence, chronic upper respiratory infection, root canalled tooth infection, ALS, etc., caused by asbestos \& mixed infections of Candida albicans, Helicobacter pylori \& cytomegalovirus with or without other microorganisms \& mercury. Acupunct Electrother Res. 2011;36(1-2):19-64.

39. De Prijck K, De Smet N, Honraet K, Christiaen S, Coenye T, Schacht E, et al. Inhibition of Candida albicans biofilm formation by antimycotics released from modified polydimethyl siloxane. Mycopathologia. 2010;169(3):167-74. doi:10.1007/s11046-009-9242-4.

40. Druglead-Octodrine. http://www.putubio.com/octodrine-cas-no-543-82-8/. Accessed 28 April 2015.

41. PubChem-Octodrine. http://pubchem.ncbi.nlm.nih.gov/compound/10982. Accessed 28 April 2015.

42. Norice CT, Smith Jr FJ, Solis N, Filler SG, Mitchell AP. Requirement for Candida albicans Sun41 in biofilm formation and virulence. Eukaryot Cell. 2007;6(11):2046-55. doi:10.1128/EC.00314-07.

43. Nobile CJ, Mitchell AP. Regulation of cell-surface genes and biofilm formation by the C. albicans transcription factor Bcr1p. Curr Biol. 2005;15(12):1150-5. doi:10.1016/j.cub.2005.05.047.

44. Hanahan D. Studies on transformation of Escherichia coli with plasmids. J Mol Biol. 1983;166(4):557-80.

45. Rasko DA, Ravel J, Okstad OA, Helgason E, Cer RZ, Jiang L, et al. The genome sequence of Bacillus cereus ATCC 10987 reveals metabolic adaptations and a large plasmid related to Bacillus anthracis pXO1. Nucleic Acids Res. 2004;32(3):977-88. doi:10.1093/nar/gkh258.

46. Jeong SY, Martchenko M, Cohen SN. Calpain-dependent cytoskeletal rearrangement exploited for anthrax toxin endocytosis. Proc Natl Acad Sci U S A. 2013;110(42):E4007-15. doi:10.1073/pnas.1316852110.

47. PubChem-BioAssay. http://pubchem.ncbi.nlm.nih.gov/assay/assay.cgi?aid=743079. Accessed 28 April 2015.

48. Fellows EJ. The pharmacology of 2-amino-6-methylheptane. J Pharmacol Exp Ther. 1947;90(4):351-8. 


\section{Supplemental Tables:}

Supplemental Table 1: Quantification of the zone of inhibition post-treatment of various drugs on $C$ albicans strain SN250.

A)

\begin{tabular}{|c|c|c|c|c|c|c|}
\hline \multirow[b]{2}{*}{ Drug } & \multicolumn{3}{|c|}{ YPD $25^{\circ} \mathrm{C}$} & \multicolumn{3}{|c|}{ YPD $37^{\circ} \mathrm{C}$} \\
\hline & $\begin{array}{c}\text { ZOI Area } \\
\left(\mathrm{mm}^{2}\right)\end{array}$ & $\begin{array}{c}\text { Number of } \\
\text { Pixels }\end{array}$ & $\begin{array}{l}\text { zol Area/ } \\
\text { Number of } \\
\text { Pixels }\end{array}$ & $\begin{array}{c}\text { zol Area } \\
\left(\mathrm{mm}^{2}\right)\end{array}$ & $\begin{array}{l}\text { Number of } \\
\text { Pixels }\end{array}$ & $\begin{array}{c}\text { zOI Area/ } \\
\text { Number of } \\
\text { Pixels }\end{array}$ \\
\hline Fluconazole & $933.84 \pm 5.92$ & $77.55 \pm 0.21$ & $12.04 \pm 0.03$ & $822.65 \pm 5.42$ & $94.35 \pm 0.11$ & $8.72 \pm 0.01$ \\
\hline Antimycin & $507.27 \pm 5.31$ & $81.57 \pm 0.34$ & $6.22 \pm 0.09$ & $541.4 \pm 4.34$ & $86.02 \pm 0.24$ & $6.29 \pm 0.02$ \\
\hline Captan & $512.19 \pm 4.31$ & $74.1 \pm 0.23$ & $6.93 \pm 0.02$ & $579.1 \pm 5.09$ & $77.46 \pm 0.25$ & $7.48 \pm 0.02$ \\
\hline Chlorquinaldol & $194.72 \pm 3.49$ & $90.86 \pm 0.22$ & $2.14 \pm 0.01$ & $365.57 \pm 4.54$ & $86.19 \pm 0.14$ & $4.24 \pm 0.01$ \\
\hline Clotrimazole & $210.77 \pm 3.21$ & $95.71 \pm 0.23$ & $2.20 \pm 0.01$ & $317.16 \pm 3.42$ & $88.2 \pm 0.15$ & $3.6 \pm 0.01$ \\
\hline Disulfiram & $340.1 \pm 5.13$ & $74.44 \pm 0.15$ & $4.57 \pm 0.01$ & $123.25 \pm 2.23$ & $76.13 \pm 0.19$ & $1.62 \pm 4.33 \mathrm{E}-3$ \\
\hline Fluvastatin & $473.13 \pm 2.45$ & $85.84 \pm 0.21$ & $5.51 \pm 0.01$ & $639.93 \pm 3.24$ & $78.11 \pm 0.12$ & $8.19 \pm 0.01$ \\
\hline Methylbenzethonium Chloride & $100 \pm 2.1$ & $70.64 \pm 0.28$ & $1.42 \pm 0.01$ & $71.46 \pm 4.21$ & $66.66 \pm 0.09$ & $1.07 \pm 2.08 \mathrm{E}-3$ \\
\hline Miconazole & $170.98 \pm 2.41$ & $88.14 \pm 0.31$ & $1.94 \pm 0.01$ & $130.88 \pm 3.54$ & $88.92 \pm 0.08$ & $1.47 \pm 1.72 \mathrm{E}-3$ \\
\hline Mycophenolic Acid & $422.4 \pm 4.21$ & $93.66 \pm 0.32$ & $4.51 \pm 0.02$ & $217.22 \pm 3.41$ & $96.66 \pm 0.15$ & $2.25 \pm 3.84 \mathrm{E}-3$ \\
\hline Nifuroxime & $31.61 \pm 3.52$ & $65.68 \pm 0.39$ & $0.48 \pm 4.28 \mathrm{E}-3$ & $33.21 \pm 1.43$ & $85.1 \pm 0.16$ & $0.39 \pm 9.02 E-4$ \\
\hline Nitroxoline & $275.28 \pm 2.36$ & $74.53 \pm 0.39$ & $3.69 \pm 0.02$ & $309.66 \pm 2.56$ & $68.44 \pm 0.09$ & $4.52 \pm 0.01$ \\
\hline Octanoic Acid & $46.25 \pm 3.21$ & $71.7 \pm 0.32$ & $0.65 \pm 3.33 \mathrm{E}-3$ & $36.04 \pm 3.69$ & $63.83 \pm 0.86$ & $0.56 \pm 0.01$ \\
\hline Octodrine & $34.32 \pm 2.12$ & $96.54 \pm 0.21$ & $0.36 \pm 9.93 E-4$ & $31.61 \pm 2.13$ & $77.91 \pm 0.08$ & $0.41 \pm 6.90 \mathrm{E}-4$ \\
\hline Pyrithione Zinc & $695.95 \pm 4.21$ & $88.19 \pm 0.26$ & $7.89 \pm 0.02$ & $553.02 \pm 2.94$ & $76.17 \pm 0.12$ & $7.26 \pm 0.01$ \\
\hline DMSO & $39.36 \pm 1.45$ & $86.17 \pm 0.17$ & $0.46 \pm 1.07 \mathrm{E}-3$ & $34.32 \pm 1.53$ & $104.84 \pm 0.09$ & $0.33 \pm 4.27 \mathrm{E}-4$ \\
\hline
\end{tabular}


B)

\begin{tabular}{|c|c|c|c|c|c|c|}
\hline \multirow[b]{2}{*}{ Drug } & \multicolumn{3}{|c|}{ Serum $25^{\circ} \mathrm{C}$} & \multicolumn{3}{|c|}{ Serum $37^{\circ} \mathrm{C}$} \\
\hline & $\begin{array}{c}\text { ZOI Area } \\
\left(\mathrm{mm}^{2}\right)\end{array}$ & $\begin{array}{c}\text { Number of } \\
\text { Pixels }\end{array}$ & $\begin{array}{l}\text { ZOI Area/ } \\
\text { Number of } \\
\text { Pixels }\end{array}$ & $\begin{array}{c}\text { ZOI Area } \\
\left(\mathrm{mm}^{2}\right)\end{array}$ & $\begin{array}{c}\text { Number of } \\
\text { Pixels }\end{array}$ & $\begin{array}{l}\text { zOI Area/ } \\
\text { Number of } \\
\text { Pixels }\end{array}$ \\
\hline Fluconazole & $39.36 \pm 1.31$ & $59.34 \pm 0.09$ & $0.66 \pm 1.22 \mathrm{E}-3$ & $36.41 \pm 1.21$ & $85.54 \pm 0.04$ & $0.43 \pm 3.40 \mathrm{E}-4$ \\
\hline Antimycin & $130.08 \pm 2.58$ & $77.61 \pm 0.11$ & $1.68 \pm 2.71 \mathrm{E}-3$ & $309.42 \pm 1.45$ & $90.16 \pm 0.21$ & $3.43 \pm 8.15 \mathrm{E}-3$ \\
\hline Captan & $107.75 \pm 2.31$ & $86.49 \pm 0.21$ & $1.25 \pm 3.29 \mathrm{E}-3$ & $89.55 \pm 2.41$ & $74.94 \pm 0.12$ & $1.19 \pm 2.24 \mathrm{E}-3$ \\
\hline Chlorquinaldol & $148.83 \pm 1.42$ & $86.24 \pm 0.18$ & $1.73 \pm 3.77 \mathrm{E}-3$ & $133.34 \pm 1.23$ & $75.17 \pm 0.15$ & $1.77 \pm 3.70 \mathrm{E}-3$ \\
\hline Clotrimazole & $52.89 \pm 2.14$ & $87.04 \pm 0.04$ & $0.61 \pm 5.25 \mathrm{E}-4$ & $123.87 \pm 1.23$ & $76.89 \pm 0.12$ & $1.61 \pm 2.67 \mathrm{E}-3$ \\
\hline Disulfiram & $113.53 \pm 1.54$ & $92.54 \pm 0.21$ & $1.23 \pm 2.95 \mathrm{E}-3$ & $118.7 \pm 0.12$ & $83.610 \pm 0.09$ & $1.42 \pm 1.54 \mathrm{E}-3$ \\
\hline Fluvastatin & $123.25 \pm 2.52$ & $104.75 \pm 0.02$ & $1.18 \pm 4.65 \mathrm{E}-4$ & $68.02 \pm 1.03$ & $106.74 \pm 0.04$ & $0.64 \pm 3.35 \mathrm{E}-4$ \\
\hline Methylbenzethonium Chloride & $86.84 \pm 1.43$ & $84.37 \pm 0.23$ & $1.03 \pm 2.98 \mathrm{E}-3$ & $85.55 \pm 1.52$ & $73.96 \pm 0.09$ & $1.16 \pm 1.61 \mathrm{E}-3$ \\
\hline Miconazole & $64.7 \pm 1.53$ & $95.27 \pm 0.08$ & $0.68 \pm 7.31 \mathrm{E}-4$ & $55.84 \pm 1.68$ & $87.16 \pm 0.12$ & $0.64 \pm 1.07 \mathrm{E}-3$ \\
\hline Mycophenolic Acid & $10.21 \pm 1.04$ & $99.84 \pm 0.21$ & $0.10 \pm 3.19 \mathrm{E}-4$ & $34.32 \pm 1.24$ & $85.38 \pm 0.14$ & $0.4 \pm 8.04 \mathrm{E}-4$ \\
\hline Nifuroxime & $41.08 \pm 2.14$ & $88.15 \pm 0.08$ & $0.47 \pm 6.66 \mathrm{E}-4$ & $49.94 \pm 1.76$ & $92.34 \pm 0.17$ & $0.54 \pm 1.19 \mathrm{E}-3$ \\
\hline Nitroxoline & $73.8 \pm 0.98$ & $85.39 \pm 0.12$ & $0.86 \pm 1.33 \mathrm{E}-3$ & $157.51 \pm 2.41$ & $83.71 \pm 0.11$ & $1.88 \pm 4.11 \mathrm{E}-3$ \\
\hline Octanoic Acid & $39.36 \pm 1.23$ & $89.45 \pm 0.03$ & $0.44 \pm 2.85 \mathrm{E}-4$ & $45.02 \pm 1.94$ & $93.96 \pm 0.09$ & $0.48 \pm 7.67 \mathrm{E}-4$ \\
\hline Octodrine & $56.83 \pm 1.94$ & $85.77 \pm 0.12$ & $0.66 \pm 1.15 \mathrm{E}-3$ & $54.25 \pm 1.04$ & $89.58 \pm 0.05$ & $0.61 \pm 7.25 \mathrm{E}-4$ \\
\hline Pyrithione Zinc & $27.8 \pm 1.34$ & $83.91 \pm 0.05$ & $0.33 \pm 3.57 \mathrm{E}-4$ & $26.82 \pm 0.89$ & $63.7 \pm 0.05$ & $0.42 \pm 4.70 \mathrm{E}-4$ \\
\hline DMSO & $25.89 \pm 1.56$ & $89.3 \pm 0.07$ & $0.29 \pm 4.02 \mathrm{E}-4$ & $20.173 \pm 0.12$ & $91.07 \pm 0.08$ & $0.22 \pm 1.35 E-4$ \\
\hline
\end{tabular}


Supplemental Table 2: Quantification of the zone of inhibition post-treatment of various serially diluted drugs on C. albicans strain SN250.

\begin{tabular}{|c|c|c|c|c|c|c|}
\hline \multirow[b]{2}{*}{ Concentration } & \multicolumn{3}{|c|}{ Antimycin $25^{\circ} \mathrm{C}$} & \multicolumn{3}{|c|}{ Antimycin $37^{\circ} \mathrm{C}$} \\
\hline & zol Area $\left(\mathrm{mm}^{2}\right)$ & $\begin{array}{l}\text { Number of } \\
\text { Pixels }\end{array}$ & $\begin{array}{l}\text { zol Area/ } \\
\text { Number of } \\
\text { Pixels }\end{array}$ & $\begin{array}{l}\text { zOI Area } \\
\left(\mathrm{mm}^{2}\right)\end{array}$ & $\begin{array}{c}\text { Number of } \\
\text { Pixels }\end{array}$ & $\begin{array}{l}\text { zol Area/ } \\
\text { Number of } \\
\text { Pixels }\end{array}$ \\
\hline 10 & $389.64 \pm 2.95$ & $97.05 \pm 0.17$ & $4.01 \pm 3.61 \mathrm{E}-3$ & $587 \pm 3.41$ & $82.23 \pm 0.31$ & $7.14 \pm 4.15 \mathrm{E}-4$ \\
\hline 5 & $314.07 \pm 0.25$ & $103.05 \pm 0.33$ & $3.05 \pm 0.01$ & $501.21 \pm 4.53$ & $82.77 \pm 0.31$ & $6.06 \pm 0.02$ \\
\hline 2.5 & $253.78 \pm 1.63$ & $114.26 \pm 0.08$ & $2.22 \pm 6.56 \mathrm{E}-3$ & $468.46 \pm 4.17$ & $90.74 \pm 0.36$ & $5.16 \pm 0.02$ \\
\hline 1.25 & $221.87 \pm 3.70$ & $104.09 \pm 0.35$ & $2.13 \pm 1.99 \mathrm{E}-3$ & $423.45 \pm 4.14$ & $93.29 \pm 0.34$ & $4.54 \pm 0.02$ \\
\hline 0.625 & $165.24 \pm 1.68$ & $91.07 \pm 0.42$ & $1.81 \pm 7.16 \mathrm{E}-3$ & $351.61 \pm 2.14$ & $85.56 \pm 0.48$ & $4.11 \pm 0.02$ \\
\hline 0.3125 & $158.27 \pm 1.69$ & $86.58 \pm 0.52$ & $1.83 \pm 9.06 \mathrm{E}-3$ & $228.21 \pm 4.01$ & $72.13 \pm 0.22$ & $3.16 \pm 0.02$ \\
\hline 0.15625 & $145.38 \pm 1.41$ & $88.69 \pm 0.68$ & $1.64 \pm 9.77 \mathrm{E}-3$ & $202.85 \pm 1.48$ & $66.23 \pm 0.52$ & $3.06 \pm 0.01$ \\
\hline 0.07812 & $113.05 \pm 2.00$ & $82.93 \pm 0.49$ & $1.36 \pm 0.901$ & $186.37 \pm 1.14$ & $73.72 \pm 0.21$ & $2.53 \pm 0.02$ \\
\hline DMSO & $35.13 \pm 0.97$ & $93.11 \pm 0.69$ & $0.38 \pm 2.86 \mathrm{E}-3$ & $43.81 \pm 0.74$ & $86.72 \pm 0.49$ & $0.51 \pm 1.31 \mathrm{E}-3$ \\
\hline 0.03906 & $66.56 \pm 1.22$ & $94.85 \pm 0.77$ & $0.7 \pm 5.23 E-3$ & $114.1 \pm 1.81$ & $89.48 \pm 0.53$ & $1.28 \pm 7.19 \mathrm{E}-3$ \\
\hline 0.01953 & $50.29 \pm 1.52$ & $94.18 \pm 0.23$ & $0.53 \pm 4.53 \mathrm{E}-3$ & $81.14 \pm 0.26$ & $84.7 \pm 0.18$ & $0.96 \pm 6.03 \mathrm{E}-3$ \\
\hline 0.009765 & $43.612 \pm 0.27$ & $102.63 \pm 0.66$ & $0.42 \pm 9.79 \mathrm{E}-4$ & $76.91 \pm 1.31$ & $93.56 \pm 0.38$ & $0.82 \pm 1.72 \mathrm{E}-3$ \\
\hline 0.004883 & $40.338 \pm 0.9$ & $100.71 \pm 0.32$ & $0.33 \pm 2.71 \mathrm{E}-3$ & $50.29 \pm 1.07$ & $97.53 \pm 0.40$ & $0.52 \pm 2.12 \mathrm{E}-3$ \\
\hline 0.002441 & $31.91 \pm 0.58$ & $96.13 \pm 0.37$ & $0.33 \pm 1.17 \mathrm{E}-3$ & $39.2 \pm 0.25$ & $102.42 \pm 0.13$ & $0.38 \pm 1.52 E-3$ \\
\hline 0.00061 & $30.85 \pm 0.45$ & $85.52 \pm 0.09$ & $0.36 \pm 1.61 \mathrm{E}-3$ & $35.08 \pm 0.59$ & $96.16 \pm 0.24$ & $0.36 \pm 5.55 \mathrm{E}-4$ \\
\hline 0.000305 & $26.2 \pm 0.51$ & $92.19 \pm 0.74$ & $0.28 \pm 3.33 \mathrm{E}-4$ & $31.91 \pm 0.36$ & $96.37 \pm 0.27$ & $0.33 \pm 8.62 \mathrm{E}-4$ \\
\hline 0.000153 & $26.2 \pm 0.78$ & $98.27 \pm 0.36$ & $0.27 \pm 2.09 \mathrm{E}-3$ & $30.85 \pm 0.45$ & $104.64 \pm 0.80$ & $0.29 \pm 8.04 \mathrm{E}-4$ \\
\hline DMSO & $26.6 \pm 0.42$ & $106.25 \pm 0.47$ & $0.25 \pm 8.88 \mathrm{E}-4$ & $35.13 \pm 0.53$ & $108.33 \pm 0.09$ & $0.32 \pm 2.44 \mathrm{E}-3$ \\
\hline
\end{tabular}




\begin{tabular}{|c|c|c|c|c|c|c|}
\hline \multirow[b]{2}{*}{ Concentration } & \multicolumn{3}{|c|}{ Captan $25^{\circ} \mathrm{C}$} & \multicolumn{3}{|c|}{ Captan $37^{\circ} \mathrm{C}$} \\
\hline & $\begin{array}{l}\text { zol Area } \\
\left(\mathrm{mm}^{2}\right)\end{array}$ & $\begin{array}{l}\text { Number of } \\
\text { Pixels }\end{array}$ & $\begin{array}{l}\text { zol Area/ } \\
\text { Number of } \\
\text { Pixels }\end{array}$ & $\begin{array}{l}\text { zol Area } \\
\left(\mathrm{mm}^{2}\right)\end{array}$ & $\begin{array}{l}\text { Number of } \\
\text { Pixels }\end{array}$ & $\begin{array}{l}\text { ZOI Area/ } \\
\text { Number of } \\
\text { Pixels }\end{array}$ \\
\hline 10 & $458.11 \pm 1.52$ & $84.93 \pm 0.13$ & $5.39 \pm 1.79 \mathrm{E}-4$ & $375.7 \pm 3.12$ & $82.48 \pm 0.31$ & $4.56 \pm 3.78 \mathrm{E}-4$ \\
\hline 5 & $407.29 \pm 2.38$ & $86.16 \pm 0.23$ & $4.73 \pm 7.41 \mathrm{E}-3$ & $260.33 \pm 2.13$ & $91.68 \pm 0.12$ & $2.84 \pm 9.83 \mathrm{E}-3$ \\
\hline 2.5 & $337.45 \pm 2.12$ & $96.46 \pm 0.32$ & $3.5 \pm 8.56 \mathrm{E}-3$ & $107.34 \pm 2.15$ & $72.4 \pm 0.12$ & $1.48 \pm 2.75 \mathrm{E}-3$ \\
\hline 1.25 & $98.47 \pm 3.45$ & $94.77 \pm 0.12$ & $1.04 \pm 3.87 \mathrm{E}-3$ & $92.13 \pm 2.12$ & $77.82 \pm 0.06$ & $1.18 \pm 2.1 \mathrm{E}-3$ \\
\hline 0.625 & $72.69 \pm 1.58$ & $86.47 \pm 0.12$ & $0.84 \pm 1.35 \mathrm{E}-3$ & $84.52 \pm 2.11$ & $68.6 \pm 0.12$ & $1.23 \pm 1.74 \mathrm{E}-3$ \\
\hline 0.3125 & $63.39 \pm 4.12$ & $78.14 \pm .23$ & $0.81 \pm 1.77 \mathrm{E}-3$ & $63.39 \pm 2.67$ & $60.27 \pm 0.11$ & $1.05 \pm 2.54 \mathrm{E}-3$ \\
\hline 0.15625 & $48.18 \pm 1.95$ & $75.3 \pm 0.15$ & $0.64 \pm 2.21 \mathrm{E}-3$ & $45.64 \pm 2.12$ & $72.43 \pm 0.04$ & $0.63 \pm 1.25 \mathrm{E}-3$ \\
\hline 0.07812 & $28.95 \pm 1.34$ & $87.55 \pm 0.11$ & $0.33 \pm 7.20 \mathrm{E}-4$ & $31.91 \pm 1.42$ & $79.82 \pm 0.12$ & $0.4 \pm 3.78 E-4$ \\
\hline DMSO & $37.46 \pm 1.54$ & $122.79 \pm 0.11$ & $0.31 \pm 3.99 \mathrm{E}-4$ & $44.02 \pm 1.69$ & $150.04 \pm 0.08$ & $0.29 \pm 3.47 \mathrm{E}-4$ \\
\hline
\end{tabular}

\begin{tabular}{|c|c|c|c|c|c|c|}
\hline \multirow[b]{2}{*}{ Concentration } & \multicolumn{3}{|c|}{ Chlorquinaldol $25^{\circ} \mathrm{C}$} & \multicolumn{3}{|c|}{ Chlorquinaldol $37^{\circ} \mathrm{C}$} \\
\hline & $\begin{array}{l}\text { zOI Area } \\
\left(\mathrm{mm}^{2}\right)\end{array}$ & $\begin{array}{c}\text { Number of } \\
\text { Pixels }\end{array}$ & $\begin{array}{l}\text { ZOI Area/ } \\
\text { Number of } \\
\text { Pixels }\end{array}$ & $\begin{array}{l}\text { zol Area } \\
\left(\mathrm{mm}^{2}\right)\end{array}$ & $\begin{array}{l}\text { Number of } \\
\text { Pixels }\end{array}$ & $\begin{array}{l}\text { zol Area/ } \\
\text { Number of } \\
\text { Pixels }\end{array}$ \\
\hline 10 & $314.84 \pm 4.12$ & $118.01 \pm .18$ & $2.67 \pm 3.49 \mathrm{E}-4$ & $549.81 \pm 6.12$ & $85.94 \pm .12$ & $6.4 \pm 7.12 \mathrm{E}-4$ \\
\hline 5 & $277.44 \pm 3.12$ & $116.52 \pm .12$ & $2.38 \pm 3.95 \mathrm{E}-3$ & $344 \pm 4.95$ & $81.11 \pm 0.24$ & $4.24 \pm 6.88 \mathrm{E}-3$ \\
\hline 2.5 & $260.33 \pm 3.98$ & $119.05 \pm 0.12$ & $2.19 \pm 2.54 \mathrm{E}-3$ & $198.2 \pm 2.1$ & $83.7 \pm 0.22$ & $2.37 \pm 7.04 \mathrm{E}-3$ \\
\hline 1.25 & $239.83 \pm 3.1$ & $126.48 \pm 0.06$ & $1.9 \pm 2.04 \mathrm{E}-3$ & $191.86 \pm 2.8$ & $90.97 \pm 0.13$ & $2.11 \pm 5.41 \mathrm{E}-3$ \\
\hline 0.625 & $208.77 \pm 2.13$ & $111.22 \pm 0.08$ & $1.88 \pm 1.2 \mathrm{E}-3$ & $175.8 \pm 2.1$ & $77.26 \pm 0.21$ & $2.28 \pm 4.10 \mathrm{E}-3$ \\
\hline 0.3125 & $158.27 \pm 2.54$ & $93.46 \pm 0.12$ & $1.69 \pm 1.72 \mathrm{E}-3$ & $94.66 \pm 2.63$ & $66.06 \pm 0.23$ & $1.43 \pm 4.95 \mathrm{E}-3$ \\
\hline 0.15625 & $103.96 \pm 2.12$ & $101.97 \pm 0.12$ & $1.02 \pm 1.41 \mathrm{E}-3$ & $32.96 \pm 1.43$ & $67.71 \pm 0.12$ & $0.49 \pm 1.86 \mathrm{E}-3$ \\
\hline 0.07812 & $30.85 \pm 1.23$ & $111.81 \pm 0.06$ & $0.28 \pm 4.06 \mathrm{E}-4$ & $30.85 \pm 1.21$ & $80.98 \pm 0.12$ & $0.38 \pm 7.14 \mathrm{E}-4$ \\
\hline DMSO & $32 \pm 0.67$ & $123.24 \pm 0.08$ & $0.26 \pm 1.81 \mathrm{E}-4$ & $31.96 \pm 1.34$ & $104.88 \pm 0.11$ & $0.3 \pm 4.76 \mathrm{E}-4$ \\
\hline
\end{tabular}




\begin{tabular}{|c|c|c|c|c|c|c|}
\hline \multirow[b]{2}{*}{ Concentration } & \multicolumn{3}{|c|}{ Clotrimazole $25^{\circ} \mathrm{C}$} & \multicolumn{3}{|c|}{ Clotrimazole $37^{\circ} \mathrm{C}$} \\
\hline & $\begin{array}{l}\text { zol Area } \\
\left(\mathrm{mm}^{2}\right)\end{array}$ & $\begin{array}{c}\text { Number of } \\
\text { Pixels }\end{array}$ & $\begin{array}{l}\text { zOI Area/ } \\
\text { Number of } \\
\text { Pixels }\end{array}$ & $\begin{array}{l}\text { zol Area } \\
\left(\mathrm{mm}^{2}\right)\end{array}$ & $\begin{array}{l}\text { Number of } \\
\text { Pixels }\end{array}$ & $\begin{array}{l}\text { zol Area/ } \\
\text { Number of } \\
\text { Pixels }\end{array}$ \\
\hline 10 & $181.93 \pm 2.13$ & $82.06 \pm 0.12$ & $2.22 \pm 2.60 \mathrm{E}-4$ & $153.41 \pm 2.14$ & $88.79 \pm 0.13$ & $1.73 \pm 2.41 \mathrm{E}-4$ \\
\hline 5 & $175.38 \pm 3.13$ & $84.84 \pm 0.21$ & $2.07 \pm 3.29 \mathrm{E}-3$ & $145.38 \pm 3.56$ & $92.97 \pm 0.15$ & $1.56 \pm 2.91 \mathrm{E}-3$ \\
\hline 2.5 & $165.24 \pm 2.57$ & $83.13 \pm 0.12$ & $1.99 \pm 5.33 \mathrm{E}-3$ & $165.24 \pm 3.12$ & $98.91 \pm 0.06$ & $1.67 \pm 2.85 \mathrm{E}-3$ \\
\hline 1.25 & $149.6 \pm 4.43$ & $89.39 \pm 0.04$ & $1.67 \pm 2.74 \mathrm{E}-3$ & $164.82 \pm 2.12$ & $105.39 \pm 0.08$ & $1.56 \pm 1.09 \mathrm{E}-3$ \\
\hline 0.625 & $145.8 \pm 2.13$ & $76.87 \pm 0.03$ & $1.9 \pm 1.26 \mathrm{E}-3$ & $171.58 \pm 3.01$ & $85.44 \pm 0.03$ & $2.01 \pm 2.23 \mathrm{E}-3$ \\
\hline 0.3125 & $140.52 \pm 1.23$ & $65.72 \pm 0.02$ & $2.14 \pm 1.16 \mathrm{E}-3$ & $141.15 \pm 2.13$ & $78.26 \pm 0.09$ & $1.8 \pm 9.64 \mathrm{E}-4$ \\
\hline 0.15625 & $113.05 \pm 3.12$ & $69.75 \pm 0.10$ & $1.62 \pm 9.12 \mathrm{E}-4$ & $113.05 \pm 1.43$ & $79.76 \pm 0.02$ & $1.42 \pm 1.78 \mathrm{E}-3$ \\
\hline 0.07812 & $92.13 \pm 2.12$ & $71.34 \pm 0.11$ & $1.29 \pm 2.11 \mathrm{E}-3$ & $103.33 \pm 0.98$ & $80.18 \pm 0.13$ & $1.29 \pm 4.44 \mathrm{E}-4$ \\
\hline DMSO & $37.46 \pm 0.81$ & $123.69 \pm 0.04$ & $0.3 \pm 3.35 \mathrm{E}-4$ & $30.9 \pm 2.58$ & $95.69 \pm 0.13$ & $0.32 \pm 7.08 \mathrm{E}-4$ \\
\hline 0.03906 & $141.15 \pm 2.13$ & $80.66 \pm 0.02$ & $1.75 \pm 1.13 \mathrm{E}-3$ & $108.61 \pm 3.12$ & $82.63 \pm 0.15$ & $1.31 \pm 2.45 \mathrm{E}-3$ \\
\hline 0.01953 & $108.61 \pm 1.58$ & $88.47 \pm 0.05$ & $1.23 \pm 4.56 \mathrm{E}-4$ & $95.3 \pm 2.12$ & $89.72 \pm 0.25$ & $1.06 \pm 2.01 \mathrm{E}-3$ \\
\hline 0.009765 & $94.66 \pm 1.23$ & $87.96 \pm 0.12$ & $1.08 \pm 7.52 \mathrm{E}-4$ & $84.1 \pm 2.53$ & $91.94 \pm 0.12$ & $0.91 \pm 2.76 \mathrm{E}-3$ \\
\hline 0.004883 & $81.14 \pm 1.11$ & $96.47 \pm 0.08$ & $0.84 \pm 1.16 \mathrm{E}-3$ & $66.56 \pm 1.42$ & $96.49 \pm 1.02$ & $0.69 \pm 1.01 \mathrm{E}-3$ \\
\hline 0.002441 & $50.71 \pm 1.47$ & $79.27 \pm 0.21$ & $0.64 \pm 8.31 \mathrm{E}-4$ & $45.64 \pm 1.56$ & $84.52 \pm 0.93$ & $0.54 \pm 6.70 \mathrm{E}-3$ \\
\hline 0.00061 & $40.57 \pm 1.41$ & $71.25 \pm 0.11$ & $0.57 \pm 1.88 \mathrm{E}-3$ & $35.08 \pm 1.21$ & $73.97 \pm 0.31$ & $0.47 \pm 6.13 \mathrm{E}-3$ \\
\hline 0.000305 & $37.4 \pm 1.41$ & $79.57 \pm 0.05$ & $0.47 \pm 8.27 \mathrm{E}-4$ & $32.96 \pm 1.94$ & $76.95 \pm 0.11$ & $0.43 \pm 1.98 \mathrm{E}-3$ \\
\hline 0.000153 & $32.96 \pm 1.03$ & $86.18 \pm 0.89$ & $0.38 \pm 3.41 \mathrm{E}-4$ & $23.67 \pm 1.03$ & $86.21 \pm 0.84$ & $0.27 \pm 4.7 \mathrm{E}-4$ \\
\hline DMSO & $34.71 \pm 1.76$ & $80.82 \pm 0.12$ & $0.43 \pm 4.95 \mathrm{E}-3$ & $33.02 \pm 1.42$ & $92.14 \pm 0.62$ & $0.36 \pm 3.42 \mathrm{E}-3$ \\
\hline
\end{tabular}




\begin{tabular}{|c|c|c|c|c|c|c|}
\hline \multirow[b]{2}{*}{ Concentration } & \multicolumn{3}{|c|}{ Disulfiram $25^{\circ} \mathrm{C}$} & \multicolumn{3}{|c|}{ Disulfiram $37^{\circ} \mathrm{C}$} \\
\hline & $\begin{array}{l}\text { zol Area } \\
\left(\mathrm{mm}^{2}\right)\end{array}$ & $\begin{array}{c}\text { Number of } \\
\text { Pixels }\end{array}$ & $\begin{array}{l}\text { zol Area/ } \\
\text { Number of } \\
\text { Pixels }\end{array}$ & $\begin{array}{l}\text { zOI Area } \\
\left(\mathrm{mm}^{2}\right)\end{array}$ & $\begin{array}{l}\text { Number of } \\
\text { Pixels }\end{array}$ & $\begin{array}{l}\text { zol Area/ } \\
\text { Number of } \\
\text { Pixels }\end{array}$ \\
\hline 10 & $181.72 \pm 3.21$ & $64.79 \pm 0.21$ & $2.8 \pm 4.95 \mathrm{E}-4$ & $103.33 \pm 1.32$ & $76.23 \pm 0.44$ & $1.36 \pm 1.73 \mathrm{E}-4$ \\
\hline 5 & $150.24 \pm 2.12$ & $70.57 \pm 0.23$ & $2.13 \pm 6.64 \mathrm{E}-3$ & $35.08 \pm 1.11$ & $71.66 \pm 0.21$ & $0.49 \pm 3.16 \mathrm{E}-3$ \\
\hline 2.5 & $40.57 \pm 1.64$ & $82.34 \pm 0.21$ & $0.49 \pm 1.58 \mathrm{E}-3$ & $34.65 \pm 1.33$ & $83.49 \pm 0.05$ & $0.42 \pm 1.20 \mathrm{E}-3$ \\
\hline 1.25 & $37.19 \pm 1.54$ & $74.6 \pm 0.24$ & $0.5 \pm 1.61 \mathrm{E}-3$ & $35.08 \pm 0.08$ & $99.74 \pm 0.21$ & $0.35 \pm 1.84 \mathrm{E}-4$ \\
\hline 0.625 & $36.34 \pm 1.08$ & $84.62 \pm 0.07$ & $0.43 \pm 1.35 \mathrm{E}-3$ & $32.96 \pm 0.92$ & $65.73 \pm 0.13$ & $0.5 \pm 1.74 \mathrm{E}-3$ \\
\hline 0.3125 & $35.08 \pm 2.42$ & $60.39 \pm 0.07$ & $0.58 \pm 1.07 \mathrm{E}-3$ & $28.1 \pm 0.87$ & $76.44 \pm 0.23$ & $0.37 \pm 7.39 \mathrm{E}-4$ \\
\hline 0.15625 & $29.58 \pm 2.09$ & $63.93 \pm 0.09$ & $0.46 \pm 8.34 \mathrm{E}-4$ & $32.96 \pm 1.21$ & $75.73 \pm 0.18$ & $0.44 \pm 1.48 \mathrm{E}-3$ \\
\hline 0.07812 & $28.74 \pm 1.03$ & $82.05 \pm 0.05$ & $0.35 \pm 5.10 \mathrm{E}-4$ & $31.27 \pm 0.85$ & $90.23 \pm 0.23$ & $0.35 \pm 7.86 \mathrm{E}-4$ \\
\hline DMSO & $32.02 \pm 0.78$ & $95 \pm 0.12$ & $0.34 \pm 2.60 \mathrm{E}-4$ & $33.02 \pm 0.68$ & $100.6 \pm 0.15$ & $0.33 \pm 8.18 E-4$ \\
\hline
\end{tabular}

\begin{tabular}{|c|c|c|c|c|c|c|}
\hline \multirow[b]{2}{*}{ Concentration } & \multicolumn{3}{|c|}{ Fluconazole $25^{\circ} \mathrm{C}$} & \multicolumn{3}{|c|}{ Fluconazole $37^{\circ} \mathrm{C}$} \\
\hline & $\begin{array}{c}\text { ZOI Area } \\
\left(\mathrm{mm}^{2}\right)\end{array}$ & $\begin{array}{l}\text { Number of } \\
\text { Pixels }\end{array}$ & $\begin{array}{l}\text { ZOI Area/ } \\
\text { Number of } \\
\text { Pixels }\end{array}$ & $\begin{array}{c}\text { ZOI Area } \\
\left(\mathrm{mm}^{2}\right)\end{array}$ & $\begin{array}{l}\text { Number of } \\
\text { Pixels }\end{array}$ & $\begin{array}{l}\text { zOI Area/ } \\
\text { Number of } \\
\text { Pixels }\end{array}$ \\
\hline 10 & $626.73 \pm 5.12$ & $88.91 \pm 0.14$ & $7.05 \pm 5.76 \mathrm{E}-4$ & $721.6 \pm 5.12$ & $97.31 \pm 0.07$ & $7.42 \pm 5.26 \mathrm{E}-4$ \\
\hline 5 & $491.49 \pm 4.21$ & $95.02 \pm 0.44$ & $5.17 \pm 8.06 \mathrm{E}-3$ & $494.03 \pm 6.12$ & $100.2 \pm 0.12$ & $4.93 \pm 4.06 \mathrm{E}-3$ \\
\hline 2.5 & $406.55 \pm 4.82$ & $106.75 \pm 0.32$ & $3.81 \pm 1.61 \mathrm{E}-2$ & $314.84 \pm 3.59$ & $113.9 \pm 0.32$ & $2.76 \pm 3.23 \mathrm{E}-3$ \\
\hline 1.25 & $375.28 \pm 3.16$ & $107.25 \pm 0.08$ & $3.5 \pm 1.07 \mathrm{E}-2$ & $216.16 \pm 3.21$ & $112.1 \pm 0.18$ & $1.93 \pm 5.79 \mathrm{E}-3$ \\
\hline 0.625 & $215.53 \pm 1.25$ & $107.53 \pm 0.46$ & $2 \pm 1.61 \mathrm{E}-3$ & $141.15 \pm 1.69$ & $93.67 \pm 0.13$ & $1.51 \pm 3.08 \mathrm{E}-3$ \\
\hline 0.3125 & $81.14 \pm 1.05$ & $97.21 \pm 0.08$ & $0.83 \pm 4.06 \mathrm{E}-3$ & $63.39 \pm 1.42$ & $86.84 \pm 0.29$ & $0.73 \pm 1.31 \mathrm{E}-3$ \\
\hline 0.15625 & $30.85 \pm 0.54$ & $97.07 \pm 0.03$ & $0.32 \pm 3.18 \mathrm{E}-4$ & $48.39 \pm 0.98$ & $107.39 \pm 0.22$ & $0.45 \pm 2.57 \mathrm{E}-3$ \\
\hline 0.07812 & $31.91 \pm 1.57$ & $122.23 \pm 0.06$ & $0.26 \pm 1.93 \mathrm{E}-4$ & $40.57 \pm 1.95$ & $98.51 \pm 0.08$ & $0.41 \pm 1.12 \mathrm{E}-3$ \\
\hline DMSO & $37.25 \pm 0.96$ & $119.78 \pm 0.04$ & $0.31 \pm 2.36 \mathrm{E}-4$ & $39.46 \pm 1.42$ & $115.93 \pm 0.06$ & $0.34 \pm 3.57 \mathrm{E}-4$ \\
\hline
\end{tabular}




\begin{tabular}{|c|c|c|c|c|c|c|}
\hline \multirow[b]{2}{*}{ Concentration } & \multicolumn{3}{|c|}{ Fluvastatin $25^{\circ} \mathrm{C}$} & \multicolumn{3}{|c|}{ Fluvastatin $37^{\circ} \mathrm{C}$} \\
\hline & $\begin{array}{c}\text { zol Area } \\
\left(\mathrm{mm}^{2}\right)\end{array}$ & $\begin{array}{l}\text { Number of } \\
\text { Pixels }\end{array}$ & $\begin{array}{l}\text { zol Area/ } \\
\text { Number of } \\
\text { Pixels }\end{array}$ & $\begin{array}{l}\text { ZOI Area } \\
\left(\mathrm{mm}^{2}\right)\end{array}$ & $\begin{array}{c}\text { Number of } \\
\text { Pixels }\end{array}$ & $\begin{array}{l}\text { ZOI Area/ } \\
\text { Number of } \\
\text { Pixels }\end{array}$ \\
\hline 10 & $48.18 \pm 2.13$ & $72.52 \pm 0.03$ & $0.66 \pm 2.94 \mathrm{E}-4$ & $484.31 \pm 4.42$ & $72.55 \pm 0.04$ & $6.68 \pm 6.09 \mathrm{E}-4$ \\
\hline 5 & $43.95 \pm 2.49$ & $74.25 \pm 0.02$ & $0.59 \pm 5.75 \mathrm{E}-4$ & $407.82 \pm 3.42$ & $82.28 \pm 0.14$ & $4.96 \pm 2.83 \mathrm{E}-3$ \\
\hline 2.5 & $37.4 \pm 1.23$ & $81.88 \pm 0.05$ & $0.46 \pm 2.62 \mathrm{E}-4$ & $381.19 \pm 2.43$ & $85.75 \pm 0.21$ & $4.45 \pm 0.01$ \\
\hline 1.25 & $43.95 \pm 0.93$ & $86.93 \pm 0.13$ & $0.51 \pm 3.98 \mathrm{E}-4$ & $286.11 \pm 1.23$ & $89.35 \pm 0.11$ & $3.2 \pm 7.66 \mathrm{E}-3$ \\
\hline 0.625 & $48.18 \pm 1.42$ & $96.48 \pm 0.21$ & $0.5 \pm 8.20 \mathrm{E}-4$ & $216.16 \pm 2.41$ & $75.34 \pm 0.06$ & $2.87 \pm 4.51 \mathrm{E}-3$ \\
\hline 0.3125 & $45.64 \pm 0.34$ & $71.42 \pm 0.31$ & $0.64 \pm 1.93 \mathrm{E}-3$ & $186.37 \pm 2.65$ & $68.63 \pm 0.32$ & $2.72 \pm 2.76 \mathrm{E}-3$ \\
\hline 0.15625 & $35.08 \pm 0.13$ & $75.21 \pm 0.12$ & $0.47 \pm 1.94 \mathrm{E}-3$ & $129.11 \pm 1.69$ & $69.07 \pm 0.31$ & $1.87 \pm 8.90 \mathrm{E}-3$ \\
\hline 0.07812 & $31.91 \pm 0.08$ & $74.05 \pm 0.21$ & $0.43 \pm 7.09 \mathrm{E}-4$ & $129.92 \pm 3.21$ & $67.74 \pm 0.12$ & $1.92 \pm 9.25 \mathrm{E}-3$ \\
\hline DMSO & $33.62 \pm 0.12$ & $75.64 \pm 0.07$ & $0.44 \pm 1.25 \mathrm{E}-3$ & $28.99 \pm 1.02$ & $93.59 \pm 0.12$ & $0.31 \pm 5.06 \mathrm{E}-4$ \\
\hline
\end{tabular}

\begin{tabular}{|c|c|c|c|c|c|c|}
\hline \multirow[b]{2}{*}{ Concentration } & \multicolumn{3}{|c|}{ Methylbenzethonium Chloride $25^{\circ} \mathrm{C}$} & \multicolumn{3}{|c|}{ Methylbenzethonium Chloride $37^{\circ} \mathrm{C}$} \\
\hline & $\begin{array}{c}\text { ZOI Area } \\
\left(\mathrm{mm}^{2}\right)\end{array}$ & $\begin{array}{l}\text { Number of } \\
\text { Pixels }\end{array}$ & $\begin{array}{l}\text { ZOI Area/ } \\
\text { Number of } \\
\text { Pixels }\end{array}$ & $\begin{array}{c}\text { zOI Area } \\
\left(\mathrm{mm}^{2}\right)\end{array}$ & $\begin{array}{l}\text { Number of } \\
\text { Pixels }\end{array}$ & $\begin{array}{l}\text { ZOI Area/ } \\
\text { Number of } \\
\text { Pixels }\end{array}$ \\
\hline 10 & $121.71 \pm 1.46$ & $61.23 \pm 0.12$ & $1.99 \pm 2.38 \mathrm{E}-4$ & $92.13 \pm 1.04$ & $69.39 \pm 0.02$ & $1.33 \pm 1.5 \mathrm{E}-4$ \\
\hline 5 & $99.74 \pm 0.59$ & $60.78 \pm 0.06$ & $1.64 \pm 3.34 \mathrm{E}-3$ & $80.3 \pm 1.41$ & $76.06 \pm 0.08$ & $1.06 \pm 4.63 \mathrm{E}-4$ \\
\hline 2.5 & $66.56 \pm 0.74$ & $63.06 \pm 0.21$ & $1.06 \pm 1.12 \mathrm{E}-3$ & $57.9 \pm 1.32$ & $68.63 \pm 0.13$ & $0.84 \pm 1.18 \mathrm{E}-3$ \\
\hline 1.25 & $45.64 \pm 0.84$ & $66.26 \pm 0.19$ & $0.69 \pm 2.31 \mathrm{E}-3$ & $47.54 \pm 1.09$ & $72.52 \pm 0.14$ & $0.66 \pm 1.33 \mathrm{E}-3$ \\
\hline 0.625 & $30.85 \pm 1.04$ & $82.81 \pm 0.09$ & $0.37 \pm 9.80 \mathrm{E}-4$ & $44.37 \pm 0.98$ & $84.45 \pm 0.05$ & $0.53 \pm 9.87 \mathrm{E}-4$ \\
\hline 0.3125 & $31.91 \pm 0.23$ & $77.26 \pm 0.08$ & $0.41 \pm 5.11 \mathrm{E}-4$ & $29.58 \pm 0.78$ & $82.05 \pm 0.07$ & $0.36 \pm 3.15 \mathrm{E}-4$ \\
\hline 0.15625 & $30.85 \pm 0.95$ & $71.97 \pm 0.02$ & $0.43 \pm 6.08 \mathrm{E}-4$ & $30.85 \pm 0.19$ & $89.59 \pm 0.12$ & $0.34 \pm 2.9 \mathrm{E}-4$ \\
\hline 0.07812 & $31.91 \pm 0.53$ & $86.09 \pm 0.09$ & $0.37 \pm 1.48 E-4$ & $24.3 \pm 1.32$ & $100.09 \pm 0.08$ & $0.24 \pm 4.23 \mathrm{E}-4$ \\
\hline DMSO & $35.13 \pm 0.23$ & $93.16 \pm 0.09$ & $0.38 \pm 3.89 E-4$ & $31.96 \pm 1.03$ & $102.71 \pm 0.04$ & $0.31 \pm 3.43 E-4$ \\
\hline
\end{tabular}




\begin{tabular}{|c|c|c|c|c|c|c|}
\hline \multirow[b]{2}{*}{ Concentration } & \multicolumn{3}{|c|}{ Miconazole $25^{\circ} \mathrm{C}$} & \multicolumn{3}{|c|}{ Miconazole $37^{\circ} \mathrm{C}$} \\
\hline & $\begin{array}{l}\text { zOI Area } \\
\left(\mathrm{mm}^{2}\right)\end{array}$ & $\begin{array}{l}\text { Number of } \\
\text { Pixels }\end{array}$ & $\begin{array}{l}\text { ZOI Area/ } \\
\text { Number of } \\
\text { Pixels }\end{array}$ & $\begin{array}{c}\text { zOI Area } \\
\left(\mathrm{mm}^{2}\right)\end{array}$ & $\begin{array}{l}\text { Number of } \\
\text { Pixels }\end{array}$ & $\begin{array}{l}\text { zOI Area/ } \\
\text { Number of } \\
\text { Pixels }\end{array}$ \\
\hline 10 & $108.61 \pm 1.32$ & $46.07 \pm 0.03$ & $2.36 \pm 2.87 E-4$ & $108.61 \pm 5.48$ & $81.88 \pm 0.02$ & $1.33 \pm 6.69 \mathrm{E}-4$ \\
\hline 5 & $92.13 \pm 1.43$ & $48.82 \pm 0.12$ & $1.89 \pm 1.45 \mathrm{E}-3$ & $99.74 \pm 1.32$ & $87.44 \pm 0.01$ & $1.14 \pm 4.12 \mathrm{E}-4$ \\
\hline 2.5 & $84.52 \pm 1.49$ & $59.34 \pm 0.14$ & $1.42 \pm 3.13 \mathrm{E}-3$ & $91.71 \pm 1.43$ & $89.97 \pm 0.12$ & $1.02 \pm 2.72 \mathrm{E}-4$ \\
\hline 1.25 & $88.96 \pm 1.46$ & $60.83 \pm 0.08$ & $1.46 \pm 3.61 \mathrm{E}-3$ & $91.71 \pm 1.23$ & $90.9 \pm 0.09$ & $1.01 \pm 1.47 \mathrm{E}-3$ \\
\hline 0.625 & $84.1 \pm 1.31$ & $65.02 \pm 0.04$ & $1.29 \pm 1.79 \mathrm{E}-3$ & $95.3 \pm 0.98$ & $90.82 \pm 0.21$ & $1.05 \pm 1.15 \mathrm{E}-3$ \\
\hline 0.3125 & $80.93 \pm 1.23$ & $57.31 \pm 0.23$ & $1.41 \pm 1.20 \mathrm{E}-3$ & $84.52 \pm 0.84$ & $73.78 \pm 0.18$ & $1.15 \pm 3.37 \mathrm{E}-3$ \\
\hline 0.15625 & $73.75 \pm 0.90$ & $54.9 \pm 0.21$ & $1.34 \pm 5.79 \mathrm{E}-3$ & $73.75 \pm 1.29$ & $71.06 \pm 0.14$ & $1.04 \pm 2.81 \mathrm{E}-3$ \\
\hline 0.07812 & $66.77 \pm 0.08$ & $52.01 \pm 0.12$ & $1.28 \pm 5.20 \mathrm{E}-3$ & $54.09 \pm 1.04$ & $87.27 \pm 0.21$ & $0.62 \pm 1.11 \mathrm{E}-3$ \\
\hline DMSO & $35.13 \pm 0.58$ & $63.24 \pm 0.18$ & $0.56 \pm 1.15 \mathrm{E}-3$ & $26.24 \pm 1.03$ & $87.03 \pm 0.08$ & $0.3 \pm 8.46 \mathrm{E}-4$ \\
\hline 0.03906 & $73.75 \pm 1.53$ & $92.62 \pm 0.03$ & $0.8 \pm 1.71 \mathrm{E}-3$ & $47.54 \pm 1.81$ & $94.41 \pm 0.03$ & $0.5 \pm 6.18 \mathrm{E}-4$ \\
\hline 0.01953 & $69.73 \pm 2.08$ & $96.8 \pm 0.09$ & $0.72 \pm 4.38 \mathrm{E}-4$ & $39.3 \pm 1.18$ & $107.03 \pm 0.18$ & $0.37 \pm 2.13 \mathrm{E}-4$ \\
\hline 0.009765 & $56.63 \pm 1.74$ & $102.95 \pm 0.14$ & $0.55 \pm 6.50 \mathrm{E}-4$ & $27.05 \pm 1.09$ & $113.44 \pm 0.09$ & $0.24 \pm 4.74 \mathrm{E}-4$ \\
\hline 0.004883 & $55.78 \pm 1.43$ & $110.23 \pm 0.05$ & $0.51 \pm 7.72 \mathrm{E}-4$ & $20.5 \pm 1.03$ & $122.95 \pm 0.07$ & $0.17 \pm 2.06 \mathrm{E}-4$ \\
\hline 0.002441 & $43.74 \pm 1.48$ & $113.07 \pm 0.03$ & $0.39 \pm 3.02 \mathrm{E}-4$ & $21.55 \pm 0.93$ & $124.48 \pm 0.03$ & $0.17 \pm 1.72 \mathrm{E}-4$ \\
\hline 0.00061 & $30.85 \pm 1.85$ & $97.49 \pm 0.04$ & $0.32 \pm 2.87 \mathrm{E}-4$ & $30.85 \pm 0.83$ & $103.51 \pm 0.11$ & $0.3 \pm 1.67 \mathrm{E}-4$ \\
\hline 0.000305 & $28.1 \pm 0.94$ & $99.35 \pm 0.07$ & $0.28 \pm 2.08 \mathrm{E}-4$ & $18.6 \pm 1.21$ & $93.57 \pm 0.12$ & $0.2 \pm 3.63 \mathrm{E}-4$ \\
\hline 0.000153 & $31.91 \pm 1.34$ & $103.46 \pm 0.14$ & $0.31 \pm 3.38 E-4$ & $28.95 \pm 1.04$ & $106.1 \pm 0.08$ & $0.27 \pm 4.07 \mathrm{E}-4$ \\
\hline DMSO & $30.9 \pm 1.48$ & $112.13 \pm 0.09$ & $0.28 \pm 4.76 \mathrm{E}-4$ & $24.34 \pm 1.02$ & $111.68 \pm 0.19$ & $0.22 \pm 2.47 \mathrm{E}-4$ \\
\hline
\end{tabular}




\begin{tabular}{|c|c|c|c|c|c|c|}
\hline \multirow[b]{2}{*}{ Concentration } & \multicolumn{3}{|c|}{ Mycophenolic Acid $25^{\circ} \mathrm{C}$} & \multicolumn{3}{|c|}{ Mycophenolic Acid $37^{\circ} \mathrm{C}$} \\
\hline & $\begin{array}{l}\text { zol Area } \\
\left(\mathrm{mm}^{2}\right)\end{array}$ & $\begin{array}{l}\text { Number of } \\
\text { Pixels }\end{array}$ & $\begin{array}{l}\text { ZOI Area/ } \\
\text { Number of } \\
\text { Pixels }\end{array}$ & $\begin{array}{c}\text { ZOI Area } \\
\left(\mathrm{mm}^{2}\right)\end{array}$ & $\begin{array}{l}\text { Number of } \\
\text { Pixels }\end{array}$ & $\begin{array}{c}\text { zOI Area/ } \\
\text { Number of } \\
\text { Pixels }\end{array}$ \\
\hline 10 & $300.47 \pm 4.12$ & $116.81 \pm 0.13$ & $2.57 \pm 3.53 \mathrm{E}-4$ & $468.46 \pm 5.43$ & $105.77 \pm 0.02$ & $4.43 \pm 5.13 \mathrm{E}-4$ \\
\hline 5 & $266.24 \pm 3.14$ & $106.15 \pm 0.21$ & $2.51 \pm 3.37 \mathrm{E}-3$ & $202.85 \pm 4.23$ & $109.95 \pm 0.04$ & $1.84 \pm 7.20 \mathrm{E}-4$ \\
\hline 2.5 & $159.11 \pm 1.94$ & $116.01 \pm 0.09$ & $1.37 \pm 2.65 \mathrm{E}-3$ & $113.05 \pm 1.40$ & $118.06 \pm 0.03$ & $0.96 \pm 4.43 E-4$ \\
\hline 1.25 & $47.54 \pm 0.58$ & $116.17 \pm 0.10$ & $0.41 \pm 3.67 \mathrm{E}-4$ & $37.4 \pm 1.23$ & $119.94 \pm 0.12$ & $0.31 \pm 1.81 \mathrm{E}-4$ \\
\hline 0.625 & $31.91 \pm 0.64$ & $109.13 \pm 0.13$ & $0.29 \pm 3.27 \mathrm{E}-4$ & $16.69 \pm 1.09$ & $103.46 \pm 0.04$ & $0.16 \pm 2.92 \mathrm{E}-4$ \\
\hline 0.3125 & $45.64 \pm 1.74$ & $96.83 \pm 0.04$ & $0.47 \pm 8.13 \mathrm{E}-4$ & $21.98 \pm 1.02$ & $87.21 \pm 0.13$ & $0.25 \pm 2.33 \mathrm{E}-4$ \\
\hline 0.15625 & $32.96 \pm 0.65$ & $89.3 \pm 0.09$ & $0.37 \pm 2.38 \mathrm{E}-4$ & $26.2 \pm 0.98$ & $90.82 \pm 0.05$ & $0.29 \pm 5.21 \mathrm{E}-4$ \\
\hline 0.07812 & $32.96 \pm 0.98$ & $99.35 \pm 0.08$ & $0.33 \pm 3.99 \mathrm{E}-4$ & $30.85 \pm 0.87$ & $106.51 \pm 0.02$ & $0.29 \pm 2.18 \mathrm{E}-4$ \\
\hline DMSO & $37.46 \pm 1.23$ & $115.57 \pm 0.19$ & $0.32 \pm 3.31 \mathrm{E}-4$ & $30.9 \pm 1.21$ & $116.85 \pm 0.08$ & $0.26 \pm 1.49 \mathrm{E}-4$ \\
\hline
\end{tabular}

\begin{tabular}{|c|c|c|c|c|c|c|}
\hline \multirow[b]{2}{*}{ Concentration } & \multicolumn{3}{|c|}{ Nifuroxime $25^{\circ} \mathrm{C}$} & \multicolumn{3}{|c|}{ Nifuroxime $37^{\circ} \mathrm{C}$} \\
\hline & $\begin{array}{c}\text { zol Area } \\
\left(\mathrm{mm}^{2}\right)\end{array}$ & $\begin{array}{l}\text { Number of } \\
\text { Pixels }\end{array}$ & $\begin{array}{l}\text { ZOI Area/ } \\
\text { Number of } \\
\text { Pixels }\end{array}$ & $\begin{array}{c}\text { ZOI Area } \\
\left(\mathrm{mm}^{2}\right)\end{array}$ & $\begin{array}{l}\text { Number of } \\
\text { Pixels }\end{array}$ & $\begin{array}{l}\text { zol Area/ } \\
\text { Number of } \\
\text { Pixels }\end{array}$ \\
\hline 10 & $117.91 \pm 1.21$ & $82.44 \pm 0.04$ & $1.43 \pm 1.47 \mathrm{E}-4$ & $30.85 \pm 2.31$ & $68.18 \pm 0.05$ & $0.45 \pm 3.39 \mathrm{E}-4$ \\
\hline 5 & $37.19 \pm 1.48$ & $85.47 \pm 0.09$ & $0.44 \pm 3.77 \mathrm{E}-4$ & $28.95 \pm 2.03$ & $91.1 \pm 0.02$ & $0.32 \pm 3.97 \mathrm{E}-4$ \\
\hline 2.5 & $26.2 \pm 1.25$ & $86.26 \pm 0.14$ & $0.3 \pm 4.62 \mathrm{E}-4$ & $30.85 \pm 1.24$ & $91.86 \pm 0.08$ & $0.34 \pm 2.08 \mathrm{E}-4$ \\
\hline 1.25 & $35.08 \pm 1.02$ & $106.37 \pm 0.21$ & $0.33 \pm 5.30 \mathrm{E}-4$ & $28.95 \pm 1.49$ & $97.82 \pm 0.21$ & $0.3 \pm 3.94 \mathrm{E}-4$ \\
\hline 0.625 & $31.91 \pm 1.92$ & $77.87 \pm 0.16$ & $0.41 \pm 1.35 \mathrm{E}-3$ & $37.4 \pm 1.09$ & $90.09 \pm 0.06$ & $0.42 \pm 1.09 \mathrm{E}-3$ \\
\hline 0.3125 & $37.4 \pm 1.32$ & $79.83 \pm 0.04$ & $0.47 \pm 1.10 \mathrm{E}-3$ & $37.19 \pm 1.24$ & $72.98 \pm 0.12$ & $0.51 \pm 5.89 \mathrm{E}-4$ \\
\hline 0.15625 & $32.96 \pm 1.25$ & $72.67 \pm 0.21$ & $0.45 \pm 4.22 \mathrm{E}-4$ & $28.95 \pm 0.78$ & $79.51 \pm 0.08$ & $0.36 \pm 6.58 E-4$ \\
\hline 0.07812 & $31.91 \pm 0.89$ & $85.06 \pm 0.09$ & $0.38 \pm 1.03 \mathrm{E}-3$ & $26.2 \pm 1.13$ & $88.64 \pm 0.08$ & $0.3 \pm 3.94 \mathrm{E}-4$ \\
\hline DMSO & $37.46 \pm 0.92$ & $98.91 \pm 0.11$ & $0.38 \pm 4.38 \mathrm{E}-4$ & $47.62 \pm 1.04$ & $99.82 \pm 0.23$ & $0.48 \pm 4.87 \mathrm{E}-4$ \\
\hline
\end{tabular}




\begin{tabular}{|c|c|c|c|c|c|c|}
\hline \multirow[b]{2}{*}{ Concentration } & \multicolumn{3}{|c|}{ Nitroxoline $25^{\circ} \mathrm{C}$} & \multicolumn{3}{|c|}{ Nitroxoline $37^{\circ} \mathrm{C}$} \\
\hline & $\begin{array}{c}\text { ZOI Area } \\
\left(\mathrm{mm}^{2}\right)\end{array}$ & $\begin{array}{c}\text { Number of } \\
\text { Pixels }\end{array}$ & $\begin{array}{l}\text { zol Area/ } \\
\text { Number of } \\
\text { Pixels }\end{array}$ & $\begin{array}{l}\text { ZOI Area } \\
\left(\mathrm{mm}^{2}\right)\end{array}$ & $\begin{array}{c}\text { Number of } \\
\text { Pixels }\end{array}$ & $\begin{array}{l}\text { zol Area/ } \\
\text { Number of } \\
\text { Pixels }\end{array}$ \\
\hline 10 & $228.21 \pm 4.12$ & $66.95 \pm 0.08$ & $3.41 \pm 6.15 \mathrm{E} 4$ & $286.11 \pm 5.31$ & $73.19 \pm 0.04$ & $3.91 \pm 7.26 \mathrm{E}-4$ \\
\hline 5 & $210.04 \pm 3.18$ & $78.06 \pm 0.12$ & $2.69 \pm 3.17 \mathrm{E}-3$ & $245.53 \pm 3.12$ & $68.46 \pm 0.12$ & $3.59 \pm 2.55 E-3$ \\
\hline 2.5 & $181.93 \pm 1.21$ & $85.43 \pm 0.21$ & $2.13 \pm 3.13 \mathrm{E}-3$ & $222.29 \pm 4.12$ & $80.96 \pm 0.03$ & $2.75 \pm 4.58 \mathrm{E}-3$ \\
\hline 1.25 & $121.92 \pm 1.97$ & $97.69 \pm 0.04$ & $1.25 \pm 2.88 \mathrm{E}-3$ & $143.69 \pm 1.92$ & $96.8 \pm 0.21$ & $1.48 \pm 6.58 \mathrm{E}-4$ \\
\hline 0.625 & $50.29 \pm 0.92$ & $82.99 \pm 0.12$ & $0.61 \pm 4.03 \mathrm{E}-4$ & $81.14 \pm 1.84$ & $89.71 \pm 0.12$ & $0.9 \pm 2.32 \mathrm{E}-3$ \\
\hline 0.3125 & $40.57 \pm 1.23$ & $74.42 \pm 0.06$ & $0.55 \pm 1.04 \mathrm{E}-3$ & $31.91 \pm 0.98$ & $83.96 \pm 0.23$ & $0.38 \pm 6.60 \mathrm{E}-4$ \\
\hline 0.15625 & $37.19 \pm 1.03$ & $88.76 \pm 0.13$ & $0.42 \pm 3.99 \mathrm{E}-4$ & $29.58 \pm 0.83$ & $94.99 \pm 0.14$ & $0.31 \pm 8.41 \mathrm{E}-4$ \\
\hline 0.07812 & $32.96 \pm 1.08$ & $96.82 \pm 0.09$ & $0.34 \pm 5.69 \mathrm{E}-4$ & $30.85 \pm 0.91$ & $103.98 \pm 0.13$ & $0.3 \pm 4.87 \mathrm{E}-4$ \\
\hline DMSO & $45.72 \pm 2.01$ & $97.98 \pm 0.17$ & $0.47 \pm 6.34 \mathrm{E}-4$ & $32.9 \pm 1.03$ & $89.64 \pm 0.14$ & $0.37 \pm 6.47 \mathrm{E}-4$ \\
\hline
\end{tabular}

\begin{tabular}{|c|c|c|c|c|c|c|}
\hline \multirow[b]{2}{*}{ Concentration } & \multicolumn{3}{|c|}{ Octanoic Acid $25^{\circ} \mathrm{C}$} & \multicolumn{3}{|c|}{ Octanoic Acid $37^{\circ} \mathrm{C}$} \\
\hline & $\begin{array}{l}\text { ZOI Area } \\
\left(\mathrm{mm}^{2}\right)\end{array}$ & $\begin{array}{c}\text { Number of } \\
\text { Pixels }\end{array}$ & $\begin{array}{l}\text { zol Area/ } \\
\text { Number of } \\
\text { Pixels }\end{array}$ & $\begin{array}{c}\text { zol Area } \\
\left(\mathrm{mm}^{2}\right)\end{array}$ & $\begin{array}{l}\text { Number of } \\
\text { Pixels }\end{array}$ & $\begin{array}{l}\text { zol Area/ } \\
\text { Number of } \\
\text { Pixels }\end{array}$ \\
\hline 10 & $181.93 \pm 2.31$ & $72.29 \pm 0.12$ & $2.52 \pm 3.20 \mathrm{E}-4$ & $31.91 \pm 2.03$ & $55.49 \pm 0.12$ & $0.58 \pm 3.66 \mathrm{E}-4$ \\
\hline 5 & $170.52 \pm 3.45$ & $72.46 \pm 0.21$ & $2.35 \pm 4.37 \mathrm{E}-3$ & $28.74 \pm 1.93$ & $69.99 \pm 0.11$ & $0.41 \pm 9.80 \mathrm{E}-4$ \\
\hline 2.5 & $129.11 \pm 1.85$ & $79.52 \pm 0.19$ & $1.62 \pm 4.52 \mathrm{E}-3$ & $26.2 \pm 0.23$ & $87.76 \pm 0.12$ & $0.3 \pm 4.00 \mathrm{E}-4$ \\
\hline 1.25 & $91.71 \pm 3.05$ & $90.09 \pm 0.09$ & $1.02 \pm 2.49 \mathrm{E}-3$ & $21.98 \pm 0.45$ & $100.89 \pm 0.03$ & $0.22 \pm 3.04 \mathrm{E}-4$ \\
\hline 0.625 & $66.77 \pm 2.58$ & $83.24 \pm 0.19$ & $0.8 \pm 1.18 \mathrm{E}-3$ & $18.17 \pm 1.25$ & $105.58 \pm 0.05$ & $0.17 \pm 1.67 \mathrm{E}-4$ \\
\hline 0.3125 & $45.64 \pm 2.12$ & $74 \pm 0.29$ & $0.62 \pm 1.87 \mathrm{E}-3$ & $14.58 \pm 1.02$ & $93.09 \pm 0.09$ & $0.16 \pm 1.94 \mathrm{E}-4$ \\
\hline 0.15625 & $37.19 \pm 2.90$ & $74.07 \pm 0.19$ & $0.5 \pm 2.36 \mathrm{E}-3$ & $35.08 \pm 1.08$ & $94.7 \pm 0.12$ & $0.37 \pm 6.37 \mathrm{E}-4$ \\
\hline 0.07812 & $24.3 \pm 1.76$ & $74.36 \pm 0.29$ & $0.33 \pm 1.07 \mathrm{E}-3$ & $35.08 \pm 1.63$ & $95.1 \pm 0.15$ & $0.37 \pm 6.37 \mathrm{E}-4$ \\
\hline DMSO & $25 \pm 1.07$ & $99.66 \pm 0.12$ & $0.25 \pm 8.37 \mathrm{E}-4$ & $30.9 \pm 1.25$ & $97.67 \pm 0.19$ & $0.32 \pm 6.14 \mathrm{E}-4$ \\
\hline 0.03906 & $35.08 \pm 1.04$ & $77.19 \pm 0.07$ & $0.45 \pm 8.41 \mathrm{E}-4$ & $30.85 \pm 1.20$ & $91.86 \pm 0.09$ & $0.34 \pm 8.25 \mathrm{E}-4$ \\
\hline 0.01953 & $32.96 \pm 1.29$ & $99.15 \pm 0.12$ & $0.33 \pm 3.65 \mathrm{E}-4$ & $30.85 \pm 1.23$ & $105.08 \pm 0.09$ & $0.29 \pm 3.69 \mathrm{E}-4$ \\
\hline 0.009765 & $35.08 \pm 1.05$ & $107.15 \pm 0.32$ & $0.33 \pm 4.65 \mathrm{E}-4$ & $29.58 \pm 1.40$ & $113.21 \pm 0.08$ & $0.26 \pm 3.31 \mathrm{E}-4$ \\
\hline 0.004883 & $23.67 \pm 2.05$ & $104.66 \pm 0.19$ & $0.23 \pm 8.87 \mathrm{E}-4$ & $14.79 \pm 1.13$ & $110.61 \pm 0.08$ & $0.13 \pm 1.99 \mathrm{E}-4$ \\
\hline 0.002441 & $26.2 \pm 1.67$ & $103.78 \pm 0.04$ & $0.25 \pm 6.23 \mathrm{E}-4$ & - & - & - \\
\hline 0.00061 & $23.67 \pm 2.39$ & $96.36 \pm 0.12$ & $0.25 \pm 3.50 \mathrm{E}-4$ & $31.91 \pm 1.64$ & $77.9 \pm 0.12$ & $0.41 \pm 2.11 \mathrm{E}-4$ \\
\hline 0.000305 & $23.67 \pm 3.12$ & $89.45 \pm 0.12$ & $0.26 \pm 7.04 \mathrm{E}-4$ & $28.74 \pm 1.41$ & $80.12 \pm 0.07$ & $0.36 \pm 7.13 \mathrm{E}-4$ \\
\hline 0.000153 & $23.67 \pm 1.28$ & $90.36 \pm 0.09$ & $0.26 \pm 4.90 \mathrm{E}-4$ & $29.58 \pm 2.20$ & $93.09 \pm 0.12$ & $0.32 \pm 4.75 \mathrm{E}-4$ \\
\hline DMSO & $27.15 \pm 1.08$ & $106.06 \pm 0.11$ & $0.26 \pm 3.19 E-4$ & $22.01 \pm 1.23$ & $84.94 \pm 0.08$ & $0.26 \pm 5.11 \mathrm{E}-4$ \\
\hline
\end{tabular}




\begin{tabular}{|c|c|c|c|c|c|c|}
\hline \multirow[b]{2}{*}{ Concentration } & \multicolumn{3}{|c|}{ Octodrine $25^{\circ} \mathrm{C}$} & \multicolumn{3}{|c|}{ Octodrine $37^{\circ} \mathrm{C}$} \\
\hline & $\begin{array}{l}\text { zol Area } \\
\left(\mathrm{mm}^{2}\right)\end{array}$ & $\begin{array}{l}\text { Number of } \\
\text { Pixels }\end{array}$ & $\begin{array}{l}\text { zol Area/ } \\
\text { Number of } \\
\text { Pixels }\end{array}$ & $\begin{array}{l}\text { zol Area } \\
\left(\mathrm{mm}^{2}\right)\end{array}$ & $\begin{array}{l}\text { Number of } \\
\text { Pixels }\end{array}$ & $\begin{array}{c}\text { ZOI Area/ } \\
\text { Number of Pixels }\end{array}$ \\
\hline 10 & $35.08 \pm 1.32$ & $104.46 \pm 0.08$ & $0.34 \pm 1.26 \mathrm{E}-4$ & $30.23 \pm 2.13$ & $98.27 \pm 0.03$ & $0.31 \pm 2.17 \mathrm{E}-4$ \\
\hline 5 & $27.27 \pm 1.53$ & $116.03 \pm 0.09$ & $0.24 \pm 2.94 \mathrm{E}-4$ & $23.02 \pm 1.94$ & $111.36 \pm 0.12$ & $0.21 \pm 2.30 \mathrm{E}-4$ \\
\hline 2.5 & $28.95 \pm 2.15$ & $117.33 \pm 0.14$ & $0.25 \pm 3.73 \mathrm{E}-4$ & $22.61 \pm 1.84$ & $127.7 \pm 0.09$ & $0.18 \pm 3.10 \mathrm{E}-4$ \\
\hline 1.25 & $29.23 \pm 1.03$ & $112 \pm 0.18$ & $0.26 \pm 4.18 \mathrm{E}-4$ & $21.98 \pm 1.59$ & $113.1 \pm 0.07$ & $0.19 \pm 2.95 \mathrm{E}-4$ \\
\hline 0.625 & $28.74 \pm 0.94$ & $103.63 \pm 0.17$ & $0.28 \pm 5.72 E-4$ & $21.98 \pm 1.94$ & $108.63 \pm 0.05$ & $0.2 \pm 3.09 \mathrm{E}-4$ \\
\hline 0.3125 & $29.2 \pm 1.25$ & $91.87 \pm 0.14$ & $0.32 \pm 7.24 \mathrm{E}-4$ & $20.82 \pm 0.93$ & $97.61 \pm 0.13$ & $0.21 \pm 2.05 \mathrm{E}-4$ \\
\hline 0.15625 & $28.1 \pm 1.04$ & $99.05 \pm 0.18$ & $0.28 \pm 5.06 \mathrm{E}-4$ & $24.3 \pm 1.31$ & $101.79 \pm 0.08$ & $0.24 \pm 4.34 \mathrm{E}-4$ \\
\hline 0.07812 & $27.99 \pm 1.23$ & $101.65 \pm 0.13$ & $0.27 \pm 6.09 \mathrm{E}-4$ & $26.2 \pm 1.09$ & $96.5 \pm 0.09$ & $0.27 \pm 3.38 E-4$ \\
\hline DMSO & $24.82 \pm 1.34$ & $106.7 \pm 0.09$ & $0.23 \pm 4.09 \mathrm{E}-4$ & $27.23 \pm 1.32$ & $104.64 \pm 0.12$ & $0.26 \pm 3.50 \mathrm{E}-4$ \\
\hline
\end{tabular}

\begin{tabular}{|c|c|c|c|c|c|c|}
\hline \multirow[b]{2}{*}{ Concentration } & \multicolumn{3}{|c|}{ Pyrithione Zinc $25^{\circ} \mathrm{C}$} & \multicolumn{3}{|c|}{ Pyrithione Zinc $37^{\circ} \mathrm{C}$} \\
\hline & zol Area $\left(\mathrm{mm}^{2}\right)$ & $\begin{array}{l}\text { Number of } \\
\text { Pixels }\end{array}$ & $\begin{array}{l}\text { ZOI Area/ } \\
\text { Number of } \\
\text { Pixels }\end{array}$ & $\begin{array}{l}\text { zol Area } \\
\left(\mathrm{mm}^{2}\right)\end{array}$ & $\begin{array}{c}\text { Number of } \\
\text { Pixels }\end{array}$ & $\begin{array}{l}\text { ZOI Area/ } \\
\text { Number of } \\
\text { Pixels }\end{array}$ \\
\hline 10 & $682.09 \pm 6.13$ & $99.8 \pm 0.23$ & $6.83 \pm 6.14 \mathrm{E}-4$ & $587 \pm 4.12$ & $80.54 \pm 0.36$ & $7.29 \pm 5.12 \mathrm{E}-4$ \\
\hline 5 & $390.07 \pm 4.12$ & $96.65 \pm 0.08$ & $4.04 \pm 0.01$ & $425.57 \pm 5.68$ & $74.46 \pm 0.43$ & $5.72 \pm 0.03$ \\
\hline 2.5 & $273 \pm 3.31$ & $99.11 \pm 0.03$ & $2.75 \pm 2.56 \mathrm{E}-3$ & $415.85 \pm 3.58$ & $86.34 \pm 0.22$ & $4.82 \pm 0.02$ \\
\hline 1.25 & $237.51 \pm 4.52$ & $111.49 \pm 0.12$ & $2.13 \pm 9.79 E-4$ & $264.34 \pm 1.65$ & $91.79 \pm 0.32$ & $2.88 \pm 7.08 \mathrm{E}-3$ \\
\hline 0.625 & $273 \pm 5.23$ & $104.09 \pm 0.22$ & $2.62 \pm 3.53 E-3$ & $229.26 \pm 1.05$ & $82.8 \pm 0.12$ & $2.77 \pm 0.01$ \\
\hline 0.3125 & $233.28 \pm 2.56$ & $86.48 \pm 0.18$ & $2.7 \pm 7.16 \mathrm{E}-3$ & $45.64 \pm 0.98$ & $69.1 \pm 0.22$ & $0.66 \pm 1.29 \mathrm{E}-3$ \\
\hline 0.15625 & $145.8 \pm 2.41$ & $89.65 \pm 0.21$ & $1.63 \pm 3.53 \mathrm{E}-3$ & $40.57 \pm 1.20$ & $67.71 \pm 0.08$ & $0.6 \pm 2.12 \mathrm{E}-3$ \\
\hline 0.07812 & $37.4 \pm 1.98$ & $92.2 \pm 0.11$ & $0.41 \pm 1.14 \mathrm{E}-3$ & $37.19 \pm 1.09$ & $85.09 \pm 0.09$ & $0.44 \pm 5.39 E-4$ \\
\hline DMSO & $40.64 \pm 2.14$ & $114.84 \pm 0.08$ & $0.35 \pm 5.25 \mathrm{E}-4$ & $5.5 \pm 0.68$ & $112.27 \pm 0.06$ & $0.05 \pm 9.98 \mathrm{E}-5$ \\
\hline
\end{tabular}




\section{Supplemental Table 3: Serial dilution experiments of Octodrine on serum and YPD plates}

\begin{tabular}{|c|c|c|c|c|c|c|}
\hline \multirow[b]{2}{*}{ Concentration } & \multicolumn{3}{|c|}{ Serum $37^{\circ} \mathrm{C}$} & \multicolumn{3}{|c|}{ YPD $37^{\circ} \mathrm{C}$} \\
\hline & zoI Area $\left(\mathrm{mm}^{2}\right)$ & $\begin{array}{l}\text { Number of } \\
\text { Pixels }\end{array}$ & $\begin{array}{c}\text { ZOI Area/ } \\
\text { Number of Pixels }\end{array}$ & zol Area $\left(\mathrm{mm}^{2}\right)$ & $\begin{array}{l}\text { Number of } \\
\text { Pixels }\end{array}$ & $\begin{array}{c}\text { zOI Area/ } \\
\text { Number of Pixels }\end{array}$ \\
\hline $\begin{array}{r}6000 \mathrm{mM} \\
\text { (Neat) }\end{array}$ & $2593.32 \pm 6.21$ & $113.67 \pm 0.12$ & $22.81 \pm 5.46 \mathrm{E}-4$ & $1154.21 \pm 2.31$ & $71.29 \pm 0.43$ & $16.19 \pm 3.24 \mathrm{E}-4$ \\
\hline $3000 \mathrm{mM}$ & $914.11 \pm 4.22$ & $103.23 \pm 0.32$ & $8.86 \pm 0.01$ & $545.84 \pm 2.54$ & $76.92 \pm 0.23$ & $7.10 \pm 0.04$ \\
\hline $1500 \mathrm{mM}$ & $635.61 \pm 2.31$ & $85.25 \pm 0.32$ & $7.46 \pm 0.03$ & $164.23 \pm 3.24$ & $74.12 \pm 0.42$ & $2.22 \pm 7.31 \mathrm{E}-3$ \\
\hline $750 \mathrm{mM}$ & $378.21 \pm 3.12$ & $98.45 \pm 0.32$ & $3.84 \pm 0.01$ & $61.24 \pm 1.21$ & $76.78 \pm 0.03$ & $0.80 \pm 4.52 \mathrm{E}-3$ \\
\hline $375 \mathrm{mM}$ & $109.83 \pm 1.41$ & $90.42 \pm 0.23$ & $1.21 \pm 4.45 \mathrm{E}-3$ & $28.32 \pm 2.12$ & $64.23 \pm 0.32$ & $0.44 \pm 5.36 \mathrm{E}-4$ \\
\hline $187.50 \mathrm{mM}$ & $73.83 \pm 1.12$ & $91.43 \pm 0.53$ & $0.81 \pm 2.15 \quad E-3$ & $26.12 \pm 1.23$ & $59.32 \pm 0.21$ & $0.44 \pm 2.58 \mathrm{E}-3$ \\
\hline $93.75 \mathrm{mM}$ & $54.55 \pm 2.12$ & $71.52 \pm 0.15$ & $0.76 \pm 5.95 \mathrm{E}-3$ & $27.98 \pm 2.31$ & $60.21 \pm 0.23$ & $0.46 \pm 2.00 \mathrm{E}-3$ \\
\hline $46.88 \mathrm{mM}$ & $40.1 \pm 2.12$ & $75.23 \pm 0.21$ & $0.53 \pm 1.34 \mathrm{E}-3$ & $26.94 \pm 2.53$ & $61.32 \pm 0.23$ & $0.44 \pm 2.06 \mathrm{E}-3$ \\
\hline $23.44 \mathrm{mM}$ & $20.29 \pm 1.32$ & $83.98 \pm 0.34$ & $0.24 \pm 7.61 \mathrm{E}-4$ & $23.41 \pm 1.23$ & $60.12 \pm 0.23$ & $0.39 \pm 1.69 \mathrm{E}-3$ \\
\hline $11.72 \mathrm{mM}$ & $24.12 \pm 2.32$ & $84.21 \pm 0.25$ & $0.29 \pm 1.43 \mathrm{E}-3$ & $22.41 \pm 2.31$ & $62.43 \pm 0.37$ & $0.36 \pm 3.70 \mathrm{E}-4$ \\
\hline $5.86 \mathrm{mM}$ & $26.21 \pm 2.56$ & $79.21 \pm 0.32$ & $0.33 \pm 1.37 \mathrm{E}-3$ & $20.31 \pm 1.25$ & $57.23 \pm 0.21$ & $0.35 \pm 2.51 \mathrm{E}-3$ \\
\hline $2.30 \mathrm{mM}$ & $22.58 \pm 1.42$ & $73.92 \pm 0.23$ & $0.31 \pm 1.51 \mathrm{E}-3$ & $18.33 \pm 2.31$ & $65.21 \pm 0.32$ & $0.28 \pm 1.26 \mathrm{E}-3$ \\
\hline DMSO & - & - & - & $16.23 \pm 0.21$ & $62.12 \pm 0.32$ & $0.26 \pm 3.38 E-5$ \\
\hline
\end{tabular}


Supplemental Table 4: Quantification of the zone of inhibition of Octodrine in neat form against Candida albicans, Escherichia coli and Bacillus cereus.

\begin{tabular}{|l|r|r|r|}
\hline \multicolumn{1}{|c|}{ Species } & ZOI Area $\left(\mathrm{mm}^{\mathbf{2}}\right)$ & Number of Pixels & ZOI Area/Number of Pixels \\
\hline Candida albicans & $2852.79 \pm 8.31$ & $86.48 \pm 0.35$ & $32.99 \pm 9.61 \mathrm{E}-4$ \\
\hline Bacillus cereus & $329.92 \pm 7.31$ & $58.54 \pm 0.24$ & $5.64 \pm 0.03$ \\
\hline Escherichia coli & $764.11 \pm 8.45$ & $70.34 \pm 0.23$ & $10.86 \pm 0.04$ \\
\hline
\end{tabular}

Supplemental Figure 1: Elucidation of Candida albicans sensitivity to Octodrine

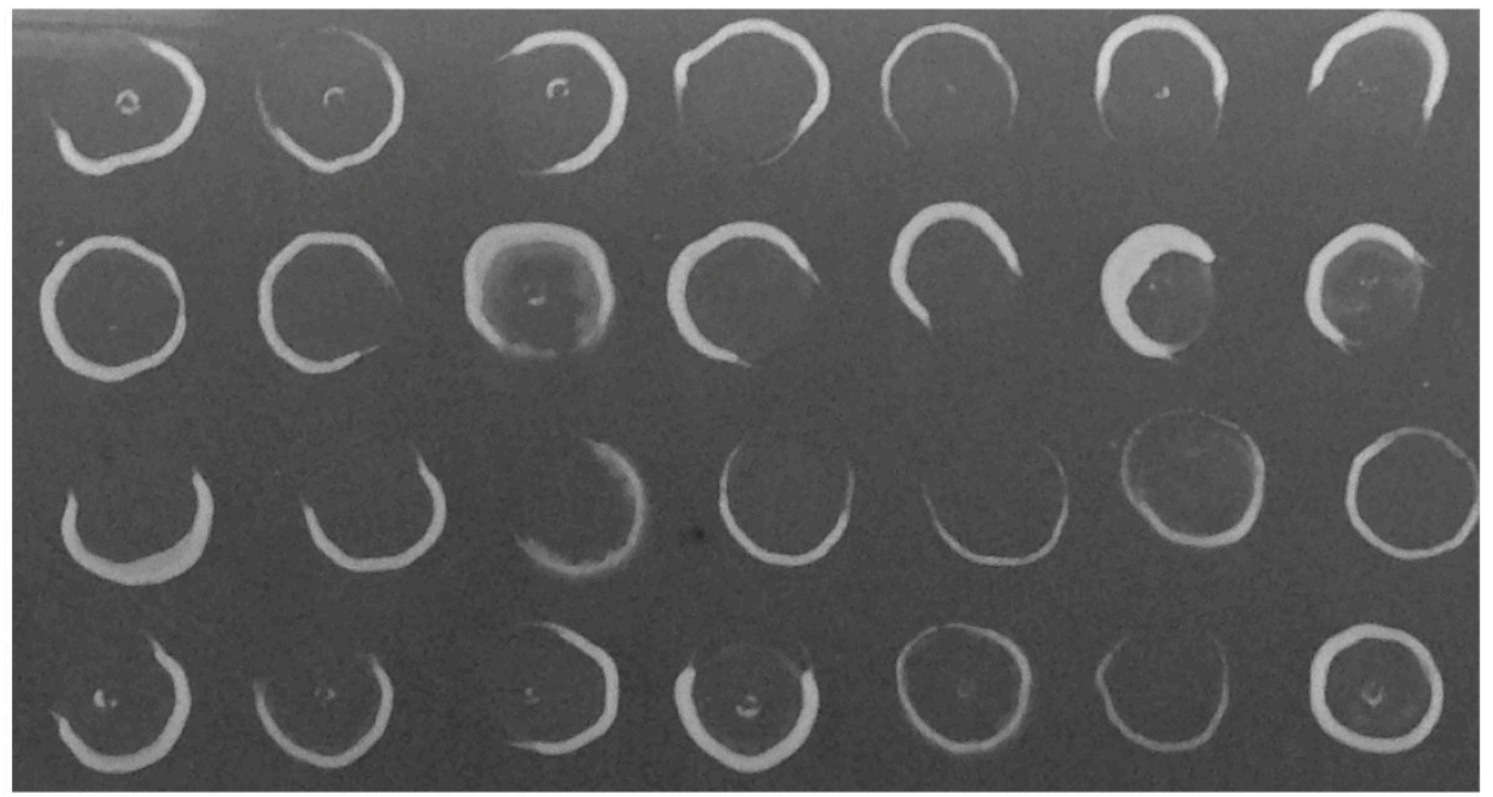




\section{Transition}

Chapter 2 is the only one in this report to describe experiments that aim to identify drugs that directly inhibit a microbe directly, specifically Candida albicans. This chapter strongly echoed the accidental findings of Alexander Fleming, yet in a more systematic fashion. Some important considerations for this work involved testing library drugs at varying concentrations as well as using serum plates to more accurately model the host environment. In addition, drug hits were tested further for their viability in cellular assays. The following chapter highlights our first attempts to find a host-oriented therapy. In Chapter 3, we describe the utilization of two similar yet disparate toxins to be used in a drug screen, with the hopes that an overlapping drug hit could potentially be hostoriented. While there was no guarantee our drug hits would in fact be hostoriented, follow-up experiments indicate that we were successful at identifying an anthrax antitoxin. 


\title{
Chapter 3
}

\section{Identification of agents effective against multiple toxins and viruses by host-oriented cell} targeting

Leeor Zilbermintz, William Leonardi, Sun-Young Jeong, Megan Sjodt, Ryan McComb, Chi-Lee C. Ho, Cary Retterer, Dima Gharaibeh, Rouzbeh Zamani, Veronica Soloveva, Sina Bavari, Anastasia Levitin, Joel West, Kenneth A. Bradley, Robert T. Clubb, Stanley N. Cohen, Vivek Gupta \& Mikhail Martchenko

\begin{abstract}
A longstanding and still-increasing threat to the effective treatment of infectious diseases is resistance to antimicrobial countermeasures. Potentially, the targeting of host proteins and pathways essential for the detrimental effects of pathogens offers an approach that may discover broad-spectrum anti-pathogen countermeasures and circumvent the effects of pathogen mutations leading to resistance. Here we report implementation of a strategy for discovering broad-spectrum host-oriented therapies against multiple pathogenic agents by multiplex screening of drugs for protection against the detrimental effects of multiple pathogens, identification of host cell pathways inhibited by the drug, and screening for effects of the agent on other pathogens exploiting the same pathway. We show that a clinically used antimalarial drug, Amodiaquine, discovered by this strategy, protects host cells against infection by multiple toxins and viruses by inhibiting host cathepsin B. Our results reveal the practicality of discovering broadly acting anti-pathogen countermeasures that target host proteins exploited by pathogens.
\end{abstract}




\section{Introduction}

Whereas medical treatments generally target specific cellular functions of patients to cure or mitigate the effects of diseases, the strategy underlying treatment of infectious disease treatment is to target the infecting pathogen [1]. Inevitably, and not surprisingly, the targeting of pathogens has led to the emergence and spread among pathogens of mutational resistance to countermeasures. Such resistance, together with a desire to expand the utility of countermeasures by increasing their range of therapeutic efficacy, has in recent years sparked interest in agents aimed at host functions that pathogens exploit to enter or be released from host cells [1]. Not infrequently, multiple pathogens or toxins that affect hosts by different mechanisms use the same host pathways [2], raising the prospect that multiplex strategies that concurrently or sequentially screen for host functions exploited by multiple pathogenic agents may lead to the discovery of broadly active and host-oriented infectious disease countermeasures.

Here we report the discovery, using a cell-based multiplex approach to screen a library of FDA-approved drugs for the ability to interfere with disparately acting pathogens. We report here, that a compound used clinically as an antimalarial agent, inhibits both the detrimental effects of multiple bacterial toxins and the entry of Ebola and other viruses into host cells. We further show that the broad antipathogenic actions of Amodiaquine result from its ability to interfere with the functioning of the host protein, cathepsin B. 


\section{Results}

Screening of FDA approved drugs for inhibitors of toxin - induced cell death

In a systematic effort to identify candidates for repurposing drugs as broad-spectrum, host-oriented, anti-toxin countermeasures, we screened members of the Johns Hopkins Clinical Compound Library (JHCCL) [3] of 1,581 agents previously approved as drugs by the US Food and Drug Administration for the ability to reduce lethality of RAW264.7 and C32 cells treated either with Bacillus anthracis lethal toxin or diphtheria toxin (Fig. 1a). These toxins were chosen because the mechanisms underlying their pathogenicity are well understood and are disparate to each other. 
Figure 3.1: The use of Johns Hopkins Clinical Compound Library (JHCCL) to screen for inhibitors of bacterial toxins

a
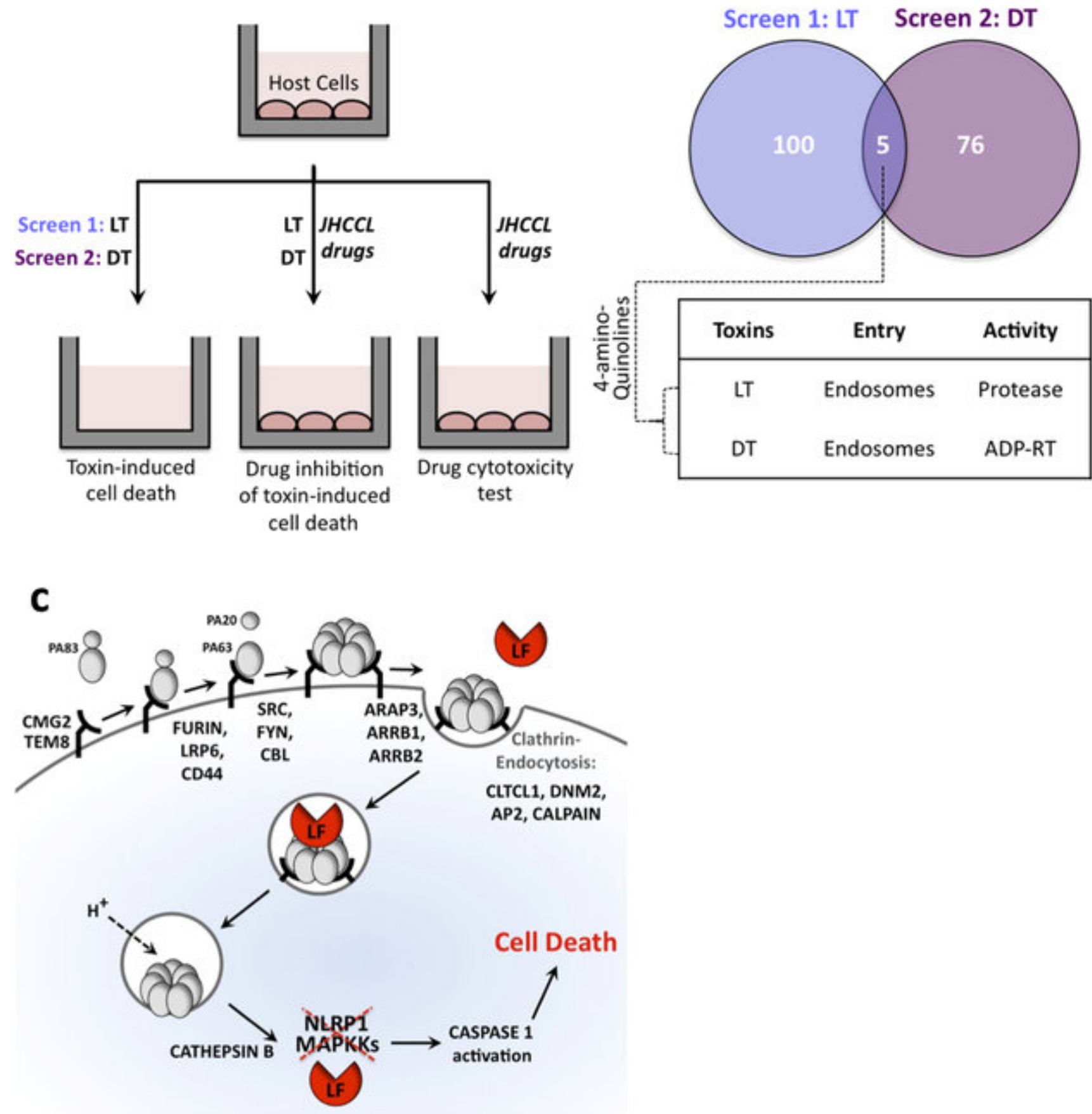

(a) Schematic diagram of cellular screens to identify drugs that reduce cellular lethality induced by anthrax lethal toxin, LF and PA (LT) and diphtheria toxin (DT). (b) The distribution of inhibitors obtained in those screens, with a table showing the routes taken by toxins to enter into cellular cytoplasm (Endocytosis), as well as the enzymatic activities of toxins (Protease or ADPrybosyltransferase (ADP-RT)). (c) Schematic depiction of the host pathway that mediates the delivery of anthrax toxin into cytoplasm. Lethal factor (LF) and edema factor (EF) interact with a third B. anthracis-generated protein, protective antigen (PA). Three host cell proteins CMG2, TEM8, and ITGB1 can serve as receptors for the bipartite PA/LF and PA/EF toxins. Fifteen additional host proteins are known to assist PA binding and/or internalization. 
Between 50 and 70 percent of cells used for these assays normally undergo cell death, as determined by MTT assay, within 6 and 24 hours of exposure to anthrax lethal toxin and diphtheria toxin respectively, under the experimental conditions employed. A "hit" in our screen was defined as an event where cells exposed to a compound at a concentration of $16 \mu \mathrm{M}$ increased cell survival by at least 16 standard deviations ( $\sim 1 \%$ hit rate) above the survival of control cells treated with either toxin, but is not cytotoxic to cells in the absence of toxins. Events defined as "multiplex hits" interfered with cell killing by both of the toxins (Fig. 1b). Five multiplex hits were identified and were tested further.

Anthrax toxin and diphtheria toxin enter the cytoplasm from acidified endosomes [4]. Whereas diphtheria toxin is an ADP ribosyl transferase, anthrax toxin is a protease that cleaves host MAPKK (Fig. 1c). To identify agents that inactivate host proteins exploited by toxins, we focused on hits that inhibit the mechanistically differently acting anthrax and diphtheria toxins. In order to elucidate host-targets inhibited by these drugs, we used only anthrax toxin, as the host cellular pathway that delivers the anthrax toxin into the cytoplasm is one of the best understood pathways5 (and Fig. 1c). Anthrax lethal toxin is an exotoxin protein complex consisting of protective antigen (PA) and lethal factor (LF), which act collectively to damage the host cell [6]. $\mathrm{PA}$ is an $83 \mathrm{kDa}$ cellular receptor-binding protein (PA83), and the combination of PA with LF is cytotoxic6. LF is a $91 \mathrm{kDa}$ zinc metalloprotease that cleaves the N-terminal substrate docking site of the mitogen-activated protein kinase kinases (MAP2K), preventing the passage of signals in the ERK1/2, p38, and c-Jun N-terminal kinase pathways [7]. Intoxication of a cell begins when PA83 binds to host cellular receptors, capillary morphogenesis protein 2 (CMG2), tumor endothelial marker 8 (TEM8), or integrin beta 1 (ITGB1) $[2,8,9]$. Once bound, host furin cleaves a $20 \mathrm{kDa}$ fragment from the $\mathrm{N}$-terminus of PA83, thus activating the $63 \mathrm{kDa}$ protein, PA63 [10]. 
Following activation, PA63 forms a heptamer and binds LF [11]. The toxin undergoes clathrinmediated endocytosis and a decrease in endosomal $\mathrm{pH}$ induces the formation of an endosomal membrane PA channel, by which LF translocates into the cytosol [12] before PA pores are transported to lysosomes for rapid degradation $[8,13,14]$. PA has been shown to induce the process of autophagy, whereby autophagosomes encapsulate endosomes and facilitate the delivery of LF into the cytoplasm [15]. A lysosomal protein, cathepsin B, is necessary for the autophagic flux, whereby LF is delivered from the intralumenal vesicles of the autophagosomeencapsulated multivesicular late endosomes into the cytoplasm through a back fusion process $[14,16,17]$.

We observed that out of five compounds that inhibited anthrax and diphtheria toxins, two compounds were structurally related 4-amino-quinolines, Chloroquine and Amodiaquine. Two anti-malarial drugs, Chloroquine (CQ) and Amodiaquine (AQ), were observed to completely protect host cells against anthrax toxin killing in 6-hours toxin killing assay (Fig. 2a). However, our assay showed that unlike AQ, CQ only has a moderate ability to protect cells against LF-PA mediated 24-hours killing (Fig. 2b). Interestingly, none of the other quinoline-containing antimalarial compounds, Cinchonine, Primaquine, and Quinidine, from JHCCL were active (Supplementary Fig. 1a-c). 
Figure 3.2: The anti-LF-PA efficacy of Amodiaquine (AQ) and its metabolite Desethylamodiaquine (DEAQ) in intro and in vivo
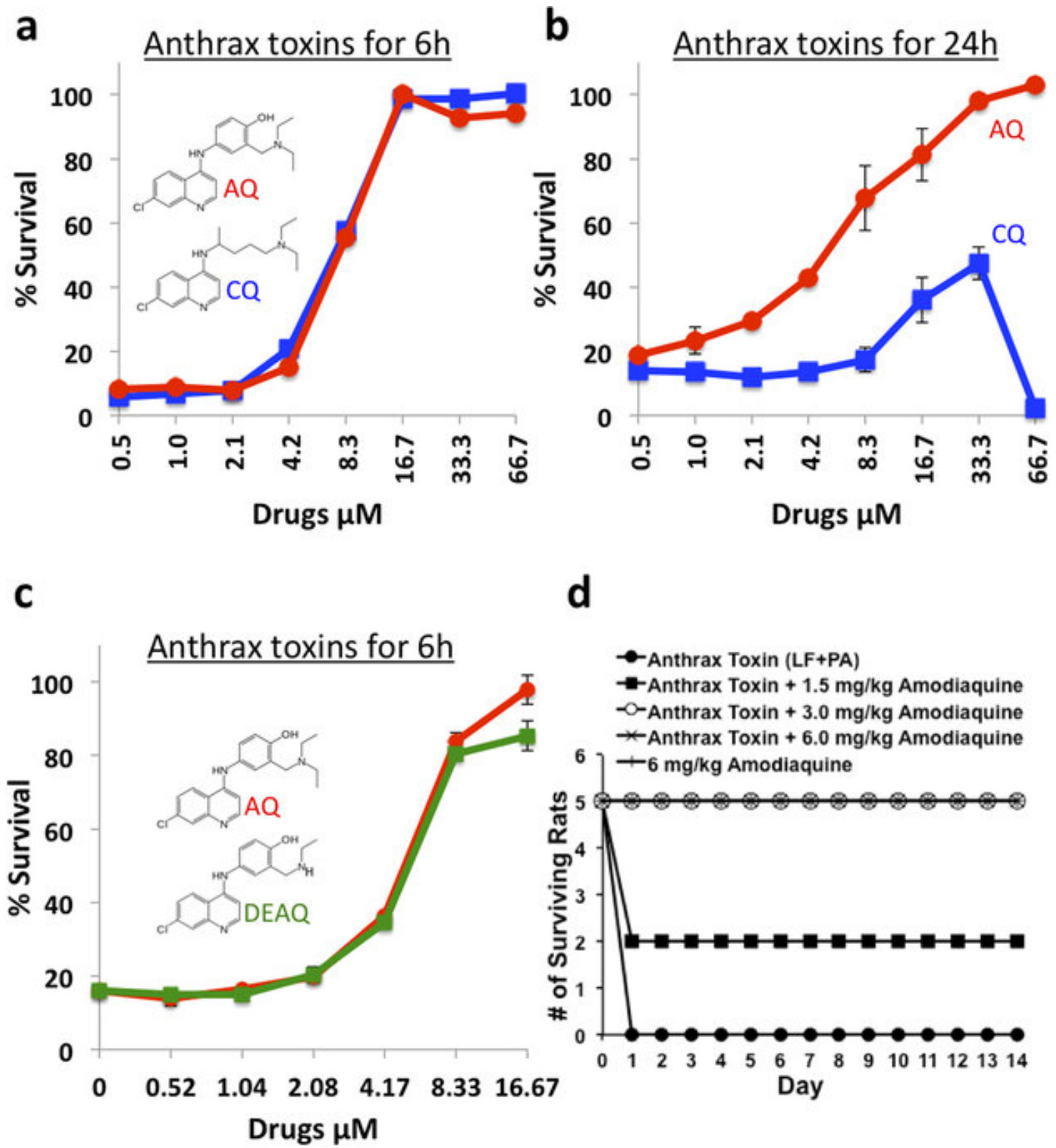

Amodiaquine and JHCCL available structural analogs were tested for their ability to inhibit LF-PA-mediated cytotoxicity. RAW264.7 cells were seeded at $1 \times 104$ cells/well on 96-well plates and the following day were incubated with indicated doses of Amodiaquine or Chloroquine for $1 \mathrm{~h}$, followed by either $6 \mathrm{~h}$ (a) or $24 \mathrm{~h}$ (b) intoxication with $500 \mathrm{ng} / \mathrm{mL} \mathrm{PA}+500 \mathrm{ng} / \mathrm{mL} \mathrm{LF}$. Cell viability was determined by MTT assay (Materials and Methods) and is shown as the percentage of survivors relative to cells not treated with drugs. AQ and DEAQ were tested for their ability to inhibit LF-PA-mediated toxicity in (c) RAW264.7 cells and in (d) Sprague-Dawley rats. RAW264.7 cells were seeded at $1 \times 104$ cells/well on 96-well plates and the following day were incubated with indicated doses of AQ or DEAQ for $1 \mathrm{~h}$, followed by $6 \mathrm{~h}$ intoxication with $500 \mathrm{ng} / \mathrm{mL} \mathrm{PA}+500 \mathrm{ng} / \mathrm{mL} \mathrm{LF}$. Survival curves of groups of male Sprague-Dawley rats challenged intravenously with $12 \mu \mathrm{g}$ LF and $40 \mu \mathrm{g}$ PA along with varying amounts of AQ $(1.5,3.0$, and $6.0 \mathrm{mg} / \mathrm{kg})$. Control groups of rats either received toxin only or $6.0 \mathrm{mg} / \mathrm{kg}$ of AQ only. 
Amodiaquine and its metabolite are potent inhibitors of LF-PA induced death in vitro and in vivo

After oral administration, AQ is rapidly absorbed and undergoes fast and extensive metabolisation by hepatocytes' cytochrome p450 enzyme to the AQ metabolite, DesethylAmodiaquine (DEAQ), the main active metabolite of AQ [16]. We tested the ability of DEAQ to reduce anthrax toxin mediated cellular killing, and we observed that just like AQ, DEAQ was able to reduce toxin-mediated cytotoxicity with an EC50 of $5 \mu \mathrm{M}$ (Fig. 2c). Since AQ and its metabolite, DEAQ, protected host cells against anthrax toxin killing, we evaluated the efficacy of $\mathrm{AQ}$ as a therapeutic agent during anthrax toxin intoxication in Sprague-Dawley rats. Animals were injected intravenously with a lethal dose of anthrax toxin (LD100) and were intravenously co-injected with AQ at $1.5,3.0$, or $6.0 \mathrm{mg} / \mathrm{kg}$. The AQ doses were selected based on the FDA approved AQ dose of $10 \mathrm{mg} / \mathrm{kg}$ [18]. Animals that received a lethal dose of anthrax toxin without AQ all died within 90 minutes post intoxication (Fig. 2d). While the administration of AQ at $1.5 \mathrm{mg} / \mathrm{kg}$ saved $40 \%$ of the rats, all of the animals in that group displayed classical signs of having undergone a toxin challenge, such as ataxia, lethargy, hyperpnea, and tachypnea. Rats that were challenged with anthrax toxin and treated with $\mathrm{AQ}$ at 3.0 and $6.0 \mathrm{mg} / \mathrm{kg}$ all survived without displaying toxin-associated symptoms (Fig. 2d).

\section{Amodiaquine Inhibits Cytosolic Entry of LF}

In order to identify the step at which AQ inhibits LF-PA-mediated lethality, we assessed the processes that mediate the cellular entry of this toxin and toxin-induced pyroptosis in the presence and in the absence of this drug. Caspase-1 activation, which occurs late in LF-PA intoxication, was monitored using a fluorescent probe, FLICA. This probe specifically binds to active caspase-1. While we observed high levels of caspase-1 activity upon LF-PA treatment in 
the absence of AQ, active caspase-1 was not detected in AQ-treated cells that were challenged with anthrax toxin (Fig. 3a). This result shows that AQ inhibits cytotoxicity upstream of caspase1 activation. 
Figure 3.3: Amodiaquine inhibits cellular entry of LF

a

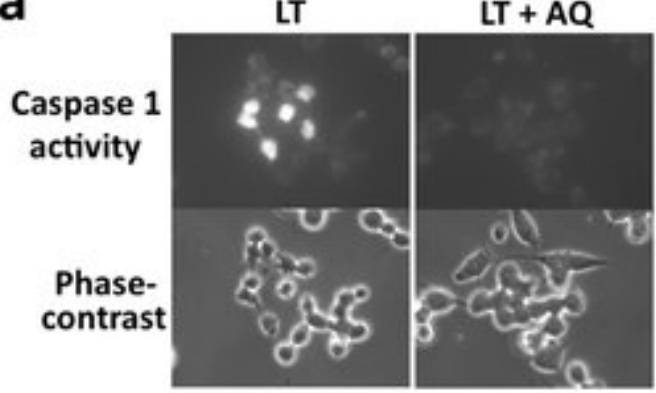

b

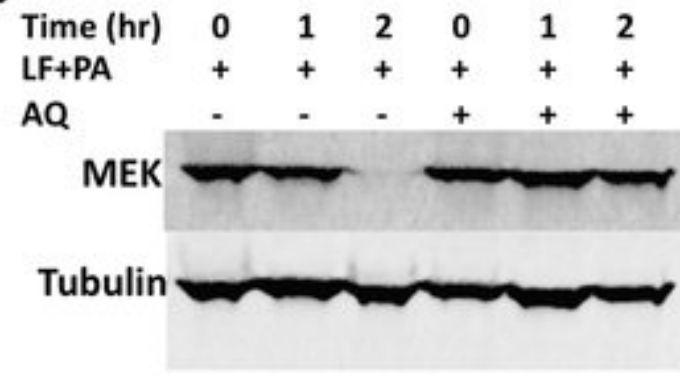

C

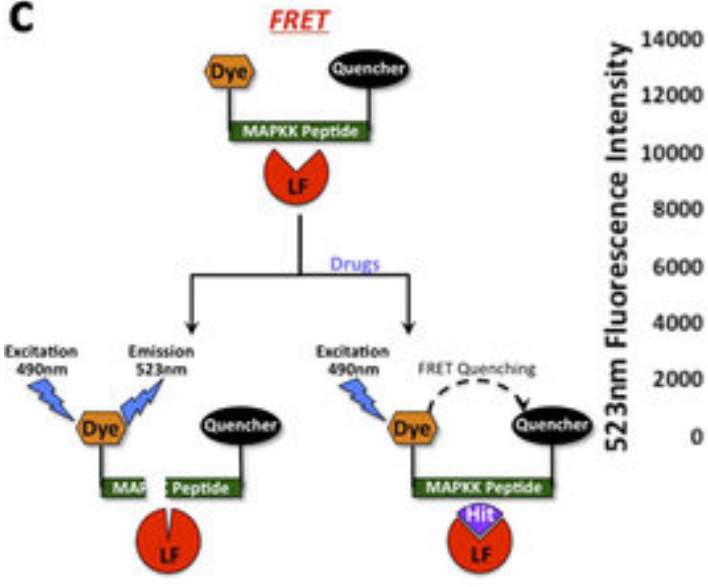

d

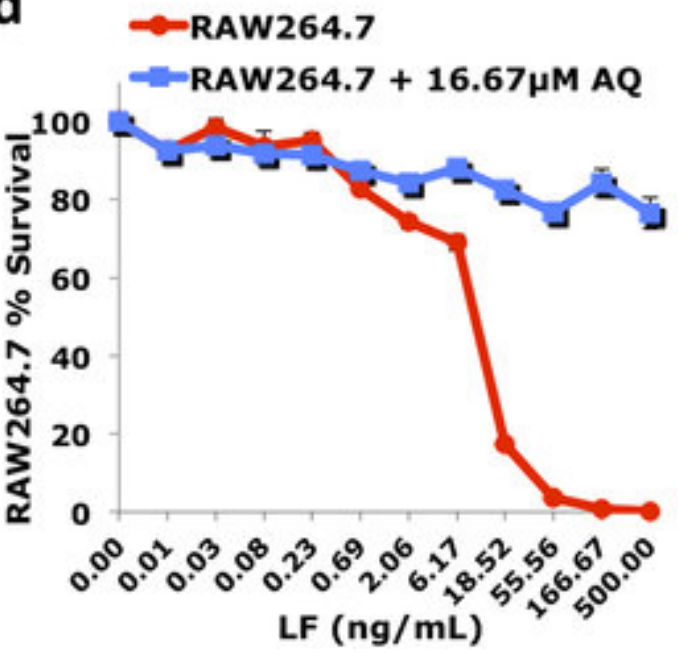

e

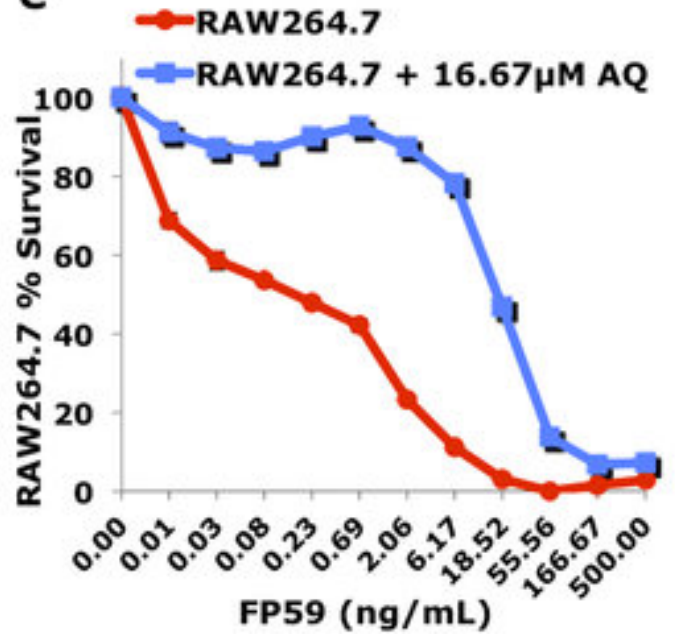

(a) AQ inhibits LT-mediated caspase-1 activation. RAW264.7 cells were seeded and allowed to adhere overnight, and then incubated with $16 \mu \mathrm{M}$ AQ or DMSO for $1 \mathrm{~h}$ before addition of $500 \mathrm{ng} / \mathrm{mL}$ PA + LF for $2 \mathrm{~h}$. FLICA was added for a further $1 \mathrm{~h}$ and then cells analyzed by fluorescence microscopy. (b) AQ inhibits LT-mediated cleavage of MEK-2. RAW264.7 cells were incubated with AQ or DMSO for $1 \mathrm{~h}$ before addition of vehicle control or $1 \mu \mathrm{g} / \mathrm{mL}$ PA + LF for up to $2 \mathrm{~h}$. Cells were lysed and analyzed via immunoblotting with a MEK-2-specific antibody. Tubulin was used as a loading control. (c) FRET data showing fluorescence emission from three reactions, where $5.8 \mu \mathrm{g} / \mathrm{ml}$ LF cleaves fluorescently labeled MAPKK peptide without drugs, in the presence of a known LF inhibitor, $16 \mu \mathrm{M}$ surfen hydrate, or in the presence of $16 \mu \mathrm{M}$ AQ. (d and e) AQ protects cells from PA + FP59. RAW264.7 cells were preincubated with a titration of AQ for $1 \mathrm{~h}$, followed by a $6 \mathrm{~h}$ intoxication with $500 \mathrm{ng} / \mathrm{mL}$ PA + LF (d) or FP59 (e). Cell viability was measured via MTT. 
Activation of caspase-1 by LF is a late step in pyroptosis and depends on LF catalytic activity [19]. To determine whether AQ blocks proteolysis of cellular MAPKKs by LF, we assessed the cleavage of MEK2 by immunobloting. While MEK2 was cleaved in LF-PA treated RAW264.7 cells, treatment with AQ completely prevented this effect (Fig. 3b). These results show that AQ inhibits either cytotoxicity upstream of MAPKK cleavage or blocks LF directly.

In order to test whether AQ inhibits the enzymatic activity of LF, we used a Fluorescence Resonance Energy Transfer (FRET) based assay, in which an MEK2 peptide containing a cleavage site for LF with a quenching DABCYL group at the N-terminus and FITC fluorogenic group at the C-terminus was used as LF substrate for in vitro assays. After cleavage by LF, the fluorescence emitted by the DABCYL increased (Fig. 3c). We tested the ability of AQ to inhibit the proteolytic activity of LF at $16 \mu \mathrm{M}$ using FRET. In the presence of a known small molecule inhibitor of LF, surfen hydrate [20], no emission at $523 \mathrm{~nm}$ was seen (Fig. 3c). In the absence of any chemical inhibitor, LF cleaved MAPKK peptide, and the fluorescence emission was observed (Fig. 3c). A similar emission at $523 \mathrm{~nm}$ was observed when LF was able to cleave MAPKK peptide in the presence of AQ, which shows that AQ does not block the proteolytic activity of LF at $16 \mu \mathrm{M}$.

AQ-treated cells were found to be less sensitive to treatment with PA + FP59 (Fig. 3d,e). FP59 is a hybrid toxin, which contains the PA binding site of LF as well as a toxin domain derived from $P$. aeruginosa exotoxin A [21], that has been widely used as an LF surrogate, and kills cells by a different mechanism [2]. This result, along with the caspase-1 and MEK2 data, strongly suggest that AQ interferes with PA mediated toxin entry. 


\section{Amodiaquine binds to and inhibits host cathepsin $B$}

In order for LF to reach the cytosol, PA83 must bind to host cell receptors, be cleaved by furin into PA63, heptamerize into a pre-pore form, bind LF, and proceed to low-pH endosomes where PA-heptamers undergo an acid-dependent conformational change from pre-pore to pore [22]. Host-cell binding of PA and its proteolytic cleavage were monitored by immunoblot in the presence and in the absence of AQ. We observed that AQ did not block binding of PA83 to cells or block proteolytic processing of PA to generate PA63 (Fig. 4a). The inability of AQ to block the activity of host furin cleavage of PA83 is consistent with our observation that AQ equally reduces sensitivity of host cells to both PA83 + LF and PA63 + LF treatments (Supplementary Fig. 2). These results indicate that AQ blocks intoxication at a step downstream of PA binding and assembly on the host-cell surface. 
Figure 3.4: Amodiaquine inhibits host cathepsin B
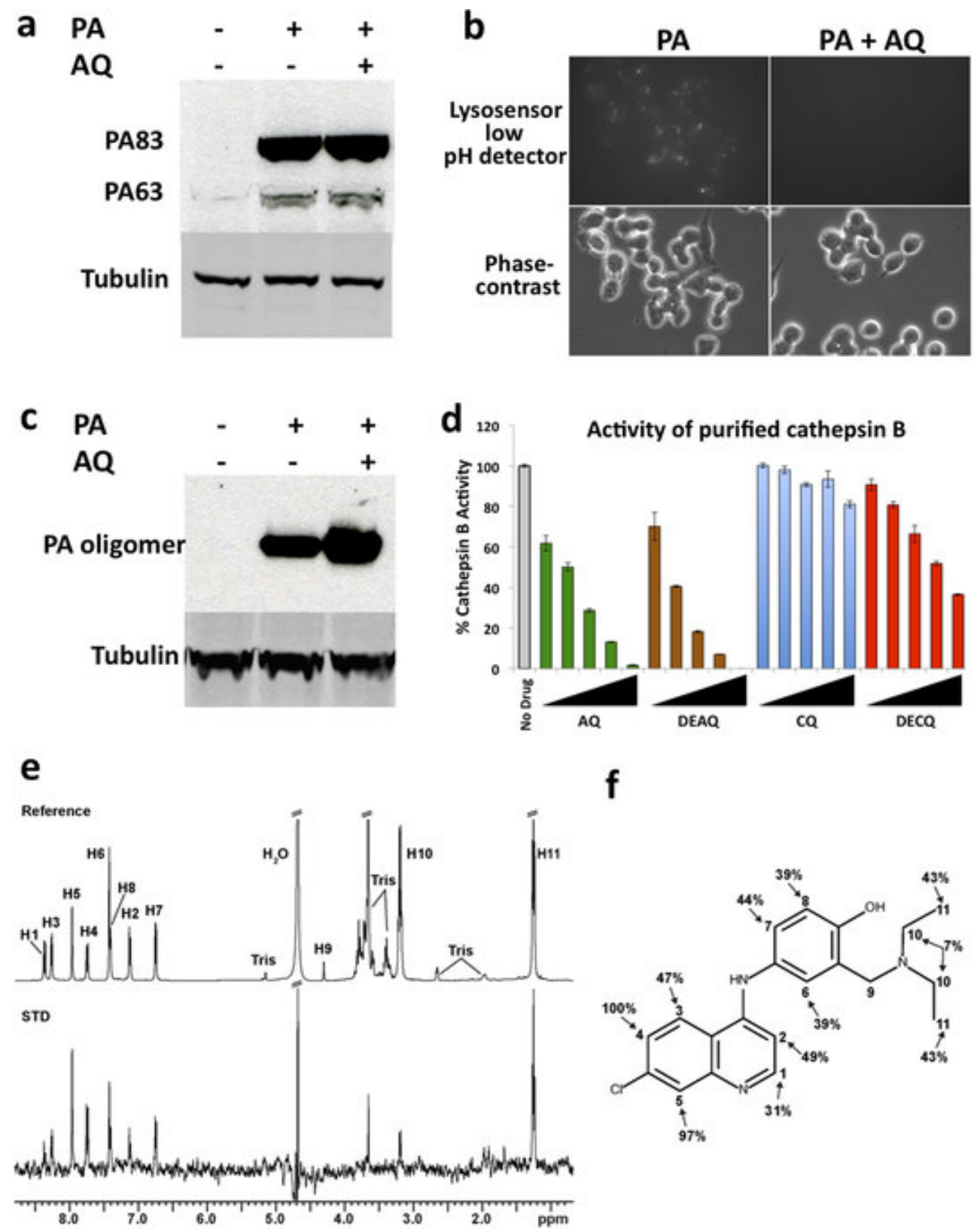

(a) AQ does not inhibit PA binding to RAW264.7 cells. Cells were incubated with AQ for $1 \mathrm{~h}$ at $4{ }^{\circ} \mathrm{C}$ before addition of $1 \mu \mathrm{g} / \mathrm{mL}$ PA for an additional $1 \mathrm{~h}$. Cells were lysed and analyzed by immunoblotting with a PA-specific antibody. (b) AQ neutralizes acidic vesicles. RAW264.7 cells were pre-treated with AQ or vehicle control for $1 \mathrm{~h}$ and then treated with $500 \mathrm{ng} / \mathrm{ml}$ of PA for an additional hour at $37^{\circ} \mathrm{C}$ before addition of Lysosensor Green DND-189 for a further $10 \mathrm{~min}$. Cells were then visualized by fluorescence microscopy. (c) AQ results in increased abundance of PA pores. Cells were pretreated with AQ for $1 \mathrm{~h}$ at $37^{\circ} \mathrm{C}$ and then were exposed to $1 \mu \mathrm{g} / \mathrm{mL}$ of PA at $37^{\circ} \mathrm{C}$ for $1 \mathrm{~h}$. Cells were lysed and analyzed by immunoblotting with a PA-specific antibody. (d). FRET assay showing the activity of purified human cathepsin B without drugs, or with addition of AQ, DEAQ, CQ, or DECQ at 4, 8, 16, 33, or $66 \mu \mathrm{M}$. (e) $1 \mathrm{H}$-NMR spectra of AQ in the presence of cathepsin B. The reference spectrum of AQ with its atoms labeled (top), and the STD spectrum (bottom) are shown. The data were collected using a protein:ligand ratio of 1:100 with on- and off-resonance saturation at $0.04 \mathrm{ppm}$ and $30 \mathrm{ppm}$, respectively. (f) Chemical structure of AQ showing the atom-specific magnitude of the STD effects. The STD effect was calculated according to the formula $A S T D=(I 0-I s a t) / I 0$. All STD effects are expressed as a percentage relative to the H4 atom $(100 \%)$. 
CQ was previously shown to prevent endosomal acidification [23]. Since AQ is structurally similar to $\mathrm{CQ}$, we tested whether AQ neutralizes anthrax toxin induced endosomal acidification. We used Lysosensor Green DND-189 to probe acidic organelles in the cells. Lysosensor is a green fluorescent dye used for tracking acidic organelles in the cell. Neutralization of these compartments can be visualized as a loss in punctate-fluorescent structures. In the absence of AQ, PA-treated cells displayed Lysosensor fluorescence, and AQ markedly decreased cell-associated Lysosensor fluorescence (Fig. 4b). These results predict that AQ may block the ability of PA to either access acidified endosomes or to form PA pores. It is known that the pore formation of $\mathrm{PA}$, which results from exposure to acidic $\mathrm{pH}$ within endosomes, is resistant to dissociation by SDS and runs as an oligomer on SDS-PAGE [22]. Surprisingly, treatment of cells with AQ resulted in higher, rather than lower, abundance of SDSresistant PA-oligomers compared to cells treated with PA only (Fig. 4c).

A similar observation was reported by Ha et al.14, who showed that an inhibition of host lysosomal cathepsin B by an unrelated small molecule CA-074, resulted in (i) elevated accumulation of PA pores in late endosomes, (ii) the inability of LF to be released from the late endosomes into the cytoplasm, and (iii) results in reduction of cellular sensitivity to LF-PA. Upon formation of the SDS-resistant PA63 pore in acidic endosomes, PA pores are then transported to lysosomes for rapid degradation24. Ha et al. showed that cathepsin B mediates the fusion of lysosomes with endosomes, and that this fusion is necessary for the release of LF from the endosomes into the cytoplasm14. In order to gain further insight into the mechanism of AQmediated protection of cells against anthrax toxin killing, we tested whether AQ inhibits cathepsin B protease activity of purified human cathepsin B using a FRET assay. We observed that both AQ and DEAQ directly inhibit cathepsin B activity in a dose dependent manner 
without drug pre-incubations, at drug concentrations used in cellular experiments (Fig. 4d). We tested whether AQ inhibits cathepsin B in RAW264.7 cells. We observed that cells pre-treated with AQ or with DEAQ for 1 hour lost cathepsin B enzymatic activity in a dose dependent manner (Supplementary Fig. 3a). In addition, we tested the ability to AQ to inhibit cathepsin B activity in a protein lysate from cells that were not exposed to drugs prior to the lysis, and we observed that AQ and DEAQ inhibited cathepsin B activity (Supplementary Fig. 3b). We determined that the addition of drugs to cathepsin $\mathrm{B}$ reactions did not change the $\mathrm{pH}(\mathrm{pH} 5.8)$ of the reaction buffer. In all of the cathepsin B experiments we observed that CQ and its metabolite, Desethyl-Chloroquine (DECQ), were weaker inhibitors of cathepsin B activity (Fig. 4d and Figure S3), which corresponds to the phenotypic data seen in Fig. 2.

The interaction between AQ and cathepsin $\mathrm{B}$ was probed using saturation transfer difference NMR spectroscopy (STD). This technique is a powerful label-free ligand-observed tool to study molecular interactions in solution $[25,26]$. STD relies on the transfer of selective saturation (excitation) of the protein's atoms to atoms located in the bound ligand. Two 1D 1HNMR spectra are acquired—one in which the protein's signals are selectively saturated ("on" resonance, Isat), and another in which no signals are saturated ("off" resonance, I0). Ligand binding is evident by the difference spectrum (I0 - Isat), as only when binding occurs are the signals of the ligand affected. Figure $4 \mathrm{e}$ shows the $1 \mathrm{H}-\mathrm{NMR}$ spectrum of $2 \mathrm{mM}$ AQ in the presence of $20 \mu \mathrm{M}$ cathepsin B (ligand:protein molar ratio of 100:1), and its corresponding STD difference spectrum. The presence of AQ signals in the difference spectrum clearly indicates that it is binding to the enzyme. An inspection of the atom-specific effects provides insight into the mode of binding. Atoms in the quinoline backbone display the largest reduction in their intensities, suggesting that they are in close proximity to cathepsin B (Fig. 4f, atoms H4 and H5 
exhibit STD effects of 100 and 97\%, respectively). In contrast, the H9 and H10 methylene protons are modestly affected, suggesting that in the complex they are located distal to hydrogen atoms in the protein. Interestingly, several atoms in the phenol ring display substantial STD effects suggesting that they are near the protein. This is consistent with the lower biological activities of AQ analogs that remove the phenol ring (Fig. 2 and Supplementary Fig. 1). The importance of the AQ quinoline ring revealed by STD is also compatible with the crystal structure of cathepsin B bound to nitroxoline, as this small molecule contains a quinoline moiety that interacts extensively with the enzyme [27].

\section{Amodiaquine inhibits pathogenicity of Ebola virus}

Upon observing that AQ protects cells from anthrax and diphtheria toxins, we hypothesized that AQ and DEAQ might also be able to inhibit the entry of Ebola virus. Ebola virus, among other viruses, requires low endosomal $\mathrm{pH}[28]$ as well as host cathepsin $\mathrm{B}$ function [29] for membrane fusion and infection of host cells. In fact, AQ and CQ have recently been reported to inhibit Ebola virus pathogenicity in cells [28,29]. We re-tested AQ and CQ's ability to inhibit Ebola virus abundance in infected HeLa cells by visualizing infected cells using immune-staining, and in addition we tested the ability of their metabolites, DEAQ and DECQ, to inhibit Eboa virus propagation in cultured cells in vitro. To test AQ-mediated inhibition of viral propagation, we compared infection by Ebola virus (Kikwit) at MOI of 0.5 with and without drugs for 48 hours. To detect infected cells, immuno-staining was completed with anti-Ebolaglycoprotein antibodies. AQ and DEAQ effectively inhibited propagation of Ebola virus in HeLa cells with EC50's in the low $\mu \mathrm{M}$ range (Table 1): the EC50's of AQ and DEAQ were 3.8 and 3.6 $\mu \mathrm{M}$ respectively. The EC50's of CQ and DECQ in HeLa were 4.8 and $7.3 \mu \mathrm{M}$ respectively. 
This data shows that DEAQ is more efficacious in inhibiting Ebola propagation compared to DECQ. Similar results were obtained by testing AQ, CQ, DEAQ, and DECQ for their ability to inhibit Ebola virus in primary human cell line, HFF-1 (Supplementary Table 1). This result confirms that anti-viral effect of AQ is not related to its effects on the host cell cycle or cellular proliferation.

Table 3.1: The effect of AQ, CQ, and its metabolites, DEAQ and DECQ, on the pathogenicity of EBOV in HeLa cells

\begin{tabular}{|l|l|l|l|l|l|}
\hline & & EC50 & SD & CC50 & \\
Pathogen & Drug, hours & $\boldsymbol{\mu M}$ & $\boldsymbol{\mu M}$ & $\boldsymbol{\mu M}$ & SI50 \\
EBOV & AQ, 48 h & 3.8 & 0.38 & 50 & 13.2 \\
EBOV & DEAQ, 48 h & 3.6 & 0.35 & 50 & 13.9 \\
EBOV & CQ, 48 h & 4.8 & 0.57 & 100 & 20.7 \\
EBOV & DECQ, 48 h & 7.3 & 0.55 & 100 & 13.8 \\
\hline
\end{tabular}

The ability of drugs to reduce the abundance of Ebola virus (EBOV) in host cells was measured in cells by fluorescent microscopy.

The life cycle of Ebola virus in cultured host cells is $20-24$ hours. To more clearly evaluate effects of AQ and DEAQ on a single viral life cycle, we compared the inhibitory effects of these drugs after 24 and 48 hours of Ebola virus infection in cells. We observed that AQ and DEAQ are at least two times more potent after $24 \mathrm{~h}$ of infection (EC50's $2 \mu \mathrm{M}$ ), compared to $48 \mathrm{~h}$, during which time the secondary round of infection occurs and possibly slightly decreases the antiviral efficacies of AQ and DEAQ (EC50's $4 \mu \mathrm{M})$ (Table 2).

Table 3.2: The effect of time of AQ and its metabolite treatments on the pathogenicity of EBOV.

\begin{tabular}{|l|l|l|l|l|l|}
\hline & & EC50 & SD & CC50 & \\
Pathogen & Drug, hours & $\boldsymbol{\mu M}$ & $\boldsymbol{\mu M}$ & $\boldsymbol{\mu M}$ & SI50 \\
EBOV & AQ, 24 h & 2.38 & 0.47 & $>50$ & $>21$ \\
EBOV & AQ, 48 h & 4.46 & 0.44 & $>50$ & $>11.2$ \\
EBOV & DEAQ, 24 h & 2.15 & 0.48 & $>50$ & $>23.3$ \\
EBOV & DEAQ, 48 h & 4.12 & 0.36 & $>50$ & $>12.1$ \\
\hline
\end{tabular}

The 50\% effective (EC50, virus-inhibitory) concentrations and 50\% cytotoxic (CC50, cell-inhibitory) concentrations were determined. CC50 divided by EC50 indicate the selectivity index (SI) value. 
Amodiaquine inhibits pathogenicity of other Category A, B, and C pathogenic agents that enter into host cytoplasm from acidified endosomes

In addition to anthrax toxin [15], diphtheria toxin [30], and Ebola virus29,31, other pathogenic agents SARS coronavirus [31], Venezuelan equine encephalitis virus (VEEV) [32], Rabies virus [33], Junin virus [34], Chikungunya virus [35], and Clostridium difficile toxin B [36] enter the cytoplasm from endosomes and all require the acidification of endosomes. We demonstrated that all of those pathogenic agents are inhibited by AQ in their respective in vitro cellular assays (Table 3 and Supplementary Fig. 4a). We also tested the ability of DEAQ to inhibit pathogenicity of Junin and Chikungunya viruses, and observed that DEAQ inhibits those two viruses with EC50's similar to those of AQ (Supplementary Table 2).

Table 3.3 Sensitivities of Category A, B, and C pathogens to Amodiaquine

\begin{tabular}{|l|l|l|l|}
\hline Pathogen & EC50 $\boldsymbol{\mu M}$ & \multicolumn{1}{l|}{ CC50 $\boldsymbol{\mu M}$} & \multicolumn{1}{|c|}{ SI50 } \\
Pathogens known to enter into cytoplasm & from Endosomes, low pH-dependent \\
Ebola Virus & 2.4 & $>50$ & $>20$ \\
SARS coronavirus & 2.4 & 32 & 13.3 \\
Venezuelan equine encephalitis virus & 3.2 & 31 & 9.7 \\
Rabies & 5.7 & $>10$ & $>2$ \\
Junin & 16.9 & 50 & 3.0 \\
Chikungunya & 18.3 & $>50$ & $>2$ \\
Clostridium difficile Toxin B & 4.6 & 30.7 & 6.7 \\
Entry into cytoplasm from Endoplasmic Reticulum & & \\
Poliovirus 3 & $>100$ & $>100$ & 1 \\
Herpes simplex virus 1 & $>60$ & $>60$ & 1 \\
Cholera Toxin & $>66.7$ & $>66.7$ & 1 \\
Pseudomonas aeruginosa Exotoxin A & $>66.7$ & $>66.7$ & 1 \\
Pathogens known to enter into cytoplasm, low pH-independent & \\
Human Cytomegalovirus & $>60$ & $>60$ & 1 \\
Respiratory syncytial virus & 32 & 32 & 1 \\
\hline
\end{tabular}

The ability of drugs to reduce the abundance of the indicated pathogens viruses or cytotoxicity induced by bacteria toxins in host cells. The analysis was done as in Table 1 .

Other pathogenic agents, including cholera toxin [37], Pseudomonas aeruginosa exotoxin A38, Poliovirus 3 [18], and Herpes simplex virus 1 [39] are transported in a retrograde fashion to the endoplasmic reticulum (ER) and retrotranslocated into the cytoplasm by the host ERassociated degradation pathway [37,38]. We observed that cytotoxicity mediated by those 
pathogens was not blocked by AQ (Table 3 and Supplementary Fig. 4b,c). In addition, the inability of AQ to inhibit cholera and Pseudomonas toxins, which are both ADPrybosyltransferases, suggests that AQ's adverse effect on diphtheria toxin (Fig. 1), which is also ADP-rybosyltransferase, occurs by inhibition of host cathepsin B only.

Another group of pathogens enter the cytoplasm by ways that do not rely on the acidification of endosomes, and include Human Cytomegalovirus [40] and Respiratory syncytial virus [41]. We determined that AQ did not reduce the pathogenicity of those viruses (Table 3). This data supports the conclusion that AQ inhibits the entry of toxins into the cytoplasm from acidified endosomes.

\section{Discussion}

The discovery and development of novel drugs against biological threat agents such as Bacillus anthracis and Ebola virus, is an important concern worldwide. We have shown that AQ is a broad-spectrum drug that could be applied rapidly to cure biological emergencies caused by the several identified pathogens (Fig. 5). For example, the current Ebola crisis has already killed more than 10,000 people in 2014 and 2015. Repurposing of a compound with well-established safety and pharmacokinetic profiles — as well as proven high-volume GMP manufacturing — may be the only way that a therapy can be tested and deployed in time to protect the $21+$ million people in the three hardest-hit West African countries. 
Figure 3.5: Mechanism of action of Amodiaquine

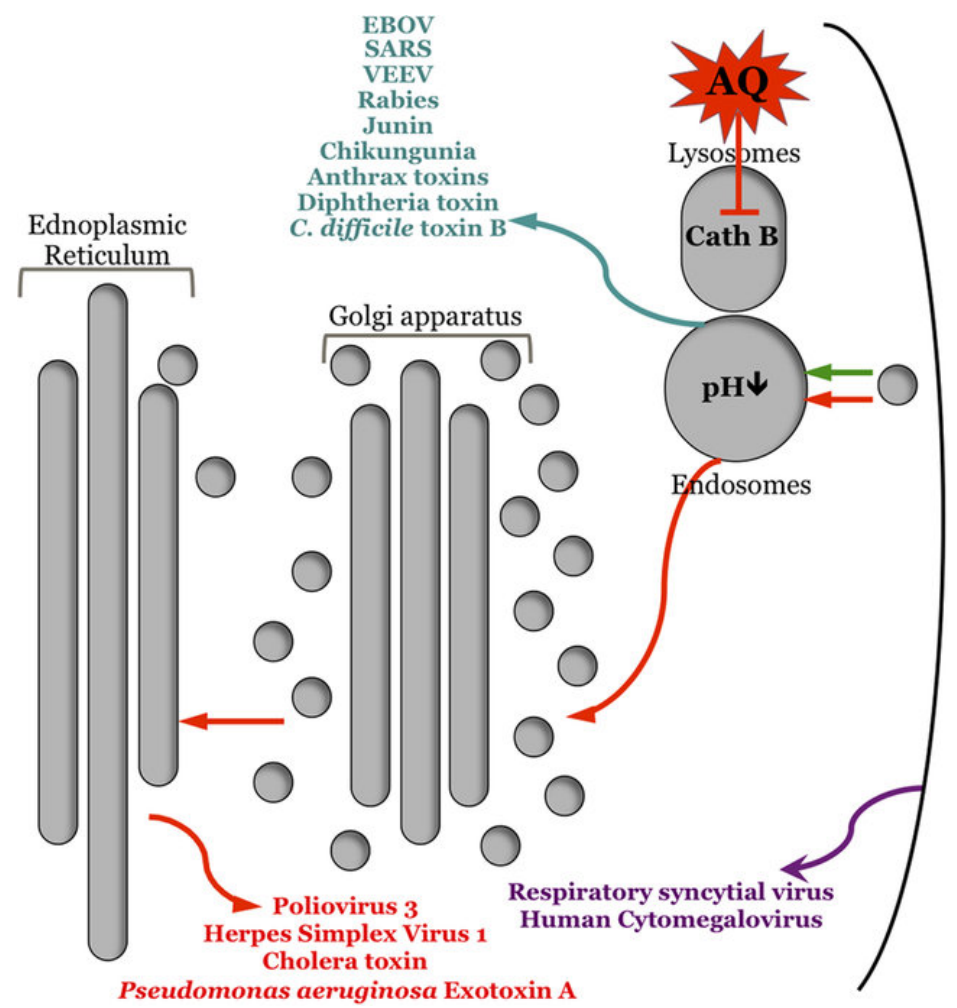

AQ reduces the activities of pathogens that enter into host cytoplasm from acidified endosomes by exploiting cellular cathepsin B. AQ does not inhibit the entry of pathogens that enter through a retrograde fashion to the endoplasmic reticulum (ER) and retrotranslocated into the cytoplasm by the host ER-associated degradation pathway or by pHindependent entry into cytoplasm.

To help address this Ebola crisis, as we were preparing this manuscript, we communicated our discoveries to Médecins Sans Frontières (MSF, Doctors Without Borders), and encouraged them to explore whether the administration of AQ in West African countries hit by Ebola epidemic is associated with a reduced mortality due to Ebola infections. MSF conducted a study and observed that the administration of AQ provided a substantial protection against Ebola mortality and reduced the mortality risk by $31 \%$, and in this study MSF acknowledged the authors of this study (https:/www.youtube.com/watch?v=rTyoc4s1Mco).

As seen in current Ebola epidemic, the human host can be co-exposed to numerous deadly pathogens and thus the infected individual will need to take numerous countermeasures 
(each with their own side-effects) to protect against multiple infectious organisms. Therefore, therapies capable of inhibiting multiple pathogens are needed. Broad-spectrum anti-pathogen drugs, capable of simultaneously inhibiting numerous unrelated pathogens, could be developed by targeting host proteins commonly exploited by those pathogens. In this work we show that AQ inhibits the host target rather than the pathogen, which makes AQ host-oriented broadspectrum antimicrobial that is less likely to be circumvented by pathogen mutations that lead to microbial resistance to the countermeasure.

AQ was discovered by Parke-Davis in the 1940s and was approved by the FDA as an anti-malarial in the late 1940s and early 1950s under the trade name Camoquine. AQ is currently on the WHO's Model List of Essential Medicines. Today AQ is recommended as a frontline antimalarial therapy in combination with artemisinin. AQ belongs to the "quinoline antimalarials" (Reviewed in [42]). AQ inhibits Plasmodium falciparum phosphoethanolamine methyltransferase, an enzyme found in malarial parasites but not in humans [43]. Here we report that AQ also binds and blocks the function of host cathepsin B protein and thus entry of key pathogens into the cytoplasm.

Since AQ has been used for the past 60 years, its safety and pharmacokinetic profiles are well known. For example, it has been determined that after oral administration in healthy subjects, AQ is quickly absorbed and biotransformed into its main active form, DEAQ, which in turn is slowly eliminated with a terminal half-life of 9-18 days. The availability of PK values for AQ allows us to compare it to our in vitro data. The EC50 values for all of the tested pathogens inhibited by AQ or by DEAQ were at low $\mu \mathrm{M}$ range. Importantly, the known Cmax values (maximal amounts of drug in the blood after oral administration) of DEAQ in humans are in low $\mu \mathrm{M}$ range $[43,44,45]$ and are comparable to the DEAQ EC50 values found in vitro for tested 
pathogens. This suggests that it is possible to achieve anti-pathogen effective AQ doses in blood by orally administered $A Q$.

\section{Methods}

Chemicals and Reagents

All toxins were purchased from List Biological Laboratories. FP59 was a kind gift from S. Leppla (National Institute of Allergy and Infectious Diseases/National Institutes of Health, Bethesda, MD). An FDA-approved drug library comprising of 1,581 drugs was purchased from Johns Hopkins, titled, Johns Hopkins Clinical Compound Library (JHCCL) version 1.0. The drugs arrived as $10 \mathrm{mM}$ stock solutions in sealed microtiter plates and were made using DMSO or water as solvents. Drugs were arrayed in 96-well plates and screened at a stock concentration of $10 \mathrm{mM}$. The library was stored at $-20^{\circ} \mathrm{C}$ until use. Prior to use, the library of drugs was thawed at $25^{\circ} \mathrm{C}$. Compounds that were determined to be compounds of interest, were isolated and reproduced from $10 \mathrm{mM}$ solutions. Amodiaquine, Chloroquine, Cinchonine, Primaquine, and Quinidine were purchased from Sigma-Aldrich (St. Louis, MO, USA). All drugs were prepared at $10 \mathrm{mM}$ using DMSO as a solvent. Desethyl-amodiaquine and desethyl-chloroquine were purchased from Toronto Research Chemicals Inc. Anti-N-terminal MEK-2, anti-tubulin, and anti-PA antibodies were purchased from Santa Cruz Biotechnology. Purified human cathepsin B protein used for NMR experiments was purchased from ACROBiosystems.

\section{Cellular Drug Screens}

RAW264.7-pGIPZ(-)2 mouse macrophage cells were maintained in DMEM (SigmaAldrich) supplemented with 10\% FBS (Bioexpress) and $100 \mu \mathrm{g} / \mathrm{mL}$ penicillin and $100 \mu \mathrm{g} / \mathrm{mL}$ 
streptomycin. RAW264.7-pGIPZ(-) cells (10,000 per well) were seeded in 96-well plates (100 $\mu 1 /$ well) 24 hours before the assay. During the drug library screen assay, $0.75 \mu 1$ of $3.3 \mathrm{mM}$ drugs were added to $150 \mu \mathrm{l}$ of cell-containing media to achieve $16 \mu \mathrm{M}$ of each compound per well. Cells were treated with compounds for 1 hour at $37{ }^{\circ} \mathrm{C} 5 \% \mathrm{CO} 2$, and then challenged with anthrax toxins, such that the final toxins concentrations were $0.5 \mu \mathrm{g} / \mathrm{ml}$. Cells were treated with toxin and drugs for 6 hours. As rodent cells are resistant to diphtheria toxin, C32 human melanoma cell line was used for diphtheria toxin screening, where cells were treated with $2 \mu \mathrm{g} / \mathrm{ml}$ for 24 hours. Determination of cell viability by 3-(4,5-dimethylthiazol-2-yl)-2,5diphenyltetrazolium bromide (MTT) assay was performed as described [46]. Cell viability is shown as the percentage of surviving cells obtained relative to cells treated with DMSO (100\%).

\section{FRET MAPKKide LF activity}

For drug testing in 96-well plates, the reaction volume was $250 \mu \mathrm{l}$ per well, containing $20 \mathrm{mM}$ HEPES $\mathrm{pH}$ 7.2, $5 \mu \mathrm{M}$ MAPKKide conjugated with DABYL and FITC (List Biological Laboratories, Inc), and $3.3 \mu \mathrm{M}$ of JHCCL compound. The reaction was initiated by adding LF to a final concentration of $6 \mu \mathrm{g} / \mathrm{ml}$. Kinetic measurements were obtained at $37^{\circ} \mathrm{C}$ every $40 \mathrm{sec}$ for $40 \mathrm{~min}$ using a fluorescent plate reader. Excitation and emission wavelengths were $490 \mathrm{~nm}$ and $523 \mathrm{~nm}$, respectively, with a cutoff wavelength of $495 \mathrm{~nm}$.

\section{Toxin Treatments}

Cells were seeded in a 96-well plate at a density of 10,000 cells/well $1 \mathrm{~d}$ before toxin treatment. Various concentrations of LF or FP59 combined with a fixed concentration of PA $\left(500 \mathrm{ng} / \mathrm{mL}\right.$ ) were added to the wells, and cells were incubated for $6 \mathrm{~h}$ at $37^{\circ} \mathrm{C}$. Cell viability was 
measured by MTT assay. In other toxin treatment experiments, cells were pre-treated with various concentrations of drugs, and then treated with constant concentrations of $8.3 \mu \mathrm{g} / \mathrm{ml}$ of $C$.

difficile toxin $\mathrm{B}, 500 \mathrm{ng} / \mathrm{ml}$ of $P$. aeruginosa Exotoxin A, or $500 \mathrm{ng} / \mathrm{ml}$ of Cholera toxin for 6 hours. RAW264.7 survival was measured by MTT assay. Each data point shown for MTT assays indicates the mean $\pm \mathrm{SD}$ value obtained in triplicate assays done in a representative experiment. At least three such experiments were routinely carried out.

\section{MEK Cleavage Assay}

RAW264.7 cells were pre-treated with $66.67 \mathrm{mM}$ of AQ for 1 hour. Following the pretreatment, the cells exposed to $1 \mathrm{mg} / \mathrm{mL}$ of PA and $\mathrm{LF}$ at $37^{\circ} \mathrm{C}$ for up to two hours in the presence of $16.67 \mu \mathrm{M}$ of AQ. The cells were then washed with cold PBS for $5 \times$ and lysed with RIPA buffer containing a protease inhibitor mixture (Roche). Cell lysates were quantified using the BCA protein quantification kit (Pierce) and loaded onto 4-12\% denaturing gels (Criterion XT Precast Gel, Bio-Rad). After electrophoresis for several hours, the gel was transferred overnight to nitrocellulose membranes; membranes were probed with anti-MEK-2 or anti tubulin antibodies. Quantitative Western blot analyses of the bands were accomplished using the VersaDoc 1000 instrument (Bio-Rad) or Odyssey infrared imaging system (LI-COR Biosciences).

\section{Biochemical Assay of PA Binding and Internalization}

Cells were pre-treated with $\mathrm{AQ}$ as described above for $1 \mathrm{~h}$, either at $4{ }^{\circ} \mathrm{C}$ for PA binding or at $37^{\circ} \mathrm{C}$ for PA internalization assays cells were exposed to $1 \mu \mathrm{g} / \mathrm{mL}$ of PA at $4{ }^{\circ} \mathrm{C}$ for $1 \mathrm{~h}$ for binding assay or at $37^{\circ} \mathrm{C}$ for $1 \mathrm{~h}$ for internalization assay. Cells were then washed with PBS 
solution three times and lysed in RIPA buffer containing a protease inhibitor mixture (Roche). Western blot analysis was performed using anti-PA antibody anti-tubulin monoclonal antibody (Sigma-Aldrich). Chemiluminescence of bands and their relative intensities were revealed using a VersaDoc 1000 instrument (Bio-Rad).

Caspase-1 Activity Assay

Cells were treated with AQ for $1 \mathrm{~h}$ before addition of $500 \mathrm{ng} / \mathrm{ml}$ LF-PA for an additional 2 h. FAM FLICA ${ }^{\text {TM }}$ Caspase 1 Assay Kit was obtained from ImmunoChemistry Technologies LLC. FLICA reagent was added for $1 \mathrm{~h}$. FLICA fluorescence was visualized as follows: cells were washed three times in PBS, fixed in 4\% (wt/vol) paraformaldehyde, and examined under a fluorescence microscope (DM5500 B; Leica).

\section{Staining Cells with Lysosensor Green DND-189}

Cells were treated with AQ for $1 \mathrm{~h}$ before an addition of $500 \mathrm{ng} / \mathrm{ml} \mathrm{PA}$ for an additional hour and then stained with Lysosensor Green DND-189 for $10 \mathrm{~min}$ at $37^{\circ} \mathrm{C}$. Cells were then washed and fluorescence was visualized as follows: cells were fixed in 4\% (wt/vol) paraformaldehyde, and examined under a fluorescence microscope (DM5500 B; Leica).

\section{Cathepsin B Activity Assay}

Cathepsin B activity in total cell lysates was determined using an InnoZyme TM cathepsin B activity assay kit (EMD Milipore) and performed according to the manufacturer's instruction. Cathepsin B activity in cellular lysates was tested in the following way: RAW264.7 cells untreated with drugs were lysed, and equal amount of cathepsin B containing protein lysate was 
added to the substrate solution (EMD Milipore) with and without AQ, CQ, DEAQ, or DECQ at concentrations of $4,8,16,33$, or $66 \mu \mathrm{M}$. Cellular cathepsin B activity with and without drugs was tested by pre-treating cells with drugs for 1 hour, followed by lysing cells and testing cathepsin B activity with a fluorescently labeled substrate. The activity of $0.5 \mathrm{ng} / \mu \mathrm{l}$ of purified human cathepsin B was mixed with and without drugs without pre-incubation and detected with a fluorescently labeled substrate. Fluorescence intensity indicating cathepsin B activity was measured at an excitation wavelength of $370 \mathrm{~nm}$ and emission wavelength of $450 \mathrm{~nm}$ (Molecular Devices, Spectra Max 384 PLUS).

\section{Rat intoxication challenge}

The rat studies were performed at Explora Biolabs, San Diego, CA following Institutional Animal Care and Use Committee (IACUC) approved protocols. Five Male Sprague-Dawley rats (226 to $250 \mathrm{~g}$; Charles River) per group were used. The toxin mixture was prepared for each group by mixing $12 \mu \mathrm{g}$ of LF with $40 \mu \mathrm{g}$ of PA or with $1.5,3.0$, or $6.0 \mathrm{mg} / \mathrm{kg}$ of Amodiaquine in a $500-\mu 1$ volume per rat. Rats were monitored for signs of clinical illness or death for 14 days after the challenge.

\section{NMR spectroscopy}

All STD experiments were performed at $25^{\circ} \mathrm{C}$ using a Bruker Avance 500-MHz spectrometer equipped with a cryogenic probe. The pulse scheme employed excitation sculpting

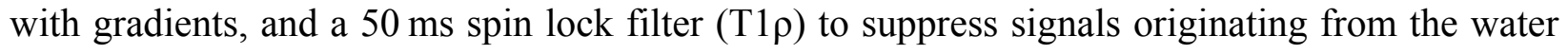
and protein signals, respectively [25]. An irradiation power of $26 \mathrm{~Hz}$ was applied on-resonance at $0.04 \mathrm{ppm}$, and off-resonance at $30 \mathrm{ppm}$, for a total saturation time of $4 \mathrm{~s}$. Spectra were collected 
in an interleaved manner to account for any temporal fluctuations. Separate control experiments were performed using samples of cathepsin B or Amodiaquine to confirm the selectivity of saturation. STD spectra were acquired with 4096 scans and $32 \mathrm{k}$ data points using a spectral width of $7002.8 \mathrm{~Hz}$ centered at $2352 \mathrm{~Hz}$. All experiments were performed in deuterated tris buffer: $50 \mathrm{mM}$ D11-Tris, $150 \mathrm{mM} \mathrm{NaCl}$, pH 7.5 supplemented with $8 \% \mathrm{D} 2 \mathrm{O}$. The sample used for STD measurements contained $20 \mathrm{mM}$ and $2 \mathrm{mM}$ cathepsin B and Amodiaquine, respectively. The STD NMR data were processed and analyzed using Topspin 3.1 software (Bruker, Billerica Ma). STD effects were calculated according to the formula: ASTD $=(\mathrm{I} 0-$ Isat $) / I 0$, where Isat and I0 are the intensity of the Amodiaquine signal recorded with and without saturation of the protein, respectively.

\section{Viral tests}

The procedures of all viral experiments are described in supplemental materials and methods. Specifically, infection of HeLa cells with Ebola was done using Ebola virus (Kikwit) $\mathrm{MOI}=0.5$ (calculated for 4,000 cells/well, assuming one complete round of replication of HeLa cells at $15 \pm 2 \mathrm{hrs}$ after cell seeding). Cells were incubated with the virus for 24 or $48 \mathrm{~h}$. Infection was terminated by fixing samples in formalin solution, and immuno-staining was used to visualize infected cells. Cells were treated with anti-GP specific monoclonal antibody (6D8) (1 to 1000 dilution) followed by anti-mouse IgG conjugated with Dylight488 (Thermo) (1 to 1000 dilution) in blocking buffer containing 3\% BSA in PBS. Nuclei were stained with Draq5 (Biostatus) diluted in PBS buffer. Images were acquired on the Opera imaging instrument (Perkin Elmer) using 10× Air objective and four images/well were acquired and analyzed using PE Acapella algorithms. 


\section{Acknowledgments}

We thank Dr. Stephen Leppla of the NIAID for a kind gift of FP59 toxin and Dr. Robert Peterson for assistance with the NMR spectroscopy. We acknowledge the Ralph M. Parson's Foundation award awarded to K.G.I. (PI Dr. Steven Casper). R.T.C. and M.S. acknowledge grant support from the National Institutes of Health (R01 AI52217 and F31GM101931, respectively).

\section{Author Information}

Leeor Zilbermintz \& William Leonardi

These authors contributed equally to this work.

\section{Affiliations}

Keck Graduate Institute, Claremont, CA 91711

Leeor Zilbermintz, William Leonardi, Ryan McComb, Anastasia Levitin, Joel West, Vivek Gupta \& Mikhail Martchenko

Department of Genetics, Stanford University School of Medicine, Stanford, CA 94305 Sun-Young Jeong \& Stanley N. Cohen

Department of Chemistry and Biochemistry, University of California, Los Angeles, CA, 90095

Megan Sjodt \& Robert T. Clubb 
US Army Medical Research Institute of Infectious Diseases (USAMRIID), Fort Detrick,

MD, 21702

Cary Retterer, Dima Gharaibeh, Rouzbeh Zamani, Veronica Soloveva \& Sina Bavari

Department of Microbiology, Immunology, and Molecular Genetics, University of California, Los Angeles, CA, 90095.

Chi-Lee C. Ho \& Kenneth A. Bradley

\section{Contributions}

V.S., S.B., A.L., J.W., K.A.B., R.T.C., S.N.C, V.G. and M.M. designed research; L.Z., W.L., S.Y.J., M.S., R.M., C.-L.C., C.R., D.G. and R.Z. performed research; all analyzed data; and L.Z., W.L. and M.M. wrote the paper.

\section{Competing interests}

The authors declare no competing financial interests.

\section{References}

1. Bekerman E. \& Einav S. Infectious disease. Combating emerging viral threats. Science 348, 282-283 (2015).

2. Martchenko M., Jeong S. Y. \& Cohen S. N. Heterodimeric integrin complexes containing beta1-integrin promote internalization and lethality of anthrax toxin. Proc Natl Acad Sci USA 107, 15583-15588 (2010).

3. Chong C. R., Chen X., Shi L., Liu J. O. \& Sullivan D. J. Jr. A clinical drug library screen identifies astemizole as an antimalarial agent. Nature chemical biology 2, 415-416 (2006).

4. Sandvig K. \& van Deurs B. Delivery into cells: lessons learned from plant and bacterial toxins. Gene Ther 12, 865-872 (2005).

5. Martchenko M., Candille S. I., Tang H. \& Cohen S. N. Human genetic variation altering anthrax toxin sensitivity. Proc Natl Acad Sci USA 109, 2972-2977 (2012). 
6. Moayeri M. \& Leppla S. H. Cellular and systemic effects of anthrax lethal toxin and edema toxin. Mol Aspects Med 30, 439-455 (2009).

7. Duesbery N. S. et al. Proteolytic inactivation of MAP-kinase-kinase by anthrax lethal factor. Science 280, 734-737 (1998).

8. Bradley K. A., Mogridge J., Mourez M., Collier R. J. \& Young J. A. Identification of the cellular receptor for anthrax toxin. Nature 414, 225-229 (2001).

9. Scobie H. M., Rainey G. J., Bradley K. A. \& Young J. A. Human capillary morphogenesis protein 2 functions as an anthrax toxin receptor. Proc Natl Acad Sci USA 100, 5170-5174 (2003).

10. Klimpel K. R., Molloy S. S., Thomas G. \& Leppla S. H. Anthrax toxin protective antigen is activated by a cell surface protease with the sequence specificity and catalytic properties of furin. Proc Natl Acad Sci USA 89, 10277-10281 (1992).

11. Kintzer A. F. et al. The protective antigen component of anthrax toxin forms functional octameric complexes. J Mol Biol 392, 614-629 (2009).

12. Thoren K. L. \& Krantz B. A. The unfolding story of anthrax toxin translocation. Mol Microbiol 80, 588595 (2011).

13. Checroun C., Wehrly T. D., Fischer E. R., Hayes S. F. \& Celli J. Autophagy-mediated reentry of Francisella tularensis into the endocytic compartment after cytoplasmic replication. Proc Natl Acad Sci USA 103, 14578-14583 (2006).

14. Ha S. D., Ham B., Mogridge J., Saftig P., Lin S. \& Kim S. O. Cathepsin B-mediated autophagy flux facilitates the anthrax toxin receptor 2-mediated delivery of anthrax lethal factor into the cytoplasm. J Biol Chem 285, 2120-2129 (2010).

15. Tan Y. K., Kusuma C. M., St John L. J., Vu H. A., Alibek K. \& Wu A. Induction of autophagy by anthrax lethal toxin. Biochem Biophys Res Commun 379, 293-297 (2009).

16. Abrami L., Lindsay M., Parton R. G., Leppla S. H. \& van der Goot F. G. Membrane insertion of anthrax protective antigen and cytoplasmic delivery of lethal factor occur at different stages of the endocytic pathway. J Cell Biol 166, 645-651 (2004).

17. Sobo K. et al. Late endosomal cholesterol accumulation leads to impaired intra-endosomal trafficking. PLoS One 2, e851 (2007).

18. Tershak D. R. Association of poliovirus proteins with the endoplasmic reticulum. Journal of virology 52, 777-783 (1984).

19. Wickliffe K. E., Leppla S. H. \& Moayeri M. Anthrax lethal toxin-induced inflammasome formation and caspase-1 activation are late events dependent on ion fluxes and the proteasome. Cell Microbiol 10, 332343 (2008).

20. Panchal R. G. et al. Identification of small molecule inhibitors of anthrax lethal factor. Nat Struct Mol Biol 11, 67-72 (2004).

21. Arora N., Klimpel K. R., Singh Y. \& Leppla S. H. Fusions of anthrax toxin lethal factor to the ADPribosylation domain of Pseudomonas exotoxin A are potent cytotoxins which are translocated to the cytosol of mammalian cells. J Biol Chem 267, 15542-15548 (1992). 
22. Miller C. J., Elliott J. L. \& Collier R. J. Anthrax protective antigen: prepore-to-pore conversion. Biochemistry 38, 10432-10441 (1999).

23. Squires R. C., Muehlbauer S. M. \& Brojatsch J. Proteasomes control caspase-1 activation in anthrax lethal toxin-mediated cell killing. J Biol Chem 282, 34260-34267 (2007).

24. Liu S. \& Leppla S. H. Cell surface tumor endothelium marker 8 cytoplasmic tail-independent anthrax toxin binding, proteolytic processing, oligomer formation, and internalization. J Biol Chem 278, 5227-5234 (2003).

25. Mayer M. \& Meyer B. Group epitope mapping by saturation transfer difference NMR to identify segments of a ligand in direct contact with a protein receptor. J Am Chem Soc 123, 6108-6117 (2001).

26. Meyer B. \& Peters T. NMR spectroscopy techniques for screening and identifying ligand binding to protein receptors. Angew Chem Int Ed Engl 42, 864-890 (2003).

27. Mirkovic B. et al. Novel mechanism of cathepsin B inhibition by antibiotic nitroxoline and related compounds. ChemMedChem 6, 1351-1356 (2011).

28. Gnirss K. et al. Cathepsins B and L activate Ebola but not Marburg virus glycoproteins for efficient entry into cell lines and macrophages independent of TMPRSS2 expression. Virology 424, 3-10 (2012).

29. Sanchez A. Analysis of filovirus entry into vero e6 cells, using inhibitors of endocytosis, endosomal acidification, structural integrity, and cathepsin (B and L) activity. J Infect Dis 196 Suppl 2, S251-258 (2007).

30. Lemichez E. et al. Membrane translocation of diphtheria toxin fragment A exploits early to late endosome trafficking machinery. Mol Microbiol 23, 445-457 (1997).

31. Mingo R. M. et al. Ebola virus and severe acute respiratory syndrome coronavirus display late cell entry kinetics: evidence that transport to NPC1 + endolysosomes is a rate-defining step. Journal of virology 89 , 2931-2943 (2015).

32. Colpitts T. M., Moore A. C., Kolokoltsov A. A. \& Davey R. A. Venezuelan equine encephalitis virus infection of mosquito cells requires acidification as well as mosquito homologs of the endocytic proteins Rab5 and Rab7. Virology 369, 78-91 (2007).

33. St Pierre C. A., Leonard D., Corvera S., Kurt-Jones E. A. \& Finberg R. W. Antibodies to cell surface proteins redirect intracellular trafficking pathways. Experimental and molecular pathology 91, 723-732 (2011).

34. Martinez M. G., Forlenza M. B. \& Candurra N. A. Involvement of cellular proteins in Junin arenavirus entry. Biotechnology journal 4, 866-870 (2009).

35. Bernard E. et al. Endocytosis of chikungunya virus into mammalian cells: role of clathrin and early endosomal compartments. PLoS One 5, e11479 (2010).

36. Qa'Dan M., Spyres L. M. \& Ballard J. D. pH-induced conformational changes in Clostridium difficile toxin B. Infect Immun 68, 2470-2474 (2000).

37. Johannes L. \& Decaudin D. Protein toxins: intracellular trafficking for targeted therapy. Gene Ther 12 , $1360-1368$ (2005).

38. Jackson M. E., Simpson J. C., Girod A., Pepperkok R., Roberts L. M. \& Lord J. M.The KDEL retrieval system is exploited by Pseudomonas exotoxin A, but not by Shiga-like toxin-1, during retrograde transport from the Golgi complex to the endoplasmic reticulum. J Cell Sci 112 (Pt 4) 467-475 (1999). 
39. Turcotte S., Letellier J. \& Lippe R. Herpes simplex virus type 1 capsids transit by the trans-Golgi network, where viral glycoproteins accumulate independently of capsid egress. Journal of virology $79,8847-8860$ (2005).

40. Haspot F. et al. Human cytomegalovirus entry into dendritic cells occurs via a macropinocytosis-like pathway in a pH-independent and cholesterol-dependent manner. PLoS One 7, e34795 (2012).

41. Krzyzaniak M. A., Zumstein M. T., Gerez J. A., Picotti P. \& Helenius A. Host cell entry of respiratory syncytial virus involves macropinocytosis followed by proteolytic activation of the F protein. PLoS Pathog 9, e1003309 (2013).

42. O’Neill P., Barton V., Ward S. \& Chadwick J. 4-Aminoquinolines: Chloroquine, Amodiaquine and NextGeneration Analogues. Springer: Basel AG, (2012).

43. Minzi O. M., Rais M., Svensson J. O., Gustafsson L. L. \& Ericsson O. High-performance liquid chromatographic method for determination of amodiaquine, chloroquine and their monodesethyl metabolites in biological samples. J Chromatogr B Analyt Technol Biomed Life Sci 783, 473-480 (2003).

44. Ntale M. et al. Field-adapted sampling of whole blood to determine the levels of amodiaquine and its metabolite in children with uncomplicated malaria treated with amodiaquine plus artesunate combination. Malaria journal 8, 52 (2009).

45. Rijken M. J. et al. Pharmacokinetics of amodiaquine and desethylamodiaquine in pregnant and postpartum women with Plasmodium vivax malaria. Antimicrob Agents Chemother 55, 4338-4342 (2011).

46. Lu Q., Wei W., Kowalski P. E., Chang A. C. \& Cohen S. N. EST-based genome-wide gene inactivation identifies ARAP3 as a host protein affecting cellular susceptibility to anthrax toxin. Proc Natl Acad Sci USA 101, 17246-17251 (2004). 


\section{Supplemental Information}

Identification of agents effective against multiple toxins and viruses by host-oriented cell targeting

\section{Supplemental:}

1. Supplemental Figures,

2. Supplemental Tables,

3. Supplemental Experimental Procedures. 


\section{Supplemental Figures:}
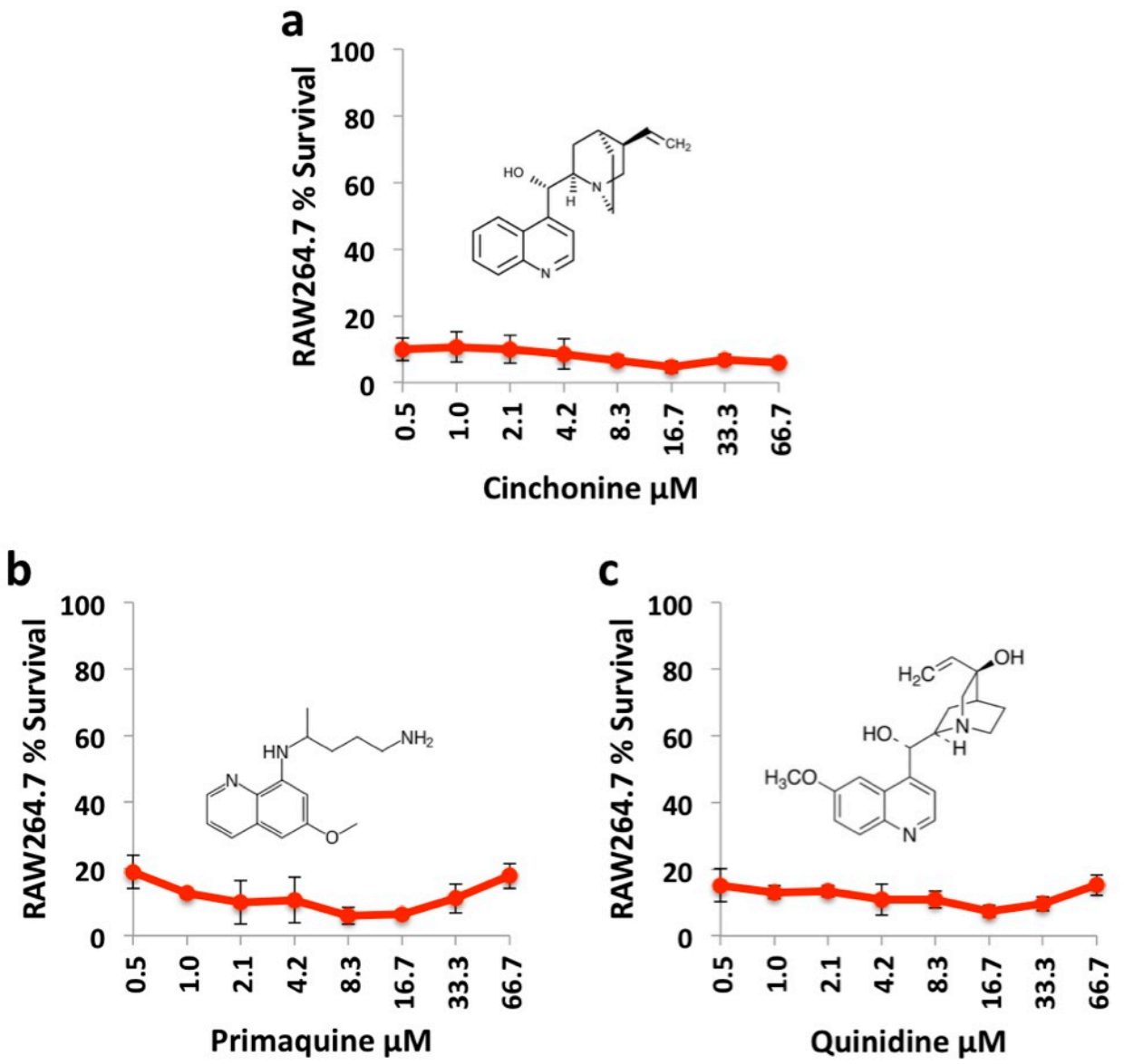

Figure 1: The effect of quinolone anti-malarials on sensitivities of cells treated with anthrax toxins. RAW264.7 cells were pretreated with indicated drugs at shown concentrations for 1 hour, and then treated with anthrax toxins for 6 hours. RAW264.7 survival was measured by MTT assay. 


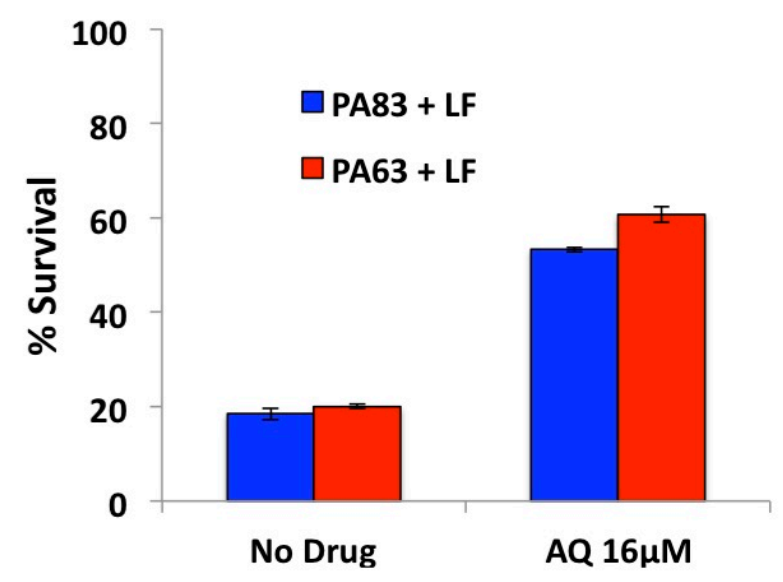

Figure 2: Amodiaquine reduces cellular sensitivity to LF+PA83 and LF+PA63. RAW264.7 cells were pretreated either with DMSO or with AQ for 1 hour, and then treated with $500 \mathrm{ng} / \mathrm{ml}$ of LF in the presence of $1.5 \mu \mathrm{g} / \mathrm{ml}$ of either of PA83 or PA63 for 6 hours 

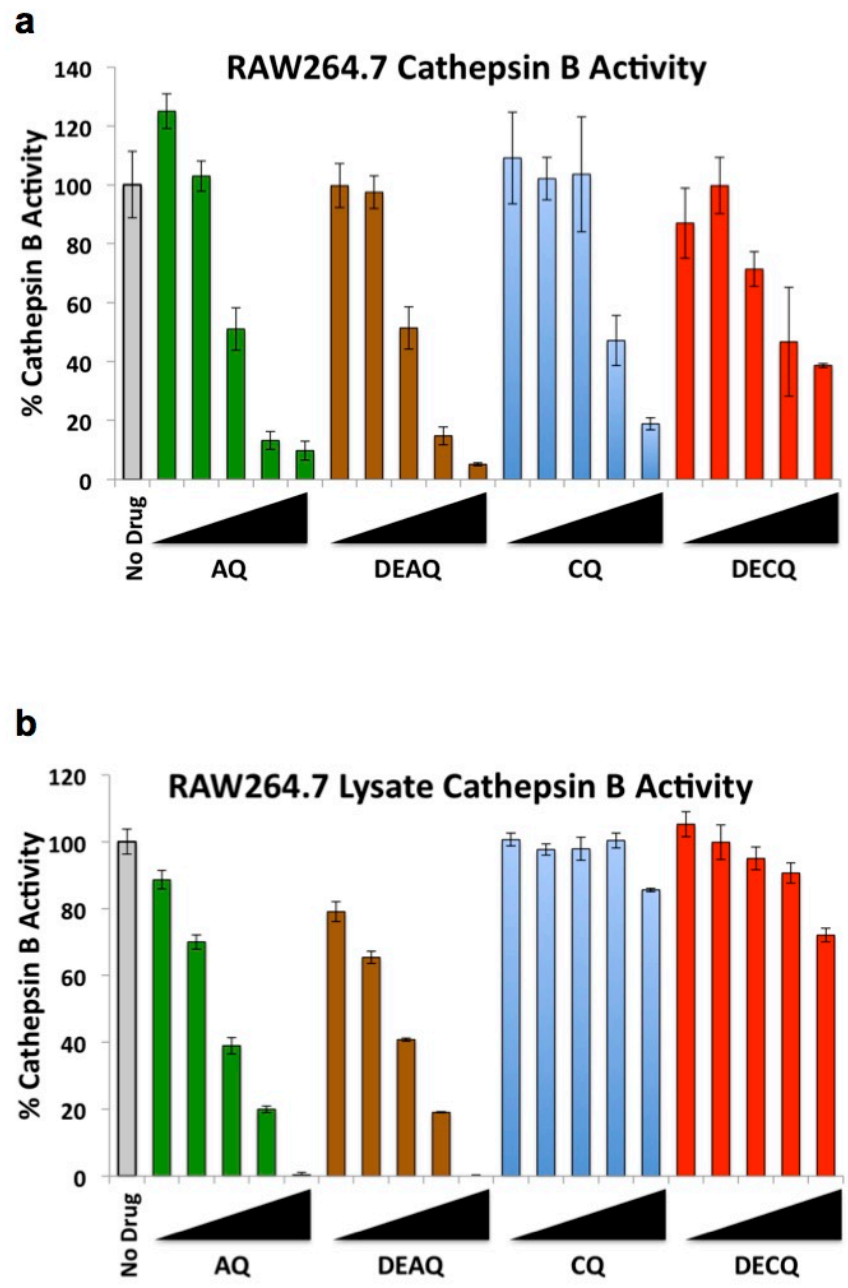

Figure 3: The effect of Amodiaquine, Chloroquine, and their metabolites on the activity of host cathepsin B. FRET assay showing the activity of cathepsin B without drugs, or with addition of $A Q, D E A Q, C Q$, or DECQ at $4,8,16,33$, or 66 $\mu \mathrm{M}$. RAW264.7 cells were treated with drugs for 1 hour prior to lysis and determination of cathepsin B activity (a), or untreated RAW264 cells were lysed, the lysate was treated with drugs, and then the activity of cathepsin B was assessed (b). 

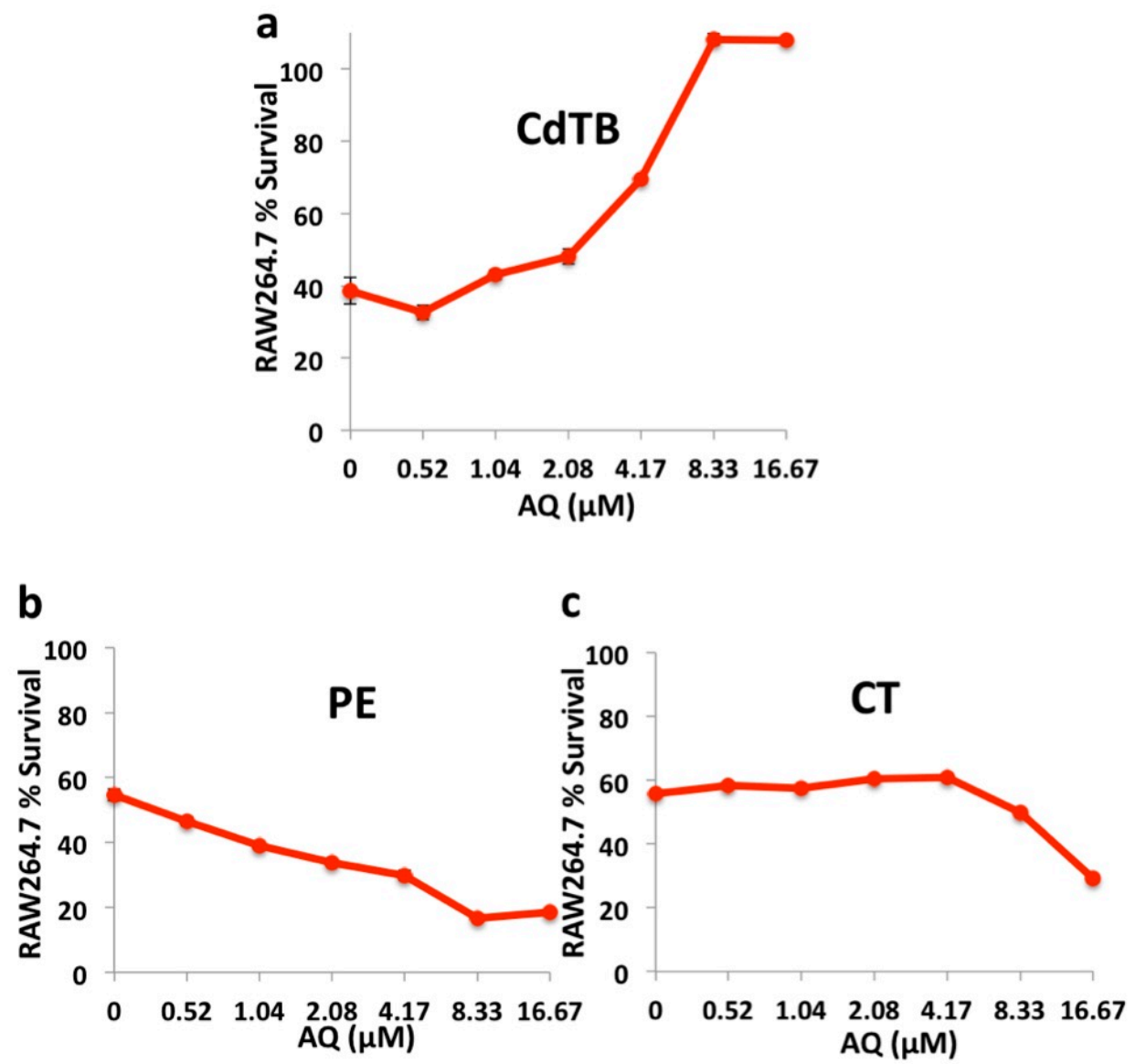

Figure 4: The effect of Amodiaquine on sensitivities of cells treated with bacterial toxins. RAW264.7 cells were pretreated with indicated AQ concentrations for 1 hour, and then treated with (a) $8.3 \mu \mathrm{g} / \mathrm{ml}$ of Clostridium difficile toxin B (CdTB), (b) $500 \mathrm{ng} / \mathrm{ml}$ of Pseudomonas aeruginosa Exotoxin A (PE), or (c) $500 \mathrm{ng} / \mathrm{ml}$ of Cholera toxin (CT) for 6 hours. RAW264.7 survival was measured by MTT assay. 


\section{Supplemental Tables:}

\begin{tabular}{cccccc} 
Pathogen & $\begin{array}{c}\text { Drug, } \\
\text { hours }\end{array}$ & EC50 $\mu \mathrm{M}$ & SD $\mu \mathrm{M}$ & CC50 $\mu \mathrm{M}$ & SI50 \\
\hline EBOV & AQ, 48h & 2.6 & 0.19 & 30 & 11.4 \\
EBOV & DEAQ, 48h & 2.1 & 0.48 & 30 & 14.4 \\
EBOV & CQ, 48h & 2.5 & 0.88 & 70 & 28.0 \\
EBOV & DECQ, 48h & 3.2 & 0.62 & 70 & 22.1
\end{tabular}

Table 1: Amodiaquine, Chloroquine and theirmetabolites inhibit Ebola virus in HFF-1 cells. The effect of $A Q, C Q$, and its metabolites, DEAQ and DECQ, on the pathogenicity of EBOV in HFF-1 cells. The ability of drugs to reduce the abundance of Ebola virus (EBOV) in host cells was measured in cells by fluorescent microscopy. The $50 \%$ effective $\left(\mathrm{EC}_{50}\right.$, virus-inhibitory) concentrations and $50 \%$ cytotoxic $\left(\mathrm{CC}_{50}\right.$, cellinhibitory) concentrations were determined. $\mathrm{CC}_{50}$ divided by $\mathrm{EC}_{50}$ indicate the selectivity index (SI) value.

\begin{tabular}{cccccc} 
Pathogen & Drug & EC50 $\mu \mathrm{M}$ & SD $\mu \mathrm{M}$ & CC50 $\mu \mathrm{M}$ & SI50 \\
\hline CHIV & AQ & 18.4 & 0.56 & $>50$ & $>2$ \\
CHIV & DEAQ & 17.3 & 0.64 & $>50$ & $>2.9$ \\
JUNV & AQ & 16.9 & 1.92 & 50 & 3.0 \\
JUNV & DEAQ & 13.8 & 2.02 & 40 & 2.9
\end{tabular}

Table 2: Amodiaquine and its metabolite inhibits Chikungunya (CHIV) and Junin (JUNV) viruses in host cells. The effect of $A Q$ and $D E A Q$ on the pathogenicity of EBOV in HFF-1cells. The ability of drugs to reduce the abundance of viruses in host cells was measured in cells by fluorescent microscopy. The $50 \%$ effective $\left(E_{50}\right.$, virusinhibitory) concentrations and $50 \%$ cytotoxic $\left(\mathrm{CC}_{50}\right.$, cell-inhibitory) concentrations were determined. $\mathrm{CC}_{50}$ divided by $\mathrm{EC}_{50}$ indicate the selectivity index (SI) value. 


\title{
Supplemental Materials and Methods:
}

\author{
Screening Assays for Ebola virus (EBOV, Strain Kikwit).
}

\author{
High Content Imaging virus infection assay
}

\section{Cell Culture and infection}

HeLa cells (ATCC) were cultured for 3 days in T175 or T225 (Corning) flasks in culture media containing Minimum Essential Medium (MEM, Corning Cellgro) supplemented with 10\% Fetal Bovine Serum (Hyclone), 1\% L-Glutammine (Hyclone), $10 \mathrm{mM}$ Hepes 7.0-7.6 (Sigma), 1\% non-essential amino acids (Sigma). Cells were lifted using Trypsin-

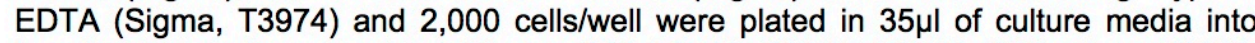
imaging 384 well assay plates (Aurora 384, IQ-EB, 384 IQ-EB/NB, 200mclear, \#105211130) and incubated for about $20 \mathrm{~h}$ before compound treatment.

\section{Compound treatment}

Treatment of the cells with test and control compounds was done $2 \mathrm{~h}$ prior infection. EC50 determination for test compound done with 2 fold step at least for 10 doses starting from highest concentration of $100 \mathrm{uM}$ (with stock concentration of $10 \mathrm{mM}$ ) using HP D-300 digital dispenser. Each dose dispensed directly from the concentrated stock with highest volume of $500 \mathrm{~nL}$. Concentration of DMSO in all wells was normalized to $1 \%$. Cells were pre-treated with serially diluted compounds for 2 hours before infection. Each dose were repeated 4 times on one plate $(n=4)$.

\section{Infection}

Infection was done using Ebola virus (Kikwit) $\mathrm{MOI}=0.5$ (calculated for 4,000 cells/well, assuming one complete round of replication of HeLa cells at $15 \pm 2 \mathrm{hrs}$ after cell seeding) and 10ul of virus dilution was dispensed in each well except column 2, representing "no infection control". Cells were incubated with the virus for 24 or $48 \mathrm{~h}$. Infection was terminated by fixing samples in formalin solution.

\section{Immuno-staining assay}

Immune-staining was used to visualize infected cells. Cells were treated with anti-GP specific monoclonal antibody (6D8) (1 to 1000 dilution) followed by anti-mouse IgG conjugated with Dylight488 (Thermo) (1 to 1000 dilution) in blocking buffer containing $3 \%$ BSA in PBS. Nuclei were stained with Draq5 (Biostatus) diluted in PBS buffer.

\section{Image and Data analysis.}

Images were acquired on the Opera imaging instrument (Perkin Elmer) using 10x Air objective and four images/well were acquired. Signal from anti-virus staining was detected at $488 \mathrm{~nm}$ emission wavelength and Nuclei at $640 \mathrm{~nm}$.

Image analysis was performed using PE Acapella algorithms. Several well-based output parameters were measured including: Number of Objects (Nuclei) and Positive Virus Number of Objects (Ave of Intensity for virus specific signal). The \% of Infected cells were calculated by Acapella directly as 


$$
\% \text { Infected cells }=\frac{\text { Positive Virus Number of Objects }(s)}{\text { Number of objects }(s)} * 100
$$

$\%$ infection rate was analyzed for each plate using Median of \% Positive virus cells (for all Neutral control wells that are infected and treated with DMSO only; S-sample

\section{Data analysis}

Data normalization

\% Inhibition. Data normalization was done using GeneData Explorer software. Data was normalized on the plate based level converting the \%Virus positive cells associated with each wells into $\%$ Activity $=\%$ of inhibition of infection (or $\%$ Inhibition or $\% \mathrm{INH}$ ). Control wells were indicated as follows:

$\mathrm{NC}=$ Neutral control; Infection + DMSO (or minimal activity of inhibitor)

$\mathrm{BC}=$ Blank control; No infection (or maximum inhibition of viral infection possible). Median of the values is used for all controls.

$$
\% \text { Inhibition }=\frac{\text { Median } \% \text { Virus positive }(N C)-\% \text { Virus positive }(S)}{\text { Median } \% \text { Virus positive }(N C)-\text { Median } \% \text { Virus positive }(B C)} * 100 \%
$$

$\%$ Viability. Number of objects represented the amount of cells in each treated well and was also used as indication of the cyto-toxic or cyto-static effect. The number of objects was converted by GeneData Condeseo to \% Viability for with a compound dose response.

$$
\% \text { Viability }=\frac{\text { Nuclei Nuber Sample }}{\text { MedianNulei number }(N C)} * 100 \%
$$

Dose response curve fitting analysis

Analysis of dose response curve for \% Inhibition and \% Viability was used to determine $\mathrm{EC}_{50}$ and $\mathrm{CC}_{50}$, and was applying GeneData Condoseo software with LevenbergMarquardt algorithm (LMA) for curve fitting strategy. The Curve-fitting applied validity criteria, such aschi ${ }^{2}$, SE $\log \mathrm{EC}_{50}$, minimal number of valid data points, to indicate if curve fitting converging was successful and indicated in table with results. $R^{2}$ value quantifies goodness of fit. Fitting strategy was considered acceptable if it gave conversion with $\mathrm{R}^{2}>0.8$.

\section{Screening Assays for Venezuelan equine encephalitis virus (VEEV, Strain TC-83).}

Primary cytopathic effect (CPE) reduction assay. Four-concentration CPE inhibition assays are performed. Confluent or near-confluent cell culture monolayers in 96-well disposable microplates are prepared. Cells are maintained in MEM or DMEM supplemented with FBS as required for each cell line. For antiviral assays the same medium is used but with FBS reduced to $2 \%$ or less and supplemented with $50 \mu \mathrm{g} / \mathrm{ml}$ gentamicin. The test compound is prepared at four $\log _{10}$ final concentrations, usually 
$0.1,1.0,10$, and $100 \mu \mathrm{g} / \mathrm{ml}$ or $\mu \mathrm{M}$. The virus control and cell control wells are on every microplate. In parallel, a known active drug is tested as a positive control drug using the same method as is applied for test compounds. The positive control is tested with each test run. The assay is set up by first removing growth media from the 96-well plates of cells. Then the test compound is applied in $0.1 \mathrm{ml}$ volume to wells at $2 \mathrm{X}$ concentration. Virus, normally at $<10050 \%$ cell culture infectious doses (CCID50) in $0.1 \mathrm{ml}$ volume, is placed in those wells designated for virus infection. Medium devoid of virus is placed in toxicity control wells and cell control wells. Virus control wells are treated similarly with virus. Plates are incubated at $37^{\circ} \mathrm{C}$ with $5 \% \mathrm{CO}_{2}$ until maximum $\mathrm{CPE}$ is observed in virus control wells. The plates are then stained with $0.011 \%$ neutral red for approximately two hours at $37^{\circ} \mathrm{C}$ in a $5 \% \mathrm{CO}_{2}$ incubator. The neutral red medium is removed by complete aspiration, and the cells may be rinsed $1 \mathrm{X}$ with phosphate buffered solution (PBS) to remove residual dye. The PBS is completely removed and the incorporated neutral red is eluted with $50 \%$ Sorensen's citrate buffer $/ 50 \%$ ethanol $(\mathrm{pH} 4.2)$ for at least 30 minutes. Neutral red dye penetrates into living cells, thus, the more intense the red color, the larger the number of viable cells present in the wells. The dye content in each well is quantified using a 96-well spectrophotometer at $540 \mathrm{~nm}$ wavelength. The dye content in each set of wells is converted to a percentage of dye present in untreated control wells using a Microsoft Excel computer-based spreadsheet. The $50 \%$ effective $\left(\mathrm{EC}_{50}\right.$, virus-inhibitory) concentrations and $50 \%$ cytotoxic $\left(\mathrm{CC}_{50}\right.$, cellinhibitory) concentrations are then calculated by linear regression analysis. The quotient of $\mathrm{CC}_{50}$ divided by $\mathrm{EC}_{50}$ gives the selectivity index $(\mathrm{SI})$ value.

\section{Screening Assays for Herpes Simplex Virus 1 (HSV-1, Strain E-377) and Human Cytomegalovirus (CMV, Strain AD169).}

Human foreskin fibroblast (HFF) cells were prepared from human foreskin tissue. The tissue was incubated at $4^{\circ} \mathrm{C}$ for $4 \mathrm{~h}$ in Clinical Medium and then placed in phosphate buffered saline (PBS) to remove the red blood cells, and resuspended in trypsin/EDTA solution. The tissue suspension was incubated at $37^{\circ} \mathrm{C}$ and gently agitated to disperse the cells, which were collected by centrifugation. Cells were resuspended in $4 \mathrm{ml}$ Clinical Medium and placed in a flask and incubated at $37^{\circ} \mathrm{C}$ in a humidified $\mathrm{CO}_{2}$ incubator for $24 \mathrm{~h}$. The media was then replaced with fresh Clinical Medium and the cell growth was monitored daily until a confluent monolayer has formed. The HFF cells were then expanded through serial passages in standard growth medium of MEM with Earl's salts supplemented with $10 \%$ FBS and antibiotics. The cells were passaged routinely and used for assays at or below passage 10.

Primary Cytopathic Effect (CPE) Reduction Assay. Low passage (3-10) HFF cells were trypsinized, counted, and seeded into 96 well tissue culture plates in $0.1 \mathrm{ml}$ of MEM supplemented with $10 \%$ FBS. The cells were then incubated for $24 \mathrm{~h}$ at $37^{\circ} \mathrm{C}$. The media was then removed and $100 \mu \mathrm{l}$ of MEM containing $2 \%$ FBS was added to all but the first row. In the first row, $125 \mu \mathrm{l}$ of media containing the experimental drug was added in triplicate wells. Media alone was added to both cell and virus control wells. The drug in the first row of wells was then diluted serially 1:5 throughout the remaining. The plates were then incubated for $60 \mathrm{~min}$ and $100 \mu \mathrm{l}$ of a virus suspension was added to each well, excluding cell control wells which received $100 \mu \mathrm{l}$ of MEM. The plates were 
then incubated at $37^{\circ} \mathrm{C}$ in a $\mathrm{CO}_{2}$ incubator for three days for HSV-1, or $14 \mathrm{~d}$ for CMV. After the incubation period, media was aspirated and the cells stained with crystal violet in formalin for $4 \mathrm{~h}$. The stain was then removed and the plates were rinsed until all excess stain was removed. The plates were allowed to dry for $24 \mathrm{~h}$ and the amount of $\mathrm{CPE}$ in each row determined using a BioTek Multiplate Autoreader. $\mathrm{EC}_{50}$ and $\mathrm{CC}_{50}$ values were determined by comparing drug treated and untreated cells using a computer program.

\section{Screening Assays for Rabies (Strain Flury).}

Confluent BHK-21 cells were prepared in T-150 flask. Cells were Trypsinized cells and made as cell suspensions. $50 \mu \mathrm{l}$ of $5 \times 10^{5} \mathrm{cells} / \mathrm{ml}$ cell suspension $(25,000 \mathrm{cells} / \mathrm{well})$ were added into each well of the 96 well plates, except row H. 2X concentration of antivirals were made (Isoprinosine and test drug(s)). 6 concentration points are done. $100 \mu \mathrm{l}$ per well that will be tested for effective concentration (drug wells) and cytotoxic concentration (tox wells) were added. The rabies virus was diluted 1:1000. 50 $\mu$ l was added per well in the drug wells and virus control wells. This gave a final dilution of 1:4000. The final volume was $200 \mu \mathrm{l}$. Additional media was added to fill up wells, ie: Tox wells were $100 \mu \mathrm{l} 2 \mathrm{x}$ drug, $50 \mu \mathrm{l}$ cells $(5 \mathrm{e} 5 \mathrm{cells} / \mathrm{ml}$ ), and $50 \mu \mathrm{l}$ media. Plates were covered and incubated $\left(37^{\circ} \mathrm{C} ; 5 \% \mathrm{CO}_{2}\right)$ for 5 days. After 5 days the Promega CellTiterGlo Luminescent Cell Viability Assay was run using the Fluoroskan FL to scan for luminescence.

\section{Screening Assays for Poliovirus 3}

Principal Viruses and Cells:

Poliovirus: WM3, Cells: LLC-MK2 clone 7.1

CellTiter 96 (Cytopathic effect/Toxicity). The primary screen is a cytopathic effect (CPE) reduction assay. Briefly, 96-well cultures of cells are infected with virus in the presence of test compounds and incubated for 4-7 days (depending on the specific virus/cells). Each virus is pre-titered such that control wells exhibit approximately $95 \%$ loss of cell viability due to virus replication. Therefore, antiviral effect, or cytoprotection, is observed when compounds prevent virus replication. Each assay plate contains cell control wells (cells only), virus control wells (cells plus virus), compound toxicity control wells (cells plus compound only), compound colorimetric control wells (compound only, no cells or virus), as well as experimental wells (compound plus cells plus virus). Cytoprotection and compound cytotoxicity are assessed by MTS (CellTiter®96 Reagent, Promega, Madison WI) dye reduction. The \% reduction in viral CPE (antiviral activity) and $\%$ cell viability (cytotoxicity) are determined and reported.

\section{Screening Assays for Respiratory syncytial virus and SARS CoV}


Principal Viruses and Cells:

Respiratory syncytial virus (RSV): Strain A-2 in Hep2 cells

SARS CoV: Strain Urbani in Vero76 cells

CellTiter-Glo (Cytopathic effect/Toxicity). The antiviral cytoprotection assays examine the effects of compounds at designated dose-response concentrations in specific cell types to test the efficacy of the compounds in preventing the virus-induced cytopathic effect. Ribavirin is included as a positive control drug for influenza and RSV, while calpain IV inhibitor is used for SARS antiviral assays. Subconfluent cultures of cells are plated into 96-well plates for the analysis of cell viability (cytotoxicity) and antiviral activity (CPE). For the standard assay, drugs are added to the cells 24 hours later. The CPE wells also received 100 tissue culture infectious doses (100 TCID 50 s) of titered virus. 72 hours later the cell viability will be determined. Measurement of viral-induced CPE is based on quantitation of ATP, an indicator of metabolically active cells. The CPE assay employs a commercially available CellTiter-Glo Luminescent Cell Viability Kit (Promega, Madison, WI), and is a reliable method for determining cytotoxicity and cell proliferation in culture. The procedure involves adding the single reagent (CellTiterGlo Reagent) directly to previously cultured, subconfluent cells in media. This induces cell lysis and the production of a bioluminescent signal (half-life greater than 5 hours, depending on the cell type) that is proportional to the amount of ATP present (which is a biomarker for viability).

\section{Transition}

The previous chapter described our first attempt to identify a host-oriented therapy using a similar yet disparate toxin screen method. Our findings identified Amodiaquine as a successful host protein inhibitor of Cathepsin B, necessary for authophagic flux. In addition, we showed that Amodiquine could act as a broadspectrum therapy for other pathogenic agents that utilize the same host protein, such as Ebola virus. However, we realized that we would need to optimize our methods in order to guarantee host-oriented drug hits. In the following chapter we describe multiplex drug screens that involved the simultaneous screens against three toxins (cellular toxin challenge) that cause an increase in caspases (signals leading to programmed cell death) as well as direct screens against caspases themselves (FRET). 


\title{
Chapter 4
}

Bithionol blocks pathogenicity of bacterial toxins, ricin, and Zika virus

William Leonardi, Leeor Zilbermintz, Luisa W. Cheng, Josue Zozaya, Sharon H. Tran, Jeffrey H. Elliott, Kseniya Polukhina, Robert Manasherob, Amy Li, Xiaoli Chi, Dima Gharaibeh, Tara Kenny, Rouzbeh Zamani, Veronica Soloveva, Andrew D. Haddow, Farooq Nasar, Sina Bavari, Michael C. Bassik, Stanley N. Cohen, Anastasia Levitin \& Mikhail Martchenko

\begin{abstract}
Diverse pathogenic agents often utilize overlapping host networks, and hub proteins within these networks represent attractive targets for broad-spectrum drugs. Using bacterial toxins, we describe a new approach for discovering broad-spectrum therapies capable of inhibiting host proteins that mediate multiple pathogenic pathways. This approach can be widely used, as it combines genetic-based target identification with cell survival-based and protein function-based multiplex drug screens, and concurrently discovers therapeutic compounds and their protein targets. Using B-lymphoblastoid cells derived from the HapMap Project cohort of persons of African, European, and Asian ancestry we identified host caspases as hub proteins that mediate the lethality of multiple pathogenic agents. We discovered that an approved drug, Bithionol, inhibits host caspases and also reduces the detrimental effects of anthrax lethal toxin, diphtheria toxin, cholera toxin, Pseudomonas aeruginosa exotoxin A, Botulinum neurotoxin, ricin, and Zika virus. Our study reveals the practicality of identifying host proteins that mediate multiple disease pathways and discovering broad-spectrum therapies that target these hub proteins.
\end{abstract}




\section{Introduction}

In recent years, a better understanding of protein interaction networks has led to the identification of highly connected hub proteins and pathways that are commonly used by a number of different pathogens and in a range of diseases [1]. These hubs represent promising targets for drug development.

Most disease networks have the "small-world" property, where proteins are only a few interactions away from any other proteins [2]. Therefore, inhibiting a given node can potentially affect the state of most nodes in its vicinity as well as the activity of the network itself. In this way, therapeutic inhibition of nodes and hubs within one disease network can affect other disease modules or pathways. Here we develop an approach to systematically identify broadspectrum drugs that target proteins exploited by multiple human disease pathways (Fig. 1a). Frequently, multiple infectious pathogens or toxins that negatively affect hosts by different mechanisms exploit the same host pathways [3]. This notion raises the prospect that multiplex approaches may lead to the discovery of broadly active and host-oriented infectious disease countermeasures that target host functions exploited by multiple pathogenic agents. We use genetics and a new drug screening methodology to identify and characterize the previously approved drug Bithionol as an inhibitor of host caspases, which reduces pathogenicity of a wide range of pathogenic agents, including ricin, anthrax lethal toxin, Botulinum neurotoxin A, diphtheria toxin, Pseudomonas aeruginosa exotoxin A, cholera toxin, and Zika virus. 
Figure 4.1: Inhibitors of hubs of human disease networks

a

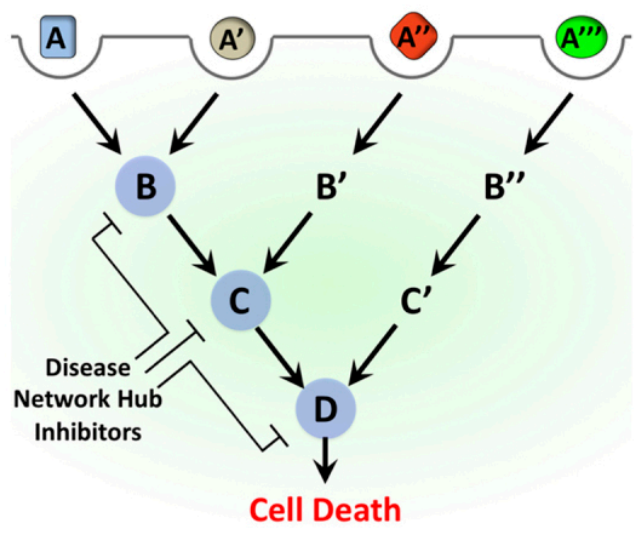

b

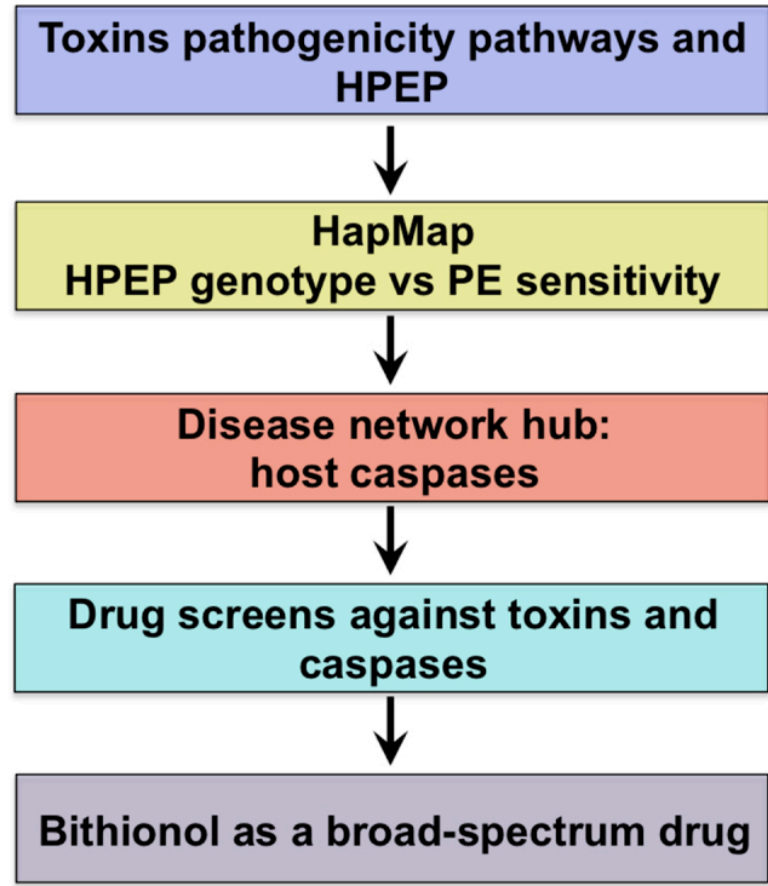

(a) Depiction of the concept where multiple pathogenic pathways overlap, and hub proteins (blue circles) mediate multiple disease pathways. This model proposes a drug screen design to look for compounds that simultaneously inhibit the function of the hub proteins and reduce cellular lethality caused by multiple pathogenic pathways. (b) A depiction of the design of the current study. The known host pathways and host proteins exploited by pathogens (HPEP) are considered. HapMap cell lines are used to study the association between cellular sensitivity to Pseudomonas aeruginosa exotoxin A (PE) and genetic mutations in genes coding for proteins exploited by PE. Mutations in host caspases are associated with altered sensitivity to PE, and these proteins are defined as disease network hubs, which will be used as targets for the following drug screens. This approach yields the broad-spectrum, host-oriented drug, Bithionol. 


\section{Results}

Identifcation of host hub proteins exploited by multiple pathogenic toxins.

Cytotoxic bacterial and plant toxins have evolved to exploit host proteins and cellular pathways that mediate the entry of those toxins into host cells and to induce cell-death. Although toxins exploit unique host pathways, these pathways are interconnected. While anthrax, diphtheria, and Botulinum toxins reach the cytoplasm from acidified endosomes, cholera, Pseudomonas aeruginosa and ricin toxins are transported into the cytoplasm through the host ER-associated degradation pathway [4]. These pathways interconnect at host "hub" proteins. Using one of those toxins, Pseudomonas aeruginosa exotoxin A (PE), we set out to identify such hub proteins by i) determining whether known genetic mutations in host proteins exploited by PE a affect the sensitivity of host cells to this toxin, and ii) investigating whether these host proteins are also exploited by additional pathogenic agents. The protein hubs will be used as targets in drug screens in order to discover broad-spectrum, host-oriented, anti-pathogenic agent drugs (Fig. 1b).

The effect of caspase mutations on the sensitivity of human B-cells to P. aeruginosa exotoxin A

It has previously been shown that PE exploits several host proteins for its binding to and entry into host cells [5] and initiates programmed cell death by inducing activities of host caspase-3, -6 , and -7 [6]. We investigated whether known mutations in host proteins exploited by PE associate with altered cytotoxicity of the toxin in cells from tissues that are naturally attacked by this toxin. The availability of human B-cells, which are physiological targets of PE [7] through the HapMap Project [8] has provided us with an opportunity to test whether mutations in host proteins that constitute the PE pathogenicity pathway affect the cellular sensitivity to this 
toxin. Our initial tests with cells from a few individuals revealed that their sensitivity to PE varies greatly. Remarkably, our further investigation of PE sensitivity of B-lymphoblastoid cells derived from 234 individuals in geographically and ethnically diverse human populations [87 Yoruba in Ibadan, Nigeria (YRI), 60 Utah residents with ancestry from northern and western Europe (CEU), 43 Japanese in Tokyo, Japan (JPT), and 44 Han Chinese in Beijing, China (CHB)] showed a prominent 200-fold difference in lethality to the toxin (Fig. 2a,b). The range in PE sensitivity, as measured by the dose required to kill $20 \%$ of the cells $[\log (1 / \mathrm{LD} 20)]$, was similar in all four human cell populations (Fig. 2c). Analysis of toxin sensitivity in parent/children trios indicated that relative sensitivity to PE is a heritable trait $(P$-value $<0.0001)$ (Fig. 2d). 
Figure 4.2: The effect of Bithionol on P. aeruginosa exotoxin A in human B-lymphoblastoid cells

a

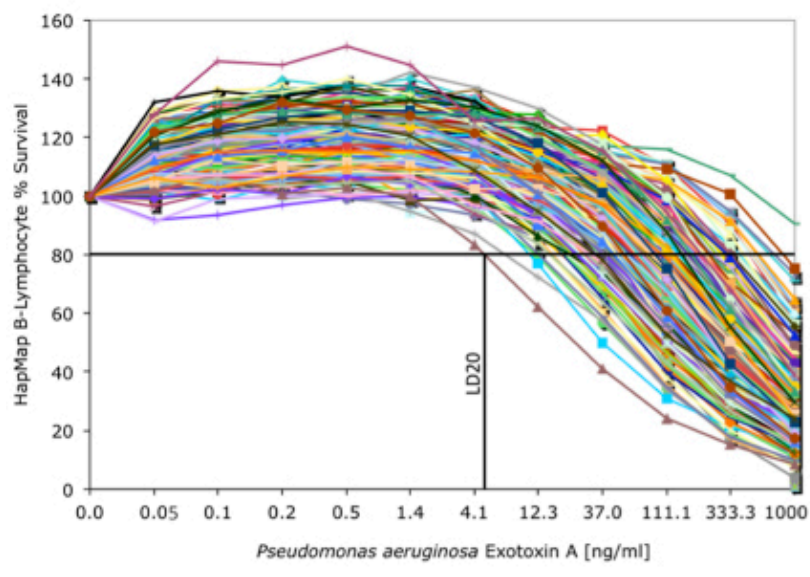

C

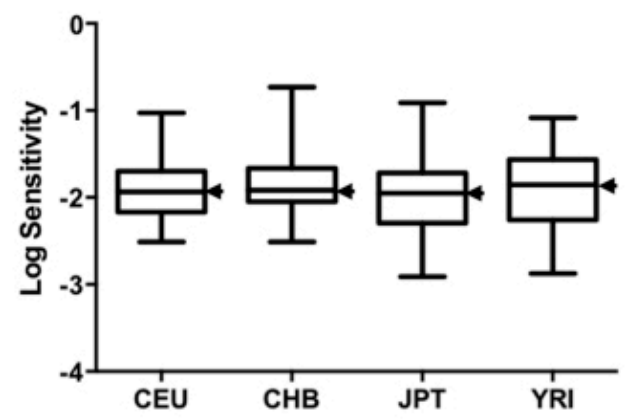

e

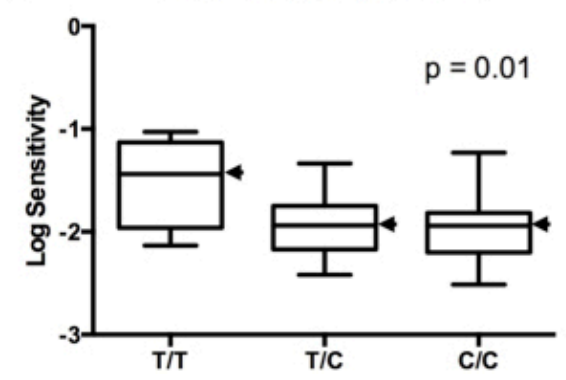

b

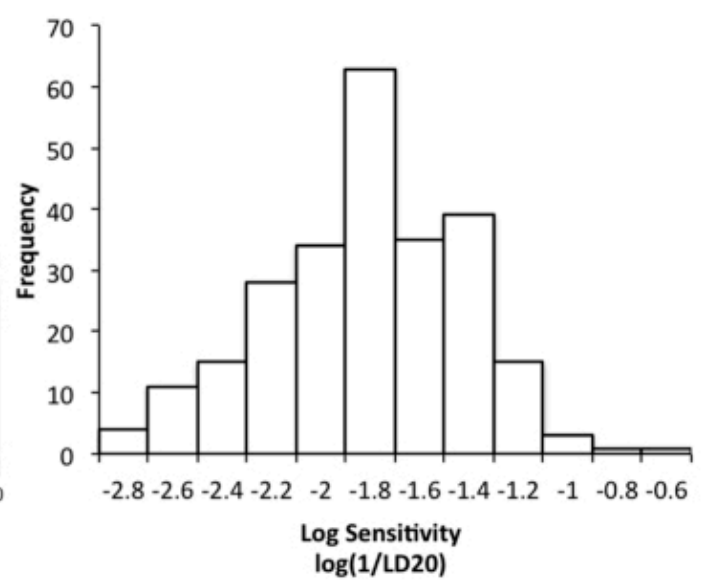

d

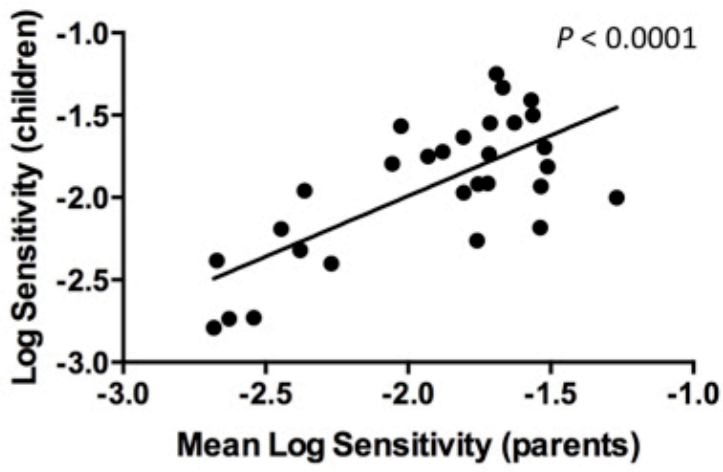

(a,b) Human lymphoblastoid cells sensitivity to P. aeruginosa exotoxin A (PE)-mediated toxicity. (a) 234 B-lymphocytes were treated with PE at concentrations shown. Cell viability was determined by Alamar Blue assay (Materials and Methods) and is shown as the percentage of survivors relative to cells treated with PE alone. The LD20 calculation for the most sensitive cell line is shown as an example. (b) LD20 values ( $\mathrm{ng} / \mathrm{ml}$ of PE) were calculated and expressed on an inverse $\log 10$ scale. For calculations, PE sensitivity is defined numerically as 1/LD20. (c) Population-specific distribution of toxins sensitivities. CEU, YRI, JPT, and CHB denote European, Yoruba, Japanese, and Chinese Han, respectively. One CHB outlier is excluded. For each population, the black bar represents the median log sensitivity; the box extends from the lower to the upper quartile and the whiskers extend to the most extreme data point. (d) Heritability of $\log$ sensitivity in Yoruba trios. Plot of the log toxin sensitivity of the children against the mean $\log$ toxin sensitivity of the parents. The heritability is estimated as the slope (0.74) of the 
regression of the children phenotype on the midparent phenotype. (e) In CEU caspase-7 SNP rs3814231 associates with log PE sensitivity.

The widespread and unimodal distribution observed for $\log (1 / \mathrm{LD} 20)$ (Fig. 2b) is likely a result of a polygenic inheritance model, consistent with evidence that multiple host proteins mediate PE lethality $[5,6]$. To learn whether genetic variations in the genes encoding for these proteins account for any of the variation in sensitivity of B-cells to PE seen in Fig. 2a, we tested the association of numerous previously reported mutations with PE sensitivity. Caspase-7 and -3 mutations that were previously reported to associate with cancer and rheumatoid arthritis $[9,10,11,12,13]$ demonstrated a significant association with PE sensitivity in the individual HapMap populations (CASP7, rs3814231, CEU, $P=0.01$; CASP7, rs2227309, CEU, $P=0.02$; CASP3, rs4647601, rs4647693, and rs1049216, East Asian populations CHB and JPT combined, $P=0.04$ for each SNP) (Figs 2e and S1). These results show that the activity of caspases affects host cell sensitivity to toxins, and that these proteins are potential therapeutic intervention points and targets for the following drug screens. In addition to PE, ricin and toxins of anthrax, diphtheria, Botulinum, and cholera induce programmed cellular death by activating host caspases $[6,14,15,16,17,18,19,20]$ (Fig. 3a). Therefore, a drug screen against hub caspases is of great interest, as these proteins are exploited by multiple pathogenic pathways, and caspase inhibitors can act as broad-spectrum drugs. 
Figure 4.3: The use of the Clinical Compound Library (CCL) to screen for inhibitors of hubs of human disease networks
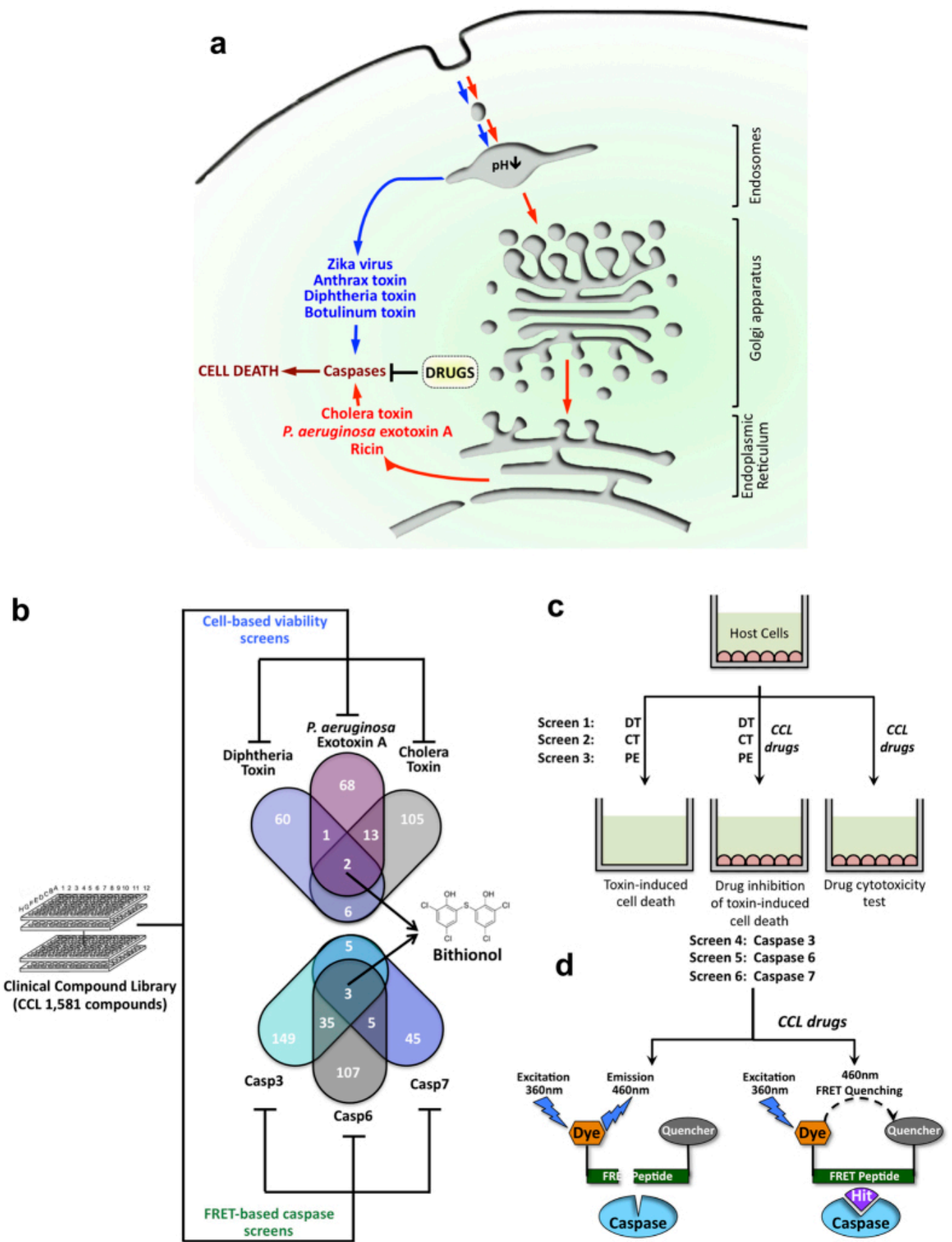

(a) Depiction of toxins as well as their pathways that induce caspase-mediated cell death. These toxins enter into host cytoplasm either from acidified endosomes or endoplasmic reticulum. Broad-spectrum anti-toxin drugs are screened to identify inhibitors of host caspases. (b) Overall approach scheme: CCL is screened by a multiplex approach that incorporates biochemical FRET and cell survival assays looking for drugs capable of simultaneously inhibiting host caspases-3/6/7 and reducing cytotoxicities of three bacterial toxins. The output of this approach is the discovery of broad-spectrum and host-oriented drug, Bithionol. (c) Schematic diagram of cellular screens to identify drugs that reduce cellular lethality induced by diphtheria toxin, Pseudomonas aeruginosa exotoxin A, and cholera toxin. Numbers are the distribution of inhibitors obtained in all screens. (d) Schematic diagram of parallel FRET screens to identify drugs that inhibit proteolytic reaction of caspases-3, -6 , and -7 . 
A multiplexed cellular screen for CCL drugs that inhibit cytotoxic activities of bacterial toxins exploiting unique but interconnected host pathways

In an effort to identify existing drugs that might be repurposed as novel, host-oriented, broad-spectrum therapies, we screened a Clinical Compound Library (CCL)21 through multiplex-based drug screening (Fig. 3b). We searched for compounds capable of both (i) reducing cytotoxicities of diphtheria toxin, cholera toxin, and PE, and (ii) inhibiting proteolytic activities of host caspases-3, -6, and -7 exploited by these toxins in biochemical assays (Fig. 3bd). In principle, a combination of biochemical and cellular drug screens could provide drug hits that reduce toxins' cytotoxicities by inhibiting host caspases, and thus, this approach could simultaneously provide drug candidates and their protein targets.

We screened members of the CCL for the ability to reduce cell death of host RAW264.7 and C32 cells treated with PE, cholera toxin, or diphtheria toxin (Fig. 3c). At the indicated doses, between 30 and 50 percent of RAW264.7 cells undergo cell death within 12 hours for Pseudomonas and cholera toxins. For C32 cells, similar cell death was observed at 24 hours of exposure to diphtheria toxin under the experimental conditions employed. A "hit" in our screen was defined as an event where cells exposed to a drug increased cell survival by at least 20 standard deviations ( $\sim 1 \%$ hit rate) above the survival of control cells treated with either toxin, and is not cytotoxic to cells in the absence of toxins. Events defined as "multiplex hits" interfered with cell killing by at least two toxins. The two multiplex hits that were identified as capable of reducing the cytotoxicities of all three toxins were Bithionol and Pyrogallol (Fig. 3b). 
A multiplex protein function-based screen for CCL drugs that inhibit proteolytic activities of host caspase-3, -6 , and -7

In parallel experiments, we screened the CCL for drugs that could inhibit the function of hub caspases-3, -6 , and -7 (Fig. 3d) that mediate cytotoxicity caused by bacterial toxins used in our multiplex cellular drug screens (Fig. 3b). Caspase activities were induced in RAW264.7 cells by PE treatment. To screen and identify drugs that inhibit proteolytic activities of caspases we utilized a fluorescence-based FRET assay. Optimized substrate peptides for caspase-3, -6, and 3/7 proteolytic activities were used with a fluorogenic 7-amino-4-methylcoumarin group at the $\mathrm{N}$-terminus and acetyl quenching group at the C-terminus. As a FRET substrate that is uniquely cleaved by caspase- 7 hasn't been identified, and since caspases-3 and -7 are close orthologues, we searched for caspase-7 inhibitors that could block proteolysis of a caspase-3/7 - specific substrate and not caspase-3 - specific substrate. After cleavage by caspase the fluorescence of AMC at $460 \mathrm{~nm}$ increases, while inhibitors of caspases prevent it. Compounds that showed greater than $80 \%$ ( $\sim 1 \%$ hit rate) inhibition were defined as hits and selected for re-validation and further studies. Events defined as "multiplex hits" interfered with proteolytic activities of at least two caspases. Bithionol was one of the three multiplex hits identified as capable of prominently reducing the proteolysis of all three caspase substrates (Figs $3 b$ and $4 a-c$ ). Since Bithionol was identified by both cellular and biochemical multiplex screens (Fig. 3b), we further investigated the efficacy of Bithionol and the breadth of its potential as a host-oriented, anti-pathogenic agent. 
Figure 4.4: Bithionol reduces pathogenicity of toxins by inhibiting host caspases
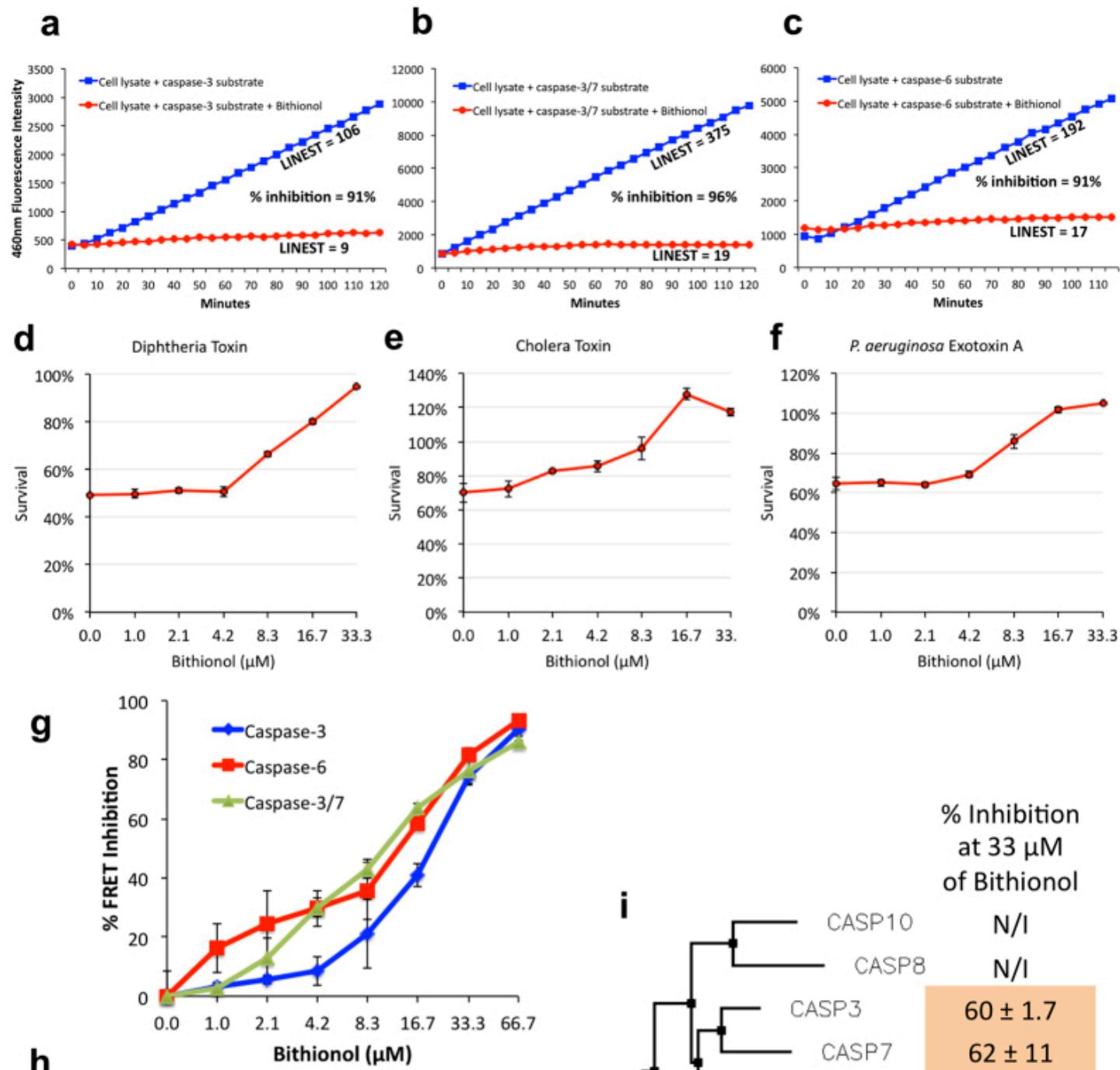

h
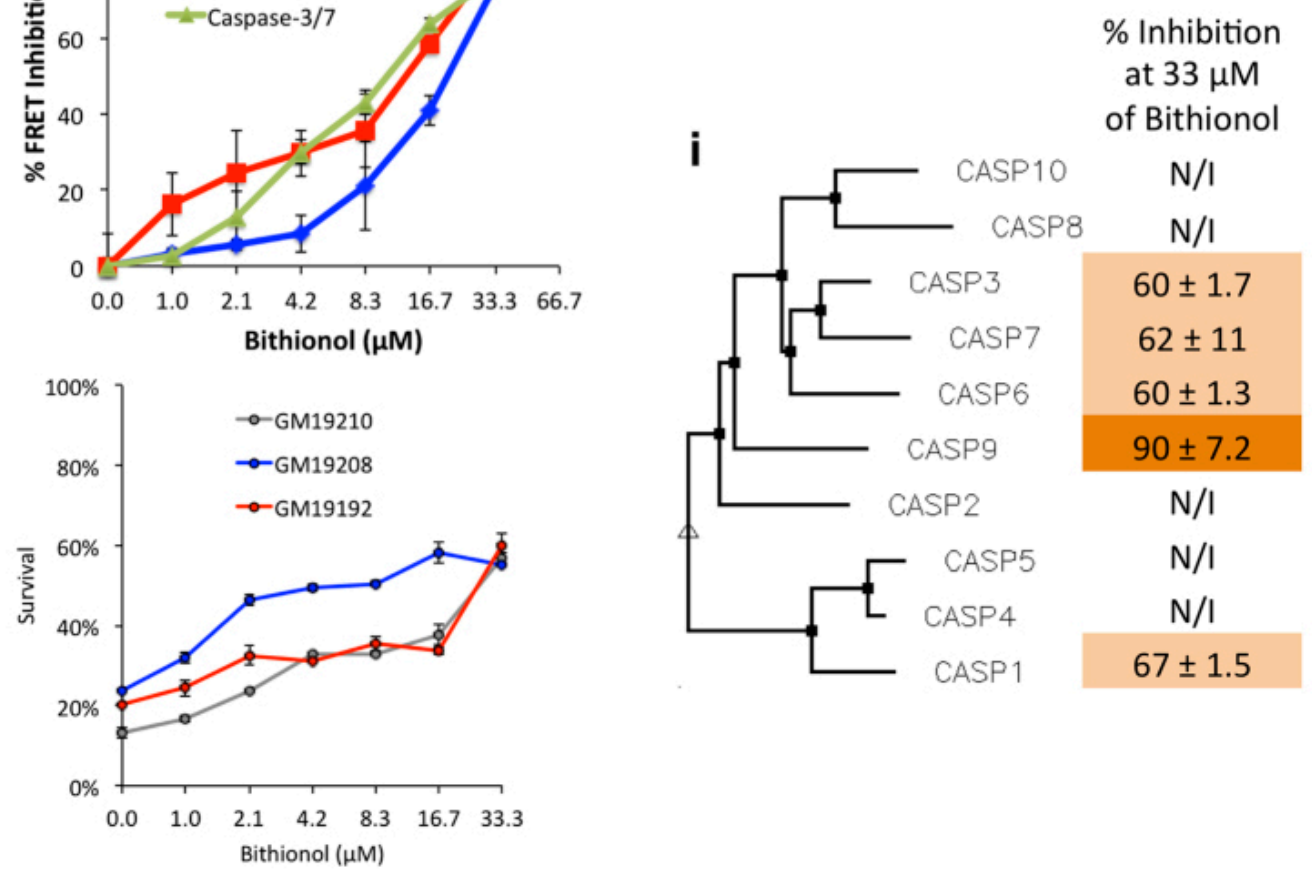

(a-c) Bithionol inhibits caspases. FRET data showing fluorescence emission from two reactions, where caspase-containing cellular lysate cleaves fluorescently labeled substrate peptide without drugs, or in the presence of $33 \mu \mathrm{M}$ Bithionol. FRET substrates were specific for cleavage by caspase-3 (a), caspase-3/7 (b), and caspase-6 (c). (d-f) Bithionol was tested for its ability to inhibit cytotoxicities mediated by toxins of cholera, diphtheria, and Pseudomonas. RAW264.7 cells were incubated with indicated doses of Bithionol for 1 hour, followed by 12 hours intoxication with Pseudomonas and cholera toxins. Diphtheria toxin was added to C32 cells for 24 hours. Cell viability was determined by MTT assay and is shown as the percentage of survivors 
relative to cells not treated with drugs. (g) Different concentrations of Bithionol are tested for their ability to inhibit caspase activity in cellular lysate of cells. Cells were pre-treated with Pseudomonas aeruginosa exotoxin A to induce caspases. FRET was done using substrates cleaved by caspases-3, -6 , and $-3 / 7$. (i) Bithionol inhibits cytotoxicity mediated by $P$. aeruginosa exotoxin A in sensitive human B-lymphocytes. B-cells were seeded at $1 \times 104$ cells/well on 96-well plates and were incubated with indicated doses of Bithionol for 1 hour, and then challenged with the toxin for 6 hours. Cell viability was determined by Alamar Blue assay and is shown as the percentage of survivors relative to cells not treated with drugs. (i) Bithionol inhibits caspases-1, $-3,-6,-7$, and -9 . Bithionol was tested at $33 \mu \mathrm{M}$ for its ability to inhibit FRET reactions of purified human caspases-1 through 10. Percent inhibition values are shown, and compared to activity of caspases untreated with Bithionol. Phenogram of ten human caspases, assembled by Multalin using Dayhoff alignment parameters, is used to demonstrate relative homology of caspases.

Bithionol reduces the pathogenicity of a range of toxins by inhibiting host caspases

To investigate the potency of Bithionol, we first performed drug titration curves in host RAW264.7 and C32 cells. We demonstrated that Bithionol was able to reduce diphtheria, cholera, and Pseudomonas toxins-mediated cytotoxicities with an EC50 of $10 \mu \mathrm{M}$ (Fig. 4d-f). We tested the effect of different concentrations of Bithionol for the ability to inhibit the proteolytic cleavage of substrates specific for cellular caspases-3, 6, and 3/7. We observed a linear dose-dependent caspase-inhibitory efficacy of Bithionol, with an IC50 of 21, 13, and $11 \mu \mathrm{M}$ for caspases-3, -6 , and $-3 / 7$, respectively (Fig. $4 \mathrm{~g}$ ). These results are consistent with antitoxins EC50's of Bithionol in cellular tests (Fig. 4d-f).

We also tested whether Bithionol reduces cellular sensitivity to PE in randomly selected PE-sensitive HapMap cells. We observed that the drug protected three cell lines treated with amounts of PE that are sufficient to kill $80 \%$ of cells (Fig. 4h). These results confirm the antitoxin potential of Bithionol in host cells.

Humans have 10 well-characterized caspases that collectively form a pathway, often referred to as "the caspase cascade", where caspases-3, -6 , and -7 are the executioners of cell death and are activated by other caspases [22]. We tested the ability of Bithionol to inhibit activities of ten purified recombinant human caspase proteins, and we demonstrated that in addition to caspases-3, -6 , and -7 , Bithionol inhibited activities of caspases-1 and -9 , while 
having no inhibitory effects on other caspases (Fig. 4i). Together, these results demonstrate that Bithionol is a direct inhibitor of a select subset of caspases, and that it reduces cellular sensitivity to toxins by targeting at least five host caspases.

Bithionol inhibits cytotoxic activity of anthrax toxins

Anthrax toxins, the major virulence factors of the Bacillus anthracis bacterium, include an exotoxin protein complex consisting of a protective antigen (PA) and lethal factor (LF) that act collectively to damage host cells. PA binds to cellular receptors, while LF acts as a protease cleaving cytoplasmic MAPKKs [23]. Three additional host proteases mediate entry and lethality of anthrax toxin: furin, cathepsin-B, and caspase-1 $[14,23,24]$.

To test the ability of Bithionol to neutralize cytotoxic activity of anthrax toxin, we examined its effect on cell viability in LF-PA - treated RAW264.7 cells. While $80 \%$ of cells used for these assays normally undergo cell death within 6 hours of exposure to anthrax toxin, Bithionol provided substantial protection against LF-PA - mediated cell killing at $33 \mu \mathrm{M}$ (Fig. $5 a)$. 
Figure 4.5: Bithionol inhibits anthrax toxin lethality
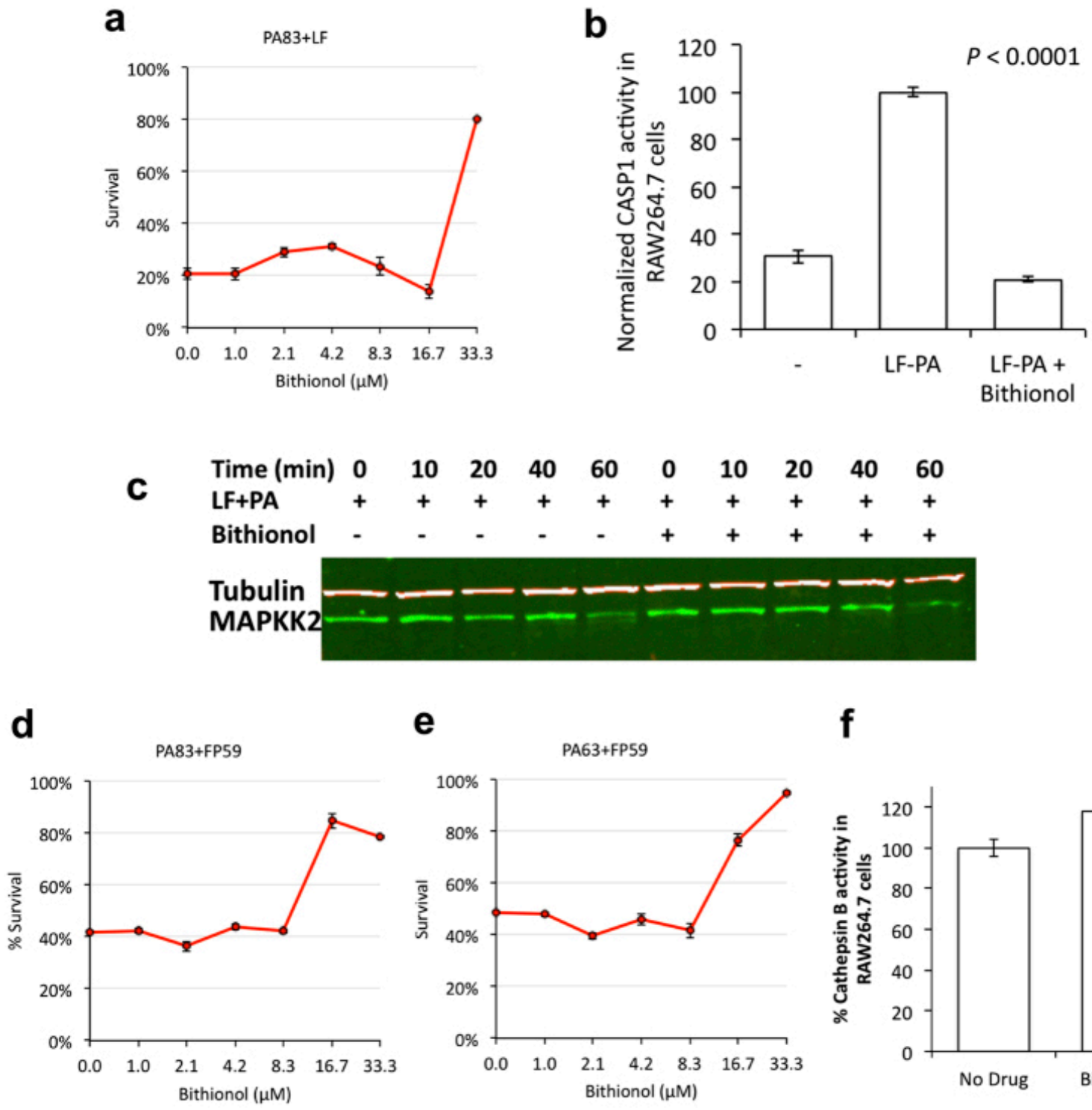

e
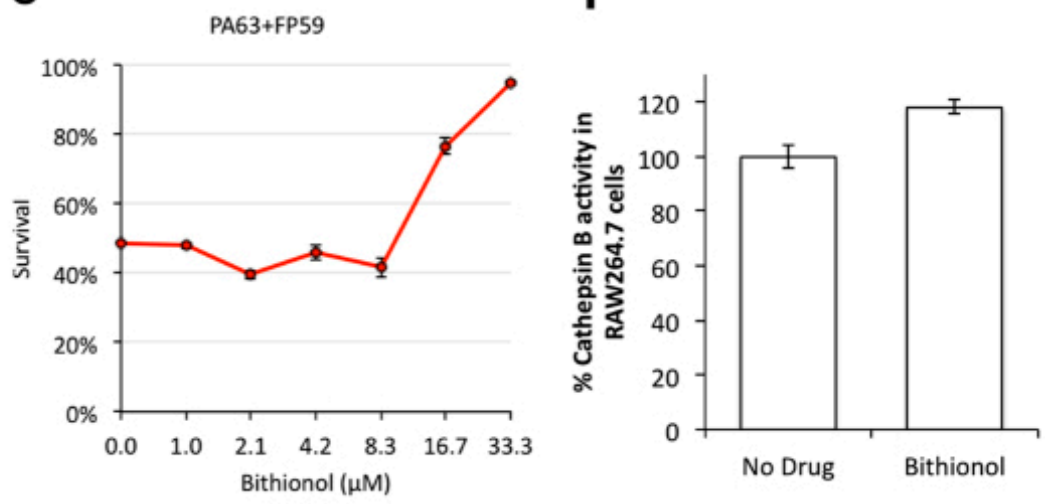

(a) Bithionol was tested for its ability to inhibit anthrax toxin-mediated cytotoxicity. RAW264.7 cells were incubated with the indicated doses of Bithionol for 1 hour, followed by 6 hours intoxication with anthrax toxin PA-LF. Cell viability was determined by MTT assay and is shown as the percentage of survivors relative to cells not treated with drugs. (b) Bithionol inhibits LF-PAinduced activity of cellular caspase-1. RAW264.7 cells were treated with LF-PA for 1 hour, and then treated either with $33 \mu \mathrm{M}$ Bithionol or DMSO for 1 hour prior to lysis and determination of caspase-1 activity. The activity of caspase-1 was measured by FRET assay. (c) MAPKK2 immunoblotting showing that Bithionol does not block proteolysis of cellular MAPKKs by anthrax LF toxin. While MAPKK2 was cleaved in LF-PA treated RAW264.7 cells, treatment with Bithionol did not affect this process. RAW264.7 cells were incubated with Bithionol or DMSO for 1 hour before addition of vehicle control or $1 \mu \mathrm{g} / \mathrm{ml} \mathrm{PA}+\mathrm{LF}$ for up to 60 minutes. Cells were lysed and analyzed via immunoblotting with a MAPKK2-specific antibody. Tubulin was used as a loading control. (d,e) Bithionol reduces cell death induced by the hybrid toxin FP59, which has been widely used as an anthrax LF surrogate and contains the PA binding site of LF, as well as a toxin domain derived from PE. Bithionol-treated cells were found to be less sensitive to treatment with PA + FP59. PA was either in the native $83 \mathrm{kDa}$ form (d), or used as $63 \mathrm{kDa}-$ lacking $20 \mathrm{kDa}$ Furin cleavage domain (e). RAW264.7 cells were preincubated with a titration of Bithionol for 1 hour, followed by a 6 hours intoxication with $0.5 \mu \mathrm{g} / \mathrm{ml} 83 \mathrm{kDa}$ PA + FP59 or Furin processed $63 \mathrm{kDa}$ PA + FP59. Cell viability was measured via MTT. (f) Bithionol doesn't inhibit cathepsin B protease activity in RAW264.7 cells. RAW264.7 cells were treated with $33 \mu \mathrm{M}$ Bithionol of DMSO for 1 hour prior to lysis, and determination of cathepsin B activity was assessed by FRET assay. 
Caspase-1 activation, which occurs in LF-PA intoxication, was monitored using a FRET assay. While we observed an induction of caspase-1 activity upon LF-PA treatment in the absence of Bithionol, caspase-1 induction was not detected in Bithionol-treated cells challenged with anthrax toxin (Fig. 5b). This result confirms that Bithionol inhibits anthrax toxin cytotoxicity by at least inhibiting caspase-1 activity.

We investigated whether additional anthrax toxin pathway proteases are inhibited by Bithionol in live cells. By utilizing MAPKK immunobloting (Fig. 5c), a hybrid toxin FP59 [25] that enters host cells by utilizing PA, but kills cells by LF-independent mechanism (Fig. 5d,e), and cathepsin-B FRET assay (Fig. 5f), we demonstrated that Bithionol does not inhibit proteolytic activities of cellular LF, furin, and cathepsin-B.

Bithionol inhibits ricin and Botulinum neurotoxin $A$ - induced death in vitro and in vivo

Ricin is another toxin known to induce host caspases-3, -6 , and $-7[15,20]$. It reaches the mammalian cytoplasm through the retrograde transport route from the plasma membrane to ER via endosomes and the Golgi apparatus (Fig. 3a). Once in the cytoplasm, ricin inhibits cellular protein synthesis by cleaving a glycosidic bond within the large rRNA of the 60S subunit of eukaryotic ribosomes [4]. We tested the ability of Bithionol to reduce ricin - mediated cellular killing and observed that the drug was able to reduce toxin-mediated cytotoxicity with an EC50 of $10 \mu \mathrm{M}$ (Fig. 6a). 
Figure 4.6: Bitionol and other pathogenic agents

a

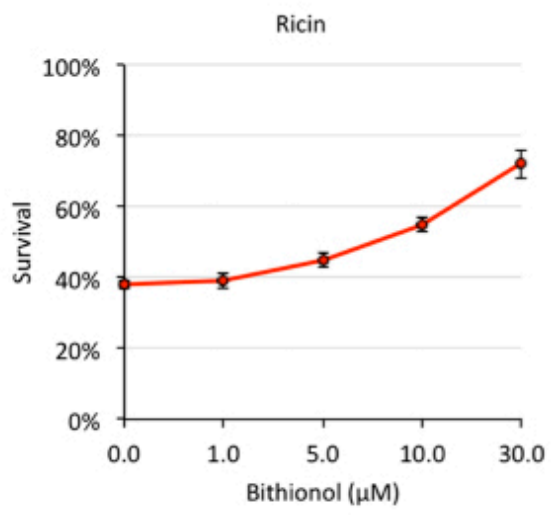

C

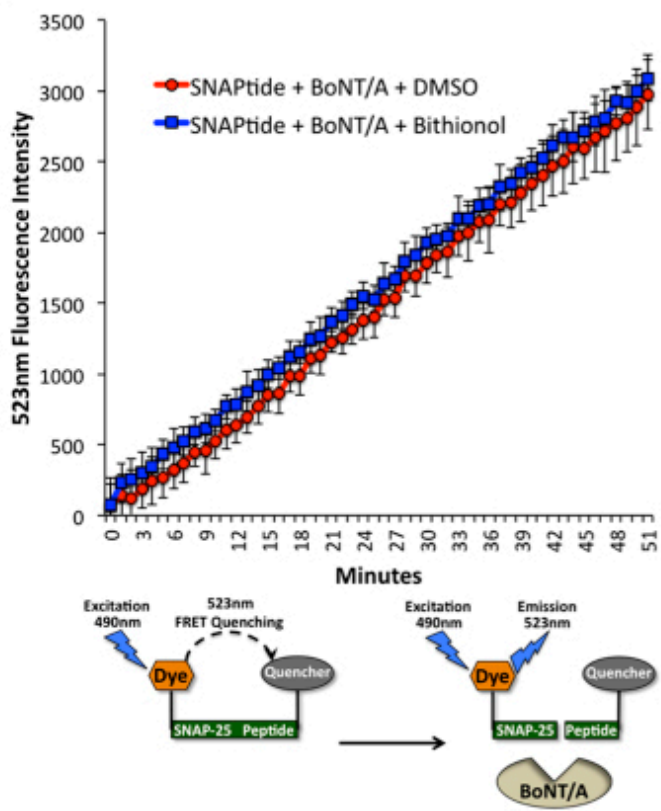

b

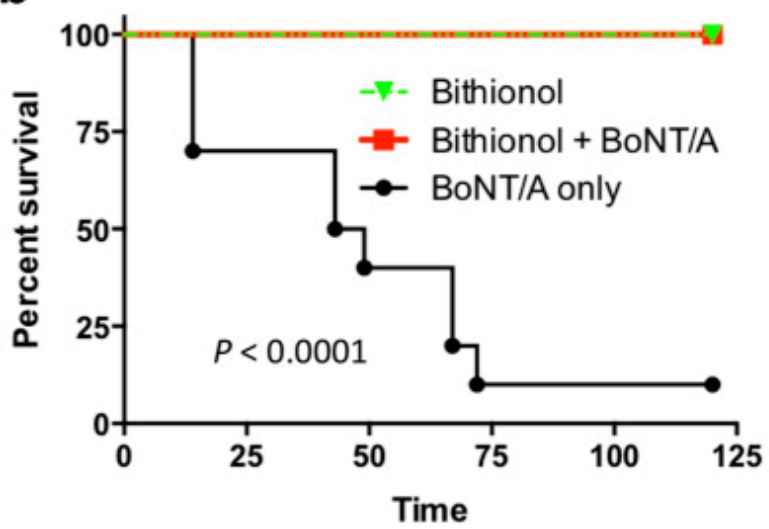

(a) Bithionol reduces ricin mediated cellular killing. Human K562 cells were incubated with indicated doses of Bithionol for 2 hours, and then challenged with ricin for 24 hours. Cell viability was determined by FSC/SSC flow cytometry. (b) Ten Swiss Webster CFW mice were treated with $6 \mathrm{mg} / \mathrm{kg}$ Bithionol in the presence or absence of botulinum neurotoxin serotype A complex (BoNT/A) by oral gavage. Animals were observed over 7 days. The Bithionol and BoNT/A survival curves are statistically different based on the Log-rank (Mantel-Cox) test, $\mathrm{P}<0.0001$. (c) Bithionol does not inhibit proteolytic activity of BoNT/A. FRET data showing fluorescence emission from two reactions, where $5 \mathrm{nM}$ BoNT/A light chain cleaves fluorescently labeled SNAP-25 substrate peptide without drugs or in the presence of $33 \mu \mathrm{M}$ Bithionol. (d) The ability of Bithionol to inhibit Zika virus (ZIKV) in host Vero E6 cells and astrocytes was measured by fluorescent microscopy. The virus-inhibitory EC50 concentrations were determined.

Botulinum neurotoxin serotype A (BoNT/A) is a protease that translocates into the host cytoplasm from acidic endosomes, where it cleaves the synaptosome-associated protein, SNAP25, and inhibits neurotransmitter release among neurons, leading to muscular paralysis [26]. 
BoNT/A has been reported to cause cellular caspases-3 and -7 - dependent apoptosis [16].

After oral administration, Bithionol crosses the intestinal epithelium and is absorbed into the bloodstream in humans and many animals [27]. We evaluated the efficacy of Bithionol as a therapeutic agent during BoNT/A intoxication in Swiss Webster mice. Animals were given a lethal oral dose of BoNT/A complex in the presence and absence of Bithionol. Ninety percent of animals that received a lethal dose of BoNT/A without Bithionol died within 3 days of intoxication (Fig. 6b). All mice that were challenged with BoNT/A and treated with Bithionol at $6.0 \mathrm{mg} / \mathrm{kg}$, survived without displaying toxin-associated symptoms, such as wasp waist and paralysis (Fig. 6b).

Since BoNT/A acts as a protease, we investigated whether Bithionol directly inhibits the proteolytic activity of BoNT/A by utilizing a FRET assay. An optimized SNAP-25 peptide with a fluorogenic FITC group at the $\mathrm{N}$-terminus and DABCYL quenching group at the C-terminus was used as the substrate [28]. After cleavage by BoNT/A the fluorescence of FITC at $523 \mathrm{~nm}$ increases. We determined that Bithionol did not affect the proteolysis rate of the fluorescent substrate (Fig. 6c). This result shows that Bithionol protects mice by inhibiting host targets, rather than by inhibiting the toxin itself.

\section{Bithionol acts as a Zika virus inhibitor}

In addition to pathogenic toxins, viruses are also known to propagate by activating host caspases and inducing programmed cell death [29]. Similarly to toxins, Zika virus (ZIKV) has been reported to lead to cell-death by inducing host caspase-3 and neuronal apoptosis during its propagation [30,31]. Moreover, caspases have previously been reported to cleave various viral proteins, affect viral protein localization, promote viral genome replication and viral assembly, 
and have been reported to be necessary for viral replication and propagation $[32,33]$.

Upon observing that Bithionol protects cells from caspase-inducing toxins, we hypothesized that Bithionol might also be able to inhibit the pathogenicity of the Zika virus. The strains utilized in this study were chosen to gauge the ability of Bithionol to inhibit Zika virus strains found within both ZIKV lineages. Both strains utilized in this study had low passage histories and had intact glycosylation sites. Furthermore, both strains were geographically and genetically divergent. Puerto Rico Zika strain, PRVABC59, is closely related to virus strains circulating in the New World including those strains isolated in Brazil and Guatemala. The African ZIKV lineage is ancestral to the Asian lineage; as such Senegal strain, DAK AR D 41525, was selected as it is a low passage strain that is mycoplasma free. We tested Bithionol's ability to inhibit Senegal and Puerto Rico isolates of ZIKV in infected Vero E6 cells and human astrocytes. To detect infected cells, immuno-staining was performed using anti-Flavi-virus envelope protein antibodies. Bithionol inhibited the abundance of Puerto Rico ZIKV in Vero E6 cells with an EC50 of $6.7 \mu \mathrm{M}$ as well as Senegal ZIKV in Vero E6 and human astrocytes with EC50's of 5.5 and $6.3 \mu \mathrm{M}$ respectively (Fig. 6d and Table S1). These data indicate that Bithionol is effective in inhibiting ZIKV in host cells.

\section{Discussion}

In order to discover the inhibitors of pathway hubs that mediate the lethality of multiple bacterial toxins, we identified host caspases as hubs and focused the discovery process on therapies that are able to inhibit caspases and reduce toxins' cytotoxicities. Collectively, utilization of both cellular- and biochemical-based multiplex drug screens provided us with i) a drug hit (Bithionol), ii) a drug-target (caspases), and iii) an assessment of breadth of spectra of 
the drug. This disease-network-based approach utilizing two diverse multiplex drug screenings, which we term "Disparate Dual Multiplexing", could significantly shorten the time needed for drug-discovery followed by target-identification steps in a historically lengthy process. In the future, additional types of drug screens could be included in disparate multiplex-based drug screens, such as genetic-based, and immunology-based screens, thus expanding our approach to Disparate Triple, Disparate Quadruple (etc.) Multiplex drug screening.

Bithionol was previously approved to treat helminthes, and although the exact target within these species is not known, it is believed that the drug inhibits oxidative phosphorylation of parasites [34]. Our study has uncovered five additional Bithionol targets: caspases-1, -3, -6, 7, and -9 , which by definition makes Bithionol a polypharmacological drug. Polypharmacological phenomena include a single drug acting on multiple targets of either a unique or multiple disease pathways. Just like in the current study, many of the polypharmacological approaches aim to discover the unknown off targets for existing drugs, and this approach is called "drug repurposing" [3,35]. Therefore, this raises the possibility that Bithionol targets additional non-caspase host proteins exploited by toxins. To our knowledge, no other drugs used in humans have been reported to inhibit caspases. In the future, Bithionol can be investigated for its efficacy to treat other non-infectious human diseases caused by detrimental activities of caspases, such as neurodegenerative diseases and inflammatory bowel disease.

Bithionol was replaced by the more effective anti-helminthic, Praziquantel [34]. Moreover, Bithionol was used as a bacteriostatic additive in cosmetic products, but was discontinued in 1967 due to photosensitizing effects [27]. Presently, Bithionol is still used to treat helminthic cases in some Asian and European countries and is included as an active 
ingredient in Fonergine ${ }^{\circledR}$, used to treat mouth and throat disorders in Argentina [36]. The current drug discovery and development process can take many years for the successful introduction of a new drug into the market. Thus, the current de novo drug discovery and development paradigm is ineffective for dealing with rapidly emerging biological threat agents. Under such circumstances, drug repurposing may offer numerous advantages. Since Bithionol already has a well-established safety and pharmacokinetic profiles in patients and animals, as well as bulk manufacturing methods [27], the drug could rapidly be made available for a new indication if a biological emergency was to occur. Most notably, it has been shown that after oral administration of $50 \mathrm{mg} / \mathrm{kg}$ of Bithionol in humans, the drug reaches serum concentrations that range from 225 to $480 \mu \mathrm{M}$ [27], which is on average 30 times higher than the EC50 achieved by our cellular tests (Figs 4,5, and 6). This suggests that it is possible to achieve effective anti-toxin and anti-Zika Bithionol doses in blood by oral administration. In addition, Bithionol was i) used to treat cerebral paragonimiasis [37] and is known to cross the brain-blood barrier [38]; ii) reported to cross the placental barrier [39]; and iii) was used to treat paragonimiasis in a population that included children and pregnant women [40]. All of these observations suggest that Bithionol is likely to achieve anti-Zika efficacy in humans.

\section{Methods}

Chemicals and reagents

All bacterial toxins were purchased from List Biological Laboratories (Campbell, CA). FP59 was a gift from Stephen Leppla (NIAID). Ricin was purchased from Vector Laboratories. Clinical Compound Library (CCL) drug library was purchased from Johns Hopkins University Bloomberg School of Public Health. Bithionol was repurchased from Sigma-Aldrich. 


\section{Cell culture and cell lines}

RAW264.7 mouse macrophage and human C32 melanoma cells (ATCC CRL-1585) were maintained in DMEM (Sigma-Aldrich). Human B-lymphocytes were grown in IMDM (Invitrogen). Human K562 chronic myelogenous leukemia cells (ATCC CCL-243) were grown in RPMI 1640 Medium (Invitrogen). Vero E6 (ATCC CRL-1586) were maintained in MEM (Corning). Primary human Astrocytes (NHA-Astrocytes-AGM, Lonza, \#CC-2565) were cultured in Astrocyte Basal Medium (Clonetics ABM, Lonza) supplemented with AGM SingleQuot Kit Supplement and Growth factors (CC-4123). All media were supplemented with FBS, penicillin, and streptomycin.

\section{Human B-lymphocytes sensitivity to Pseudomonas toxin-mediated lethality}

Human B lymphocytes were treated with serial dilutions of $P$. aeruginosa exotoxin A for 48 hours. The viability of B cells was determined by Alamar Blue (AbD Serotec, BioRad) fluorescence, as described by the manufacturer. Each data point shown in Fig. 2a represents the average and SD of results from three wells. Cell viability is shown as the percentage of survivors obtained relative to cells in the absence of the toxin (100\% survival). LD20 was calculated for each cell line. Statistical analysis and graphical presentation were performed using GraphPad Prism software. A $P$ value $<0.05$ was considered statistically significant. Homozygous medians were compared by an unpaired t test. CHB and JPT, two East Asian populations, were pooled in order to obtain a more accurate estimate of effect size in the larger combined population. Because linear regression is sensitive to outliers, we removed one outlier in $\mathrm{CHB}$, as the $\log$ sensitivity of this cell line couldn't be determined within the toxin range tested. 


\section{Cellular drug screens}

RAW264.7 cells $(10,000$ per well) were seeded in 96-well plates 24 hours before the assay. Cells were treated with compounds for 1 hour, and then challenged with either $2 \mu \mathrm{g} / \mathrm{ml} \mathrm{PE}$ or $4 \mu \mathrm{g} / \mathrm{ml}$ cholera toxin for 12 hours. As rodent cells are insensitive to diphtheria toxin, C32 cells were treated with $2 \mu \mathrm{g} / \mathrm{ml}$ of diphtheria toxins for 24 hours. Determination of RAW264.7 and C32 viability was performed by MTT assay. Cell viability is defined as the percentage of surviving cells obtained relative to cells treated with DMSO (100\% survival).

\section{Caspases FRET drug tests}

Caspases were induced in RAW264.7 by treating cells with $2 \mu \mathrm{g} / \mathrm{ml}$ of PE for 4 hours. Caspases were extracted and their activity was measured using Caspase Assay Kit (SigmaAldrich) with or without drugs.

The FRET reaction was performed in 96 well plates, and each reaction contained $16 \mu \mathrm{M}$ substrate peptides (Peptides International) conjugated with a 7-amino-4-methylcoumarin group at the $\mathrm{N}$-terminus and acetyl group at the $\mathrm{C}$-terminus. The amino acid sequences of substrates were: DNLD for caspase-3, DQTD for caspases-3 and -7, and VEID for caspase-6. CCL compounds were tested at the final concentration of $33 \mu \mathrm{M}$, as pilot testing indicated that $\mathrm{CCL}$ screen at $16 \mu \mathrm{M}$ would not yield a sufficient number of multiplex hits. Reactions were initiated by adding caspase - containing lysate to a final concentration of $6 \mu \mathrm{g} / \mathrm{ml}$. Kinetic measurements were obtained at $37^{\circ} \mathrm{C}$ every 5 minutes for 2 hours using a fluorescent plate reader. Excitation and emission wavelengths were $360 \mathrm{~nm}$ and $460 \mathrm{~nm}$, respectively, with a cutoff wavelength of $365 \mathrm{~nm}$. Rates of reactions were quantified by the Microsoft Excel LINEST function. A BioVision kit was used to test Bithionol's ability to inhibit FRET reactions of purified 
recombinant human caspases-1 through 10. One unit of caspase was used in a single FRET reaction.

\section{Toxins treatments and cell viability assays}

Cells $(10,000$ per well) were seeded in 96-well plates 24 hours before the assay. Cells were treated with Bithionol for 1 hour. RAW264.7 cells were challenged with anthrax toxins that include LF or FP59 and PA83 or PA63 (for 6 hours), PE (for 12 hours), or cholera toxin (for 12 hours) at $0.5,2$, and $4 \mu \mathrm{g} / \mathrm{ml}$ respectively. C32 cells were treated with $2 \mu \mathrm{g} / \mathrm{ml}$ of diphtheria toxin for 24 hours. Determination of cells viability was performed by MTT assay. Blymphocytes cells were seeded in a 96-well plates at 10,000 cells/well 1 hour before toxin treatment, treated with Bithionol for 1 hour, and then challenged with $8 \mu \mathrm{g} / \mathrm{ml}$ PE for 6 hours. Determination of lymphocyte viability was determined by Alamar Blue (AbD Serotec, BioRad) fluorescence, as described by the manufacturer. Each data point shown for MTT and Alamar Blue assays indicates the mean $\pm \mathrm{SD}$ value obtained in triplicate assays done in a representative experiment. At least three such experiments were carried out.

\section{MAPKK2 cleavage assay}

N-terminal MAPKK2, anti-tubulin, and anti-PA antibodies were purchased from Santa Cruz Biotechnology. RAW264.7 cells were pre-treated with $33 \mu \mathrm{M}$ of Bithionol for 1 hour. Following pre-treatment, the cells were exposed to $0.5 \mu \mathrm{g} / \mathrm{ml}$ of PA and $\mathrm{LF}$ at $37^{\circ} \mathrm{C}$ for up to three hours in the presence of $33 \mu \mathrm{M}$ of Bithionol. The cells were then washed with cold PBS five times and lysed with RIPA buffer containing a protease inhibitor mixture (Santa Cruz Biotechnology, Inc.). Cell lysates were quantified using the BCA protein quantification kit 
(Pierce) and loaded onto 4-12\% denaturing gels (Criterion XT Precast Gel, Bio-Rad). After electrophoresis for several hours, the gel was transferred overnight to nitrocellulose membranes; membranes were probed with anti-MAPKK2 or anti tubulin antibodies. Quantitative Western blot analyses of the bands were accomplished using the Odyssey infrared imaging system (LICOR Biosciences).

Cellular cathepsin B and caspase-1 activity assays

Cathepsin B and caspase-1 activities in total cell lysates were determined using an InnoZyme cathepsin B activity assay kit (EMD Millipore) and caspase activity assay kit (BioVision), performed according to the manufacturers' instructions. Cellular cathepsin B or caspase-1 activities with and without Bithionol were tested by pre-treating cells with $33 \mu \mathrm{M}$ of Bithionol for 1 hour, followed by lysing cells and testing protease activities with fluorescently labeled specific substrates. Caspase-1 activities were induced by 1 hour pretreatment of cells with $0.5 \mu \mathrm{g} / \mathrm{ml}$ of LF $+\mathrm{PA}$, and was compared to cells un-induced by the toxin. Fluorescence intensities indicating cathepsin B or caspase-1 activities were measured (Molecular Devices, Spectra Max 384 PLUS).

\section{Ricin treatment and cell viability assay}

K562 cells were seeded at a density of $2 \times 105$ cells/well in 24 -well plates. Cells were pre-treated with Bithionol for 2 hours and $0.4 \mathrm{ng} / \mathrm{ml}$ ricin was added to the treated wells. Following the 24-hour ricin treatment, the percent of viable cells (within the live gate by FSC/SSC) was measured by flow cytometry using a BD Accuri C6 Flow Cytometer. Experiment was performed in duplicate for each condition. 


\section{Mice intoxication studies}

10 Swiss Webster (CFW) mice (6 weeks old) were treated with $0.125 \mathrm{mg} / \mathrm{mouse}$ Bithionol in the presence or absence of BoNT/A complex $(3 \mu \mathrm{g} / \mathrm{mouse}$, Metabiologics, Madison WI) in phosphate gelatin buffer $(0.028 \mathrm{M}$ sodium phosphate $\mathrm{pH} 7.0,0.2 \%$ gelatin) by oral gavage. Animals were observed over a period of 7 days. Methods were carried out in accordance with approved guidelines. All experiments were performed in accordance with relevant guidelines and regulations. All animal experiments have been approved by the Western Regional Research Center IACUC. Euthanasia protocols follow recommendations established by the American Medical Veterinary Association Guideline for Euthanasia to minimize animal pain and suffering.

\section{BoNT/A light chain FRET assay}

The reaction volume was $250 \mu \mathrm{l}$ per well in 96 wells plate, containing $50 \mathrm{mM}$ HEPES pH 7.4 containing 0.05\% TWEEN 20, $5 \mu \mathrm{M}$ SNAPtide (BoNT/A substrate peptide) conjugated with DABCYL and FITC (List Biological Laboratories, Inc), and $33 \mu \mathrm{M}$ of Bithionol. Reactions were initiated by adding BoNT/A light chain to a final concentration of $5 \mathrm{nM}$. Kinetic measurements

were obtained at $37^{\circ} \mathrm{C}$ every $1 \mathrm{~min}$ for $50 \mathrm{~min}$ using a fluorescent plate reader. Excitation and emission wavelengths were $490 \mathrm{~nm}$ and $523 \mathrm{~nm}$, respectively, with a cutoff wavelength of $495 \mathrm{~nm}$. At least three such FRET experiments were carried out. 


\section{Zika virus high content imaging infections assay}

We utilized strains from both ZIKV lineages (African and Asian) to assess the potential for Bithionol to inhibit viral abundance. ZIKV strain DAK AR D 41525 was originally isolated from a pool of Aedes africanus mosquitoes in Senegal in 1984 (passage history: AP61\#1, C6/36\#1, Vero 3) and strain PRVABC59 was originally isolated from human sera in Puerto Rico in 2015 (passage history: Vero 6). Cells were pre-treated with Bithionol for 2 hours prior to infection. Vero E6 cells were exposed to ZIKV at an MOI of 0.5; astrocytes were infected with ZIKV at an MOI of 15 . Infection was terminated after 48 hours by fixing samples in formalin solution. For visualization of Zika infection cells were treated for 1 hour with anti-Flavi-virus envelop protein monoclonal antibody 4G2, followed by anti-mouse IgG conjugated with Dylight488 (Thermo). Cells were stained with Hoechst (Life Technologies) for nuclei staining and with Cell Mask Red (Life technologies) for cytoplasm staining. Nuclei were stained with Draq5 (Biostatus) diluted in PBS buffer. Images were acquired on the Opera imaging plate reader (Perkin Elmer) and analyzed using Harmony and Acapella PE software. A detailed protocol is described in the supplemental file.

\section{Acknowledgments}

We thank Dr. Stephen Leppla of the NIAID for a kind gift of FP59 toxin. A.L. acknowledges support from The Kenneth T. and Eileen L. Norris Foundation.

\section{Author Contributions}

M.M. L.W.C., M.C.B., S.N.C., S.B. and A.L., designed research; W.L., L.Z., L.W.C., J.Z., S.H.T., J.H.E., K.P., R.M., V.S., D.G., R.Z., T.K., X.C., A.D.H., F.N. and A. Li performed 
research; all analyzed data; and M.M. wrote the paper.

\section{References}

1. Barabasi, A. L., Gulbahce, N. \& Loscalzo, J. Network medicine: a network-based approach to human disease. Nature reviews. Genetics 12, 56-68, doi: 10.1038/nrg2918 (2011).

2. Watts, D. J. \& Strogatz, S. H. Collective dynamics of 'small-world' networks. Nature 393, 440-442, doi: 10.1038/30918 (1998).

3. Zilbermintz, L. et al. Identifcation of agents effective against multiple toxins and viruses by host-oriented cell targeting. Scientific reports 5, 13476, doi: 10.1038/srep13476 (2015).

4. Johannes, L. \& Decaudin, D. Protein toxins: intracellular tracking for targeted therapy. Gene therapy 12, 1360-1368, doi: 10.1038/ sj.gt.3302557 (2005).

5. Tafesse, F. G. et al. GPR107, a G-protein-coupled receptor essential for intoxication by Pseudomonas aeruginosa exotoxin A, localizes to the Golgi and is cleaved by furin. The Journal of biological chemistry 289, 24005-24018, doi: 10.1074/jbc.M114.589275 (2014).

6. Payne, A. M. et al. Caspase activation as a versatile assay platform for detection of cytotoxic bacterial toxins. Journal of clinical microbiology 51, 2970-2976, doi: 10.1128/JCM.01161-13 (2013).

7. Vidal, D. R., Garrone, P. \& Banchereau, J. Immunosuppressive effects of Pseudomonas aeruginosa exotoxin A on human B-lymphocytes. Toxicon: official journal of the International Society on Toxinology 31, 27-34 (1993).

8. Sabeti, P. C. et al. A haplotype map of the human genome. Nature 437, 1299-1320, doi: 10.1038/nature04226 (2005).

9. Park, C. et al. Association between CASP7 and CASP14 genetic polymorphisms and the risk of childhood leukemia. Human immunology 73, 736-739, doi:

10.1016/j.humimm.2012.04.017 (2012).

10. Garcia-Lozano, J. R. et al. Caspase 7 influences susceptibility to rheumatoid arthritis. Rheumatology (Oxford) 46, 1243-1247, doi: 10.1093/rheumatology/kem096 (2007).

11. Li, B. et al. Molecular epidemiologic correlation analysis between caspase 3 gene polymorphism and gastric cancer susceptibility. Cell biochemistry and biophysics 70, 1647-1653, doi: 10.1007/s12013-014-0108-0 (2014). 
12. Hosgood, H. D. 3rd et al. Caspase polymorphisms and genetic susceptibility to multiple myeloma. Hematological oncology 26, 148-151, doi: 10.1002/hon.852 (2008).

13. Chen, K. et al. CASP3 polymorphisms and risk of squamous cell carcinoma of the head and neck. Clinical cancer research: an offcial journal of the American Association for Cancer Research 14, 6343-6349, doi: 10.1158/1078-0432.CCR-08-1198 (2008).

14. Wickliffe, K. E., Leppla, S. H. \& Moayeri, M. Anthrax lethal toxin-induced in ammasome formation and caspase-1 activation are late events dependent on ion uxes and the proteasome. Cellular microbiology 10, 332-343, doi: 10.1111/j.14625822.2007.01044.x (2008).

15. Komatsu, N., Oda, T. \& Muramatsu, T. Involvement of both caspase-like proteases and serine proteases in apoptotic cell death induced by ricin, modeccin, diphtheria toxin, and pseudomonas toxin. Journal of biochemistry 124, 1038-1044 (1998).

16. Lourenssen, S., Miller, K. G. \& Blennerhassett, M. G. Discrete responses of myenteric neurons to structural and functional damage by neurotoxins in vitro. American journal of physiology. Gastrointestinal and liver physiology 297, G228-G239, doi: 10.1152/ ajpgi.90705.2008 (2009).

17. Kayagaki, N. et al. Non-canonical in ammasome activation targets caspase-11. Nature 479, 117-121, doi: 10.1038/nature10558 (2011).

18. Allam, M., Bertrand, R., Zhang-Sun, G., Pappas, J. \& Viallet, J. Cholera toxin triggers apoptosis in human lung cancer cell lines. Cancer research 57, 2615-2618 (1997).

19. Monnier, P. P. et al. Involvement of caspase- 6 and caspase- 8 in neuronal apoptosis and the regenerative failure of injured retinal ganglion cells. The Journal of neuroscience: the official journal of the Society for Neuroscience 31, 10494-10505, doi: 10.1523/ JNEUROSCI.0148-11.2011 (2011).

20. Wahome, P. G., Ahlawat, S. \& Mantis, N. J. Identification of small molecules that suppress ricin-induced stress-activated signaling pathways. PloS one 7, e49075, doi: 10.1371/journal.pone.0049075 (2012).

21. Chong, C. R., Chen, X., Shi, L., Liu, J. O. \& Sullivan, D. J. Jr. A clinical drug library screen identifies astemizole as an antimalarial agent. Nature chemical biology 2, 415416, doi: 10.1038/nchembio806 (2006).

22. Kroemer, G., Galluzzi, L. \& Brenner, C. Mitochondrial membrane permeabilization in cell death. Physiological reviews 87, 99-163, doi: 10.1152/physrev.00013.2006 (2007).

23. Liu, S., Moayeri, M. \& Leppla, S. H. Anthrax lethal and edema toxins in anthrax pathogenesis. Trends in microbiology, doi: 10.1016/j. tim.2014.02.012 (2014). 
24. Ha, S. D. et al. Cathepsin B-mediated autophagy flux facilitates the anthrax toxin receptor 2-mediated delivery of anthrax lethal factor into the cytoplasm. e Journal of biological chemistry 285, 2120-2129, doi: 10.1074/jbc.M109.065813 (2010).

25. Arora, N., Klimpel, K. R., Singh, Y. \& Leppla, S. H. Fusions of anthrax toxin lethal factor to the ADP-ribosylation domain of Pseudomonas exotoxin A are potent cytotoxins which are translocated to the cytosol of mammalian cells. e Journal of biological chemistry 267, 15542-15548 (1992).

26. Dolly, J. O., Wang, J., Zurawski, T. H. \& Meng, J. Novel therapeutics based on recombinant botulinum neurotoxins to normalize the release of transmitters and pain mediators. The FEBS journal 278, 4454-4466, doi: 10.1111/j.1742-4658.2011.08205.x (2011).

27. In e MAK-Collection for Occupational Health and Safety (Wiley-VCH Verlag GmbH \& Co. KGaA, 2002).

28. Boldt, G. E. et al. Synthesis, characterization and development of a high-throughput methodology for the discovery of botulinum neurotoxin a inhibitors. Journal of combinatorial chemistry 8, 513-521, doi: 10.1021/cc060010h (2006).

29. Mocarski, E. S., Upton, J. W. \& Kaiser, W. J. Viral infection and the evolution of caspase 8-regulated apoptotic and necrotic death pathways. Nature reviews. Immunology 12, 7988, doi: 10.1038/nri3131 (2012).

30. Tang, H. et al. Zika Virus Infects Human Cortical Neural Progenitors and Attenuates Their Growth. Cell stem cell, doi: 10.1016/j. stem.2016.02.016 (2016).

31. Dang, J. et al. Zika Virus Depletes Neural Progenitors in Human Cerebral Organoids through Activation of the Innate Immune Receptor TLR3. Cell stem cell, doi: 10.1016/j.stem.2016.04.014 (2016).

32. Wurzer, W. J. et al. Caspase 3 activation is essential for efficient influenza virus propagation. The EMBO journal 22, 2717-2728, doi: 10.1093/emboj/cdg279 (2003).

33. Richard, A. \& Tulasne, D. Caspase cleavage of viral proteins, another way for viruses to make the best of apoptosis. Cell death \& disease 3, e277, doi: 10.1038/cddis.2012.18 (2012).

34. Saborio, P., Lanzas, R., Arrieta, G. \& Arguedas, A. Paragonimus mexicanus pericarditis: report of two cases and review of the literature. The Journal of tropical medicine and hygiene 98, 316-318 (1995).

35. Oprea, T. I. \& Mestres, J. Drug repurposing: far beyond new targets for old drugs. The AAPS journal 14, 759-763, doi: 10.1208/ s12248-012-9390-1 (2012). 
36. Cosme, A. et al. Sonographic findings of hepatic lesions in human fascioliasis. Journal of clinical ultrasound: JCU 31, 358-363, doi: 10.1002/jcu.10189 (2003).

37. Choi, D. W. Paragonimus and paragonimiasis in Korea. Kisaengch'unghak chapchi. The Korean journal of parasitology 28 Suppl, 79-102 (1990).

38. Eleuteri, S. et al. Novel therapeutic strategy for neurodegeneration by blocking Abeta seeding mediated aggregation in models of Alzheimer's disease. Neurobiology of disease 74, 144-157, doi: 10.1016/j.nbd.2014.08.017 (2015).

39. Takahashi, T., Yoshikawa, M. \& Yoshishige, S. Studies on the Distribution of Radioisotopes by Whole Body Autoradiography (XIX). Distribution of 35S-bis- (3, 5dichloro-2-hydroxyphenyl) sulfoxide in Mice, Rats and Cockerels. Radioisotopes 18, 552-558 (1969).

40. Nwokolo, C. Endemic paragonimiasis in Africa. Bulletin of the World Health Organization 50, 569-571 (1974). 


\section{Supplemental Material}

\section{Bithionol blocks pathogenicity of bacterial toxins, ricin, and Zika virus}

William Leonardi, ${ }^{1}$ Leeor Zilbermintz, ${ }^{1}$ Luisa W. Cheng, ${ }^{2}$ Josue Zozaya, ${ }^{1}$ Sharon $\mathrm{H}$. Tran, ${ }^{1}$ Jeffrey H. Elliott, ${ }^{1}$ Kseniya Polukhina, ${ }^{1}$ Robert Manasherob, ${ }^{3}$ Amy Li, ${ }^{3}$ Xiaoli Chi, ${ }^{4}$ Dima Gharaibeh, ${ }^{4}$ Tara Kenny, ${ }^{4}$ Rouzbeh Zamani, ${ }^{4}$ Veronica Soloveva, ${ }^{4,5,6}$ Andrew D. Haddow, ${ }^{4}$ Farooq Nasar, ${ }^{4}$ Sina Bavari, ${ }^{4}$ Michael C. Bassik, ${ }^{3}$ Stanley N. Cohen, ${ }^{3}$ Anastasia Levitin, ${ }^{1}$ and Mikhail Martchenko ${ }^{1, *}$

${ }^{1}$ Keck Graduate Institute, Claremont, CA 91711

2 Foodborne Toxin Detection and Prevention Research Unit, Western Regional Research Center, United States Department of Agriculture (USDA), Albany, CA 94710

${ }^{3}$ Department of Genetics, Stanford University School of Medicine, Stanford, CA 94305

${ }^{4}$ US Army Medical Research Institute of Infectious Diseases (USAMRIID), Fort Detrick, MD, 21702

${ }^{5}$ Henry M. Jackson Foundation, Bethesda, MD, 20817

${ }^{6}$ Biotechnology High Performance Computing Software Applications Institute (BHSAI), Frederick, MD, 21702

*Contact: mikhail_martchenko@kgi.edu 


\section{SUPPLEMENTAL MATERIALS AND METHODS:}

Zika virus High Content Imaging infections assay: Vero E6 cells were seeded in 384 plates (Aurora \#1052-11130) at 2,000 cells/well in $40 \mu \mathrm{l}$ of culture media for Zika virus infection assay. Astrocytes were lifted after culturing for 4 days using trypsin/EDTA (Lonza, \#CC-5012) neutralized after 5 min by Trypsin neutralizing solution (Lonza, \#CC5002). Cells suspension was diluted with cultured media and plated at 20,000 cells/well in 96 well (Greiner, \#655090). After 24 hours of incubation at $37^{\circ} \mathrm{C}$ with $5 \% \mathrm{CO}_{2}$ cells were treated with Bithionol to determine its antiviral activity. Ten serial dilutions of Bithionol in quadruplicate were added directly to the Vero E6 cell cultures using the HP D300 digital dispenser (Hewlett Packard, Palo Alto, CA) in 2-fold dilution increments starting at $100 \mu \mathrm{M}$ at 2 hours prior to infection. Astrocytes were treated with 6 serial dilutions in 3-fold increment and starting at $50 \mu \mathrm{M}$. To generate Negative control column 3 in 384 well plate or row $\mathrm{H}$ in 96 well plates were treated with DMSO only (1\%). The DMSO concentration in each well was normalized to $1 \%$ using an HP D-300 digital dispenser.

The ZIKV isolates used in this study were strain DAK AR D 41525 which was originally isolated from a pool of Ae. africanus mosquitoes in Senegal in 1984 (passage history: AP61\#1, C6/36\#1, Vero 3) and strain PRVABC59 which was originally isolated from human sera in Puerto Rico in 2015 (passage history: Vero 6). Two hours after treatment with compounds Vero E6 cells were infected with Zika virus at $\mathrm{MOI}=0.5$ (calculated for 4,000 cells/well, assuming one complete round of replication of Vero E6 cells at $15 \pm 2$ hrs after cell seeding). Human primary astrocytes were infected with Zika at $\mathrm{MOI}=15$ calculated for seeded density of astrocytes. Column 2 in 384 well plates 
and row A in 96 well plates were left uninfected for positive control of inhibition. Infection was terminated after 48 hours by fixing samples in formalin solution.

Antiviral assays were done using a high content imaging technique for 384 or 96 well plates to quantify virus antigen production as a measure of virus infection. After pre-incubation of the cells for 30 min with blocking solution containing 1X PBS with $3 \%$ BSA (Sigma) supplements with $0.1 \%$ Triton X-100 (Sigma) the primary Anti-Flavi virus Group Antigen Antibody, clone D1-4G2 was diluted 1000-fold in blocking buffer (1X PBS with $3 \% \mathrm{BSA}$ ) and added to each well of the assay plate. The assay plates were incubated for 60 minutes at room temperature. The primary antibody was removed and the cells were washed 3 times with 1X PBS. The secondary detection antibody was an anti-mouse IgG conjugated with Dylight488 (\#405310, Thermo Fisher Scientific, Waltham, MA) diluted 1,000-fold in blocking buffer and was added to each well in the assay plate. The assay plates were incubated for 60 minutes at room temperature. Nuclei were stained using Hoechst 33342 ( $\mathrm{H} 3570$, Invitrogen), and the cytoplasm of cells was counter-stained with Cell Mask Deep Red (Cat \#C10046, Thermo Fisher Scientific, Waltham, MA) diluted in 1X PBS. Cell images were acquired using Perkin Elmer Opera confocal plate reader (Perkin Elmer, Waltham, MA) using 10X Air objective to collect five images per each well. Virus-specific antigen was quantified by measuring fluorescence emission at a $488 \mathrm{~nm}$ wavelength, the nuclei staining was quantified by measuring fluorescence emission at a $400 \mathrm{~nm}$ and cytoplasm staining with Cell Mask at $640 \mathrm{~nm}$. Analysis of acquired images was done using Acapella PE software. A "no virus" control (Column 2) and a "1\% DMSO" control (Column 3) were included on each plate to determine the $0 \%$ and $100 \%$ virus infection, respectively. Hoechst 33342 signal 
was used to generate nuclei mask and define each cell in the image. Cell Mask dye was used to better-defined area within the borders of the cells. The viral-antigen signal was compartmentalized within the cell mask. The intensity of signal in the $488 \mathrm{~nm}$ channel collected from the control wells containing no virus infection was used to determine the threshold for low signal. Those cells that exhibited antigen signal higher than selected threshold were counted as positive for viral infection. Ratio of virus positive cells to total number of analyzed cells was used to determine percent of infection positive cells for each well on assay plate.

$\%$ Infected cells $=\frac{\text { Positive Virus Number of Objects }(s)}{\text { Number of objects }(s)} * 100$

Two parameters, total the number of nuclei in each well and total percent of infected cells collected for each well on the plates were exported from PE Acapella into PE Columbus Image data storage system and GeneData Screener (Genedata Inc, Lexington, MA) software for further data management and analysis.

Data normalization was done on the plate level to allow comparison of the results from different experimental tests. The percent of inhibition of viral infection (\% Activity or $\%$ Inhibition) was used to reflect decrease in percent of virus positive cells. The median of the values from the neutral control (NC) wells containing cells with viral infection and treated with DMSO were used as a minimal activity of inhibitor or $0 \%$ inhibition. The median of values from Blank control wells $(\mathrm{BC})$ containing cells not infected with virus were used as a threshold for the low signal and values were converted into the maximum inhibition of viral infection or $100 \%$ inhibition. (S)- samples, values from the wells treated with compounds. 
$\%$ Inhibition $=\frac{\text { Median } \% \text { Virus positive }(N C)-\% \text { Virus positive }(S)}{\text { Median } \% \text { Virus positive }(N C)-\text { Median } \% \text { Virus positive }(B C)} * 100 \%$

The values of $\%$ of infection and \% of viability for each well was used in GraphPad

Prism for curve fitting analysis using 2-4 parameter logistic (AC50, MAX, MIN, nHill) non-linear regression model to derive $\mathrm{EC}_{50}$ values corresponding to $50 \%$ of inhibition. 
SUPPLEMENTAL FIGURE 1.
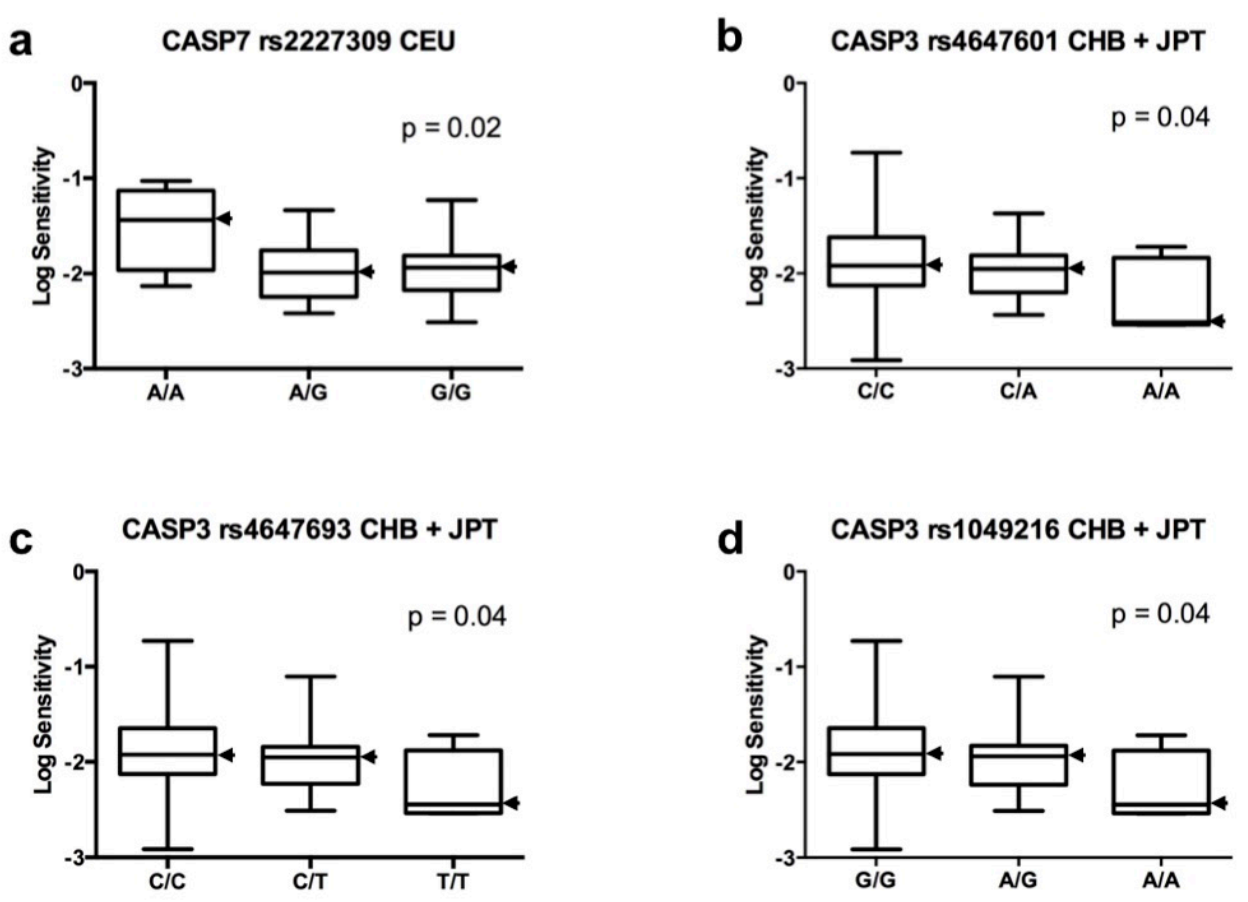

(A-D) Caspase-7 and Caspase-3 SNPs associate with log sensitivity of Blymphoblastoid cells to Pseudomonas aeruginosa exotoxin A in indicated populations. 


\section{SUPPLEMENTAL TABLE:}

Table S1: The effect of Bithionol on the pathogenicity of Zika Virus in cells. The ability of Bithionol to reduce the abundance of Zika virus in host cells (Vero E6 and human astrocytes) was measured by fluorescent microscopy. The $50 \%$ effective (EC50, virus-inhibitory) concentrations were determined.

\begin{tabular}{|c|c|c|c|c|}
\hline Drug & Cells & Virus (strain) & EC50, $\mu \mathrm{M}$ & SD, $\mu \mathrm{M}$ \\
\hline Bithionol & Vero E6 & Zika (Puerto Rico) & 6.66 & 1.15 \\
\hline Bithionol & Vero E6 & Zika (Senegal) & 5.52 & 0.29 \\
\hline Bithionol & Human Astrocytes & Zika (Senegal) & 6.28 & 0.22 \\
\hline
\end{tabular}

\section{Transition}

The previous chapter describes our first attempt at multiplex screening. In these studies we screened drugs for their ability to inhibit caspases in FRET screens, as well as toxin-challenge cell survival assays against Pseudomonas exotoxin A, Cholera toxin, and Diphtheria toxin (all cause an increase in cellular caspases). Our one drug hit that was successful in all screens is Bithionol. Multiplex screening allowed us to more accurately indentify an HPEP as well as to identify a broad-spectrum therapy. As a proof of Bithinol's ability to inhibit caspases, we were able to show that Bitionol could be successful in toxin challenges against Botulinum toxin as well as being capable of reducing Zika virus in cellular studies. The following chapter will describe an attempt to identify single drugs that could be HPEPs and anti-pathogen simultaneously on account of the observation that anthrax toxins and the host proteins that anthrax toxin exploit are both proteases, with the hopes to create a more effective anti-anthrax therapy. 


\title{
Chapter 5
}

\section{Cross-inhibition of pathogenic agents and the host proteins they exploit}

Leeor Zilbermintz, William Leonardi, Sharon H. Tran, Josue Zozaya, Alyssa Mathew-Joseph, Spencer Liem, Anastasia Levitin, and Mikhail Martchenko

\begin{abstract}
The major limitations of pathogen-directed therapies are the emergence of drugresistance and their narrow spectrum of coverage. A recently applied approach directs therapies against host proteins exploited by pathogens in order to circumvent these limitations. However, host-oriented drugs leave the pathogens unaffected and may result in continued pathogen dissemination. In this study we aimed to discover drugs that could simultaneously cross-inhibit pathogenic agents, as well as the host proteins that mediate their lethality. We observed that many pathogenic and host-assisting proteins belong to the same functional class. In doing so we targeted a protease component of anthrax toxin as well as host proteases exploited by this toxin. We identified two approved drugs, ascorbic acid 6-palmitate and salmon sperm protamine, that effectively inhibited anthrax cytotoxic protease and demonstrated that they also block proteolytic activities of host furin, cathepsin B, and caspases that mediate toxin's lethality in cells. We demonstrated that these drugs are broad-spectrum and reduce cellular sensitivity to other bacterial toxins that require the same host proteases. This approach should be generally applicable to the discovery of simultaneous pathogen and host-targeting inhibitors of many additional pathogenic agents.
\end{abstract}




\section{Introduction}

The traditional method of treating most human diseases is to direct a therapy against targets in the host patient, whereas conventional therapies against infectious diseases are directed against the pathogen. Unfortunately, the efficacy of pathogen-oriented therapies and their ability

to combat emerging threats such as genetically engineered and non-traditional pathogens and toxins have been limited by the occurrence of mutations that render pathogen targets resistant to countermeasures. Thus, host proteins exploited by pathogens are potential targets for therapies $[1]$.

Host proteins and pathways exploited by Bacillus anthracis toxins are well understood [2]. B. anthracis causes anthrax infections and leads to toxemia in humans and animals, rendering antibiotic therapies ineffective in the later stages of infection. The major virulence factors of the bacterium include an exotoxin protein complex consisting of protective antigen (PA) and lethal factor (LF), which act collectively to damage the host [2]. Proteases play important roles in anthrax toxin mediated host-cell killing. PA binds to host cellular receptors in the native form of $83 \mathrm{kDa}$ (PA83) ]3,4], and once bound, host protease furin cleaves a $20 \mathrm{kDa}$ fragment from the N-terminus of PA, thus activating the PA protein of $63 \mathrm{kDa}$ (PA63) [5]. Following activation, PA forms a heptamer and binds LF6. The toxin undergoes clathrin-type endocytosis, mediated by another set of host proteases, calpains and cathepsin B7,8. A decrease in endosomal $\mathrm{pH}$ induces the formation of an endosomal membrane PA channel, by which LF translocates into the cytosol9.

Once in the cytosol, LF itself acts as a protease that cleaves and inactivates host mitogenactivated protein kinase kinases (MAPKK) 1-4, 6, and 710. The MAPKK cleavage event 
prevents the passage of signals in the ERK1/2, p38, and c-Jun N-terminal kinase pathways10,11, which mediate responses to a variety of cellular stresses. In addition, rat NLRP1 and mouse NLRP1b proteins can also be directly cleaved by LF at sites near their $\mathrm{N}$ termini11,12. The cleavage of host proteins by LF results in the activation of the inflammasomes, resulting in rapid macrophage cell death mediated by additional host proteases, caspases-1 and $-311,12$.

While the discovery of LF inhibitors has focused on new chemical compounds that either inhibit its protease activity or its cytoplasmic entry (reviewed in13), repurposing of existing drugs that simultaneously inhibit LF and the host proteases that assist LF, offers potential advantages. We used a fluorescence resonance energy transfer (FRET) assay, where LF cleaves a MAPKK2 peptide, to screen and identify approved drugs that affect the rate of the proteolytic reaction. We identified chemical and peptidic compounds that effectively inhibited cleavage of MAPKK2 peptide, as well as host furin, calpain, cathepsin B, and caspases. Two of those chemicals, ascorbic acid 6-palmitate and salmon sperm protamine, suppressed LF-induced cell death, as well as the cytotoxicity induced by cholera toxin and Pseudomonas aeruginosa exotoxin A. This study offers new solutions to treat these infectious diseases by using drugs that cross-inhibit pathogen and host targets.

\section{Results}

Observation of functional similarities between pathogenic agents and the host proteins exploited by them

Cytotoxic bacterial and plant toxins have evolved to exploit host proteins and cellular pathways that mediate the entry of those toxins into host cells and induce cell-death pathways. We observed a widespread phenomenon of structural or functional similarity between pathogenic 
proteins of bacteria, viruses, fungi, or other parasites and the host proteins that are exploited by them (Table 1). For example, similarities were reported for proteases of anthrax $[7,8,14,15]$ and botulinum toxins [16,17], as well as HIV-1 $[18,19,20,21]$ and Hepatitis C $[22,23,24]$ proteases and endocytosis-mediating host proteases. Furthermore, shiga glycosidase $\mathrm{H}$ toxin exploits host glycosidase H [25]; Candida albicans cell wall adhesins bind to structurally similar host cadherins during fungal invasion [26]; and Streptokinase and Staphylokinase exploit host plasminogen activators kinases [27,28]. A drug screen against multiple proteins within the same pathway is possible if these proteins are similar in function or structure. Therefore, finding therapies that cross-inhibit multiple proteins within a single pathway is of great interest.

Table 5.1: The observation that many pathogenic and host proteins they exploit belong to the same functional class.

\begin{tabular}{|c|c|c|c|}
\hline $\begin{array}{l}\text { Pathogenic } \\
\text { agent }\end{array}$ & $\begin{array}{l}\text { Exploited host } \\
\text { protein }\end{array}$ & Shared function & References \\
\hline $\begin{array}{l}\text { Anthrax Lethal } \\
\text { Toxin }\end{array}$ & $\begin{array}{l}\text { Furin, calpain, } \\
\text { cathepsin B, caspase- } \\
1 \text {, caspase- } 3\end{array}$ & Proteases & $7,8,14,15$ \\
\hline $\begin{array}{l}\text { Botulinum } \\
\text { neurotoxins }\end{array}$ & caspase-3/7 & Proteases & 16,17 \\
\hline $\begin{array}{l}\text { Candida albicans } \\
\text { Als3 }\end{array}$ & $\begin{array}{l}\text { E-cadherin and N- } \\
\text { cadherin }\end{array}$ & Adhesins & 26 \\
\hline $\begin{array}{l}\text { Hepatitis C NS2- } \\
3 \text { and NS3-4 }\end{array}$ & $\begin{array}{l}\text { Furin, calpain, } \\
\text { caspase-3 }\end{array}$ & Proteases & $22,23,24$ \\
\hline HIV-1 PR & $\begin{array}{l}\text { Furin, calpain, } \\
\text { cathepsin B, caspase- } \\
1 / 3\end{array}$ & Proteases & $\begin{array}{c}18,19,20 \\
21\end{array}$ \\
\hline $\begin{array}{l}\text { Pasteurella } \\
\text { Multocida toxin }\end{array}$ & $\begin{array}{l}\text { A2B Adenosine } \\
\text { Receptor }\end{array}$ & $\begin{array}{l}\text { Adenosine } \\
\text { deaminases }\end{array}$ & 45 \\
\hline $\begin{array}{l}\text { Plasmodium } \\
\text { berghei ALAS } \\
\text { and FR }\end{array}$ & ALAS- 1 and FECH & $\begin{array}{l}\text { Heme- } \\
\text { biosynthesis }\end{array}$ & 46 \\
\hline Shiga toxin & Endoglycosidase $\mathrm{H}$ & Glycosidases & 25 \\
\hline $\begin{array}{l}\text { Staphylokinase } \\
\text { and } \\
\text { Streptokinase }\end{array}$ & $\begin{array}{l}\text { Plasminogen } \\
\text { activators (PLAT and } \\
\text { PLAU) }\end{array}$ & Kinases & 27,28 \\
\hline
\end{tabular}

In an effort to identify existing drugs that might be repurposed as novel cross-inhibitors of pathogenic agents and the host proteins exploited by them, we screened the Johns Hopkins 
Clinical Compound Library (JHCCL) of chemicals [29]. We looked for compounds capable of i) inhibiting the proteolytic activities of Bacillus anthracis lethal toxin and the host proteases exploited by it (Fig. 1a) in biochemical FRET assays (Fig. 1d), and ii) reducing cytotoxicities of B. anthracis lethal toxin, Cholera toxin, and Pseudomonas aeruginosa exotoxin A (Fig. 1c). These toxins were chosen for this study because their pathways of entry into host cells are well understood [30], making these toxins good tools for identification of broad-spectrum drugs.

Figure 5.1: The use of the Johns Hopkins Clinical Compound Library (JHCCL) to screen for inhibitors of anthrax lethal toxin and host proteases

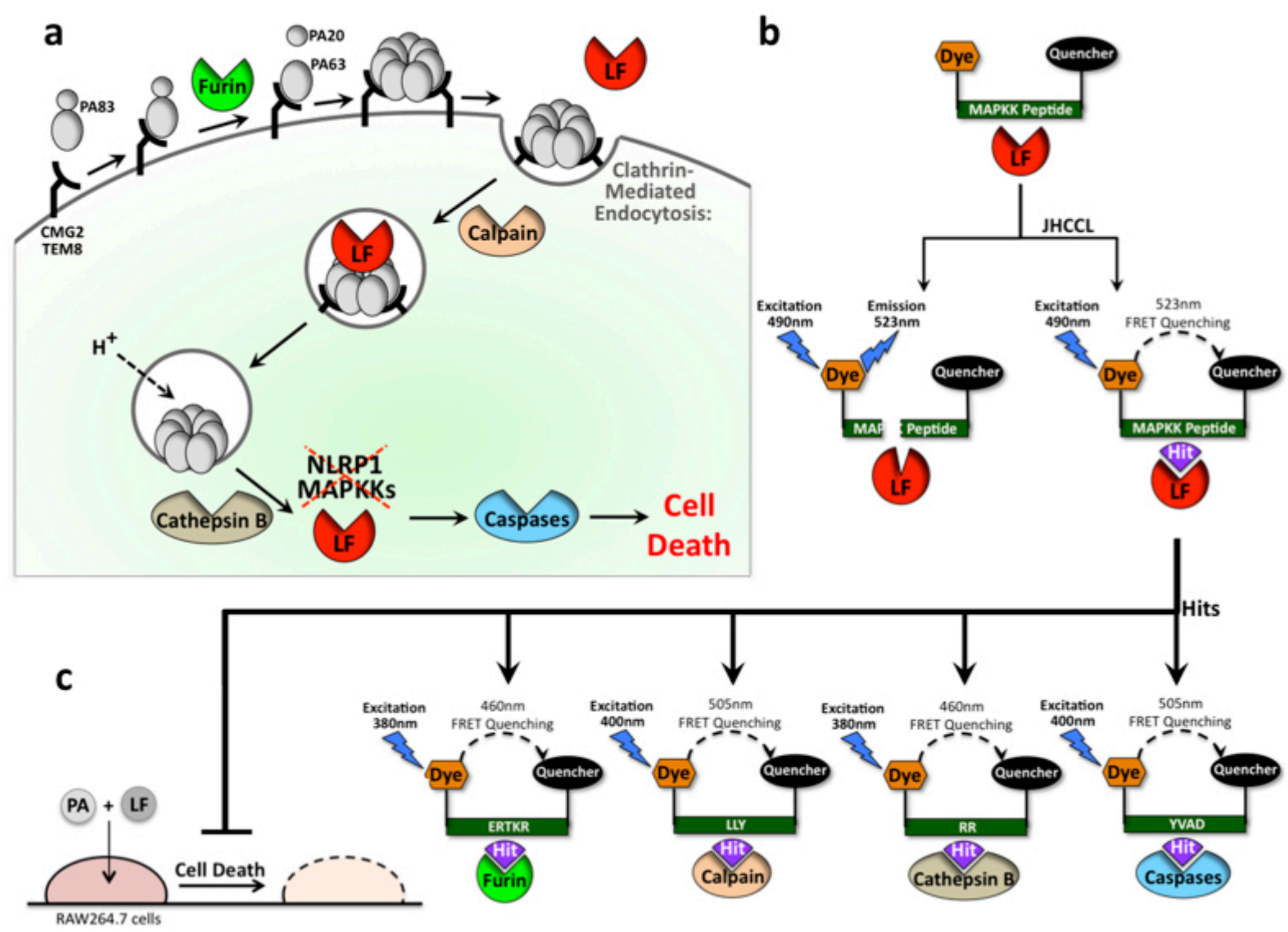

(a) Schematic depiction of host protease components within the pathway that mediates the delivery of anthrax toxin into cytoplasm. Lethal factor (LF) interact with a second B. anthracis protein, protective antigen (PA), whose role is to bind to host cell receptors, CMG2 and TEM8. Three host cell proteins furin, calpain, and cathepsin B mediate the endocytosis of the toxin complex. Once in the cytoplasm, LF cleaves host MAPKK's and NLRP1, and initiates apoptosis through induction of proteolytic activity of host caspases-1 and -3. (b,c) Overall approach scheme: JHCCL is screened by biochemical FRET assay looking for drugs that are able to reduce proteolytic activities of anthrax toxin and five host proteases that mediate toxin lethality. (b) Schematic diagram of FRET screen to identify drugs that inhibit proteolytic reaction of LF, (c) followed by FRET reactions to test the ability of LF inhibitors to also inhibit proteolytic reactions mediated by host furin, calpain, cathepsin B, caspase-1, and caspase-3. In addition, LF FRET inhibitors are tested for their ability to reduce LF-PA cytotoxicity of mouse macrophage cells. 
A biochemical screen for JHCCL drugs that cross-inhibit proteolytic activities of anthrax toxin and host proteases that mediate its lethality

In our initial screen we searched for the drugs that were capable of simultaneously inhibiting the proteolytic activities of anthrax LF as well as of host proteases that mediate the toxin's lethality in cell-free FRET assays. To screen and identify drugs that inhibit LF proteolytic activity we utilized a fluorescence-based FRET assay. An optimized MAPKK2 peptide with a fluorogenic FITC group at the $\mathrm{N}$ terminus and DABCYL quenching group at the $\mathrm{C}$ terminus was used as the LF substrate. After cleavage by LF the fluorescence of FITC at $523 \mathrm{~nm}$ increases, while a known inhibitor of LF, surfen hydrate [31], prevents it from cleaving the substrate and producing fluorescence (Fig. 1b). We screened 1,585 previously approved drugs for their ability to reduce the rate of the LF proteolytic reaction. Surfen hydrate is not included in JHCCL because is it not used clinically. Compounds that showed greater than $66 \%(\sim 1 \%$ hit rate $)$ inhibition when tested at $33 \mu \mathrm{M}$ were selected for re-validation and further studies. We discovered ten compounds that effectively inhibited LF in the FRET assay, nine of which were chemical molecules and one which was a 33 amino acid long peptide called salmon sperm protamine (Table 2). Of the ten chemical hits, six drugs were structurally similar to each other and contained carbon chains of at least 12 carbons (Table 2). These drugs are cetylpyridinium bromide, domiphen bromide, cetalkonium chloride, sodium lauryl sulfate, ascorbic acid 6palmitate, and sodium dodecylbenzenesulfonate. Three other small molecule drugs, docusate sodium, thyropropic acid, candesartan cilexetil, successfully inhibited the LF proteolytic reaction and were of various structures (Table 2). Moreover, one of the drugs that successfully inhibited the LF FRET reaction was a peptide, salmon sperm protamine. We determined that the IC50 values for the LF FRET reaction of these ten drugs were in the high $\mathrm{nM}$ to low $\mu \mathrm{M}$ range (Table 
2), with cetalkonium chloride showing the lowest IC50 of $160 \mathrm{nM}$, while arginine-rich salmon protamine displaying the lowest potency of $18 \mu \mathrm{M}$.

Table 5.2: The potencies of ten JHCCL drugs for inhibition of anthrax LF, as well as human proteases exploited by it (furin, caspase, cathepsin B (Cath B), caspase-1 (Casp 1), and caspase-3 (Casp 3)) in biochemical FRET assays.

\begin{tabular}{|c|c|c|c|c|c|c|c|c|c|}
\hline \multirow[b]{2}{*}{ Drug Name } & \multirow{2}{*}{$\begin{array}{l}\text { Previous } \\
\text { approval }\end{array}$} & \multirow[b]{2}{*}{ Drug Structure } & \multirow{2}{*}{$\underset{\mathrm{IC} 50 \mu \mathrm{M}}{\mathrm{LF}}$} & \multicolumn{6}{|c|}{ Percent Inhibition with $33 \mu \mathrm{M}$ of drug } \\
\hline & & & & LF & Furin & Calpain & Cath B & Casp 1 & Casp 3 \\
\hline $\begin{array}{l}\text { Cetylpyridinlum } \\
\text { bromide }\end{array}$ & $\begin{array}{l}\text { Antuceptic } \\
\text { mouthwash }\end{array}$ & & $0.36 \pm 0.09$ & $107 \pm 1.07$ & $\mathrm{~N} / \mathrm{I}^{*}$ & $\mathrm{~N} / \mathrm{I}$ & $\mathrm{N} / \mathrm{I}$ & $14 \pm 6.59$ & $84 \pm 2.7$ \\
\hline Domıphen bromıde & $\begin{array}{l}\text { Anticeptic } \\
\text { mouthwash }\end{array}$ & & $0.29 \pm 0.03$ & $103 \pm 0.82$ & $7 \pm 6.64$ & $\mathrm{~N} / \mathrm{I}$ & $23 \pm 1.5$ & $17 \pm 2.17$ & $\mathrm{~N} / 1$ \\
\hline $\begin{array}{l}\text { Cetalkontum } \\
\text { chloride }\end{array}$ & $\begin{array}{l}\text { Anticeptic } \\
\text { mouthwash }\end{array}$ & & $0.16 \pm 0.09$ & $106 \pm 1.21$ & $8 \pm 6.10$ & $68 \pm 14.8$ & $\mathrm{~N} / \mathrm{I}$ & $32 \pm 1.17$ & $\mathrm{~N} / \mathrm{I}$ \\
\hline $\begin{array}{l}\text { Sodlum lauryl } \\
\text { sulfate }\end{array}$ & $\begin{array}{l}\text { Anticeptic } \\
\text { mouthwash }\end{array}$ & & $2.9 \pm 0.08$ & $93 \pm 0.57$ & $2 \pm 4.56$ & $95 \pm 6.02$ & $540 \pm 0.7$ & $7 \pm 3.06$ & $83 \pm 2.7$ \\
\hline $\begin{array}{l}\text { Ascorblc acld } \\
\text { 6-palmittate }\end{array}$ & $\begin{array}{l}\text { Antloxidant } \\
\text { food addittve }\end{array}$ & & $0.46 \pm 0.26$ & $99 \pm 1.90$ & $16 \pm 0.67$ & $24 \pm 19.43$ & $\mathrm{~N} / \mathrm{I}$ & $18 \pm 1.12$ & $88 \pm 2.9$ \\
\hline $\begin{array}{l}\text { Sodium dodecyl } \\
\text { benzenesulfonate }\end{array}$ & Antsseptuc & & $0.59 \pm 0.08$ & $104 \pm 0.40$ & $6 \pm 3.34$ & $26 \pm 7.01$ & $96 \pm 2.5$ & $14 \pm 2.06$ & $77 \pm 2.5$ \\
\hline Docusate sodium & Laxattve & & $0.67 \pm 0.05$ & $95 \pm 0.28$ & $69 \pm 0.13$ & $130 \pm 0.19$ & $\mathrm{~N} / \mathrm{I}$ & $35 \pm 0.01$ & $\mathrm{~N} / \mathrm{I}$ \\
\hline Thyropropic acid & $\begin{array}{c}\text { Antl- } \\
\text { hyperlipidemic }\end{array}$ & & $1.2 \pm 0.05$ & $77 \pm 1.07$ & $88 \pm 0.03$ & $\mathrm{~N} / \mathrm{I}$ & $56 \pm 1.1$ & $10 \pm 0.01$ & $81 \pm 2.6$ \\
\hline $\begin{array}{l}\text { Candesartan } \\
\text { cllexetil }\end{array}$ & $\begin{array}{c}\text { Antl- } \\
\text { hypertenstve }\end{array}$ & & $0.40 \pm 0.02$ & $100 \pm 0.07$ & $88 \pm 0.12$ & $\mathrm{~N} / \mathrm{I}$ & $10 \pm 3.1$ & $16 \pm 0.10$ & $\mathrm{~N} / \mathrm{I}$ \\
\hline $\begin{array}{l}\text { Salmon Sperm } \\
\text { Protamine }\end{array}$ & $\begin{array}{c}\text { Antidote } \\
\text { for heparin } \\
\text { overdose; } \\
\text { Prolongs } \\
\text { Insulin action }\end{array}$ & MPRRRRSSSRPVRRRRRPRVSRRRRRRGGRRRR & $18 \pm 0.01$ & $107 \pm 1.4$ & $96 \pm 1.2$ & $\mathrm{~N} / \mathrm{I}$ & $65 \pm 0.5$ & $\mathrm{~N} / \mathrm{I}$ & $87 \pm 2.8$ \\
\hline
\end{tabular}

Conditions where no FRET inhibition is observed denoted as N/I.

We tested several truncated versions of salmon protamine and showed that while the N' terminal region of the peptide (amino acids 1-10) lost the anti-LF and anti-furin FRET efficacies, and the $C^{\prime}$ terminal (amino acids 23-33) showed potency similar to the full length protamine, the central portion of protamine (amino acids 11-22) displayed improved anti-LF 
activity (Table 3). Additionally we observed that a truncated version of protamine that contains the $\mathrm{N}^{\prime}$ terminal and central portions of protamine showed an even further improvement of protamine anti-toxin efficacy of just $1 \mu \mathrm{M}$. A truncated version of protamine that contains the central and $\mathrm{C}^{\prime}$ terminal regions of protamine demonstrated anti-LF efficacy that is comparable to the full-length protamine.

Table 5.3: The potencies of truncated versions of salmon sperm protamine and full-length human protamines in LF and furin FRET assays are shown. N/I stands for no inhibition

\begin{tabular}{|c|c|c|c|c|}
\hline $\begin{array}{l}\text { Peptide Name } \\
\text { (amino acids) }\end{array}$ & $\begin{array}{l}\text { Peptides amino acid } \\
\text { sequences }\end{array}$ & $\begin{array}{l}\mathrm{LF} \\
\mathrm{IC50} \mu \mathrm{M}\end{array}$ & $\begin{array}{l}\text { Percent } \\
\text { Inhibition } \\
\text { with } \\
33 \mu M \text { of } \\
\text { drug } \\
\text { LF }\end{array}$ & Furin \\
\hline Salmon Sperm & MPRRRRSSSRPVRRRRR & $18 \pm 0.01$ & $107 \pm 1.4$ & $96 \pm 1.2$ \\
\hline Protamine (1-33) & PRVSRRRRRRGGRRRR & & & \\
\hline $\begin{array}{l}\text { Salmon Sperm } \\
\text { Protamine }(1-10)\end{array}$ & MPRRRRSSSR & $298 \pm 0.01$ & $28 \pm 1.0$ & $\mathrm{~N} / \mathrm{I}$ \\
\hline $\begin{array}{l}\text { Salmon Sperm } \\
\text { Protamine (11- } \\
\text { 22) }\end{array}$ & PVRRRRRPRVSR & $5 \pm 0.13$ & $95 \pm 0.1$ & $84 \pm 33$ \\
\hline $\begin{array}{l}\text { Salmon Sperm } \\
\text { Protamine (23- } \\
\text { 33) }\end{array}$ & RRRRRGGRRRR & $15 \pm 0.01$ & $93 \pm 2.4$ & $150 \pm 5.3$ \\
\hline $\begin{array}{l}\text { Salmon Sperm } \\
\text { Protamine }(1-22)\end{array}$ & $\begin{array}{l}\text { MPRRRRSSSRPVRRRRR } \\
\text { PRVSR }\end{array}$ & $1 \pm 0.04$ & $98 \pm 0.6$ & $91 \pm 1.8$ \\
\hline $\begin{array}{l}\text { Salmon Sperm } \\
\text { Protamine (11- } \\
\text { 33) }\end{array}$ & $\begin{array}{l}\text { PVRRRRRPRVSRRRRRR } \\
\text { GGRRRR }\end{array}$ & $10 \pm 0.04$ & $99 \pm 0.2$ & $86 \pm 1.2$ \\
\hline $\begin{array}{l}\text { Human Sperm } \\
\text { Protamine }(1-51)\end{array}$ & $\begin{array}{l}\text { MARYRCCRSQSRSRYY } \\
\text { RQRQRSRRRRRRSCQT } \\
\text { RRRAMRCCRPRYRPRC } \\
\text { RRH }\end{array}$ & $14 \pm 0.32$ & $88 \pm 1.2$ & $97 \pm 1.7$ \\
\hline
\end{tabular}

We observed that arginine-rich human sperm protamine exhibited an anti-LF FRET IC50 comparable to that of salmon protamine (Tables 3 and 4). We tested several truncated versions of human protamine and showed that while the N' terminal region of the peptide (amino acids 117) showed a decreased anti-LF FRET efficacy, central (amino acids 18-34) and C' terminal (amino acids 35-51) regions showed potency similar to the full length human protamine (Table 4). 
Table 5.4: The potency of full length and truncated versions of human protamine in LF FRET assay

\begin{tabular}{|c|c|c|c|}
\hline $\begin{array}{l}\text { Peptide } \\
\text { Name (amino } \\
\text { acids) }\end{array}$ & Peptides amino acid sequences & $\begin{array}{l}\text { LF } \\
\text { IC50 } \\
\mu M\end{array}$ & $\begin{array}{l}\text { Percent } \\
\text { Inhibition } \\
\text { with } \\
33 \mu \mathrm{M} \text { of } \\
\text { drug } \\
\mathrm{LF}\end{array}$ \\
\hline $\begin{array}{l}\text { Human Sperm } \\
\text { Protamine (1- } \\
\text { 51) }\end{array}$ & $\begin{array}{l}\text { MARYRCCRSQSRSRYYRQRQRSRRR } \\
\text { RRRSCQTRRRAMRCCRPRYRPRCRR } \\
\mathrm{H}\end{array}$ & $\begin{array}{l}14 \pm \\
0.32\end{array}$ & $88 \pm 1.2$ \\
\hline $\begin{array}{l}\text { Human Sperm } \\
\text { Protamine (1- } \\
\text { 17) }\end{array}$ & MARYRCCRSQSRSRYYR & $\begin{array}{l}67 \pm \\
0.01\end{array}$ & $37 \pm 0.7$ \\
\hline $\begin{array}{l}\text { Human Sperm } \\
\text { Protamine } \\
(18-34)\end{array}$ & QRQRSRRRRRRSCQTRR & $\begin{array}{l}24 \pm \\
0.15\end{array}$ & $72 \pm 2.1$ \\
\hline $\begin{array}{l}\text { Human Sperm } \\
\text { Protamine } \\
(35-51)\end{array}$ & RAMRCCRPRYRPRCRRH & $\begin{array}{l}28 \pm \\
0.03\end{array}$ & $55 \pm 0.9$ \\
\hline
\end{tabular}

All ten LF-inhibitors were also tested for their ability to inhibit proteolytic FRET reactions of host furin, calpain, cathepsin B, caspase-1, and caspase-3, all of which mediate LF cytotoxicity (Fig. 1c). With the exception of caspase-1, all human proteases were effectively inhibited by several LF inhibitors (Table 2). The only drug that exclusively inhibited LF was domiphen bromide. None of the drugs inhibited all proteases.

Ascorbic acid 6-palmitate and salmon sperm protamine inhibit cytotoxic activity of anthrax toxins

In order to test the ability of LF inhibitors to neutralize the cytotoxic activity of anthrax toxin (Fig. 1c), we examined the effect of ten JHCCL hits on cell viability in LF-PA treated mouse macrophage RAW264.7 cells. Between 80 and 90 percent of cells used for these assays normally undergo cell death within 3 hours of exposure to anthrax lethal toxin under the experimental conditions employed. Ascorbic acid 6-palmitate and salmon sperm protamine were the only two drugs that provided complete protection against LF-PA mediated cell killing (Fig. 
2a). In contrast, the remaining eight compounds failed to protect cells against LF-PA mediated cellular killing due to their cytotoxicity in RAW264.7 cells. These experiments indicate that ascorbic acid 6-palmitate and salmon sperm protamine display target-specific biological activity and are therefore candidates for further development into broad-spectrum therapeutics.

Figure 5.2: Ascorbic acid 6-palmitate and salmon sperm protamine act as broad-spectrum antitoxins

a Anthrax Toxin (LF + PA83)

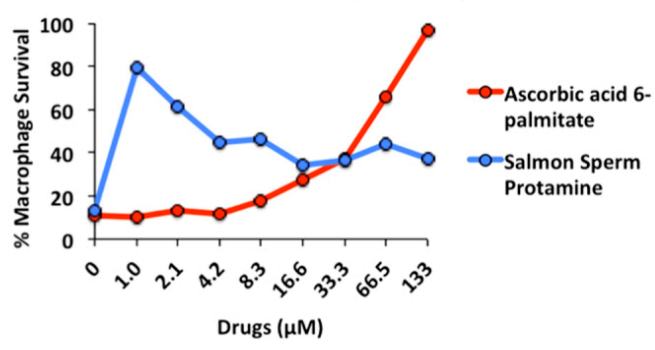

b

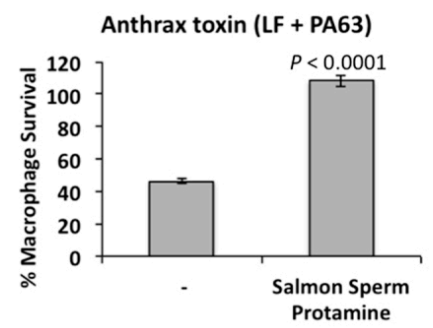

C

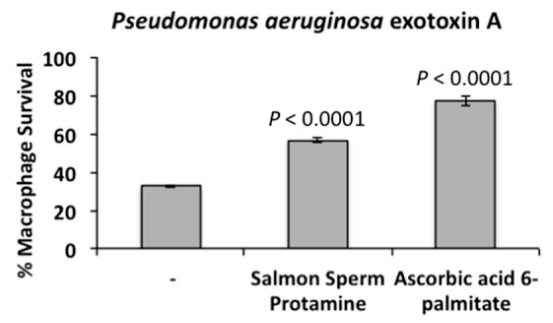

d

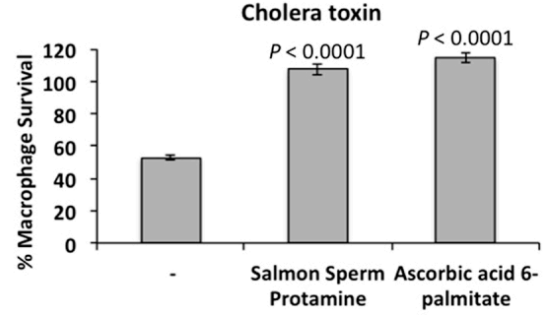

(a) Ascorbic acid 6-palmitate and salmon sperm protamine were tested for their ability to inhibit LF-PA83-mediated cytotoxicity. RAW264.7 cells were seeded at $1 \times 104$ cells/well on 96-well plates and the following day were incubated with indicated doses 
of drugs for 1 hour, followed by 3 hours intoxication with $0.5 \mu \mathrm{g} / \mathrm{ml} \mathrm{PA} 83+\mathrm{LF}$. (b) Sixteen $\mu \mathrm{M}$ of salmon sperm protamine reduces cellular sensitivity to LF + PA63. RAW264.7 cells were pretreated either with DMSO or with protamine for 1 hour, and then treated with $0.5 \mu \mathrm{g} / \mathrm{ml}$ of LF and PA63 for 6 hours. Averages, standard deviations, and $P$ values are shown for each condition. (c,d) Ascorbic acid 6-palmitate and salmon sperm protamine were tested for their ability to inhibit cytotoxicities mediated by Pseudomonas aeruginosa exotoxin A and Cholera toxin. RAW264.7 cells were seeded at $1 \times 104$ cells/well on 96well plates and the following day were incubated with indicated doses of drugs for 1 hour, followed by 12 hours intoxication with 2 and $4 \mu \mathrm{g} / \mathrm{ml}$ of Pseudomonas (c) and Cholera (d) toxins respectively. Cell viability was determined by MTT assay (Materials and Methods) and is shown as the percentage of survivors relative to cells not treated with drugs. Averages, standard deviations, and $P$ values are shown for each condition. Each $P$ value represents a comparison of drug-treatment condition to a condition without drugs.

Poly-arginine peptides were previously shown to simultaneously inhibit furin and lethal factor in biochemical and cellular assays $[32,33]$. We tested the ability of arginine-rich protamine to reduce the cell death induced by LF and PA in the $63 \mathrm{kDa}$ form - lacking the $20 \mathrm{kDa}$ furin cleavage domain (Fig. 2b). Fifty percent of cells used for these assays normally undergo cell death within 6 hours of exposure to LF-PA63 under the experimental conditions employed. We observed that protamine effectively protected all cells when used at $16 \mu \mathrm{M}$, compared to cells treated with LF-PA63 in the absence of drugs $(P<0.0001)$. Since this form of PA bypasses the need for furin protease cleavage, this data argues that protamine reduces toxin-mediated cell death by inhibiting LF directly.

Ascorbic acid 6-palmitate and salmon sperm protamine act as broad-spectrum anti-toxins

It has been previously shown that Pseudomonas aeruginosa exotoxin A (PE) and Cholera toxin exploit several host proteins for their binding and entry into host cells and initiate programmed cell death by inducing activities of host caspase-3 [34,35]. To test the ability of ascorbic acid 6-palmitate and salmon sperm protamine to neutralize cytotoxic activity of the two toxins, we examined their effects on cell viability in toxin-treated RAW264.7 cells. While 50\% and $70 \%$ of cells used for these assays normally undergo cell death within 6 hours of exposure to CT and PE respectively, ascorbic acid 6-palmitate and salmon sperm protamine provided substantial protection against PE and CT-mediated cell killing at $16 \mu \mathrm{M}$ compared to cells treated 
with toxins in the absence of drugs $(P<0.0001)$ (Fig. 2c,d).

\section{Discussion}

This study identified drugs that simultaneously target pathogenic factors and host proteins exploited by them. This approach is based on the observation that some virulence proteins and host proteins they utilize, belong to the same functional class. However, this approach has possible limitations such as potentially low efficacy of drugs, or if a pathogenic factor exploits multiple redundant host proteins, some of which could be functionally unrelated to the toxin. Moreover, host protein inhibiting therapies may cause side effects, and this is a possible explanation as to why many drugs that were shown to have potency in biochemical FRET assays were cytotoxic in cellular anti-toxin assays (Fig. 2). Some of the drugs that caused the cytotoxicity display structural properties that resemble detergents, while other drugs could be cross-reacting with essential host proteins.

Detergents are compounds comprised of a hydrophobic hydrocarbon tail and a hydrophilic charged headgroup. When dissolved in water at a given concentration, detergent molecules will form micelles, with the hydrophobic tail in the interior of the micelle and the headgroup at the exterior. The minimal detergent concentration at which micelles are observed at a specific temperature is called "Critical Micelle Concentration" (CMC). It is known that at or above the $\mathrm{CMC}$, detergents cooperatively bind to most proteins, which thereafter undergo denaturing rearrangements of their protein structures. Micelles act as detergents with the hydrophobic core of the micelle binding to the hydrophobic regions of proteins. It is also known that at submicellar concentrations, detergents may bind to specific binding sites of several proteins [36,37]. For example, the CMC of one of our FRET hits, sodium lauryl sulfate, a molecule commonly known as SDS, is $8 \mathrm{mM}$ [38]. In our study the IC50 of SDS was found to be 
$2.9 \mu \mathrm{M}$, four orders of magnitude of concentrations below the CMC. Similarly, the IC50 of ascorbic acid 6-palmitate in our study is $0.4 \mu \mathrm{M}$, while its $\mathrm{CMC}$ is $0.8 \mathrm{mM}$ [39], four orders of magnitude difference. Therefore, since all of our detergent-like molecules displayed potencies well below their respective CMC's, we believe that their interaction with the studied protein targets is specific. The data shown in Table 2 argues that these drugs are selective in their inhibition of targets, and none of the drugs inhibited all targets indiscriminately. Lastly, with the exception of ascorbic acid 6-palmitate, all detergent-like molecules discovered in this study belong to the common ionic category of detergents, as their headgroups bear a charge. In contrast, ascorbic acid 6-palmitate is a non-ionic molecule, and this class of detergent-like molecules are known to less likely act as detergents.

Protamines are arginine-rich peptides that package DNA into chromatin in vertebrate sperm. It is thought that the $\mathrm{N}^{\prime}$ terminus of protamine is unstructured, contains a lesser number of arginine residues, and bends back and over the central arginine-rich portion of protamine before binding the DNA [40]. There could be several reasons why the $\mathrm{N}^{\prime}$ termini of salmon and human protamines are less potent than their full-length equivalents. The N'termini of protamines contain the lowest number of arginines, which could be necessary for inhibiting LF protease activity. We hypothesize that in addition to arginine numbers, the secondary structure of protamine is also important, as protamine constructs that include the $\mathrm{N}$ ' terminal and central portions are the most potent anti-LF peptides.

The anti-toxin efficacies of drugs in cellular assays were observed to be lower than the efficacies seen in FRET assays, possibly because some of the host protein targets are intracellular, and drugs are required to cross cell membrane barrier. Moreover, the experimental timing used to determine drugs' inhibitory activity on proteases in FRET assays is very different 
from the timing used to measure the ability of drugs to block toxins in cellular assays. Cellular assays are done by pre-incubating cells with drugs for 1 hour, following by 6-24 hours of toxin treatments, depending on the kind toxin used. In contrast, FRET reactions were performed for up to 2 hours without drug pre-incubation. Finally, one protease activity unit of a single protease was used per FRET reaction. In contrast, the number of protease activity units per one cell is not known and may not be the same used in FRET assays.

The pharmacokinetics and safety of both identified drugs are well characterized. Ascorbic acid 6-palmitate is fat-soluble form of vitamin $\mathrm{C}$ formed from ascorbic acid and palmitic acid. It is used as a source of vitamin C as well as an antioxidant food additive (E number E304), which is approved for use as a food additive in the EU, the U.S., Australia, and New Zealand [41]. Salmon sperm protamine is used as an antidote for heparin overdoses [42]. In addition, protamine is used to slow down the onset and increase the duration of insulin action [43].

Numerous screens for LF inhibitors have been attempted in the past decade, however, none of the identified hits have been approved for use in humans because of the long and rigorous process of drug discovery and development. The current drug discovery and development process can take 8 to 12 years for the successful introduction of a new drug into the market [44]. Thus, the current de novo drug discovery and development paradigm is ineffective for dealing with rapidly emerging biological threat agents. Drug repurposing may offer numerous advantages under these circumstances. Since currently approved drugs already have well-established safety and pharmacokinetic profiles in patients as well as bulk manufacturing and distribution networks, they could rapidly be made available for a new indication if a biological emergency were to occur. 


\section{Methods}

\section{Chemicals and Reagents}

All bacterial toxins were purchased from List Biological Laboratories (Campbell, CA, USA). An FDA-approved drug library comprising of 1,585 drugs was purchased from Johns Hopkins University Bloomberg School of Public Health, titled, Johns Hopkins Clinical Compound Library (JHCCL). The drugs in the library were kept at $-20^{\circ} \mathrm{C}$ as $3.3 \mathrm{mM}$ stock solutions in sealed microtiter plates and were made using DMSO as solvent. Compounds of interest were repurchased and reproduced from $3.3 \mathrm{mM}$ solutions. Salmon sperm protamine, cetylpyridinium bromide, domiphen bromide, cetalkonium chloride, sodium lauryl sulfate, ascorbic acid 6-palmitate, sodium dodecylbenzenesulfonate, docusate sodium, and candesartan cilexetil were purchased from Sigma-Aldrich (St. Louis, MO, USA). Thyropropic acid was purchased from Toronto Research Chemicals Inc (Toronto, Ontario, Canada). All drugs were prepared at $3.3 \mathrm{mM}$ using DMSO as a solvent. Full-length human and truncated salmon and human protamines were synthesized by LifeTein (Hillsborough, NJ, USA). All chemicals and peptides in this study had purities greater than $98 \%$.

\section{LF FRET Drug Screen and Data Analysis}

For screening JHCCL drugs in 96-well plates, the reaction volume was $250 \mu 1$ per well, containing $20 \mathrm{mM}$ HEPES pH 7.2, $5 \mu \mathrm{M}$ MAPKKide conjugated with DABCYL and FITC (List Biological Laboratories, Inc), and $33 \mu \mathrm{M}$ of JHCCL compound. Reactions were initiated by adding anthrax LF to a final concentration of $6 \mu \mathrm{g} / \mathrm{ml}$. Kinetic measurements were obtained at $37^{\circ} \mathrm{C}$ every $40 \mathrm{sec}$ for $50 \mathrm{~min}$ using a fluorescent plate reader. Excitation and emission wavelengths were $490 \mathrm{~nm}$ and $523 \mathrm{~nm}$, respectively, with a cutoff wavelength of $495 \mathrm{~nm}$. A 
known LF inhibitor, surfen hydrate [31], was included as a control. Rates of reactions were quantified by the Microsoft Excel LINEST function. Drugs that inhibited at least $66 \%$ of FRET reaction at $33 \mu \mathrm{M}$ were re-tested at decreasing concentrations in order to determine IC50.

\section{Host Proteases FRET Tests}

Drug hits that inhibited at least $66 \%$ of LF FRET reaction were also tested for their ability to inhibit FRET reactions of human furin (New England Biolabs), calpain 1 (BioVision), cathepsin B (EMD Millipore), and caspases-1 and -3 (BioVision). The fluorescently labelled substrate peptide for furin FRET assay was purchased from Peptides International. The positive control furin Inhibitor I was purchased from EMD Millipore. The calpain Inhibitor 1, ALLN, was purchased from BioVision and used as a control. Amodiaquine (Sigma-Aldrich) was used as

a control inhibitor of cathepsin B. The universal caspase inhibitor Z-VAD-FMK (BioVision) was used as a control. Rates of reactions were quantified by the Microsoft Excel LINEST function.

\section{Cell Culture, Toxins Treatments, and Cell Viability Assays}

RAW264.7 mouse macrophage cells were maintained in DMEM (Invitrogen) supplemented with 10\% FBS (Corning) and $100 \mu \mathrm{g} / \mathrm{ml}$ penicillin and streptomycin. RAW264.7 cells $(10,000$ per well $)$ were seeded in 96 -well plates $(100 \mu 1 /$ well $) 24$ hours before the assay. Cells were treated with drug hits for 1 hour at $37^{\circ} \mathrm{C} 5 \% \mathrm{CO} 2$. RAW264.7 cells were challenged with anthrax toxins that include LF and native $83 \mathrm{kDa}$ PA (for 3 hours), LF and PA in the $63 \mathrm{kDa}$ form (for 6 hours), P. aeruginosa exotoxin A (for 12 hours), or Cholera toxin (for 12 hours), which were also pre-treated with identical drug concentrations, such that the final toxins concentrations were $0.5,0.5,2.0$, and $4.0 \mu \mathrm{g} / \mathrm{ml}$ respectively. Determination of RAW264.7 
viability was performed by 3-(4,5-dimethylthiazol-2-yl)-2,5-diphenyltetrazolium bromide (MTT) assay was performed as described1. Cell viability is defined as the percentage of surviving cells obtained relative to cells treated with DMSO (100\%). At least three such experiments were carried out. Statistical analysis was performed using GraphPad Prism software (http://www.graphpad.com/scientific-software/prism/). Each $P$ value represents a comparison of drug-treatment condition to a condition without drugs, and values $<0.05$ were considered statistically significant.

\section{Acknowledgments}

We would like to thank Dr. Kenneth Bradley of UCLA for a kind gift of Lethal Toxin. A.L. acknowledges support from The Kenneth T. and Eileen L. Norris Foundation.

Author Contributions A.L. and M.M. designed research; L.Z., W.L., S.H.T., J.Z., A.M.-J. and

S.L. performed research; all analyzed data; and M.M. wrote the paper.

\section{References}

1. Zilbermintz L. et al. . Identification of agents effective against multiple toxins and viruses by host-oriented cell targeting. Scientific reports 5, 13476, 10.1038/srep13476 (2015).

2. Liu S., Moayeri M. \& Leppla S. H. Anthrax lethal and edema toxins in anthrax pathogenesis. Trends in microbiology, 10.1016/j.tim.2014.02.012 (2014).

3. Bradley K. A., Mogridge J., Mourez M., Collier R. J. \& Young J. A. Identification of the cellular receptor for anthrax toxin. Nature 414, 225-229, 10.1038/n35101999 (2001).

4. Scobie H. M., Rainey G. J., Bradley K. A. \& Young J. A. Human capillary morphogenesis protein 2 functions as an anthrax toxin receptor. Proceedings of the National Academy of Sciences of the United States of America 100, 5170-5174, 10.1073/pnas.0431098100 (2003). 
5. Klimpel K. R., Molloy S. S., Thomas G. \& Leppla S. H. Anthrax toxin protective antigen is activated by a cell surface protease with the sequence specificity and catalytic properties of furin. Proceedings of the National Academy of Sciences of the United States of America 89, 10277-10281 (1992).

6. Kintzer A. F. et al. . The protective antigen component of anthrax toxin forms functional octameric complexes. Journal of molecular biology 392, 614-629, 10.1016/j.jmb.2009.07.037 (2009).

7. Ha S. D. et al. . Cathepsin B-mediated autophagy flux facilitates the anthrax toxin receptor 2-mediated delivery of anthrax lethal factor into the cytoplasm. The Journal of biological chemistry 285, 2120-2129, 10.1074/jbc.M109.065813 (2010).

8. Jeong S. Y., Martchenko M. \& Cohen S. N. Calpain-dependent cytoskeletal rearrangement exploited for anthrax toxin endocytosis. Proceedings of the National Academy of Sciences of the United States of America 110, E4007-E4015, 10.1073/pnas.1316852110 (2013).

9. Thoren K. L. \& Krantz B. A. The unfolding story of anthrax toxin translocation. Molecular microbiology 80, 588-595, 10.1111/j.1365-2958.2011.07614.x (2011).

10. Duesbery N. S. et al. . Proteolytic inactivation of MAP-kinase-kinase by anthrax lethal factor. Science 280, 734-737 (1998).

11. Levinsohn J. L. et al. . Anthrax lethal factor cleavage of Nlrp1 is required for activation of the inflammasome. PLoS pathogens 8, e1002638, 10.1371/journal.ppat. 1002638 (2012).

12. Chavarria-Smith J. \& Vance R. E. Direct proteolytic cleavage of NLRP1B is necessary and sufficient for inflammasome activation by anthrax lethal factor. PLoS pathogens9, e1003452, 10.1371/journal.ppat.1003452 (2013).

13. Turk B. E. Discovery and development of anthrax lethal factor metalloproteinase inhibitors. Current pharmaceutical biotechnology 9, 24-33 (2008).

14. Molloy S. S., Bresnahan P. A., Leppla S. H., Klimpel K. R. \& Thomas G. Human furin is a calcium-dependent serine endoprotease that recognizes the sequence Arg-X-X-Arg and efficiently cleaves anthrax toxin protective antigen. The Journal of biological chemistry 267, 16396-16402 (1992).

15. Popov S. G. et al. . Lethal toxin of Bacillus anthracis causes apoptosis of macrophages. Biochemical and biophysical research communications 293, 349-355, 10.1016/S0006-291X(02)00227-9 (2002). 
16. Bandala C., Perez-Santos J. L., Lara-Padilla E., Delgado Lopez G. \& Anaya-Ruiz M.Effect of botulinum toxin A on proliferation and apoptosis in the T47D breast cancer cell line. Asian Pacific journal of cancer prevention: APJCP 14, 891-894 (2013).

17. Berliocchi L. et al. . Botulinum neurotoxin $C$ initiates two different programs for neurite degeneration and neuronal apoptosis. The Journal of cell biology 168, 607-618, 10.1083/jcb.200406126 (2005).

18. Tikhonov I., Ruckwardt T. J., Berg S., Hatfield G. S. \& David Pauza C. Furin cleavage of the HIV-1 Tat protein. FEBS letters 565, 89-92, 10.1016/j.febslet.2004.03.079 (2004).

19. Passiatore G., Rom S., Eletto D. \& Peruzzi F. HIV-1 Tat C-terminus is cleaved by calpain 1: implication for Tat-mediated neurotoxicity. Biochimica et biophysica acta1793, 378-387, 10.1016/j.bbamcr.2008.10.010 (2009).

20. Zenon F. et al. . HIV-infected microglia mediate cathepsin B-induced neurotoxicity. Journal of neurovirology 21, 544-558, 10.1007/s13365-015-0358-7 (2015).

21. Song J. et al. . Longitudinal changes in plasma Caspase-1 and Caspase- 3 during the first 2 years of HIV-1 infection in CD4Low and CD4High patient groups. PloS one 10, e0121011, 10.1371/journal.pone.0121011 (2015).

22. Esumi M. et al. . Transmembrane serine protease TMPRSS2 activates hepatitis $\mathrm{C}$ virus infection. Hepatology 61, 437-446, 10.1002/hep.27426 (2015).

23. Kalamvoki M. \& Mavromara P. Calcium-dependent calpain proteases are implicated in processing of the hepatitis C virus NS5A protein. Journal of virology 78, 11865-11878, 10.1128/JVI.78.21.11865-11878.2004 (2004).

24. Wang Q., Chen J., Wang Y., Han X. \& Chen X. Hepatitis C virus induced a novel apoptosis-like death of pancreatic beta cells through a caspase 3-dependent pathway. PloS one 7, e38522, 10.1371/journal.pone.0038522 (2012).

25. Johannes L., Tenza D., Antony C. \& Goud B. Retrograde transport of KDEL-bearing Bfragment of Shiga toxin. The Journal of biological chemistry 272, 19554-19561 (1997).

26. Liu Y. \& Filler S. G. Candida albicans Als3, a multifunctional adhesin and invasin. Eukaryotic cell 10, 168-173, 10.1128/EC.00279-10 (2011).

27. Parry M. A., Zhang X. C. \& Bode I. Molecular mechanisms of plasminogen activation: bacterial cofactors provide clues. Trends in biochemical sciences 25, 53-59 (2000).

28. Serrano R. L., Rodriguez P., Pizzo S. V. \& Gonzalez-Gronow M. ATP-regulated activity of the plasmin-streptokinase complex: a novel mechanism involving phosphorylation of streptokinase. The Biochemical journal 313 (Pt 1), 171-177 (1996). 
29. Chong C. R., Chen X., Shi L., Liu J. O. \& Sullivan D. J. Jr. A clinical drug library screen identifies astemizole as an antimalarial agent. Nature chemical biology 2, 415-416, 10.1038/nchembio806 (2006).

30. Sandvig K. \& van Deurs B. Delivery into cells: lessons learned from plant and bacterial toxins. Gene therapy 12, 865-872, 10.1038/sj.gt.3302525 (2005).

31. Panchal R. G. et al. . Identification of small molecule inhibitors of anthrax lethal factor. Nature structural \& molecular biology 11, 67-72, 10.1038/nsmb711 (2004).

32. Goldman M. E. et al. . Cationic polyamines inhibit anthrax lethal factor protease. BMC pharmacology 6, 8, 10.1186/1471-2210-6-8 (2006).

33. Peinado J. R., Kacprzak M. M., Leppla S. H. \& Lindberg I. Cross-inhibition between furin and lethal actor inhibitors. Biochemical and biophysical research communications 321, 601-605, 10.1016/j.bbrc.2004.07.012 (2004).

34. Payne A. M. et al. . Caspase activation as a versatile assay platform for detection of cytotoxic bacterial toxins. Journal of clinical microbiology 51, 2970-2976, 10.1128/JCM.01161-13 (2013).

35. Tafesse F. G. et al. . GPR107, a G-protein-coupled receptor essential for intoxication by Pseudomonas aeruginosa exotoxin A, localizes to the Golgi and is cleaved by furin. The Journal of biological chemistry 289, 24005-24018, 10.1074/jbc.M114.589275 (2014).

36. Ragone R. Comment on 'Critical micellar concentration and protein-surfactant interaction (Comment to 'Destructive and protective action of sodium dodecyl sulphate micelles on the native conformation of Bovine Serum Albumin: A study by extrinsic fluorescence probe 1-hydroxy-2-naphthaldehyde')'. Chemical Physics Letters 483, 182183, 10.1016/j.cplett.2009.10.034 (2009).

37. Singh R., Mahanta S. \& Guchhait N. Destructive and protective action of sodium dodecyl sulphate micelles on the native conformation of Bovine Serum Albumin: A study by extrinsic fluorescence probe 1-hydroxy-2-naphthaldehyde. Chemical Physics Letters 463, 183-188, 10.1016/j.cplett.2008.08.017 (2008).

38. Zhang X., Jackson J. K. \& Burt H. M. Determination of surfactant critical micelle concentration by a novel fluorescence depolarization technique. Journal of biochemical and biophysical methods 31, 145-150 (1996).

39. Palma S., Lo Nostro P., Manzo R. \& Allemandi D. Evaluation of the surfactant properties of ascorbyl palmitate sodium salt. European journal of pharmaceutical sciences: official journal of the European Federation for Pharmaceutical Sciences 16, 37-43 (2002).

40. Balhorn R. A model for the structure of chromatin in mammalian sperm. The Journal of cell biology 93, 298-305 (1982). 
41. Mikova K. in Antioxidants in Food Ch. 11, 267-284 (2001).

42. Weiler J. M. et al. . Serious adverse reactions to protamine sulfate: are alternatives needed? The Journal of allergy and clinical immunology 75, 297-303 (1985).

43. Owens D. R. Insulin preparations with prolonged effect. Diabetes technology \& therapeutics 13 Suppl 1, S5-14, 10.1089/dia.2011.0068 (2011).

44. Avorn J. The \$2.6 billion pill-methodologic and policy considerations. N Engl J Med372, 1877-1879, 10.1056/NEJMp1500848 (2015).

45. Ryzhov S., Goldstein A. E., Biaggioni I. \& Feoktistov I. Cross-talk between G(s)- and $\mathrm{G}(\mathrm{q})$-coupled pathways in regulation of interleukin-4 by A(2B) adenosine receptors in human mast cells. Molecular pharmacology 70, 727-735, 10.1124/mol.106.022780 (2006).

46. Nagaraj V. A. et al. . Malaria parasite-synthesized heme is essential in the mosquito and liver stages and complements host heme in the blood stages of infection. PLoS pathogens 9, e1003522, 10.1371/journal.ppat.1003522 (2013). 


\section{Concluding Remarks}

The host proteins involved in the anthrax toxin internalization targets have proven to be potential broad-spectrum therapies against other pathogenic agents that utilize those same host proteins. We started off using a method that utilized similar yet disparate toxins, then moved on to a multiplexing methodology, and finally we identified a drug that simultaneously interferes with LF as well as host proteins that are exploited by LF to gain entry into host cells. In the future more multiplex drug screening will be done for other pathogens and pathogenic agents that span different protein families. In addition to cellular and FRET based assays we will incorporate other screens, such as genetic and immunology-based screens. Using previously approved drugs such as those in the John Hopkins Clinical Compound Library could shorten the historically expensive and timely drug development process, due to the known pharmacokinetics and pharmacodynamics of those drugs. In addition a benefit of repurposing those drugs could mean that there exists manufacturing and distribution networks, this giving patients quicker access to those therapies.

Amodiaquine, a previously approved antimalarial, is currently being tested in the hopes that it could become a complimentary therapy for anthrax in addition to the commonly prescribed antibiotics. Therapies for Anthrax and other deadly diseases fall under the FDA's “Animal efficacy rule," whereby safety and efficacy must be shown in two animal models. In addition, phase I clinical trials for humans must be completed, with any further trials in humans being unethical for obvious reasons. Plans are underway to test Amodiaquine as an anthrax antitoxin in rabbits and macaques. If Amodiaquine gets FDA approved, it could become the first in a new class of host-oriented drugs, anti-pathogen therapies. 